Florida International University

FIU Digital Commons

FIU Electronic Theses and Dissertations

University Graduate School

3-23-2011

\title{
The Influence of Study and Travel Abroad on the Personal and Professional Development of Students in Architecture Design Programs
}

Lyle D. Culver

Florida International University, lculver1@mdc.edu

DOI: $10.25148 /$ etd.FI1 1042601

Follow this and additional works at: https:// digitalcommons.fiu.edu/etd

\section{Recommended Citation}

Culver, Lyle D., "The Influence of Study and Travel Abroad on the Personal and Professional Development of Students in Architecture Design Programs" (2011). FIU Electronic Theses and Dissertations. 360.

https://digitalcommons.fiu.edu/etd/360 


\section{FLORIDA INTERNATIONAL UNIVERSITY \\ Miami, Florida}

THE INFLUENCE OF STUDY AND TRAVEL ABROAD ON THE PERSONAL AND PROFESSIONAL DEVELOPMENT OF STUDENTS IN ARCHITECTURE

DESIGN PROGRAMS

A dissertation submitted in partial fulfillment of the

requirements for the degree of

DOCTOR OF EDUCATION

in

HIGHER EDUCATION

by

Lyle D. Culver 


\section{To: Dean Delia Garcia}

College of Education

This dissertation, written by Lyle D. Culver, and entitled The Influence of Study and Travel Abroad on the Personal and Professional Development of Students in Architecture Design Programs, having been approved in respect to style and intellectual content, is referred to you for judgment.

We have read this dissertation and recommend that it be approved.

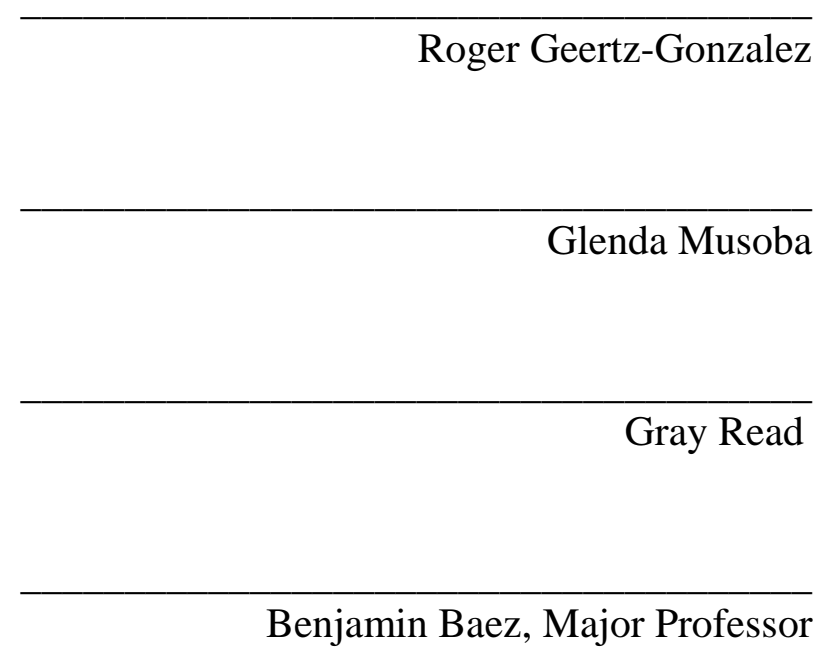

Date of Defense: March 23, 2011

The dissertation of Lyle D. Culver is approved.

\begin{tabular}{r}
$\begin{array}{r}\text { Dean Delia Garcia } \\
\text { College of Education }\end{array}$ \\
\hline Interim Dean Kevin O'Shea \\
University Graduate School
\end{tabular}

Florida International University, 2011 
(C) Copyright 2011 by Lyle D. Culver

All rights reserved. 


\section{DEDICATION}

I dedicate this work to Astrid, Ari, and Jonfelix. I also dedicate this work to my parents and my grandparents who helped make my education and travel a reality. 


\section{ACKNOWLEDGMENTS}

I would like to thank the member of my committee Major Professor Dr. Benjamin Baez, Dr. Gray Read, Dr. Glenda Musoba, and Dr. Roger Baez for their help, support, and patience. I would like to especially thank Dr. Benjamin Baez for his inspiration in helping me to discover and to develop a topic of research that was of great personal interest. I would like to thank the participants of my study who made this dissertation possible. I would also like to thank and acknowledge the deans, associate deans, and directors of the architecture programs at the University of Miami and Florida International University for their assistance and allowing me to conduct research in their schools. Special thanks go to Denis Hector and Nathaniel Belcher.

I want to thank my family, friends, and colleagues for their support. Cheers to Patricia, Don, and Ernest. Thank you to Dr. Lois Willoughby for being my auditor. Thank you also to Caprila Almeida who made certain that I submitted on time all of the paperwork necessary for this degree. 


\author{
ABSTRACT OF THE DISSERTATION \\ THE INFLUENCE OF STUDY AND TRAVEL ABROAD ON THE PERSONAL \\ AND PROFESSIONAL DEVELOPMENT OF STUDENTS IN \\ ARCHITECTURE DESIGN PROGRAMS \\ by
} Lyle D. Culver

Florida International University, 2011 Miami, Florida Professor Benjamin Baez, Major Professor International travel has significant implications on the study of architecture. This study analyzed ways in which undergraduate and graduate students benefited from the experience of international travel and study abroad. Taken from the perspective of 15 individuals who were currently or had been architecture students at the University of Miami and Florida International University or who were alumni of the University of Florida and Syracuse University, the research explored how international travel and study abroad enhanced their awareness and understanding of architecture, and how it complemented their architecture curricula. This study also addressed a more personal aspect of international travel in order to learn how the experience and exposure to foreign cultures had positively influenced the personal and professional development of the participants.

Participants’ individual and two-person semi-structured interviews about study abroad experiences were electronically recorded and transcribed for analysis. A second interview was conducted with five of the participants to obtain feedback 
concerning the accuracy of the transcripts and the interpretation of the data. Sketch journals and design projects were also analyzed from five participants and used as data for the purposes of better understanding what these individuals learned and experienced as part of their study abroad.

Findings indicated that study abroad experiences helped to broaden student understanding about architecture and urban development. These experiences also opened the possibilities of creative and professional expression. For many, this was the most important aspect of their education as architects because it heightened their interest in architecture. These individuals talked about how they had the opportunity to experience contemporary and ancient buildings that they had learned about in their history and design classes on their home campuses. In terms of personal and professional development, many of the participants remarked that they became more independent and self-reliant because of their study abroad experiences. They also displayed a sense of global awareness and were interested in the cultures of their host nations. The study abroad experiences also had a lasting influence on their professional development. 


\section{TABLE OF CONTENTS}

CHAPTER $\quad$ PAGE

I. INTRODUCTION 1

Architecture Education and Curriculum ..................................................... 3

Problem Statement............................................................................... 5

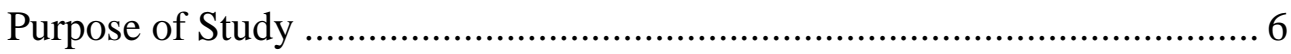

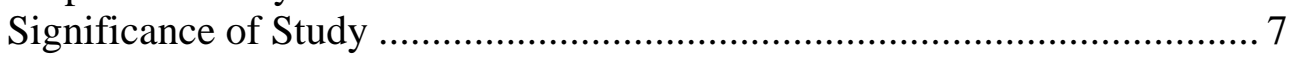

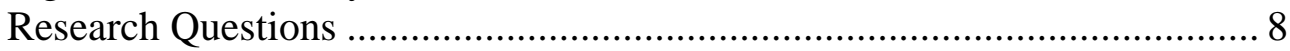

Assumptions and Delimitations of the Study ……………........................... 9

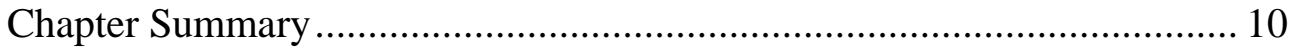

II. REVIEW OF RELATED LITERATURE 11

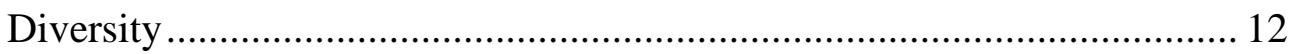

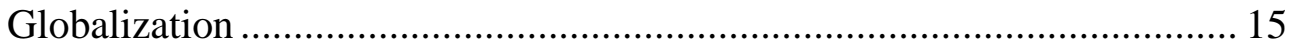

Architecture Curriculum, Pedagogy, and Methodology................................ 17

Implications of International Travel and Architecture .................................. 21

Travel Pedagogy and Higher Education ....................................................... 24

Experiential Learning ............................................................................ 27

Phenomenology \& Architecture ............................................................. 29

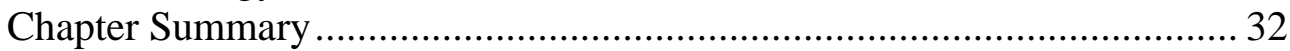

III. METHODS 33

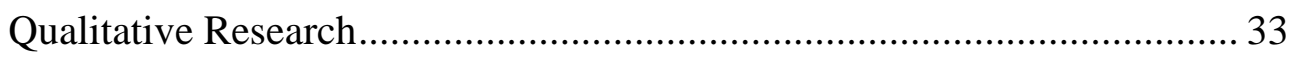

Experiential Learning .............................................................................. 36

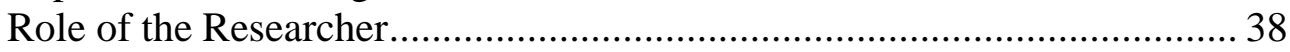

Site and Participant Selection ................................................................ 46

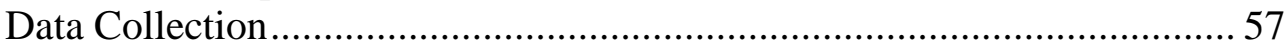

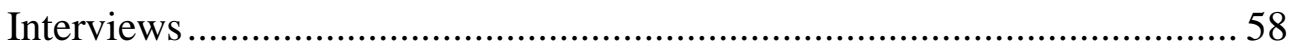

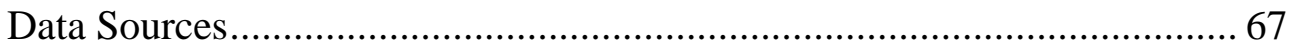

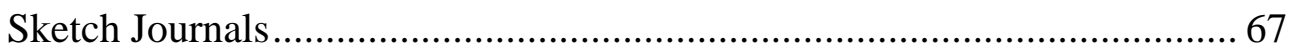

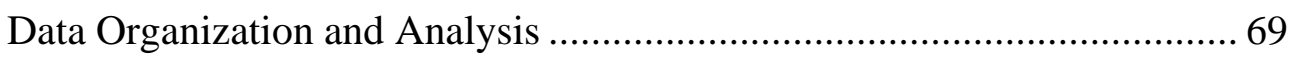

Dependability and Consistency of Study .................................................. 71

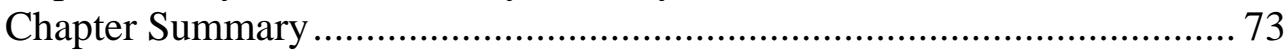

IV. PROFILES OF THE PARTICIPANTS 74

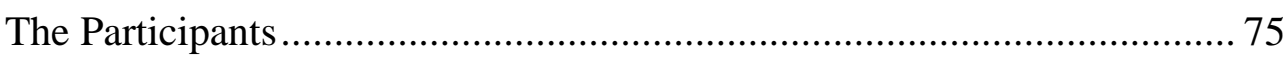

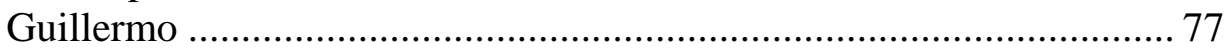

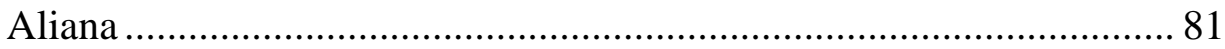

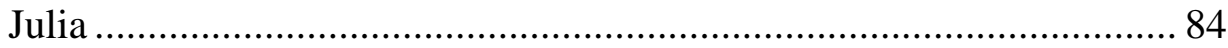

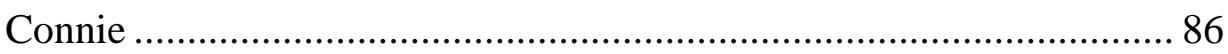

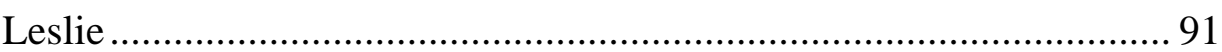

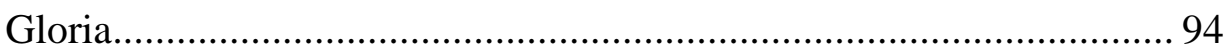

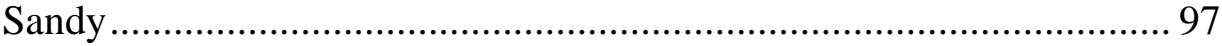

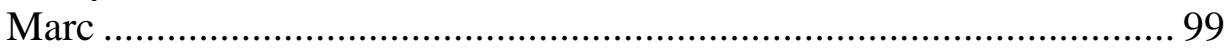




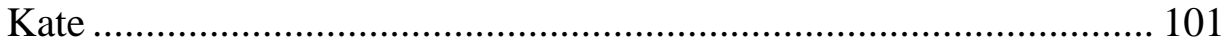

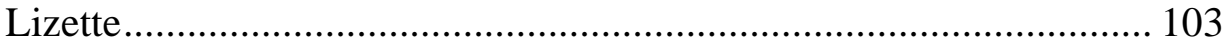

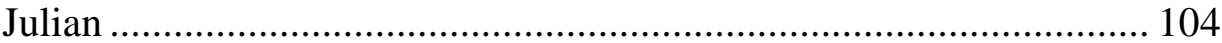

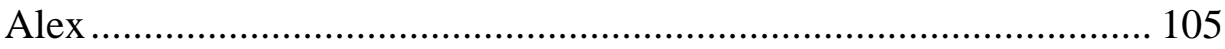

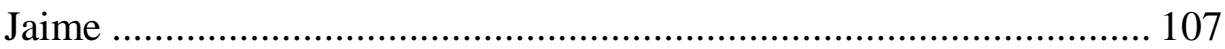

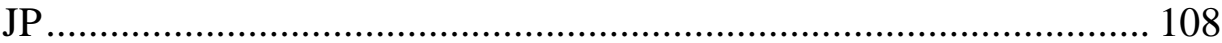

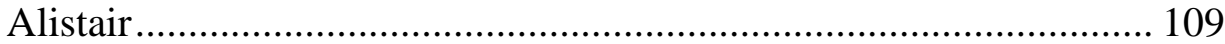

The Reasons for Studying Architecture ................................................. 110

Chapter Summary .................................................................... 116

V. THE ROLE OF TRAVEL IN ARCHITECTURE EDUCATION 117

Study Abroad and the Educational Experience....................................... 117

Study Abroad and the Architecture Curricula.......................................... 136

Study Abroad and Architecture Appreciation......................................... 154

Study Abroad and Personal Development ............................................. 188

Study Abroad and Professional Development ....................................... 207

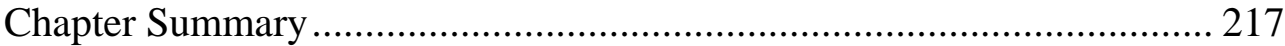

VI. DISCUSSION AND RECOMMENDATIONS 218

Review of the Study ..................................................................... 218

Discussion of Primary Research Questions ............................................ 222

Primary Research Question \#1...................................................... 223

Primary Research Question \#2..................................................... 226

Primary Research Question \#3...................................................... 229

Primary Research Question \#4.................................................... 231

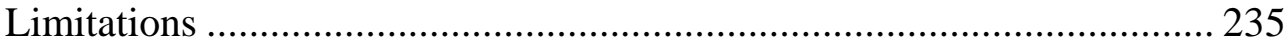

Recommendations or Practice and Study.......................................... 237

Recommendations for Research ......................................................... 241

Summary and Final Thoughts......................................................... 243

REFERENCES 245

$\begin{array}{ll}\text { APPENDICES } & 253\end{array}$

$\begin{array}{lr}\text { VITA } & 259\end{array}$ 


\section{LIST OF FIGURES}

FIGURE

PAGE

1. Lyle Culver in Asturias completing the Camino de Santiago, August 2000....... 38

2. City Hall on the day of a festival. Pen \& Ink sketch from Lyle Culver's

Camino de Santiago journal, August 2000.

3. Calle de Toledo, Madrid. Pen \& ink sketch from Lyle Culver's Camino de Santiago journal, August 2000.

4. Section drawing of the Cathedral of Santander. Graphite, pen \& ink sketch from Lyle Culver’s Camino de Santiago journal, August 2000.

1. Elevation of the front façade of the Cathedral of Limoges. Pen \& ink wash sketch from Lyle Culver’s Camino de Santiago journal, August 2000.

2. Interior of the Cathedral of Santiago de Compostella, Pen \& ink sketch from Lyle Culver’s Camino de Santiago journal, August 2000. 42

7. Hurricane Resistant Architecture Design Model by Guillermo ........................ 79

8. Panoramic photograph taken by Leslie Sanchez of Xalapa, Mexico. ............... 125

9. Section analysis of site in Xalapa, Mexico drawn by Leslie Sanchez ............... 126

10. Design Model created by Leslie Sanchez of a Walkway, Church, and Community Center in Xalapa, Mexico.

11. Plan by Leslie Sanchez.... 128

12. Axonometric by Leslie Sanchez. 128

13. Photographic image of the proposed project...... 129

14. Perspective graphite rendering by Leslie Sanchez.. 130

15. Section by Leslie Sanchez.. 130

16. Section model by Leslie Sanchez. 131

17. Photograph of Guadalajara by Leslie Sanchez. 149

18. Aerial Plan-View by Leslie Sanchez 150 
19. Isometric rendering by Leslie Sanchez ............................................................ 151

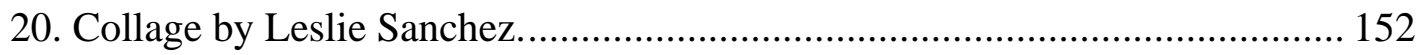

21. Scaled model by Leslie Sanchez..................................................................... 153

22. Scaled model by Leslie Sanchez...................................................................... 153

23. Scaled Model by Leslie Sanchez .................................................................... 154

24. Study abroad design project by Guillermo. .................................................... 160

25. Plans, elevations, \& sections of a Pompeian Inspired Villa by Aliana............. 162

26. Plans, elevations, \& sections of a Pompeian Inspired Villa by Aliana............. 162

27. Pen \& ink rendering of the Piazza del Popolo by Guillermo. ........................... 165

28. Pen \& ink rendering of the Church of the Holy Name of Mary

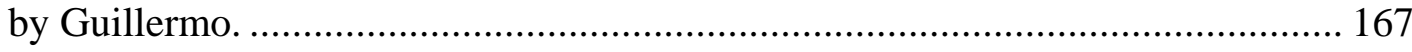

29. Pen \& ink rendering of Florence by Guillermo................................................. 169

30. Pen \& ink rendering of the Vatican by Guillermo ......................................... 170

31. Pen \& ink rendering of the Tempietto in Monotorio by Guillermo................... 172

32. Pen \& ink rendering of Constantine by Guillermo ......................................... 173

33. Pen \& ink rendering of the Dome of the Cathedral of

Florence by Guillermo.......................................................................................... 174

34. Pen \& ink rendering of the Dome of San Ivo della Sapienza by Guillermo.... 175

35. Axonometric diagram by F.D.K. Ching....................................................... 177

36. Pen \& ink rendering of the Basilica of Santa Maria Assunta by Jaime........... 178

37. Pen \& ink rendering of the Basilica of Santa Maria Assunta by Jaime............ 180

38. Graphite rendering of the Façade of the Basilica of Santa

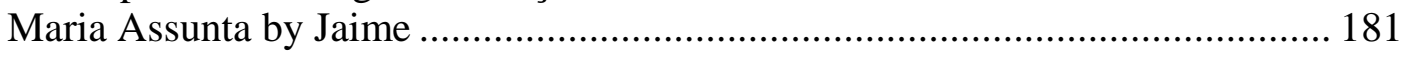

39. Graphite sketches of the Church of Sant Ignazio by Jaime ............................... 183 
40. Graphite sketches by Jaime.

41. Axonometric Sectional Diagram of the Pazzi Chapel by Lizette. .

42. Graphite sketches of the Church of Santa Maria de la Pace and Piazza by Lizette. 


\section{Chapter I}

\section{INTRODUCTION}

International travel has important implications in the study of architecture. This study focuses on how architecture students and architects benefited from the exposure to foreign cultures through study and travel abroad programs. I interviewed students who were currently enrolled in the graduate and undergraduate architecture design programs at the University of Miami and Florida International University. I also interviewed alumni from these institutions and the University of Florida and Syracuse University to assess how study and travel abroad experiences had complemented their education and influenced their understanding of and appreciation for architecture. The participants of this study were also questioned about the influence of these experiences on their professional and personal development.

As one of the strongest forms of human artistic and cultural expression, architecture is both an art and science that can vary dramatically from one culture to another and from one historic period to another (Frampton, 1993). Indeed, the most effective means of conveying a design idea is for one to experience space in the context of a particular time and culture. The most profound way to understand the influence of culture on the development of architecture is to immerse oneself within that particular culture. It is for this reason that travel is an integral part of the education of an architect. Some of the most influential modernist and post-modernist architects, such as Le Corbusier and Tadao Ando, lacked formal architecture schooling and instead based their architectural education on their own empirical observations of cities and buildings while traveling abroad (Jones, 2001). 
Travel can make the designer sensitive to the subtleties that distinguish architecture from a mere building form or activity. Exposure to varying modes and means of cultural expression forces a sense of openness to the possibilities that can further enhance one's ability to become a creative thinker and designer (Jones, 2001). As an architecture graduate student, for example, I benefited greatly from my international research and study opportunities. Upon my return from each of these international experiences, I always had a renewed sense of what I wanted to accomplish academically, and my motivation to learn more about architecture would increase. I returned to the domestic studios after my sojourns abroad with an abundance of ideas that I wished to explore through my design work. Indeed, my thesis was developed from a journey that I had undertaken as part of an international study abroad program during the summer semester before graduation.

As a professor of architecture and interior design at Miami Dade College, I have also noticed that students who return from summer travel abroad programs are much more enthusiastic about the study and pursuit of architecture as both an academic and professional outcome. Whereas these students might have demonstrated a certain degree of complacency or resistance to design critiques, those who return from the summer travel abroad programs that the college offers are more serious about their studies and more open to explore a variety of design ideas and concepts. These same students, furthermore, are more likely to remain within the design program and graduate with an Associate of Arts degree in Architecture or Interior Design. 


\section{Architecture Education and Curriculum}

The implications of international travel and study abroad can enhance and transform the architecture curriculum in most design programs in the U.S. As a course of study, an architecture curriculum has a specific format and structure that includes a series of design studio classes that are taken in sequence. In addition to the design studio, architecture students must also take other courses specifically related to architecture that include history, theory, structures, and graphic communication classes. This structure can make integrating international travel and study abroad a little challenging for many students. Understanding the structure of an architecture curriculum is important if changes are to be made to integrate fully foreign travel and study into the educational experience. There are also aspects of the curriculum that may hinder students from the experience of an international study opportunity. These were considered and were part of my investigative process as I asked students to reflect upon their international study experience in light of the architecture curriculum.

Architecture education is notorious for an exceptionally high rate of attrition amongst its students, and those students who would benefit from an international study experience may no longer be within the design program. About 50 to $60 \%$ of incoming freshmen eventually drop out of architecture before graduating because of a variety of misconceptions about the education and profession (Dalton, 1999; Domer \& Johnson, 1982; McMinn, 1986). The architecture curriculum is also very challenging and not all students may have the time, money, or even energy needed to spend a semester abroad. Those who decide to pursue an architectural education are exposed to countless hours working to complete design projects as well as to maintain adequate GPAs in order to 
remain within these very demanding programs. The curriculum and intensity of an architectural and interior design program is such that many students are unable to fulfill the workload expectations or produce projects that merit creative consideration (Bachman \& Bachman, 2006).

The structure of the architecture curriculum is also such that certain courses must be taken in sequence. Failure to do so will potentially lengthen the time required to complete all of the prescribed courses for graduation. Those students who participate in international study or travel programs must make certain that they are fulfilling the degree course requirements. The most important required course is the design studio that usually accounts for 6 credit hours per semester. The design studio is a sequential course taken every semester and most architectural study abroad programs integrate an international design studio component as part of the experience. The design studio is important because it provides the necessary platform for students to explore and experiment with a host of ideas, concepts, and strategies. In the design studio, students also learn about structure and gain knowledge of materials through the act of making and creating their design projects. The architectural design studio also helps to foster a communal atmosphere as students begin to interact with each other and critique each other's work (Quantrill, 1992).

In addition to the design studio, students are also required to take many other courses designed to complement the studio experience. Some of these courses can be taken as electives in semester abroad programs but there are other courses, however, that are only offered in the home institutions. The required architecture courses include sections dealing with structures, mechanical and electrical systems, architectural history 
and theory, graphic presentation, and materials and methods of construction. These additional courses, however, add to the intensity and stress level of the program. The inability to complete successfully the required elective and general education courses can negatively impact a student's chance of continuing and progressing to the next level of the curriculum. Many students eventually drop out of architectural design programs because of the excessive workload, lack of sleep, and demands placed on time, money, and creativity (Bachman \& Bachman, 2006).

Although there are aspects of the architecture curriculum and education that are very progressive, especially those courses that deal with computer-aided design and graphics animation, there are many aspects of the curriculum that have changed little since the inception of the first design schools. The structure of the design studio, for example, is a tradition that dates back to the time when artisans apprenticed under the auspices of a master artisan or artist (Quantrill, 1992). Travel is another longstanding tradition in the architecture curriculum. Although many schools of architecture offer international travel and study opportunities during the course of the degree program, historically travel was something that students would undertake upon the completion of their design programs. In fact, the notion of the Grand Tour involving travel to countries like Italy, France, Germany, and England was essentially viewed as an extension of a classical education in Ancient Greek and Latin during the 18th and 19th centuries (Younes \& Asay, 2003).

\section{Problem Statement}

There is limited literature or research pertaining to the influences of travel on architectural education even though a great many noted architects have for centuries 
relied on travel as integral part of their education as architects (Jones, 2001). Although there are many opportunities to study abroad in design programs throughout the U.S., there is also very limited research on the influence of international travel and study on undergraduate or graduate architecture students. This is surprising, considering the tremendous opportunity for added learning and personal growth that international study and travel offer. Many design programs encourage their students to participate in institutionally sponsored study abroad programs, but there is limited literature about the benefits of international travel or study. There exists an implicit perception on the part of faculty and administrators that international study and travel is beneficial, but there is limited documentation as to how these experiences benefit architecture students specifically (Jones, 2001). There is also limited understanding taken directly from the students' point of view about how they benefited from international travel and study, and how their perceptions about architecture changed because of the experience.

\section{Purpose of Study}

Although it is commonly understood that international travel and study have positive educational implications for undergraduate and graduate students (Jones, 2001), very limited literature exists about how architectural students benefit from the experience. An understanding of how international travel and study motivates and transforms architecture students is important if design programs are to promote their international study programs. This understanding is also crucial in helping to make international study and travel an integral part of the architecture curriculum. As it stands now, international travel and study opportunities are offered as an optional education experience (Waldrep, 
2006). International travel and study programs could greatly enhance architecture design curricula and provide students with vital exposure to the global environment.

International study and travel can also greatly enhance an architecture student's understanding of architecture and provide perspectives about this field that extend beyond what is taught in the home institution. Those students who experience foreign cultures through their studies and travels ultimately will have an even greater exposure to the variety of architectural expressions in the world. I believe this will further their curiosity about design and make them even more sensitive to the multitude of factors that shape and define architecture. From personal experience, my travels through Asia and the African continent left me with vivid memories of how people in these countries developed architecture that was unique to their culture, time, and place. This experience has also furthered my intellectual curiosity about the arts, philosophy, and world religions that have enriched the manner in which I express myself creatively.

\section{Significance of the Study}

The study shed light upon an unexplored, yet important aspect of the architecture curriculum, and provided insight into the benefits of international study and travel. This study was an empirical investigation and reflected the perspectives and views of students and practitioners. It was not limited to a theoretical understanding of the benefits of study abroad programs. This study also addressed another serious shortcoming in the literature about the architecture curriculum because the findings were based on student and alumni responses. The current literature on architecture is predominantly theoretical, taken from the perspective of academics and practitioners (Bachmann \& Bachmann, 2006). Because the study was based in part on narrative interviews, the participants were encouraged to 
engage in open conversation about their study abroad. They were encouraged to relate stories about their experiences living and travelling overseas. They were also encouraged to talk about what they learned in terms of architecture and urban design during their study abroad.

\section{Research Questions}

The influence of study and travel abroad on the study of architecture has significant implications. This study analyzed ways in which undergraduate and graduate students benefited from these experiences. Taken from the perspective of professional architects and students who are currently enrolled in the undergraduate and graduate architecture design programs of institutions identified earlier, this investigation addressed a number of questions about how study abroad and travel enhanced awareness and understanding of architecture and complemented the architecture curriculum. It also explored a more personal aspect of travel: how the experience and exposure of foreign cultures influenced the personal and professional development of the participants. This development included a changed perception or appreciation of specific foreign cultures. It also included a greater appreciation of and understanding about architecture.

This study addressed the implications of travel and study abroad experiences by investigating the following questions:

1. How have travel and study abroad shaped the educational experiences of those who are studying or have studied architecture?

2. How have travel and study abroad complemented the architecture curricula? 
3. How have travel and study abroad experiences enhanced the understanding and appreciation of architecture of those who are studying or have studied architecture?

4. How have travel and study abroad influenced the personal and professional development of those who are studying or have studied architecture?

These questions were answered from the participants' points of view. These questions also made travel and study abroad central to an understanding of their experiences and of the architecture education.

\section{Assumptions and Delimitations of the Study}

In this study it was assumed that travel and study abroad experiences benefited architecture students. This study also assumed that the students chosen for the interviews were in good standing academically and had chosen to participate in international travel and foreign study because of an interest in architecture. It was also assumed that the participants had a basic understanding of architectural theory and history, which ultimately made their observations of architectural and urban space more informed. This study also assumed that students or graduates had taken courses in architectural design and were able to communicate verbally and graphically using appropriate design terminology and design related graphics. This study assumed that students who participate in study abroad programs were able to afford the cost of the experience either through their own wealth or financial aid.

An important delimitation of this study was the limited sample population. I interviewed only a select number of architecture students from the University of Miami and from the Florida International University and alumni from these institutions, and the 
University of Florida and Syracuse University. Although these institutions are ethnically diverse, the majority of students studying at Florida International University, for example, are Hispanic. The student population at this institution was not indicative or representative of the general ethnic distribution of undergraduate and graduate students studying architecture in design programs nationally. I addressed this issue by selecting a sample that was ethnically diverse. The University of Miami and Syracuse University students, furthermore, were probably not financially representative of the general population of architecture majors. These institutions' selective status in terms of its academics and tuition also precluded a more general socioeconomic representation of the national population in terms of its students.

\section{Chapter Summary}

In this chapter, I have discussed the importance of international travel in the study of architecture and provided examples of how international travel and study can enhance the curriculum. I have also identified the specific research questions that addressed the issue of international travel from the perspective of the architecture students studying at Florida International University and the University of Miami, and alumni from these institutions and the University of Florida and Syracuse University. In Chapter 2, I investigate the literature pertaining to the implications of international travel and study abroad in higher education and in architecture more specifically. 


\section{Chapter II}

\section{REVIEW OF RELATED LITERATURE}

The implications of international travel can be significant for those who study and practice architecture. My study analyzed the influence of international travel and study abroad on undergraduate or graduate architecture students. Taken from the perspective of architecture students at the University of Miami and Florida International University, and alumni from these institutions and the University of Florida and Syracuse University, my study addressed how international travel and study enhanced an understanding of global architecture, and how it complemented the curricula. My study addressed a more personal aspect of international travel in order to learn how this experience transformed aspects of the students' personal and professional development.

Studies pertaining to architecture education, however, are generally limited. Some of the articles written in peer-reviewed journals about the architecture academy have focused on issues of diversity, the effects of globalization, and methodology. There is a lack of research on how students can enhance their understanding of architecture or even enhance their educational experience through travel. There is even an apparent lack of literature in the Journal of Architecture Education about the implications of study abroad experiences for architecture students. This is surprising considering the importance travel has had historically on the education of architects (Jones, 2001). Very little reference is made of the historical significance of the Grand Tour or even of the foreign academies of architecture in Rome or Paris for aspiring architects in any of the peer-reviewed articles written within the past couple of decades (Younes \& Asay, 2003). Although there are any number of papers and dissertations that examine the implications of foreign travel from a 
number of areas, none address the issue from an architectural pedagogical perspective. This lack of research provided me the opportunity to interview architecture students, who had travelled abroad as part of semester- or year-long study programs, in order to understand how their perceptions of architecture had changed and how the international experience had complemented their architectural studies.

In this chapter, I review the literature pertaining to the impact of international travel and study abroad in higher education and architecture more specifically. I discussed how international travel functions within the architecture academic framework, and how it responds to a number issues affecting the academy and profession. I begin with a discussion about the lack of diversity and how international travel helps to promote diversity and foster greater tolerance of minorities within the profession and study of architecture. I also introduce the issue of globalization and how international travel and study helps architecture students and future practitioners to function successfully within a changing global environment. I introduce a section about how the experience and opportunity of international travel and study functions within the profession and the established architecture curriculum. I also address the lack of research on international travel and study in architecture education and discussed the impact of study abroad programs as they apply more generally to higher education. I investigated the use of qualitative research methods as a means of learning about the benefits of foreign travel and study from the student participants.

\section{Diversity}

Although my study does not deal specifically with the issue of diversity or even the lack of diversity in architecture, international travel and study abroad experiences can 
help to promote greater tolerance for and acceptance of minorities in the study and profession of architecture. Over the past several years, for example, there has been a growing concern about the inequities and lack of adequate diversity within the academy and profession of architecture, which has been the subject of a number journal-related articles and studies conducted by academic institutions and the American Institute of Architects (AIA). The finding of one report sponsored by the AIA revealed that women and racial minorities are poorly represented in the profession and the study of architecture and do not come close to representing their percentage distribution in the general population (Holland \& Knight LLP, 2005). Those minorities who are enrolled in architectural programs tend to feel somewhat discriminated against and isolated because the architectural pedagogy is not gender or culturally sensitive. (Bachman \& Bachman, 2006; Dixon, 1994; Groat \& Ahrentzen, 1996; Shannon, 2006). According to Groat and Ahrentzen (1996), the studio pedagogy, which is based on the master-apprentice approach, may also have a

Differential impact on female and minority students; not only is the master nearly always a mister, but women may be less comfortable with a format that privileges persuasion over dialogue, and minority students may resent the Eurocentric design emphasis that channels students into becoming custodians of the status quo. (pp. 166-167)

International travel and study can help to dispel this sense of inequity by challenging students to break from their own preconceived personal and cultural boundaries to change the way they view the world (Younes \& Asay, 2003). Students travelling abroad, for example, will experience architectural forms that are shaped by cultural standards designed by people who are from a variety of ethnic and cultural backgrounds. This is especially true for those students who experience third world or 
developing countries. In fact, the Eurocentric design emphasis would be seriously challenged if more students and faculty alike were to travel and experience cultures that have not directly been influenced by the effects of globalization (Dekaney, 2008).

International travel and study also has the ability to create a consciousness of tolerance for diversity (Hoffmann, 2008), and could possibly be enough to transform this current condition of inequity within the profession and study of architecture. Architecture students, faculty, and even administrators who engage people with different life experiences through travel may begin to accept and tolerate differences (Hoffman, 2008), which can help bring about a more inclusive pedagogical approach for minorities within the studio experience. Students who study abroad understand what is to be a minority and tend to display greater empathy towards others upon their return. The issue of prejudice or acceptance of minority stereotypes, furthermore, greatly diminishes in those students who travelled and encountered foreign cultures through international study abroad programs (Pascarella \& Terenzini, 2005).

Although the topic of my study does not deal directly with the perceived implications of travel for faculty or administrators of architectural design programs, it is also important to note that students are influenced by their instructors' implicit perceptions on travel. Faculty who see the advantages of international study will ultimately encourage their students to experience a summer, a semester, or a year living and studying abroad (Jones, 2001). Travel pedagogy and institutionalized study abroad programs, however, are not adequately supported by academic institutions and remain peripheral to architectural academics (Jones, 2001). A critical review of the benefits of international travel for architecture students could influence the development of expanded 
programs and opportunities of international study for undergraduates and graduates in architectural design programs (Jones, 2001).

\section{Globalization}

The issue of diversity not only dominates the discussion of architecture and its future for the academy and profession, but globalization has begun to alter the manner in which architecture is created and practiced (Dekaney, 2008; Walker, 2001). Globalization has had a negative impact on regional architecture by overshadowing the concept of place in light of a world economy where labor, products, and capital dominate (King, 2007; Walker, 2001). The subsequent result has been a "McDonaldization” of the built environment that seriously challenges the concept of cultural identity and expression in architecture (Walker, 2001). A response to the effects of globalization has been Kenneth Frampton’s architectural call for “critical regionalism” (Frampton, 1983; Nesbitt, 1994), and the "resistance to the homogenization of product manufacturing and construction techniques” (Nesbitt, 1994, p. 469). Frampton is particularly concerned about the global proliferation of a consumer-based culture at the expense and detriment of traditional cultures (Frampton, 1983). What Frampton proposes is not the rejection of Modernism and the subsequent adoption of vernacular architecture, but the development of an authentic architecture that relates specifically to place and one that embodies a clear understanding of tectonics (Frampton, 1983; Nesbitt, 1994).

In this age of globalization, international travel and study experiences are especially important to expose architecture students to the significance of place and culture as critical components on the development of architecture. Although no specific studies exist about the effects of international education or travel on architecture students, 
there is mounting research to indicate that studying abroad enhances interest in art, architecture, and history (Carsello \& Creaser, 1976). International travel also promotes a greater sense of global awareness and understanding of cultural differences (Kisantas, 2004; Sandell, 2007). A study abroad experience teaches students to be globally minded, inquisitive about other cultures, and more interested in international affairs and world politics (Kisantas, 2004; Sandell, 2007; Van Reken \& Rushmore, 2009). Those architecture students who travel abroad are exposed to many different ways of culturally expressing architecture. They may also understand that architecture is not an endeavor limited to one racial or ethnic group, but is an activity undertaken by people from all ethnicities, both male and female, globally and historically (Callihan, 2009).

International travel and study may also change the manner in which students perceive themselves in relation to their greater environment. No longer is their immediate and personal environment limited to specific boundaries of city or county, but students who travel may begin to realize that they are part of a much greater experience that transcends their current understanding of time and place. The experience of walking through a set of ancient ruins, for example, can be transformative especially for those students who have never been exposed to buildings that are more than three generations old. To behold a structure that is two thousand years old may change the manner in which one considers the reality of time, and the reality of one's own personal existence. Probably the greatest realization is that civilizations have come and gone, and all that remains as physical evidence of these one great empires are the ruins of their most significant buildings (Callihan, 2009). An important personal revelation, however, is the understanding that change is the only permanent experience. Some day in the future, 
archaeologists may uncover the remains of buildings that define our present civilization and begin to speculate about we lived our lives.

Another outcome of globalization is the increased interaction of people from varying cultures, and the subsequent need for students to develop intercultural competence and skills in cross-cultural communication (Van Reken \& Rushmore, 2009). As the profession of architecture becomes an increasingly international endeavor with firms operating, collaborating, and competing for projects globally, it is important that architecture students learn to function and adapt to this changing environment. International travel and study abroad opportunities can provide the necessary experience to make these students competitive in this global economy (Sandell, 2007). Aside from the economic and career benefits that international education can offer (Sandell, 2007), there is also an added personal dimension that students gain from living and travelling abroad. Travel is a multidisciplinary experience. Students who participate in international study abroad programs are not only exposed to foreign languages, but will potentially encounter and experience a different way of life, which will greatly impact the experience of their own lives (Kitsantas, 2004). I believe that the quality of my life has been positively influenced through travel, and my appreciation and understanding of architecture has also been greatly enhanced. I value the importance of cultural expression in architecture. I have also come to appreciate other cultures by learning to incorporate aspects of those cultures into my own life.

\section{Architecture Curriculum, Pedagogy, and Methodology}

In order to understand how architecture students benefit from international travel and how their perceptions about architecture change, it is also important to understand 
how this experience and opportunity functions within the profession and the established architecture curriculum. Architecture education is notorious for its exceptionally high rates of attrition amongst its students regardless of their gender or ethnicity. Most students drop out of the program by the third and fourth years, which is usually the time when students partake in their junior year or semester abroad. According to research conducted by McMinn (1984), Domer (1986), and Dalton (1999), about 50 to $60 \%$ of incoming freshmen eventually drop out of architecture due to a variety of misconceptions about the education and profession. Admittance to a design program is also very competitive, and often times requires a portfolio of creative work in addition to a high GPA and standardized entrance examination scores on the SATs and ACTs as part of the application process. The curriculum and intensity of an architectural and interior design program is such that many students are unable to fulfill the workload expectations and produce projects that merit creative consideration. International travel and study abroad opportunities could provide incentives for students to continue their studies in architecture though there is limited literature or research supporting this notion.

Students who wish to enroll as freshman in an architectural design program generally have traditionally one of two options. They can either enroll in a professional or pre-professional design program. The professional Bachelor of Architecture program (B.Arch.) takes 5 years to complete and is required if an individual wishes to pursue professional registration as an architect. The pre- professional Bachelor of Design, Bachelor of Arts or Bachelor of Science in Architecture Studies degree takes only 4 years to complete, but it is not a professional degree. If they intend to pursue professional registration, students must either complete the fifth year at another accredited program or 
pursue the professional Master of Architecture 1 (M. Arch 1), which requires an additional two years to complete. Students who have under graduate degrees in fields other than architecture can also pursue the M. Arch 3 degree, but this requires an additional three to four years to complete depending upon the degree granting institution. The M. Arch 2, on the other hand, is a post-professional degree designed for students who have completed a professional degree but wish to study or do research on a specific area of architecture.

Successfully completing an accredited professional architectural degree program is only part of the process to become a professionally licensed architect. In addition to the education, a graduate must also complete a prescribed internship phase of approximately 3 years and be exposed to a variety of different work related experiences. This internship is referred to as Internship Development Program (IPD) and must be documented, and registered with the National Council of Architectural Registration Board (NCARB). The individual must then pass a series of 9 professional examinations that are specific in areas of design, construction, environmental systems, materials, history, and structures. Not everyone who graduates from an architectural program pursues registration. Because of the time required to become an architect and the difficulty of the professional examinations, limited numbers of graduate will pursue registration. Many, however, will continue to work in the profession or pursue careers that are related to design.

The architectural design education is time consuming, challenging, and integrating a study abroad or travel experience into the curriculum may prove difficult. At the core of the curriculum is the design studio, which accounts for 6 credit hours and meets three times weekly usually for 4 hours each session. Each design studio falls in 
sequence and cannot be skipped; otherwise the architecture student may risk waiting an entire year before retaking the class. The studio provides the necessary platform for students to explore and experiment with a host of design related ideas, concepts, and strategies. Students also gain knowledge of materials through the act of making and creating their design projects in the form of models and rendered images. The studio not only serves to teach students about design, it is also helps to foster a communal atmosphere where architecture students interact with one another and learn to critic each other's work.

Architecture, according to Rawes (2007), is also a unique education where students develop "drawing, conceptual, and critical skills that are informed by their ability to reflect upon the production of ideas in design processes and in the urban, environmental, social, historical, and cultural contexts that define architecture and the built environment” (p.74). In addition to creativity, the ability to reflect upon the design process is one of the most challenging and critical aspects of the education and professional work of an architect. Reflective thinking, furthermore, is the means through which students can constructively engage the discipline and "transform aesthetic judgments into embodied knowledges in the production of the built environment” (Rawes, 2007, p.74). International travel and study abroad is important to an architectural education because it not only enhances the ability to learn and engage in reflective thinking (Callihan, 2009), but it also complements the curriculum methodology by challenging students to expand the realities they understand (Hoffman, 2008). Based on what I encountered travelling through India, for example, my conventional ideas about my environment changed and, through this experience, I learned to become more open to 
varying means and modes of expression. India expanded my boundaries of reality and I learned to engage in reflective thought through my sketch journaling.

\section{Implications of International Travel and Architecture}

Although there are a number of published works about study abroad programs for specific undergraduate disciplines (Dekaney, 2008; Sandell, 2007) none deal with the implications of travel and study abroad for architecture. There is very little literature about the impact of international travel on architecture pedagogy and its influence on the profession. This is surprising considering the importance of experiential and observational learning through travel that practitioners and academics historically considered a critical part of the architect's education. Only one recent publication, Unpacking the suitcase: Travel as process and paradigm in constructing architectural knowledge (Jones, 2001), seriously addresses the issue of travel pedagogy in architecture both in terms of the lack of adequate international study abroad programs, and the subsequent lack of research pertaining to the impact that this type of academic student learning experience.

Jones's study is taken from a feminist perspective and she examines the work and writings of various female artists and photographers about their impressions of historical and global architecture. Jones makes a fundamental distinction between the manner in which men and women perceive and document the built and natural environments through travel. Her emphasis in research is to provide an alternative to the prescribed male impression of architecture as authored by the mid twentieth century texts of Le Corbusier, Alvar Aalto, and Louis Kahn, all whom had travelled and documented their observations rather extensively in their sketch journals. The male quest for travel, 
according to Jones, tends to reinforce Joseph Campbell's concept of the mythic voyage. The journey is one of validation, a rite of passage into manhood, a heroic quest of sorts. The act of documenting through sketches was a means of learning validated through travel. Based on her study of the works of select women artists and writers, Jones writes that the female quest for travel tends to have a spiritual purpose because it represents an internalized search for self-development. Women tend to document their experiences in more empathetic terms with a greater sensitivity to the actual sites they describe (Jones, 2001).

Whereas I agree in principle that men and women may experience and document architectural urban conditions in different ways, I find Jones's sentiments about this male - female dichotomy to be overly generalized and somewhat biased. Her reference to male architects and female artists and writers is limited, and taken only from a purely historical perspective. She does not reference the work of any contemporary architects, but relies on the work of Louis Kahn, Le Corbusier, Alvar Aalto to make her assertions about male perceptions of travel and architecture. Men may not always feel the need to travel in order to experience a personal heroic quest or find a "life validating experience" (Jones, 2001). There may exist instances when the experience of travel represents a need for selfdevelopment for men as they delve introspectively into their own personal sense of being. My pilgrimage along the Camino de Santiago in Spain, for example, combined a personal interest in spirituality with a fascination of sacred architecture and sacred space. The manner in which I documented my experiences was not in the form of words, but a series of sketches in which the contour lines attempted to depict the built structures and the emotion and sanctity of their spatial experience. 
I found Jones's work to be compelling for a number of reasons. Jones's feminist methodology draws light on perceived differences between men and women on experiential learning. The research also highlights the inadequacies of studio design methodology in attempting to integrate cultural learning objectives within a study abroad program. Jones strongly advocates the need for the travel pedagogy in architecture, but lists the shortcomings of the current study abroad programs and the intellectual failure of scholars to integrate study abroad initiatives properly into the architecture pedagogy.

I also fully concur with Jones's critique of tourism and the distinction she makes with travel. Tourism has implied negative connotations. It can be culturally exploitative and not always based on any need for substantive learning. Tourism tends to be a temporary experience that is often commercially focused. Travel, on the other hand, is about self-discovery, learning, and acquisition of knowledge. I personally know this to be true because of my own travels. I sought a personal transformation as the main reason for leaving the comforts of familiar surroundings to experience the unfamiliar in foreign lands. What I experienced in India, for example, was so foreign to my senses that it took days before my mind was adequately able to process the experiences of the country. What ensued was a complete self-awareness juxtaposed against the disarray of intense sounds, smells, sights, and tastes. Much of this transformation did not become as apparent until I returned home and began to transcribe my journals. Indeed, my desire to study architecture was strongly influenced by my travel experiences captured in the form of sketches, photography and writings.

Jones also presents the historical tradition of architecture and travel, and the influence travel on the education of the architect. This is an important concept because 
architects were not only educated within the confined walls of a studio or atelier, but were also exposed to the actual works of antiquity and the contemporary manifestations of architecture through travel. Thomas Jefferson, although not professionally trained architect, relied heavily on his observations of Roman and Renaissance architecture to develop the designs for Monticello, the University of Virginia and the Virginia State Capital in Richmond. Even the Roman general and emperor Hadrian, after years traveling throughout the empire, spent his retirement designing his opulent villa in Tivoli based on the architectural impressions he brought from his many voyages.

There has also been a long established tradition of aristocrats travelling abroad and embarking on the "Grand Tour" to the European Continent from England. This was seen as a rite of passage, a means through which to receive learning and understanding. Some of the great English and Scottish architects of the 17th and 18th centuries, such as Inigo Jones, Lord Boyle, and Robert Adam, spent considerable time in Italy observing and documenting the works of ancient Rome and Palladio. Both the archaeological discoveries of Rome and the architectural works of Palladio introduced a transformation of the English architectural grammar during these centuries. Neoclassicism made a strong entrance during the period of the Enlightenment, and its influence is very apparent in the stately homes and palaces of the English aristocracy (Fazio, Moffett \& Wodehouse 2009).

\section{Travel Pedagogy and Higher Education}

Since there is a serious lack of literature pertaining to travel pedagogy and its effect on architecture students, much of the supporting literature review focuses on research pertaining to study abroad programs and its impact on college level students in 
more general terms. This information was useful to understand the importance of international education and travel on a student’s intellectual development. How international study and travel influences architecture students was the focus of my own qualitative study of architecture students at the University of Miami and Florida International University, and alumni from these institutions and the University of Florida and Syracuse University.

Study abroad has been the subject of a number of quantitative and a limited number of qualitative dissertations, which all tend to support and employ Chickering and Reiser's (1993) theories pertaining to the psychosocial development of students. In fact, the use of these theories tends to be a repetitive factor in much of the research, and the application of any other substantive theoretical models to measure the effects of international study on undergraduates is limited (Wortman, 2002). Some of the quantitative research relies on models developed to measure the effects of increased global mindedness on students who participate in study abroad programs. In one such study, Golay (2006) used the Global Mindedness Scale and the Host Culture Contact (HCC) to measure the global-mindedness of Florida State University undergraduates who studied abroad. Her findings confirmed the fact that students were globally more conscious after having studied abroad one semester when compared to those who remained on their home campus. For a quantitative study, I found Golay’s sample size, $\mathrm{n}=76$, to be somewhat limited and the conclusion of the study itself predictable. I think one can generally conclude that a student who spends a semester abroad will tend to be more global minded tendencies than one who remains on the home campus. 
Not all quantitative studies, however, support the positive effects of study abroad programs. In one example, students form University of California, University of Colorado, University of Massachusetts and Kalamazoo who studied abroad where surveyed in comparison to students who remained at the University of California and the University of Massachusetts to determine the impact of the study abroad experiences. Using multivariate statistical procedures, Yachimowicz (1987) concluded that those students who studied abroad really did not show any significant increase in international understanding, but these same students did demonstrate a greater knowledge about their host countries. These students also demonstrated positive attitudes towards themselves after their junior year abroad and experienced a certain degree of readjustment issues when they returned to the United States (Yachimowicz, 1987). Yachimowicz's findings are also supported in another study measuring the effects of identity change on students from the University of Texas-Austin. According to Angulo (2006), students who spent 12 weeks abroad reported higher satisfaction with life, self-competence, and personal change than those who remained at the home university. The quantitative analysis also demonstrated that students who studied abroad measured marginally higher on personal growth (Angulo, 2006).

Much of the research on the effects of international travel, however, tends to be quantitative. I also found this surprising since understanding the implications of travel and study abroad may only be effectively accomplished using a qualitative research method. Asking students about their travel abroad experiences can elicit insightful conversation about the transformative nature of the experience itself. There are, however, other means of understanding the impact of travel on a student's perception of 
architecture, which have not been considered or discussed in any published material in my literature review. Rather than relying on questionnaires or interviews, for example, the manner in which an architecture student documents his/her experience abroad through the use of a sketch journal can also be used as the basis for a qualitative study. In fact, the use of visual aids, such as photography, has been used rather extensively in qualitative research to help researchers understand aspects of life that cannot be done so through other means (Bogdan \& Biklen, 2006). The subject matter of a particular sketch, for example, may indicate a point of personal interest or something of importance to the artist. Even before I considered studying architecture or becoming an architect, I maintained journals that not only documented my experience in words, but also illustrated my feelings and emotions in the form of diagrams. These journals were probably the most valuable means of how I captured and documented the experience of travel and the spatial experience of architecture. The manner in which I sketched and the subject matter of my drawings not only depicted physical reality, but also illustrated how I perceived and understood the buildings in question.

\section{Experiential Learning}

The qualitative process also offers greater opportunities to better understand the impact of international travel through various perspectives. Since I am interested in culture and the role culture plays in our life, for example, I could conduct a qualitative research on travel and its effect on students' perceptions of architecture from an ethnographic perspective. Having been brought up in an Anglo/Hispanic household abroad, made me wonder about my own cultural group in light of my foreign surroundings. I often found myself identifying with not only one specific group, but also 
two or three simultaneously. Understanding a given culture may also require having to understand its religion, language, and elements that identify one specific group of people over another.

As an architecture professor, I am also interested in the manner in which individuals experience and describe their physical environment. As a designer, I am particularly interested in the role design plays in creating spatial experiences to elicit certain emotional responses. The combination of materials, spatial configurations, and specific proportions can evoke a sentiment of wellbeing, or conversely one of tension and imbalance depending upon their usage. Asking people what is to like to have a certain experience, or even what it is like to experience space in an architectural sense may fundamentally draw on the individual's emotions. In terms of my study, the use of an experiential learning framework helped me develop an understanding of the influence of international travel or study abroad experiences for the architecture students that I am interviewing. It also helped me to better understand how the students experienced the architecture of the countries they visited as part of their travels and participation in the international study abroad programs.

In addition to referencing Kolb’s (1984) theoretical work on the process of experiential learning, I also referenced the work of Montrose (2002) who supports the notion that study abroad provides some of the most profound experiential learning experiences. Montrose provides a fairly extensive review of the theoretical literature of experiential learning to illustrate its significance and the educational values that can be derived from it. Based on her reflection of Kolb’s (1984) learning cycles, Montrose (2002) concludes that experiential education "involves the student in a concrete 
experience, adds pre-determined educational outcomes, and engages the learner in critically analyzing the situation in order to form new knowledge that can be utilized the next time a similar situation is encountered” (p. 6). The educational value of experiential education is not so much the activity but the "analysis of the activity through personal reflection, discussion, writing, or projects that help the learner transitions form the experience to integrated meaning and finally to subsequent understanding” (Montrose, 2002, p. 6). This notion is important because study abroad experiences not only provide some of the best opportunities for experiential learning, but architecture education is also based on experiential learning.

\section{Phenomenology and Architecture}

Although my study uses an experiential learning conceptual framework, I did explore the relationship between phenomenology and architecture to gain a better understanding of how individuals experience architecture. Much has been written about the experience of architecture dating back to Martin Heidegger's distinctions between notions of space and place, and more recently in the witting of architectural theorists and practitioners like Christian Norberg-Schulz, Kenneth Frampton, Tadao Andoa, and Juhani Pallasmaa (Nesbitt, 1996). According to Seamon (2002), the experience of architecture is phenomenological because it "entails a critical distinction between livedspace and geometric space, between the experience of place and the geometric simulations which are a means to its effective transformation” (p. 131). In one such work written by the Finnish architect and theorist, Pallasmaa (1986), the idea that architecture can give form to meaning is substantiated. He writes that architecture has embodied memories that also evoke primary feeling of enclosure, protection, expectation, 
fulfillment, strangeness and familiarity. According to Pallasmaa (1986), architecture offers a multisensory experience and is a "direct expression of existence, of human presence in the sense that it is largely based on a language of the body of which neither the creator of the work nor the person experiencing it is aware” (pp. 23-24). Tadao Ando (1991) not only elaborates on the experience of architecture and its importance to the creation of place, but he also acknowledges how Japanese cultural sensitivities influence the development of Japanese architecture. The interaction with nature, for example, has a profound impact in the Japanese spiritual and religious tradition that becomes an integral aspect in Japanese architecture.

Probably the most significant of these phenomenological writers is NorbergSchulz who expanded upon Heidegger to propose his own theories pertaining to the experience, meaning, and purpose of architecture. According to Norberg-Schulz, for example, the purpose of architecture is to "provide an existential foothold, one which provides orientation in space and identification with a specific charter of a place" (Nesbitt, 1996, p. 429). What I find important in Norberg-Shulz's (1976) writing is that he addresses the meaning of architecture from the basis of qualitative totalities that include material, texture, color, form, and shape. Together, these elements create an environmental character that not only defines the architecture but helps to create the genius loci or the spirit of a place (Nesbitt, 1996; Norberg-Schulz, 1976). Place, according to Norberg Schulz (1976), is a "qualitative, 'total' phenomenon” (p. 3), that cannot be deduced from purely abstract or objective knowledge. Place is really what defines architecture in terms of its totality, which can only be experienced through a phenomenological method and experiential process. 
I agree with Norberg-Schulz's (1976) statement that architecture comes into being when the entire environment is made visible. I believe this to be a fundamental truth that becomes more revealing when experiencing architecture in unfamiliar or foreign surroundings. When travelling, the concept of place becomes much more apparent because the forms, materials, and even compositions that actually inform the character of the architecture of a particular location and culture are more evident. This understanding serves as a basis for Frampton's (1993) work on Critical Regionalism and his espousal of a culturally and regionally conscious architecture. Although Heidegger's and NorbergSchulz's concepts on the phenomenology of architecture are very theoretical, they do elicit thought on the experiential nature of architecture. This served as a means through which to formulate questions and develop conversation on how the students in my study not only experienced architecture and urban environment while travelling abroad, but also how their perceptions of place developed through the experience of travel.

These architectural theorists and practitioners have acknowledged directly or indirectly that the experience of architecture transcends literal description because of the feelings and emotions connected with the buildings. In the case of my study, I elicited responses from students that addressed the manner in which, consciously or not, students interacted emotionally with architectural and urban spaces while travelling abroad. This interaction develops a fundamental awareness of the built environment and goes far to create a greater appreciation of the manner in which architecture begins to create physical environments (Norberg-Schulz, 1976). 


\section{Chapter Summary}

In this chapter, I reviewed the literature about the implications of travel pedagogy in higher education and discussed the lack of literature on the influence and implications of international travel and study abroad in architecture. I have, however, provided examples of ways in which international travel and study abroad address issues of diversity, globalization, and the curriculum and pedagogy of architecture. In Chapter 3, I address the lack of research pertaining to the implications of international travel and study abroad for students pursuing undergraduate and graduate degrees in architecture. 


\section{Chapter III}

\section{METHODS}

This chapter examines the method of investigation on the influence of international travel and study abroad on undergraduate or graduate architecture students. Within the context of this chapter, I include information about data gathering, participant selection, interviewing procedure, methods of participant response coding, and delimitations of the study. Taken from the perspective of the architecture student participants at the University of Miami and Florida International University, and alumni from these institutions and the University of Florida and Syracuse University, this information and these discussions center on the principle research questions of this study that include: (a) How have international travel and study abroad shaped the educational experience of those studying or have studied architecture? (b) How have international travel and study abroad complemented the architecture curricula? (c) How have international study and travel experiences enhanced the understanding and awareness of global architecture of those studying architecture or have studied architecture? (d) How have international travel and study abroad influenced the personal and professional development of those studying architecture or have studied architecture?

\section{Qualitative Research}

This study used a qualitative method of research that was based on interviews of architecture students at the University of Miami and Florida International University, and alumni from these institutions and the University of Florida and Syracuse University to learn about their study abroad and international travel experience, and how this experience influenced their learning about architecture. Qualitative research method 
involves collecting descriptive data within a setting to formulate an understanding or meaning of a specific aspect of social experience (Bogdan \& Biklen, 2006). Unlike quantitative research that identifies specific relationships between variables and seeks to reject or fail to reject hypotheses with collected data, qualitative research is inductive and establishes its premises from generalities gathered in the inquiry (Borrego, Douglas, \& Amelink, 2009). As such, qualitative research focuses on the "qualities of entities and on processes and meanings that are not experimentally examined or measured in terms of quantity, amount, intensity, or frequency” (Denzin \& Lincoln, 2003, p. 10). Qualitative researchers, therefore, attempt to create connections within the lived experience through the variety of empirical material gathered in the investigation. More specifically, however, qualitative researchers in education are interested in finding out what individuals experience, how they make sense of their experiences, and how they structure the social world in which they live (Bogdan \& Biklen, 2006; Psathas, 1973).

Philosophically, the decision to employ one specific paradigm over another within a qualitative study depends largely upon the researcher's own perception of the empirical word that is shaped by his or her own personal biography, ethnicity, religion, socio/economic background, and gender (Denzin \& Lincoln, 2003). As such, there are many interpretative paradigms that address and include issues of gender, race, and class but are drawn from a phenomenological, feminist, ethnic, or Marxist perspective, each using a different form of theory and type of narration. Qualitative research has historically developed using positivist and post positivist, constructivist, and critical theory inquiry paradigms to address the fundamental ontological, epistemological, and methodological questions of any given study. (Denzin \& Lincoln, 2003). Whereas 
positivist and post positivist paradigms can be used in a qualitative study, the critical theory and constructivist paradigms have greater application because of the attempt to create meaning from events and interactions of people in given circumstances (Bogdan \& Biklen, 2006). Developing an understanding of how international travel and study abroad shapes an architecture student's experience of the curricula lends itself to a qualitative research method. This lived experience may only be shared and inductively gathered through an open dialogue between participant and researcher. The subtleties of lived experience, furthermore, and its subsequent impact on the understanding and perception of architecture are far too many to quantify in terms of mere variables or numerical data (May, 2002).

One of the advantages of using a qualitative research mode for my particular study is that it involves the use of a variety of methods and materials as part of the data gathering. In addition to the interview, Denzin and Lincoln (2003) suggest that qualitative researchers may employ "case study; personal experience; introspection; life story; artifacts; cultural texts and productions; observational, historical, interactional, and visual texts - to describe and study routine and problematic moments and meaning in individuals’ lives” (p. 5). In fact, I used life stories, artifacts, personal experiences, and sketch journals to learn about the international travel and study abroad experiences of architecture students at the University of Miami and Florida International University, and the alumni form these institutions and the University of Florida and Syracuse University.

A qualitative investigation also lends itself perfectly to my study on travel and study abroad experiences for architecture students because the process of qualitative research is very similar to the process of travel (Kvale, 1996). As a traveler and 
researcher, I am most compelled by this idea. In a qualitative study, for example, the researcher embarks upon a metaphorical journey interviewing the subjects that eventually develops into a story or narrative. Kvale (1996) draws this analogy of the interviewer as a traveler, and writes that the interviewer/traveler metaphorically wanders into foreign environments and locations while engaging people through conversation, which is the basis of the research. Knowledge and understanding of the participant's experience while travelling is imparted through a series of interviews that begin to develop into each student’s personal story. According to Kvale (1996), “the potentialities of meanings in the original stories are differentiated and unfolded through the traveler's interpretations: the tales are remolded into new narratives, which are convincing in their aesthetic form and are validated through their impact upon the listeners” (p. 4). In fact, I am reminded of my own travel experiences talking to people en route to common destinations to find out more about themselves, their lives, and experiences. Without knowing it, I was already engaging in qualitative research by interviewing fellow travelers about their experiences of particular places or spaces. Many of my decisions of where to travel were based upon these interviews and discussions.

\section{Experiential Learning}

As travelers take specific routes and means of travel to better experience a country, researchers employ specific interpretative paradigms or methods of research to understand the significance of their studies (Kvale, 1996). These methods also help the researcher develop a mode of inquiry and a means to understand the implications of the research. I find Kvale's analogy of travel and research compelling because, as a traveler, I have often chosen specific routes and means of travel to better experience the countries 
I visited. Although I had initially used a phenomenological approach to my research, my study was essentially focused on experiential learning. I was interested in understanding how students learned and made sense of what they learned while abroad. To this end, I used Kolb’s (1984) experiential learning cycle method as the basis of my study. Based on the work of Kurt Lewin (1952), Kolb’s experiential learning cycle begins with the concrete experience and is followed by observations and reflection. The third aspect of the cycle includes the assimilation of the observations into the formation of abstract concepts and generalization which finally lead into the testing of these concepts in new situations (Montrose, 2002). Kolb’s experiential learning cycle provides a conceptual framework to understand the relevance and significance of experiential learning in travel and study abroad programs.

The international learning experience provides many opportunities for experiential learning because it "constitutes an educational, spiritual, and even creative atmosphere that broadens an understanding of both the individual and other cultures (Mouton, p. 37). International travel and study abroad opportunities also directly correspond to Kolb’s (1984) experiential learning cycles. According to Montrose (2002), the first part of the experiential learning cycle is the initial exposure to the international environment of the study abroad experience. The observations and reflections stage is the individual's "stepping back from the experience and noticing differences, comparing and contrasting what is familiar with experiences that are new" (p. 6). The most important part of the cycle is the conceptualization stage. Here the student interprets and generalizes the events while at the same time questioning the meaning of the experience. The final stage is the most critical because the student has "an opportunity to change 
behaviors or thinking and apply these changes to a new set of circumstances” (p.6). According to Montrose (2002), these changes are intentionally planned and the knowledge is subsequently transferred into concrete actions.

\section{The Role of the Researcher}

My decision to conduct a study on the implications of international travel and study of architecture students stemmed from my own personal experiences of travel and teaching. My travels globally have been rather extensive, and I have had the opportunity to live, study, and work in a number of European countries. As an independent study project in architectural history, I proposed embarking upon the Camino de Santiago, the ancient pilgrimage route to the holy city of Santiago de Compostella in Galicia, as a means exploring the architectural heritage of Spain and France. For an entire month, I rode my bicycle through central France to the Pyrenees, along the northern coast of Spain

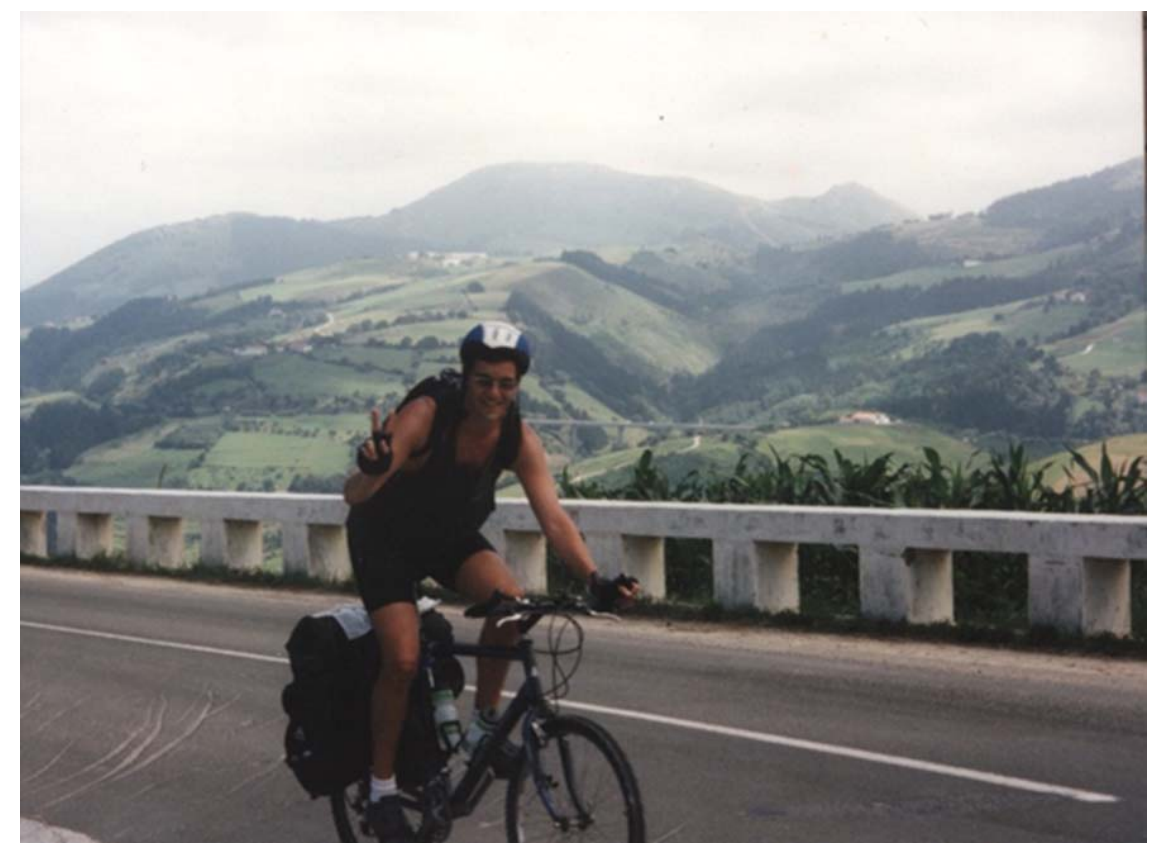

Figure 1. Lyle Culiver in Asturias completing the Camino de Santiago, kugtst 2000. 
to Asturias, and then from the city of Leon, I crossed the provinces of Castillo and Leon to Galicia. As a pilgrim, a number of French and Spanish Benedictine monasteries offered me overnight accommodations, and I had the opportunity to engage with the monks. My interest in monasticism and ecclesiastical architecture grew. By the time the pilgrimage was completed, I was intent on investigating aspects of Benedictine architecture as a possible thesis project. Though the final topic of investigation took time to develop, my project centered on issues pertaining to time, space, and order as applied to the design of a Cistercian Monastery on a prescribed site in North Carolina.

Because of this pilgrimage, I was able to draw from my personal experiences as I contemplated the design issues for my thesis project. I was also able to reference my sketch journals to help me develop ideas for the design work. As part of this doctoral study, I intended to further my original thesis topic to explore and understand how international travel and study could enhance other students' appreciation of and understanding about architecture. I also wanted to learn what areas of these individuals' personal and professional lives were positively influenced because of their study abroad experiences. Because of my interest in art, I also wanted to examine how architecture students used their sketch journals to document their memories and impressions of their travels. 


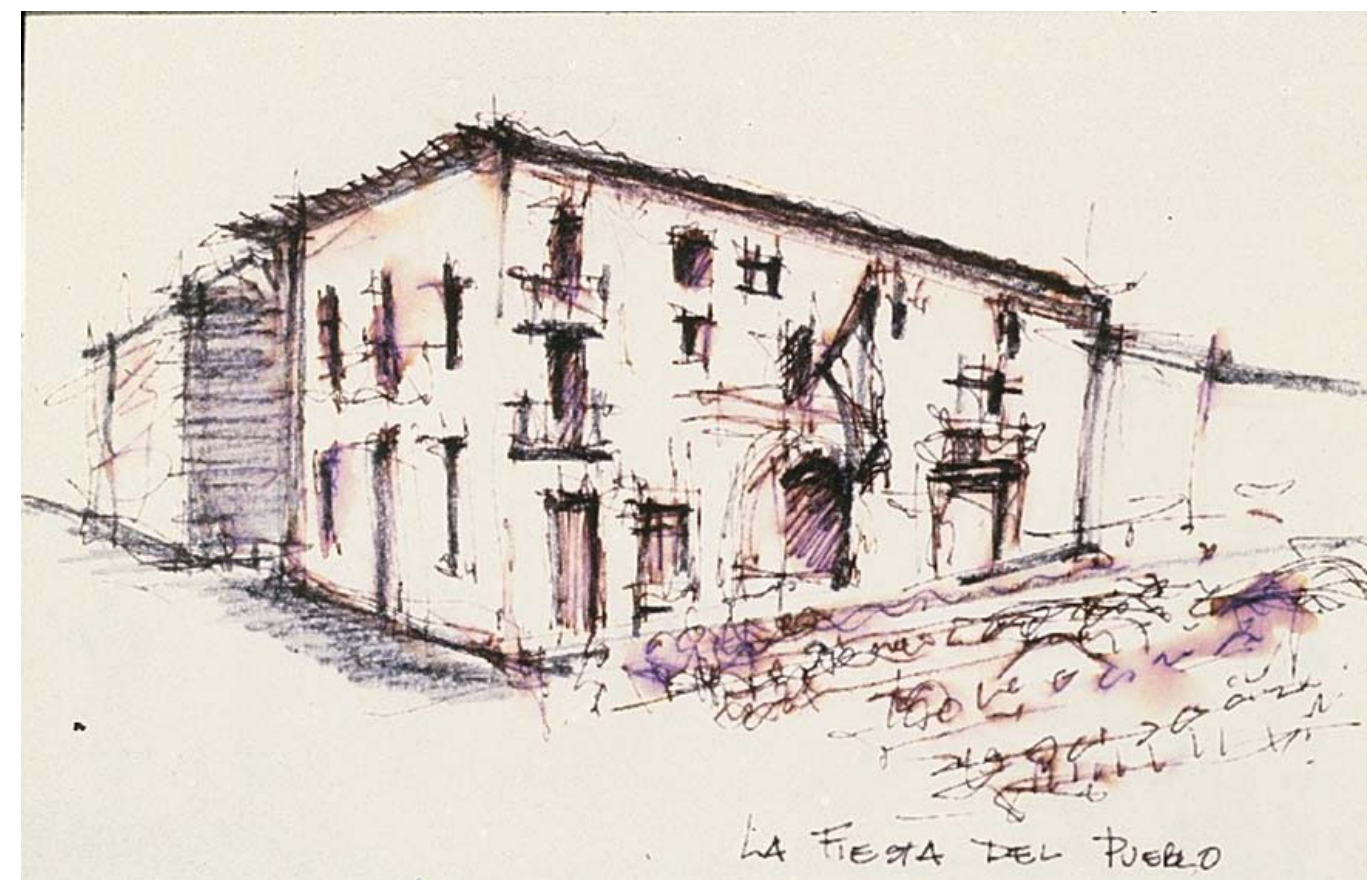

Figure 2. City Hall on the day of a festival. Pen \& Ink sketch from Lyle Culver's Camino de Santiago journal, August 2000.

Figures 2 through 6 illustrate the architecture and my experience of the pilgrimage to Santiago de Compostella. They were taken directly from my own personal sketch journals that I used to document the memories. Many of these renderings were made in a matter of minutes usually drawn as I stood alongside a road. The drawings are for the most contour sketches and attempt to capture specific architectural details of buildings that I found to be interesting. The image in Figure 2, for example, shows the city hall of a small Basque village. The image also represents memories of meeting people from the village and celebrating with them in the plaza directly in front of the building. 
Figure 3 shows an urban condition in Madrid. I remember sitting in one of the main thresholds to the Plaza Mayor looking towards the Calle de Toledo. As I sketched, a street artist who was selling some of his own paintings approached me to take a curious

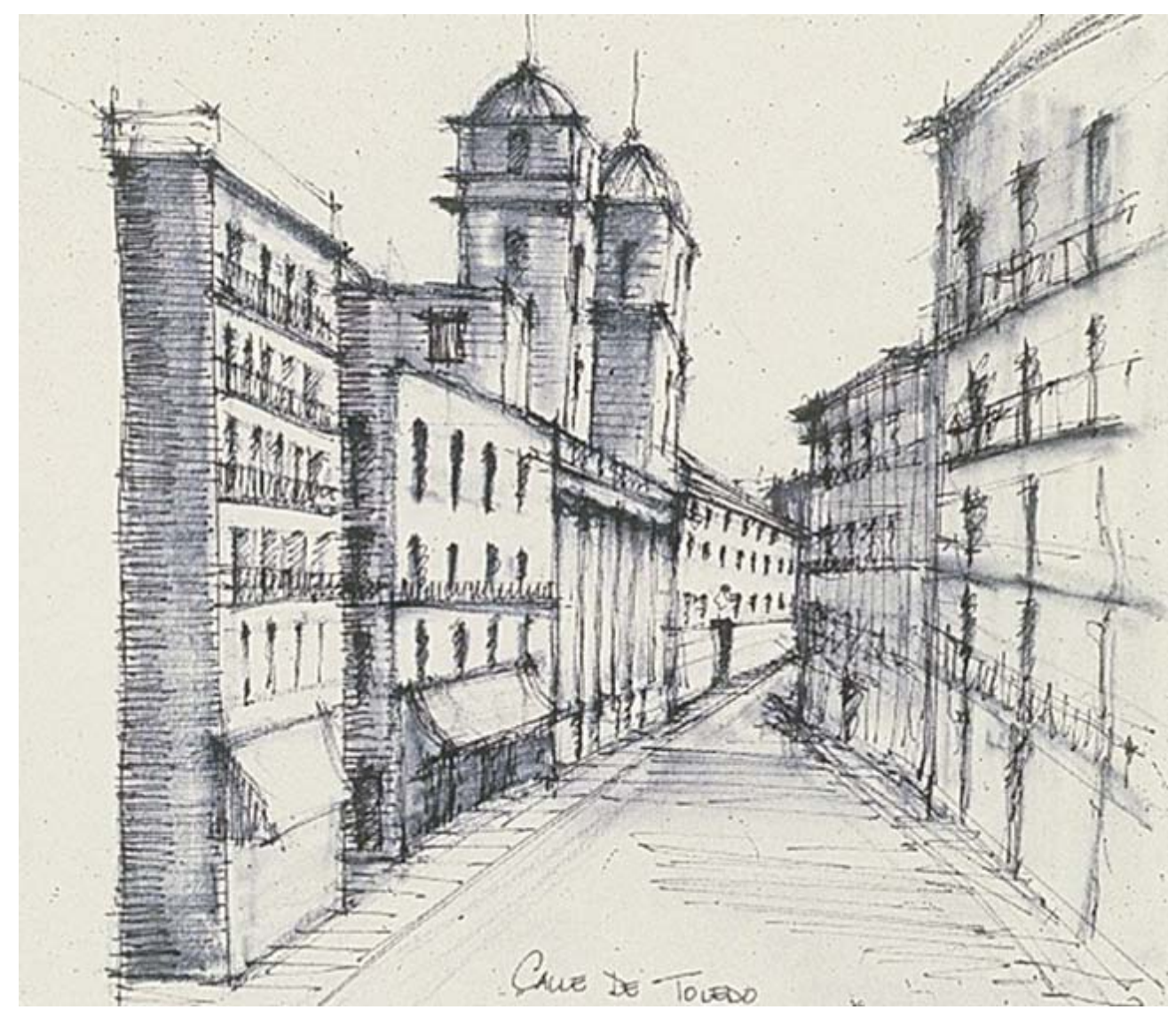

Figure 3. Calle de Toledo, Madrid. Pen \& ink sketch from Lyle Culver’s Camino de Santiago journal, August 2000.

look at my work. After a few moments, he began to advise me on some rendering techniques. I realized that the sketch journal was not only a means of documenting what I was seeing, but it was also an opportunity to engage people. In fact, on many occasions people would stop to see what I was drawing and comment on the sketches. I actually quite enjoyed this aspect of the exercise because the act of drawing was a social activity and an opportunity to engage with local nationals. 
Figures 4 and 5 show two different cathedrals that I visited along the pilgrimage.

The renderings also highlight different aspects of the buildings that I found of interest.

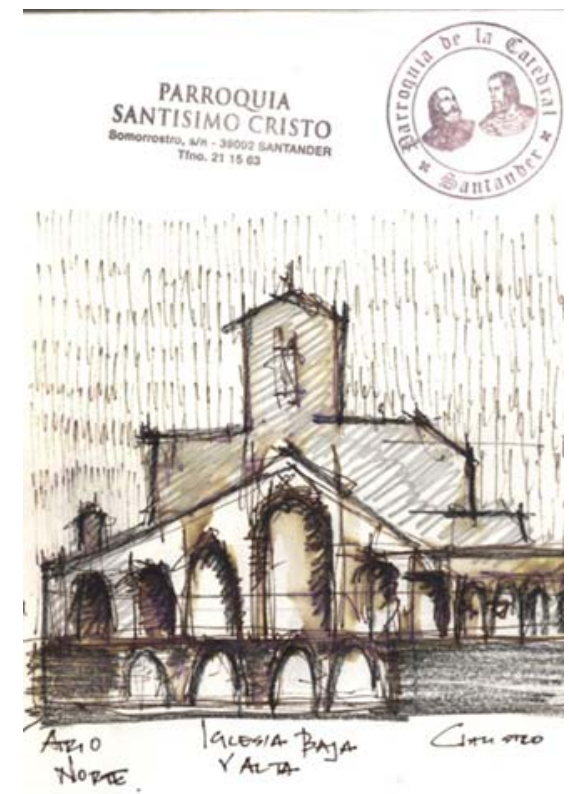

Figure 4. Section drawing of the Cathedral of Santander. Graphite, pen \& ink sketch from Lyle Culver's Camino de Santiago journal, August 2000.

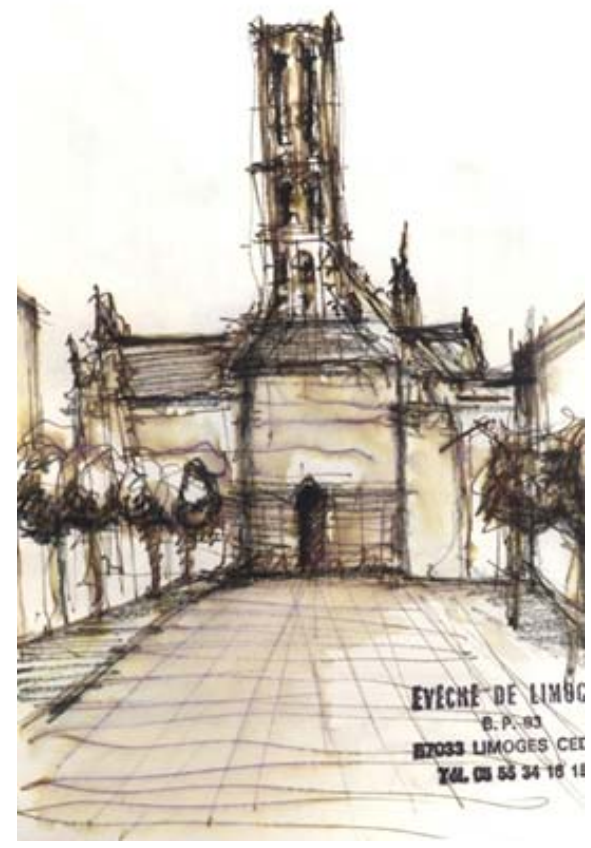

Figure 5. Elevation of the front façade of the Cathedral of Limoges. Pen \& ink wash sketch from Lyle Culver's Camino de Santiago journal, August 2000.

The image on the left, for example, illustrates a section of the Cathedral of Santander that was drawn to illustrate the spatial and structural configuration of the edifice. Also apparent from the image is the style of architecture to which it corresponds. Since the arches are rounded, it is evident that church was built in the Romanesque. The image on the right depicts the Cathedral of Limoges and shows the front elevation of the building. In this image, I wanted to illustrate the simple and rather plain façade of the cathedral with its very minimalist entrance defined by a Gothic arch. 
Some of my sketches reveal interior spatial configurations and were drawn using perspective techniques to create a sense of depth. Figure 6 shows the interior of the Cathedral of Santiago and illustrates the main altar and the shrine dedicated to St. James. I vividly remember sketching the interior while I was listening to a live music performance of Handel. As I listened to the music and sketched, I began to associate the contour lines of my sketch with the music. The drawing became increasingly fluid, and I

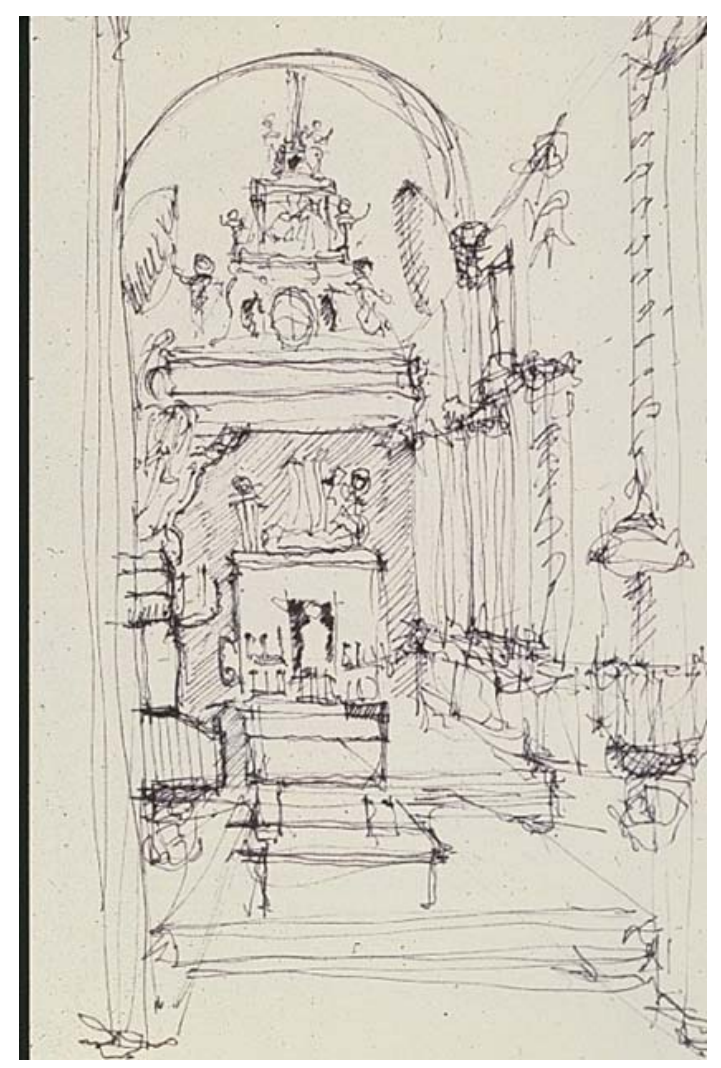

Figure 6. Interior of the Cathedral of Santiago de Compostella, Pen \& ink sketch from Lyle Culver’s Camino de Santiago journal, August 2000

found myself projecting the pen in a multitude of directions across the page as I sought to keep pace with the music. I also began to gain a greater understanding of the significance 
of the shapes and forms of the interior of the cathedral because of this drawing. The space around the altar started to transform as my attention focused on the architectural elements of columns, arches, stairs, and platforms that define this sacred condition.

From my own personal experience, the uses of art and sketching in particular have been important aspects of my development as a designer and professor. I have gained a greater appreciation for architecture and the natural environment because I enjoy sketching. As a professor, I try to impart this enthusiasm to my own students as I encourage them to be observant of their environments. I encourage them to document in their sketch journals what they see and experience. In fact, I continue to use and teach to my students many of the rendering techniques that I experimented with in my own travel journals. Even the architectural aspects of my thesis project continue to be issues that I contemplate in practical and theoretical terms.

As a professor of architecture at Miami Dade College (MDC) I am very much engaged in the process of educating. I am also very involved in a number of architecture and interior design related courses and projects with students. I have been teaching at Miami Dade College, School of Architecture \& Interior Design for the past 7 years fulltime, and was recently tenured and promoted to the position of Associate Professor. In 2010, I was awarded the Dr. Robert H. McCabe Endowed Teaching Chair as recognition for my success in teaching and extensive participation in college and community affairs. In addition to the courses that I teach, I also serve on a number of campus and institution wide committees and learning initiatives that include the MDC Learning Outcomes Assessment and the College Academic \& Student Support Council, Institutional Effectiveness Committee. My participation in these institution wide initiatives has 
provided me with valued experience on conducting and evaluating assessments in addition to establishing general learning and institution operational objectives. As faculty, I have also familiarized myself with many architecture and design programs nationally including those at the University of Miami and Florida International University in addition to those of the University of Florida and Syracuse University, which served as the sites for my research. Many of my former students transfer to these institutions to continue their architectural education at the upper division level.

In terms of the research, I chose to conduct a qualitative study because I wanted to interview architecture students to learn about their experiences travelling abroad and the impact it has had on their education. As an architecture professor, I am accustomed to a personal interaction with students, particularly in the design studio environment. In many respects, the method of education in the architecture design studio most closely approximates the interview process of a qualitative research project because I try to understand the student's implementation and meaning of a particular design concept through dialogue and discussion.

Although the interviewing process is important to the research, it was not my only focus. In addition to asking questions and documenting accounts of travel experiences, I also examined how students captured their travel experience through their sketch journals. This was yet another area where personal experience helped me to analyze this information. As a traveler, I learned to keep graphic and written accounts of my travel experiences in the form of journals. As a professor, I teach architectural sketching and travel journaling. In my architectural history courses, I make it mandatory that students submit their notes in the form of sketches of the buildings discussed in the lectures. The 
ability for an aspiring architect to document his/her experience through graphic depictions is a very important and a vital tool. Observing and recording architecture and architectural details are a means through which the student can critically analyze the structure (Jones, 2001).

\section{Site and Participant Selection}

Initially, my study only dealt with undergraduate and graduate students studying architecture at Florida International University and the University of Miami. Architecture students who were part of a semester abroad study program at either institution were the selection criteria for this study. Some of the names of students who had participated in the international study programs from the University of Miami and Florida International University were provided by the academic deans and foreign studies program directors. I sent these students written invitations to participate in my study and I interviewed 10 participants from both institutions. In some instances, I also engaged these students for a second interview as a follow up and a means to study in more detail their travel journals, drawings, photography, and images of their studio design projects they provide during the initial interview. Specifically, I wanted to understand how the influence of travel and study abroad influenced their understanding of global architecture, as seen through their creative work.

I did not limit my interviews to either graduate or undergraduate students. Architecture students, however, who participate in the Florida International University semester abroad, tend to be in the fourth year graduate studios of the 5 year accelerated Master of Architecture (M. Arch.) program. At the University of Miami, Syracuse University, and the University of Florida undergraduate and graduate architecture 
students have the option to travel and study abroad as part of the design program, and were selected to participate in my study.

I had initially chosen to only conduct my study at the University of Miami and Florida International University because they offer well-established international study programs. My intention, however, was not to conduct a study of institutions or architecture programs but to conduct a study of architecture students and alumni from these institutions.

According to the University of Miami, School of Architecture website, many opportunities exist for undergraduate and graduate architecture students to travel and study abroad. As part of the curriculum, the University of Miami sponsors fall and spring semester study abroad in Rome for upper and graduate level architecture students. In addition to the semester abroad, the University of Miami also promotes a variety of travel study programs that vary in location, and range in time and duration from one week to a year. Students also have the opportunity to participate in several University of Miami sponsored exchange programs. Florida International University, on the other hand, offers a fall semester study abroad study program in Genoa, which is available for fourth year and graduate students. As part of a post professional graduate degree in architecture, students at Florida International University also have the option to spend an entire year at the Florida International University Genoa Center pursuing advanced design studios in addition to courses in architectural theory, history, and contemporary Italian design.

I also initially chose to interview architecture students at University of Miami and Florida International University because these institutions offer many potential points of comparison. Much of the research and understanding about both institutions comes from 
a variety of sources, which includes my interaction with faculty and administrators from both design programs over the past several years, and my participation as a juror on design critiques. I am also familiar with the types of design work students from each design program are required to do based upon my participation in mid and end of term design reviews and my personal association with the design faculty. I have also seen the annual architecture student exhibited work of the University of Miami and Florida International University at the American Institute of Architects (AIA) Miami Chapter sponsored academic exhibitions.

I am also familiar with both design programs because I have reviewed the architecture program websites from the University of Miami and Florida International University. I have become very familiar with the types of degrees offered by both institutions in addition to the application requirements for entry at both the undergraduate and graduate levels. Because many of my former students at Miami Dade College have transferred to both institutions, I am also aware of the types of students the University of Miami and Florida International University attract. Over the past 7 years, I have also helped hundreds of Miami Dade College architecture, landscape architecture, and interior design students transfer to both institutions by writing letters of recommendation and reviewing their applications and portfolios.

The institutional cultures at University of Miami and Florida International University, for example, are different and the students who are attracted to either vary in terms of their socio economic backgrounds and their academic and professional aspirations. The University of Miami, for example, is a private institution offering a 5year professional Bachelors of Architecture (B.Arch). In addition to this degree, the 
University of Miami also offers a 6-year Bachelor of Architectural Engineering and Master of Architecture degree program (B.S.A.E. /M.Arch) which allows students to pursue professional registration in both architecture and engineering. A variety of graduate professional degrees in architecture are also offered that include the 3.5-year M.Arch first professional, and an advanced 2-year M.Arch track for students who have design related degrees. The University of Miami also offers additional research related post professional M.Arch degrees. In addition to architecture, graduate degrees and certificates are also offered in Suburb and Town Planning, Real Estate Development and Urbanism (MRED + U), and Historical Preservation.

Florida International University, on the other hand, is a public institution now offering an accelerated 5-year professional M.Arch 1 degree. Students also have the option to pursue the 3.5-year M.Arch 3 track for those with no prior architecture educational experience, and the 2-year M.Arch 2 for those who are graduates of a 4-year nonprofessional undergraduate degree in architecture. In addition to architecture, Florida International University students also have the option of pursing graduate professional degrees in Interior Design (Master of Interior Design-MID) and Landscape Architecture (Master of Landscape Architecture-MLA).

Whereas the University of Miami, School of Architecture, offers undergraduate and graduate professional degrees in architecture and graduate degrees in town planning and real estate development, Florida International University has recently changed its focus to offer only graduate professional degrees in architecture, landscape architecture, and interior design. In addition to the professional M.Arch degrees, Florida International University also offers the Master of Arts in Architecture (MAA) for students who already 
possess professional degrees in architecture but wish to expand their education in specific areas of research. Three separate tracks leading to the MAA include; urban development, Miami based advanced design studies, and the Genoa based advanced design studies.

The structure of the architecture programs at both institutions also vary. Unlike the University of Miami's architectural program that is a separate entity within the institution, the architectural program at FIU is part of the College of Architecture and the Arts. In fact, architecture is only one of several disciplines offered within the College of Architecture and the Arts, which include art and art history, music, theatre, interior design, and landscape design. A department head chairs architecture at Florida International University and the school shares its facilities with the other departments within the college. The University of Miami, on the other hand, has its own dean and recently inaugurated a new building that houses the School of Architecture. The manner in which a discipline is integrated within an institution and the manner in which it is managed can greatly influence the overall culture of the department. This may also have an impact on how students view themselves within the greater institution based on the perceptions of their chosen discipline of study and the department (Pascarella \& Terenzini, 2005). Students studying architecture at the University of Miami may exhibit heightened expectations towards their study since the discipline has a perceived independent status within the institution. Though there is no research to support this idea, a new building and a dean may be significant in how the students view themselves in light of other academic programs and disciplines.

Both institutions also exhibit different design teaching methodologies. The University of Miami, School of Architecture, for example, has a reputation of being 
classically focused and historically based in its approach to architectural pedagogy, which may have much to do with the professional and personal interests of its faculty and administrators. Some of its professors have included well-known architectural historians such as Vincent Scully and its current dean, Elizabeth Plater-Zyberk, who is a co-founder of the Congress of New Urbanism—a national movement of urban and community design that supports the restoration of urban community centers while preserving their historical character (Leccese \& McCormick, 1999). Elizabeth Plater-Zyberk is also a board member of the Institute of Classical Architecture \& Classical America, an organization that serves to promote and create greater understanding and awareness of the classical tradition in architecture, urbanism, and the allied arts ( Institute of Classical Architecture and Classical America).

Even the student architectural projects featured on the academic prospectus and recruitment material of the University of Miami, School of Architecture (2007-2008), are very reminiscent of the French Beaux Arts Academy work of the 18th and 19th centuries. Some of the represented work is very neoclassical in its orientation, and there is a strong emphasis placed on hand-rendered drawings (2007-2008 University of Miami, School of Architecture Prospectus). The prospectus material says much about the educational directive of the University of Miami, School of Architecture, especially when the examples provided include watercolor studies of Italian Baroque architecture, and design proposals for entrance gateways and water pump pavilions for the Vizcaya Museum (2007-2008 University of Miami, School of Architecture Prospectus).

Florida International University, however, focuses an important part of its curriculum on the use of technology and its integration in the design process. There is 
great referencing of modern and contemporary architecture in the curriculum, which is reinforced by the lecture series and the discussions presented by leading practicing architectures. The award winning Paul Cejas Building, which houses the Florida International University, School of Architecture, also exemplifies the program’s educational directive and reinforces the school's identity by creating a series of dynamic spaces that serve as a generator for creative expression (Florida International University, School of Architecture Website).

Since the University of Miami is a private institution, tuition costs are much higher than at Florida International University. According to institutional information provided by both universities, the cost per undergraduate credit at University of Miami for the academic year $2009-2010$ is $\$ 1,480.00$ compared to $\$ 340.68$, including fees, at Florida International University. Although not a general rule, students who are financially constrained may not readily apply to the University of Miami. Those who attend this institution may come from more privileged backgrounds than their Florida International University counterparts because they can afford the tuition.

Although ethnically diverse as an institution, White non-Hispanics accounted for $55 \%$ of the undergraduate student body at the University of Miami, School of Architecture. Black non-Hispanics accounted for 8\% and Hispanics 29\%. Representing $36 \%$ of the undergraduate student population, international students also account for a large percentage of the school's student body (2007-2008 University of Miami, School of Architecture Prospectus). At the Florida International University, School of Architecture, however, the percentage of minority undergraduates enrolled in the program is even more significant. According to 2007-2008 information provided by the Florida International 
University Office of Planning \& Institutional Effectiveness (OPIE), 69\% of architecture undergraduates are Hispanic. White non-Hispanics account for 18\% and African Americans only 5\%.

After I had started interviewing students from Florida International University and the University of Miami, I realized that the sample that I used was too limited. I wanted to expand the scope of the study to include working professionals who had graduated from other architectural programs. I had only managed to include 2 working professionals who had graduated from Florida International University and a recent graduate from the University of Miami to be part of this study. I had some degree of difficulty locating more graduates from these institutions and decided to include alumni from other design programs. Although my study was not intended to be a comparison of design programs, I managed to meet and invite graduates of the University of Florida and Syracuse University to take part in my study. Some of the participants I had known as faculty colleagues. Others had been introduced through mutual friends and they had consented to be interviewed as part of this study. My interaction with these institutions, however, is not as in depth as my interaction with the University of Miami and Florida International University. I do not have the same level of contacts with the faculty or understanding of the teaching methodology as I do with the Miami-based institutions. As a result, I was unable to comment as much in depth about the architecture programs at Syracuse University and the University of Florida as I was of Florida International University and the University of Miami.

Although I was somewhat aware of the reputation of the architecture program at Syracuse University, I learned more about the program by interviewing an alumna. 
Syracuse University is a private institution located in central New York. According to report published by its Division of External and Public Affairs, total enrollment in 20092010 was 19,368 students. Racial and ethnic minority students represented about $22 \%$ of the student body and $57 \%$ of the undergraduates were women. According to information provided by Syracuse University, 2010-2011 undergraduate tuition is $\$ 34,970.00$ and graduate tuition is \$20,196.00 (FACTS, 2010). Like the University of Miami, students who are financially constrained may not readily apply to Syracuse University. Those who attend this private institution may come from more privileged backgrounds than their public school counterparts.

The architectural program at Syracuse University is one of the oldest programs in the nation and has a reputation of being one of the finest in the U.S. Admissions to both the graduate and undergraduate programs are very competitive and applicants must have a strong sense of creativity and the ability to take on a rigorous academic regimen of course and studio work. Students must also submit portfolios for entrance into the undergraduate and graduate programs as a demonstration of their creative abilities and academic promise. Syracuse offers the 5-year profession B.Arch degree in architecture for undergraduates. It also currently offers the M.Arch I degree, a 2-year course of study for students who have already completed a B.S. in Architectural Studies. Also offered is a post professional research based M. Arch II degree for students who already have a professional architectural degree but wish to concentrate their studies in a particular area of research. What is apparently no longer offered, however, is the year-long post professional degree in Florence that my interviewee had participated in years earlier. This 
option has apparently been discontinued but Syracuse University does continue to maintain its center in Florence.

The architecture program at Syracuse University has very well established international programs for its undergraduate and graduate students. At Syracuse University, graduate and undergraduate students are able to spend a summer or semester abroad on one of its three "Global Campuses" located in Florence, London, and New York City. The program also offers a host of short term travel study opportunities to various European and Asian countries offered during the summer months. It also offers a pre-Architecture program in Florence for students who are not currently enrolled in architectural studies but have an interest in the field.

I interviewed four graduates of the University of Florida undergraduate and graduate programs in architecture. These individuals were working as architects, educators, and urban designers. Some were also teaching and two were actually going to pursue post graduate degrees in architecture and landscape architecture at the University of Pennsylvania. My interaction with University of Florida, School of Architecture, is somewhat limited though I have had a number of students transfer form MDC to its upper divisions program in architecture. The University of Florida is one of the largest public institutions in the U.S. with over 50,000 students. As a public institution, its tuition is considerably less that the private schools listed in this study. According to its 2010 tuition report, instate undergraduate students pay $\$ 168.16 /$ credit hour. In state graduate students pay $\$ 454.83 /$ credit hour. These rates are considerably lower than those of the Syracuse University or the University of Miami making it much more affordable to study 
architecture. Out-of-state tuition is considerably higher than the instate option and is actually not much lower than the private school alternatives.

The University of Florida, School of Architecture, is located in Gainesville and offers a variety of graduate and undergraduate degree options. The architecture program is often listed as one of the finest in the U.S. and its application process is also highly competitive. Undergraduates can pursue the B. Design that is a 4-year nonprofessional degree in architecture. Within the Graduate School of Architecture (G/SoA), students can continue their education to purse the professional M. Arch in 2 years. Also offered is the 4-year M.Arch Core alternative for students who lack any formal education in architecture. The G/SoA also offers a variety of 2-year Master of Science degrees with specialties in Historic Preservation, Architecture Pedagogy, Architecture History \& Theory, and Building Technologies.

The University of Florida, School of Architecture, has well established study abroad programs that vary in length from long-term to short-term programs in Italy, Mexico, Hong Kong, India, and Jamaica. Three of the participants who I interviewed had spent a semester abroad in the University of Florida’s Architecture Center in Vicenza. This program is offered for both graduates and undergraduates. These students live in Vicenza and take their courses at the center. The curriculum is structured according to a set list of required courses in architecture design, theory, and history that students are required to take. The program also includes travel excursions that the students take with their professors to other parts of Italy and other European countries.

One of the University of Florida participants talked about her experiences on the travel study abroad programs offered by the University of Florida in Mexico. According 
the organizers of this study abroad program, the main emphasis of this international studio "pays close attention to the impact of climate, culture and construction on the design of new public spaces and building tectonics.” This particular program is organized as a vertical studio where students take courses in Mexico and then later complete the design studios in Gainesville. The program is only offered during the summer months and is based in Jalisco. Excursions to other cities and areas of Mexico are also included as part of the experience.

\section{Data Collection}

Data collection for this study on the implications of foreign travel and study for architecture students at the University of Miami and Florida International University, and graduates of these institutions and alumni of the University of Florida and Syracuse University primarily involved participant interviews, and the use of my field journals and my observational notes. I also examined the students' sketch journals and photography during the course of the interviews. Since my research was based on a phenomenological mode of study, my questions were drawn from this perspective in an attempt to understand the meaning of specific events and interactions of the participants in particular situations as suggested by Bogdan and Biklen (2006).

The challenge for the interviewer, however, is to build upon the answers and explore the responses in order to have the participants reconstruct their experiences (Seidman, 2006). In the case of my study, having students recount experiences as individual stories was a means to better understand how international travel influenced each individual's perception of architecture. The experience of sitting in a piazza in Vicenza, for example, or sitting in a Parisian café drinking an espresso while observing 
pedestrians illustrates how these students begin to engage the urban context and possibly appreciate the urban spaces of these European cities. In my own personal experience, I have often sat in urban cafés just to observe people and architecture. In fact, one of my most memorable experiences was sitting in an open café directly in front of the Cathedral of Strasbourg in a late summer afternoon just observing how the changing sunlight affected the visual perception of this Gothic cathedral.

\section{Interviews}

The interview process was important to develop an understanding of the transformative nature of travel, and how international travel and study can develop into experiences that influence or change the way the traveler thinks about him or herself. As part of this study, I selected four architecture students who had participated in international travel and study abroad programs from the University of Miami, and five from Florida International University to interview. I also interviewed four graduates from the University of Florida and an alumna from the University of Syracuse who had also experienced semester and year-long study abroad programs. I used open-ended questions that are listed in Appendix B to develop an understanding of how each student benefited from the experience of international travel and study, and how it impacted their experience of their curricula and influenced their learning about architecture. The questions listed in the Appendix A served only as a guide and were modified to suit the special situations of each interview. Each interview lasted approximately 35 to 90 minutes and was electronically recorded for analysis.

I interviewed the participants of this study individually and in pairs. The circumstances of my contacts with the participants usually dictated whether or not the 
interview was on an individual basis or not. I encouraged some of the individuals, for example, to invite their student colleagues who had participated in the same study abroad programs to interview together. I thought that the discussions generated between these individuals during the interviews would be insightful and possibly provide perspectives about the study abroad experiences not possible in the individual interviews. The paired interviews were usually the longest and I did notice that the participants often engaged in conversation about the study abroad experiences with one another during the course of the interviews. The information generated from these discussions provided interesting insight into the nature of the experiences.

As far as the paired interviews are concerned, I interviewed Marc and Kate as a pair. As husband and wife, I felt that it would be interesting to listen to them both talk about their study abroad experiences. Our interview lasted almost 90 minutes. Gloria and Leslie were interviewed together at a restaurant. Gloria had introduced her friend, Leslie, to me the night of our encounter. Our initial interview also lasted approximately 90 minutes and was followed up with individual meetings and phone calls to verify that the information presented in the study was accurate. I also talked to Leslie on a number of occasions after our initial introduction to discuss her creative work and to develop a better understanding of her design projects. I interviewed JP and Alistair together at the University of Miami. Alistair's name had been provided to me by the director of the University of Miami semester abroad program and JP had been introduced by a mutual acquaintance who worked in the dean's office. I interviewed both students simultaneously because it was the only time that they had available. I was unable to continue any further discussions with Alistair because he had moved from Miami after 
the interview. Although Alistair did provide sufficient information about his experiences, I felt that JP was a little more reserved and as such the interview only last 45 minutes.

I met with Julian and Lizette at the Florida International University, Green Library. I had known Julian as a former student and he had agreed to help me locate students who would be willing to talk about their study abroad experiences in Genoa. Julian introduced me to Lizette the day of our interview. I found that both individuals talked rather openly about their study abroad experiences and the interview lasted approximately 60 minutes. Alex and Julian were also interviewed simultaneously at Florida International University. Both students had participated in the Genoa program at the same time. In comparison to Jaime, I found Alex to be somewhat reserved. As such, our interview was one the shortest lasting only 40 minutes. Jaime also provided examples of his creative work after the initial interview.

My interview with Connie, for example, was one of the longest and most involved. The interview itself lasted for about 90 minutes and we continued to communicate via email after our initial contact. Connie was very open about her personal experiences and I was able to use her data as a primary source of information. I also interviewed Guillermo individually and met with him on several occasions after the initial contact to discuss the transcripts and analyze his creative work. Of all the participants, I met with Guillermo the most after our initial conversation that lasted over 60 minutes. Guillermo was very willing to offer examples of his creative work for this study. I also met with Aliana and Julia individually at different times and locations. Both interviews lasted approximately 35 minutes. Aliana provided examples of her creative work after our initial conversation. 
The interviews varied in length depending upon how much the participants were willing to talk about their study abroad experiences. Some of the individuals were very willing to disclose even personal information about their experiences. Others, on the other hand, were somewhat reserved. I also conducted a second interview with seven individuals to address any further questions that I had from the initial interview. The second interview also provided me with an opportunity to conduct member checking to verify that the transcripts accurately captured the information from the first interview. The second interview also provided me with the opportunity to study the students' sketch journals, photography, and studio design projects to understand how study abroad had influenced their understanding of global architecture. The second interview with each student also varied in length, and I asked questions to learn about their study abroad experience in light of the creative work and the images they provided. Sketches and photography provided important information about what each student found important during their travels and studies abroad (Bogdan \& Biklen, 2006). The studio design projects also illustrated and provided examples of what each student learned in terms of architecture and design while studying abroad.

Although there are many different types of interviews, I used a narrative interview that "centers on the stories the subjects tell, on the plots and structures of their accounts" (Kvale \& Brinkmann, 2009, p. 153). In a narrative interview, short stories develop about significant experiences that are seen through the eyes of the interviewees and often shaped by their own life history. The use of narratives also facilitate the flow of the interview process because it is one of the more natural cognitive and linguistic forms 
through which individuals organize their ideas and experiences (Kvale \& Brinkmann, 2009).

According to Seidman (2006), there are three interviews used in a phenomenological study that can help the researcher understand the meaning of the participant's experience in question. The focused life history, the details of experience, and the reflection on the meaning of the experience interviews are all necessary to "understand people's behavior in the context of their lives and the lives of those around them” (pp. 16-17). Although these interviews are conducted separately and independently with each student, I used aspects of each and collapsed them into one interview, and I used a second interview as a follow-up and opportunity to study the students' creative work. I decided to conduct one interview with a follow-up because the architecture student participants tend be a transient sample, and eliciting their input proved challenging because of their academic time constraints.

Prior to beginning the interview, however, it is important to set the stage by briefing the interviewee about the purpose of the study, the role and rights of the participant, and the use of recording devices (Kvale \& Brinkmann, 2009). This is intended to make the interviewing process as comfortable as possible for the participant, and ensure that whatever concerns the individual may have about the interview are adequately addressed. In as much as the briefing serves to create a sense of ease between the interviewer and interviewee, a debriefing serves to dispel any tensions after the interview (Kvale \& Brinkmann, 2009). In this study, I asked the participants if they had anything further to add concerning their travel abroad and study experiences at the 
conclusion of the interview. I also invited them to comment about the interview and interview process.

As an introduction, the focused life history helps the interviewer understand the participant's personal background in relation to the experience (Seidman, 2006). Understanding a student's biographical background helped me to later understand the significance of the international travel experience in light of the student's ethnic and socio economic background, and gender. Not all students, for example, may have had the prior opportunity to travel abroad, or have had exposure to foreign cultures. The initial shock of landing in a foreign country might be factor of how these students relate to foreign environments. Certain prejudices may also become apparent if students have had limited foreign exposure (Scheunpflug, 1997). The possibility of automatically associating a mosque with terrorism, for example, may exist because of misperceptions about Islam currently exploited in the public media.

Establishing the level of understanding about architecture in relation to global history, geography, religion, and even linguistics are also important factors in the initial phase of the interview to determine student awareness about the built environment and the influences that shape the development of architecture. Graduate students, for example, were generally better able to articulate their understanding about architecture and convey a greater appreciation for the cultural influences that shape the built environment because they were intellectually and emotionally more mature than undergraduates, and had a greater awareness of themselves and their environment based on the courses that they had previously taken. Knowing the types of courses students took allowed me to understand how their educational experience influenced how they 
perceived architecture while studying and travelling abroad. From my own personal experience, I benefited greatly from the undergraduate courses I took in history, philosophy, linguistics, and international economics to understand better how architecture in one culture differs from another.

The focused life history not only served as a means of introduction but also, in the case of my study, gave me a better understanding of why the student chose to study architecture and participate in an international study or travel program. Asking students why they spent a semester or year abroad also revealed certain aspects of their academic priorities and professional goals. Some students, for example, decided to travel abroad for curiosity and saw it as an opportunity for some adventure and escape. Others travelled as a means of complementing their undergraduate or graduate experience. As an undergraduate, I travelled and studied abroad mostly for curiosity and adventure. As a graduate student, however, I chose to participate in international study programs as a means of complementing my education and enhancing my professional aspirations. Seidman (2006), however, recommends asking students "how" they accomplished certain tasks rather "why" because it encourages them to reconstruct their experience and disclose information about their past that is relevant to the topic being studied. From my own personal experience, understanding how I became an architect or how I travelled, for example, reveals aspects of my personal history and disclose some of my own personal priorities.

Seidman's second interview deals with the experience and its purpose is "to concentrate on the concrete details of the participants' present lived experience in the topic area of the study” (Seidman, 2006, p. 18). In this instance, I encouraged the students 
to develop a narrative of their travel experiences and a discussion about the courses they took while studying abroad. I asked questions about the countries they had visited and buildings they had encountered. I also asked these architecture students to comment about how they experienced the culture in terms of the food, music, language or lifestyle. These questions provided some insight about the students' interests and the manner in which these interests complement their study abroad experiences. Questions about the courses taken also helped to establish an understanding of the specific structure and intended outcomes of the study abroad program. Did the students, for example, take courses related to culture or was it entirely based on an architectural studio format? I also wanted to know how much free time students had and what they did with their free time. This was important to establish how independent and proactive the students wer in experiencing their foreign environment. From my own personal experience, I gained more from my study abroad interacting with foreign nationals than listening to a lecture. As part of this study, I also wanted to know specifically what the students saw. Did they only see historical structures? How much of the vernacular was experienced and to what degree did they experience modern works? Understanding what students saw and experienced elicited responses as to how the architecture touched them emotionally. I can remember on many occasions in my own travels becoming emotionally overwhelmed in certain secular and sacred spaces. Students developed preferences in the types of architecture they wished to experience. For some, the sacred held greater meaning than the profane. For others, modern and postmodern architecture incited greater excitement than examples of architecture from antiquity. Understanding what students saw and experienced revealed if their exposure to the architecture of their 
host nations was balanced in terms of historical significance. Although it is impressive to experience a fortress from the 13th century, much of what is lived on a daily basis is vernacular. Sitting in a tavern or "pub" from the 15th century can also provide a valued lesson in architectural history, not to mention the opportunity to personally interact with foreign nationals in a culturally explicit environment.

Details rather than opinions are important for the participant to develop the meaning of the experience, which constitutes Seidman's (2006) third and final interview. According to Seidman (2006), the meaning of an experience does not necessary refer to satisfaction or reward but it "addresses the intellectual and emotional connections between the participants' work and life” (p. 18). In the case of my study, I wanted to understand how international travel and study abroad influenced the students' understanding of global architecture, and how it directly affected their experience of the curricula. The experience of travel and the manner in which it affects the curricula can be viewed from an intellectual and emotional perspective. Students realized, for example, the intellectual connection between what was learned in a history course and what they experience when visiting a structure in question. Students have told me on many occasions that their travels were greatly enhanced by having taken prior courses in architectural history and theory. For some of the participants of this study, visiting a structure that was studied in class was an emotional experience. The significance of the Pantheon, for example, was not as apparent in a slide show presentation as it was when they actually experienced the exterior and interior space of this iconic structure. In my own personal experience, visiting the Hagia Sophia in Istanbul was an emotional experience because of the scale, magnitude, and beauty of the structure. Although I had 
heard and read about the Hagia Sophia, the experience of being in that space was unparalleled to any historical or intellectually based description of the structure that I had read or heard.

\section{Data Sources}

In addition to the interviews, the use of a variety of empirical materials including photography and sketch journals are used in qualitative research because they "provide strikingly descriptive data, are often used to understand the subjective, and are frequently analyzed inductively” (Bogdan \& Biklen, 2006, p. 141). I asked the participants to provide examples of their travel sketches and photography as a means of understanding what they saw. I was not as concerned about the level of technique or talent in the drawings, as I was about analyzing the images in terms of what they to intended to show. Documenting specific details of a building, for example, revealed a curiosity and understanding of specific building construction methods. These images transcended a mere documentation of architectural details, but also revealed how each student saw and defined their world and physical surroundings (Bogdan \& Biklen, 2006).

\section{Sketch Journals}

Students' exploration of a country and its culture is greatly enhanced if they acquire a personal sense of travel through the use of a travelogue or sketch journal (Brady, 1999). In terms of the journals, I specifically observed how the images began to capture details of design and appreciation for the subtleties of architectural or urban space. In essence, I was interested in how the individuals' understanding of architectural theory and history were documented in their travel journals and how, over time, this understanding had intensified through the images. Transcending the basic image of a 
building, these diagrams revealed architectural ideas pertaining to the primary elements, organization of space, form, function, circulation, proportion, scale, and ordering principles (Ching, 1998). These diagrams also indicated the level of student understanding about important design concepts and their awareness of how these architectural ideas were implemented in buildings. In terms of experiential learning, the sketches are a means by which the students are able to conceptualize what they have experienced and learned about architecture.

The use of sketch journals is important to the education and professional practice of an architect. Sketching, after all, is a means through which the student or professional documents observations and ideas. Drawing and sketching are required courses that every undergraduate and graduate architecture student takes. Although it is commonly understood within the academy that drawing and sketching are important components of the design process, very little research exists about their implementation in the pedagogy. The sketches of Aldo Rossi and Le Corbusier, however, have been published and offer important insights about their creative imaginations and the manner in which these renowned modernist architects engaged in the process of observing (Jones, 2001; Portoghesi, 2002). In the case of Le Corbusier's sketches and journals, his drawing of the buildings on the Acropolis reveal "the sublime poetry of well-proportioned, timeless spaces defined by classical decorum and the effort he made to know architecture” (Jones, 2002, p. 141). The act of observing and drawing can develop into a complete awareness and understanding of any given object or condition (Franck, 1973), and one can learn a great deal from these sketches because of what they expose and reveal about the structure, site, and context. 


\section{Data Organization and Analysis}

Documenting the experience and providing an understanding of what the experience means for the individual having the experience is the essence of phenomenological research (Moustakas, 1994). Once the experience has been reconstructed and documented, the interviewer next analyzes this information within a phenomenological framework to determine the general meaning of the experiences and the specific relations found in the descriptions (Moustakas, 1994). An understanding of these relations, however, can only occur through an effective analysis that includes working with the transcripts, organizing and synthesizing the information, searching for patterns, categorizing and determining what is important and what is to be learned (Bogdan \& Biklen, 2006).

In terms of the interviews, all dialogue and conversations were taped and recorded. Notes were also taken in the course of the interviews as an initial part of the analysis. I observed how the participants responded to the questions in terms of body language, inflection, anticipation, or even hesitation (Kvale \& Brinkmann, 2009). I also encouraged the participants to share their travel sketches, journals, and photography as part of the interviews for me to better understand what they saw, experienced, and how the travel abroad potentially transformed their perception of architecture.

Once the interviews were conducted, recorded, and transcribed, the next undertaking was to analyze the responses in terms of observations. The task of coding was necessary to organize the data into categories to uncover or discover specific themes and potential patterns of experience. According to Bogdan and Biklen (2006), there exist different types of codes that are established according to categories which help in sorting 
and analyzing the data. The codes of this study were initially created and organized based on the types of questions posed. A context code, for example, was also used in my study to observe the responses of Florida International University, University of Miami, Syracuse University and the University of Florida students and alumni. I also used a context to code the responses of graduate and undergraduate design students from these institutions. Because I interviewed a variety of individuals about their international travel and study abroad experiences, understanding how they perceived themselves in terms of their word views established yet another set of codes. I created these codes based on their social economic and ethnic backgrounds, gender, and professional and academic aspirations.

Since international travel and study abroad offer a host of transformative experiences, categorizing and coding these experiences served to illustrate the importance of international travel on the personal and professional development of undergraduate or graduate architecture students. Process codes, for example, were helpful in documenting how students' perceptions of architecture changed throughout the course of the travel. I also documented how the participants' perceptions of themselves changed while living abroad and upon their return to the U.S. From personal experience, I remember definite stages of development that occurred during my junior year abroad and how they became manifest upon my return to the U.S. The ability to communicate with local nationals and the ability to use public means of transportation were key stages that not only made me more self-confident, but it also allowed me to assimilate into the culture more freely.

I also developed analysis codes to document the types of activities that the participants undertook while abroad. I felt that it was important to understand how 
students took advantage of their time while travelling and living abroad. There were specific activities, for example, that illustrated a sense of independence and self-reliance. Using public transportation and learning to buy groceries, for example, was an indication of self-reliance maturity for some of the participants. Attending lectures, visiting museums, sketching in a piazza, or sharing an afternoon of conversation with a local national were memorable events. These events were also transformative because they revealed how certain individuals began to show greater cultural appreciation and awareness of their foreign environment (Younes \& Asay, 2003).

Once the responses were codified, the next phase of the study was to contextualize the information and seek possible themes and relationships within the data. The process of phenomenological research analysis, according to Moustakas (1994), involves a number of steps that include bracketing, horizonalizing, and clustering of horizons into themes to develop the textual descriptions of the experience. Bracketing refers to organizing the data according to codes as dictated by the questions and answers. Horizonalizing is the process of identifying relevant expressions of the topic which are then subsequently clustered into common categories to develop the textual descriptions of the experience. In terms of my study, I organized the data according to specific codes and I used bracketing and clustering techniques to develop thematic relationships and to identify commonalities in the responses.

\section{Dependability and Consistency of Study}

Although a phenomenological study may be well suited for my study on the impact of international travel on students studying architecture, there were, however, some issues and constraints that were considered and addressed in the course of the 
research and investigations. Since I interviewed racial and ethnic minority students and addressed their responses from the point of view of culture and ethnicity, my status as a White male architecture professor had to be taken into consideration. According to Seidman (2006), "the issues of equity in an interviewing relationship are affected by the social identities that participants and interviewers bring to the interview” (p. 99). Seidman (2006) also writes that the interviewing process is fraught with issues of power, which stem from how we perceive ourselves in terms of ethnicity, education, social class, and gender. To overcome this issue, I was sensitive and aware of these potential constraints when conducting the interviews and addressing the subjects in question.

Another limitation was the subjective nature of the research and my ability to accurately establish the meaning of a participant's experience. The challenge for the phenomenological researcher is the ability to understand the subject's sense of reality. According to May (2002), "the effort is to become the actor in order to go beyond empathy and establish understanding of the meanings that the actors of a given encounter gave to the encounter while it was occurring” (p. 149). Being aware of my own personal thoughts and reactions to the given responses enabled me to better understand the meaning of the experience from the participant's perspective. As a planned measure, I recorded my thoughts and reactions in my researcher journal.

Lincoln and Guba $(1985,1986)$ address another set of limitations in qualitative research or study. In their article, But Is It Rigorous? Trustworthiness and Authenticity in Naturalistic Evaluation, Lincoln and Guba (1986) not only advocate greater rigor in qualitative research, but they also introduce notions pertaining to credibility, transferability, dependability, and confirmability. These issues or techniques seek to 
create a sense of trustworthiness regarding qualitative research to ensure that the study is value-free, objective, consistent, and applicable. In terms of my study, I attempted to make the work credible through prolonged and lengthy contacts with the architecture student participants. I used member checking to verify that the transcripts accurately captured the participants' interviews. To facilitate transferability, I provided extensive descriptive data about the context so that others could make a judgment or decision to use my findings based on the degree of fit or similarity of the study. For dependability and confirmability of my study, I took Lincoln and Guba’s recommendation into consideration and developed an external audit to review the process and the data of the study. I selected someone who has no affiliation with either institution or academic discipline to audit my work (Lincoln \& Guba, 1986).

\section{Chapter Summary}

In this Chapter 3, I have discussed the method of investigation on how architecture students may benefit from the exposure to foreign cultures through international study and travel. I have also included information about data gathering, participant selection, interviewing procedure, methods of participant response coding, and the delimitations of the study. Chapter 4 introduces the participants and provides a discussion on the interview process. 


\section{Chapter IV}

\section{PROFILES OF THE PARTICIPANTS}

This study focused on how architecture students benefited from the exposure to foreign cultures through study and travel abroad programs. I interviewed professional architects and students who were enrolled in the graduate and undergraduate architecture design programs at the University of Miami, Florida International University, the University of Florida, and Syracuse University in order to assess how their study and travel abroad experiences complemented their education and influenced their understanding and appreciation for architecture. The participants of this study were also questioned about the influence of these experiences on their professional and personal development.

Study and travel abroad have significant implications on the study of architecture. Taken from the perspective of professional architects and students who were enrolled in the undergraduate and graduate architecture design programs of the previously mentioned institutions, this investigation addressed the implications of travel and study abroad experiences by investigating the following questions:

1. How have travel and study abroad shaped the educational experiences of those who are studying or have studied architecture?

2. How have travel and study abroad complemented the architecture curricula?

3. How have travel and study abroad experiences enhanced the understanding and appreciation of architecture of those who are studying or have studied architecture? 
4. How have travel and study abroad influenced the personal and profession development of those who are studying or have studied architecture?

These questions were answered from the students' points of view. These questions also made travel and study abroad central to an understanding of students' experiences and of the architecture education.

In Chapter 4, I introduce each of the participants of this study. I used the information gathered from the lengthier discussions as primary sources. Some of the participants shared more information than others and I used their information as primary sources. The shorter discussions were used to support the findings of the primary sources. These have been identified in the following chapter.

\section{The Participants}

To understand the influence of international study programs on the personal and professional development of architects and architecture students, I interviewed 15 participants. These individuals varied in age and ethnic backgrounds and included men and women. The participants also varied in terms of their personal aspirations and their academic and professional attainments. In some cases, I had known these individuals as professional colleagues or former students. In other cases, I was provided names of students to contact and interview by the deans of the architecture programs and the study abroad program directors of the University of Miami and Florida International University. I also relied upon the help of former students to help me locate willing participants for this study.

The following section introduces the participants of this study. My initial interview with each individual lasted between 35 and 90 minutes. I conducted the 
interviews in a variety of locations chosen by the participants that included restaurants and coffee shops, classrooms, conference rooms, and offices. In some cases I interviewed the participants individually. In others, I interviewed the participants in pairs. In some cases, I encouraged some of the individuals to invite a spouse or friend who had participated in the same study abroad programs to interview together.

All of interviews were electronically recorded and later transcribed for the analysis and coding. To maintain anonymity of participation, I changed the names of each participant mentioned in this study with the exception of Leslie who insisted that I use her name. I also kept notes in a journal to record my thoughts about the discussions that were generated during the course of the interviews.

The profile descriptions of the participants vary in length. Some of the individuals, for example, talked at length about themselves and their experiences while other participants were somewhat reserved. Some of the individuals were also quite willing to share their creative work while some were reluctant to do so. As such, several of the participants provided sufficient data to serve as primary sources of information for this study. I used the information provided by the other participants as a means of justifying and supporting the information provided by my primary data sources. Guillermo, Connie, Aliana, Gloria, Leslie, Marc, and Kate, for example, were my primary sources of information because of the significant amount of information that they shared with me regarding their study abroad experiences. These individuals also disclosed more information about themselves than the others and as such I was able to write more about them in the profiles section of this chapter than the other participants. 
The fact that the individuals who served as primary sources of information were graduates and not current students of design programs came to me as no surprise. Because these individuals had had time to reflect upon their study abroad experiences, they were much better prepared to talk about the transformative aspects of their study abroad. They could better relate about how their travels and study abroad experiences had influenced aspects of their personal and professional development. These individuals were also older and had more to convey about their personal and professional lives. I did not, however, consider the students to be less important top the study. In fact, I later realized that the information provided by the current students in many respects supported what the graduates had mentioned in terms of their experiences studying architecture abroad. In terms of my analysis of the data, the fact that I tended to reference past graduates of design programs more frequently than the current students had little effect on how I interpreted the data. What was significant for this study was the fact that all of the participants had participated on a semester abroad study program and were either current students or had been architecture students enrolled in a design program.

\section{Guillermo}

Guillermo is a 36-year-old adjunct faculty member at Miami Dade College who had worked for a number of years as an architect before dedicating much of his current activities towards teaching and art. I choose to interview Guillermo because of his diverse academic and professional background. Guillermo was a primary source because of the amount of time that I spent interviewing him and the amount of information he was willing to share in terms of his creative work. Guillermo holds an undergraduate degree from the University of Miami in Fine Arts and Anthropology. Upon graduation, he 
applied to the University of Florida to pursue a Master of Architecture but left after the first year and returned to Miami to be with his mother who was ill at the time. He transferred his credits to Florida International University and continued his architectural education eventually graduating with the M.Arch 3 years later. When asked why he did not apply to his alma mater at the University of Miami, he cited financial costs as the reason for his decision to continue his education at a state institution. The international study abroad was not initially a factor in his decision to attend Florida International University.

Guillermo is of Hispanic and Arabic ethnicity and grew up speaking Spanish in his home. He had lived most of his life in Miami and only moved away to Gainesville to study architecture at the University of Florida for a year. Guillermo has lived in a number of areas of Miami, including Little Havana, and provided a rather painted description of his childhood home. He described the structure as a wooden framed building, raised on platforms, with opening in the roof where he could see the stars at night. During the wet season, the furniture and living arrangements had to be reorganized to accommodate the leakage that was collected in buckets placed throughout the house. His description of his home was an interesting part of our initial conversation because it illustrated his ability to describe conditions and situations as they pertained to a more personal aspect of architecture and building. His conversations about his childhood home also provided some personal insight about Guillermo’s life that had not been shared in our previous social interactions.

My conversations with Guillermo tended to flow quite freely. This may have been due in part to the fact that I have known Guillermo personally and professionally for the 
past 5 years. It may also have to do with his age and maturity. Guillermo has a number of academic degrees and interests outside the field of architecture. I found that his interest in art, and his ability to document his experiences graphically added to the richness of his experience. He talked at length about sitting in piazzas just observing and documenting what he experienced in his travel journals. As an artist, Guillermo was also willing to provide examples of his creative work done in Rome during the semester abroad program with Florida International University. His art and architecture design is well documented, and I was able to use much of the work to illustrate what he had learned and observed during his semester abroad in Rome. In terms of his architecture education, Guillermo talked about enjoying the design process the most. "What I enjoyed about the design process was sitting down and thinking of an initial idea, working at that idea and carrying it through and ending up with a structure.” Guillermo associated this type of experience with his earlier work in ceramics. "It tied into my first interest which was art and ceramics and sculpture. How do you create something from a single line, and it ends up being something completely different?” The design process is the same for architecture as it is for any art form. The only difference is the outcome. Guillermo is an avid artist and sculptor who likes to synthesize art with architecture.

On our second interview, Guillermo shared an example of some of his recent design work which is the development and exploration of a hurricane proof shell that serves as a main structural component for a single family residence. Figure 7 is a model depicting his design idea. The proposed shells are made from a single form of cast concrete, and their shapes are developed sculpturally and organically from examples 
found in nature. Guillermo shared these design ideas with me on our second interview as examples of some of his ongoing creative work.

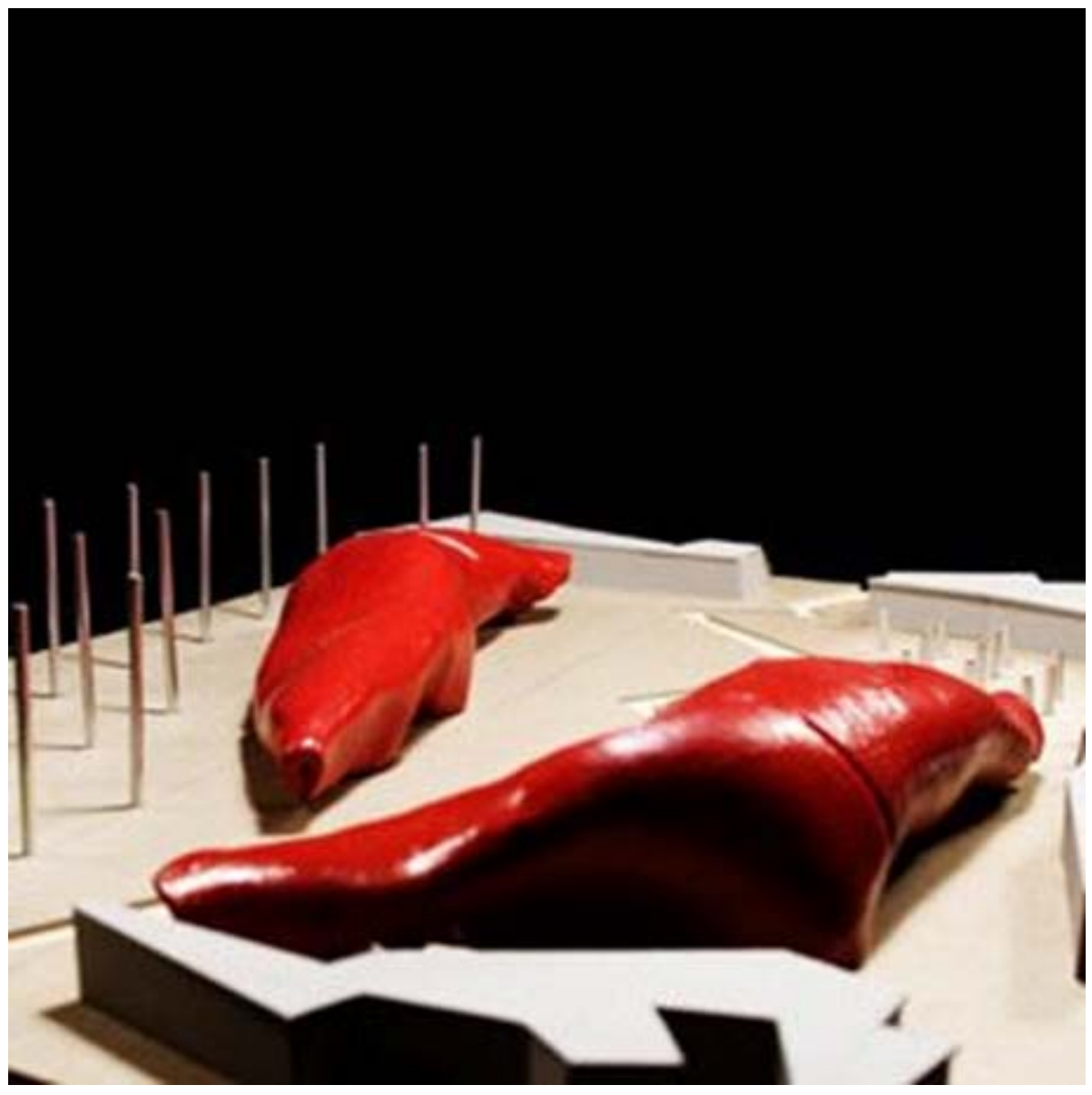

Figure 7. Hurricane Resistant Architecture Design Model by Guillermo

Guillermo, however, also mentioned what he disliked about architecture and was the only participant to do so:

I didn't like the competition. I think architecture is an art, and you do what is best for the sake of having a good project. If your project is the best project and if your classmate's project is not the best, then you help them further their project.

I believe what Guillermo experienced in terms of competition amongst students is something that is very prevalent within the study of architecture. By its very nature, the 
profession and study of architecture is a competitive endeavor. The process of becoming an architect can take 10 to 15 years from the time a student enters a design program to graduating and passing the Architecture Registration Exams (Waldrep, 2006). In professional practice, many design projects are initially offered and awarded as competitions. The design studio is also a competitive environment. Often, students do compete with one another for the best designs and highest grades. Failure to perform adequately in design studio is one of the contributing factors that increases a sense of anxiety in the design curriculum. In fact, fear of failure was seen by architecture students as a determining factor motivating them to study but it has had the adverse effect of contributing to high levels of stress and anxiety (Bachmann \& Bachmann, 2006).

\begin{abstract}
Aliana
Aliana is a graduate of Miami Dade College and continued her studies at the University of Miami. She earned the B.Arch and has been working in architectural practice for the past 4 years. Her parents are from Columbia and Honduras, but she has lived her entire life in Miami. She was raised speaking Spanish, but has an excellent command of the English language. I used Aliana’s discussions and design work as a primary source of data for this study.
\end{abstract}

Aliana had limited travel experience prior to her study abroad experience; much of her travels were to South and Central America where she would visit her family. She talked a little about one of her trips to Honduras and the impression it left on her as a young child:

You see immediately that it's a culture shock when you step out the door of the airport. The day we arrived on one of our trips to Honduras they were regulating the water and electricity. The first time we were there we had no water and electricity for a week. Right there, it's a slap in the face welcome to our country. 
I could not help but remember my own experiences travelling in Honduras and the power outages in some of the towns that I visited.

Aliana was very cooperative when I initially approached her to participate in my study. I had known Aliana as a Miami Dade College student and had always noticed her professional demeanor. I was aware of the fact that I had been her professor, and I was careful not to approach our meeting from a professor-student relationship. Although I never taught Aliana in a design studio, I did not want to project myself in an authoritative position. If anything, I wanted to acknowledge her accomplishments in terms of what she had achieved both professionally and academically. I attempted to create an intellectual friendship that would serve to highlight Aliana's accomplishments, and provide me with necessary insight about the influence of study abroad on her professional and personal life. When asked what she enjoyed most about studying architecture, Aliana was quick to reply that she enjoyed designing and working with materials.

My favorite classes were definitely the design courses, the opportunity to work with materials. I'm very visual so I immediately could think of something and build it in my mind. So I had that opportunity there and just the aspect of architecture that I really liked.

Aliana had participated in a 6-week Grand Tour of Europe study abroad program which was later complemented by courses taken at the University of Miami during the remainder of the semester. When I initially contacted Aliana, I was under the impression that she had participated in the semester abroad program in Rome. It was only during our interview that I quickly realized that she had enrolled in the Grand Tour. I decided, nonetheless, to proceed with the interviews because I felt that I could use Aliana’s experiences as a possible comparison since her program was a relatively short term travel 
and study abroad experience. The Grand Tour is not a stationary program located in one city, but is an actual tour of various European countries. The courses offered during the program were often conducted in the bus and trains that the students and faculty took to get from one destination to another.

Although there is more focus placed on the implications of long terms study abroad experiences, short term international field study has become increasing attractive to many students. "Short-term courses are a means to achieving the active and engaging learning benefits of conventional subject areas while offering a somewhat internationalized program of study” (Dekaney, 2008, p. 14). There are a number of reasons why students may opt for a short-term study. These may include financial limitations or time constraints that students sometimes face (Stanitski \& Fuellhart, 2003). Whereas short term travel experiences may be more affordable and offer students an opportunity to visit a number of countries within a short period of time, there are, however, challenges inherent in travel tours. Making observations about everyday life, according to Callihan (2009) is more difficult than trying to do so while living in one place for a prolonged period of time. Aliana was not really able to answer specific questions as they pertained to her observations and interaction with the local nationals of the countries she visited. In fact, one of the common issues that travelers experience when on tours is that they are less prone to interacting with host nationals. Many tend "to stick together, speak their common language, and do not get involved in the day to day happenings of the place where they are visiting” (Callihan, 2009, p.28). This was very evident in my conversation with Aliana and not with the students who had participated in the semester or yearlong study abroad programs. 
Although Aliana was not able to address certain aspects of the interviews, I still felt that her discussions had value and merit to the research. I was particularly interested in what she learned, and how she was able to integrate the travel experience in her design work. In fact, Aliana was able to discuss what she appreciated about European architecture, "I definitely think about the approach towards a building more than what I did prior to going to Europe.” She also listed a series of observations that included the use of materials and the creation of intimate spaces, large spaces, and circulation in and around specific structures, as design related ideas that interested her. Aliana provided me with some examples of her studio design work that illustrate what she had learned and observed during her study abroad in Europe. She also talked about how her travel experience actually made her want to travel and experience more beyond her familiar surroundings,

I'm going to continue travelling. Right now my husband and I are travelling the United States. We like to pick various locations to visit and spend some time in each state to learn and experience the different types of architecture that we have here in the United States.

Aliana, however, was not the only participant express an interest in American architecture because of her study abroad experience in Europe. Other individuals had also expressed an interest and intent to travel and learn more about the architecture and urban design or American cities after their return from Europe.

\section{Julia}

Julia is a 25-year-old recent graduate of Florida International University School of Architecture. She obtained the 4-year undergraduate nonprofessional degree and is now working for an importer of high-end Brazilian furniture in Miami. Of Brazilian ancestry, Julia spent much of life in Miami. In addition to her travels to visit family in Brazil, Julia 
had travelled to Europe as a teenager as part of high school exchange programs. When asked if she remembered some of the sites she visited, Julia answered, "The sites, yes. Because I was 14 though, there where places like the Sistine Chapel that I didn’t remembered at all. You don't appreciate it as much when you're that young." Julia did mention, however, that her decision to participate in a study abroad was in part influenced from her earlier travel to Europe.

Julia had studied architecture at the Florida State University for 2 years before transferring to Florida International University to complete her design degree. When I asked her why she left FSU, Julia replied:

I graduated high school and, like a lot of the kids, I wanted to get away from the house so I moved to Tallahassee. I studied at FSU for 2 years taking the perquisites but I didn’t like Tallahassee. It was a small city and not a lot to do there. There was also not a lot of diversity. I decided to come back to Miami and I started architecture at Florida International University.

Julia opted for Florida International University because of its affordability and location. She had also taken courses at Miami Dade College and completed some lower-division courses concurrent with her architecture studies at Florida International University.

I was happy that Julia had agreed to be part of the study because I had known her as one of my students. In fact, Julia had enrolled in my Architecture Design 3 course and had demonstrated much talent as an artist and designer. Julia excelled in the design class and her work was excellent in terms of the design and craftsmanship of the models and presentation materials. Julia mentioned that she enjoys architecture because it "allows you to be creative and come up with completely different things, and be freer than I guess some traditional 9-5 office type of jobs.” I associated with this response because my reasons for becoming an architect and studying architecture were also an attempt to find a 
more satisfying career. I had worked in a number of 9-5 jobs prior to enrolling in architecture school. Like Julia, I was also looking for the freedom of expression that I thought a creative based profession could offer.

Since I had known Julia as a student, I was interested in learning how her understanding of architecture had developed over the course of a couple of years. I was also interested in learning how the study abroad had complemented her educational experience. Because I had been her professor, I was careful to note any tendencies of asserting myself in the capacity of a professor or in an authoritative role. I tried to diminish these tendencies by engaging her as a professional. I no longer viewed her as a student, but as someone who was ready to enter the field of architecture, and make a contribution to the profession. In fact, when I asked her about her professional aspirations I was not surprised that she intended to pursue graduate studies in business,

For right now, I'm working. I want to eventually tap into a Master's in Business Administration because my goal ultimately is to own my business. I am not certain whether I want to be an architect or an interior designer.

Regardless of her eventual decision to become an architect or interior designer, it was clear that Julia’s study abroad experience had given her a greater sense of self confidence to pursue her personal and professional goals and aspirations.

\section{Connie}

My conversations with Connie were the longest and the most involved. I had not known Connie prior to the interview, but she had been referred to her by a mutual friend. Because of the length of our conversations, Connie provided much insight into her study abroad expediencies and she served as primary source of information for this investigation. Connie was currently employed by Miami Dade County Cultural Affairs 
Department and was working on the completion of a large scale project that involved the design and construction of performing arts facility in South Miami. We actually conducted our initial interviews at the job site which did provide me with a unique perspective about Connie's professional responsibilities as she had been reviewing some the blueprints prior to my arrival. Connie had also participated in a year-long program in Florence through the Syracuse University. Since she had participated in the longest program, I was particularly interested in learning if Connie’s experience was any different from the other participants that I interviewed.

Of the professionals that I interviewed, Connie had the most diverse and extensive experience in architecture. Connie was ethnically diverse since her parents were of Greek and Italian ancestry. In fact, Connie talked at length about her need to connect culturally with her family as a reason that motivated her to study and travel abroad. Connie talked the most about her cultural background and she even mentioned regret about not having been taught Greek or Italian by her parents:

So even though my father was first generation American, and my mother was second generation, we were taught to speak only English at home. I'm amazed about how many people in Miami still hold onto and speak Spanish. I think that it's just really wonderful. I wish we had that experience. I also wish my parents had that experience. My mom went to Greek schools and she was ashamed of it. She spoke Greek, she even used to write Greek, but she hated it because she felt like a misfit in her Brockton High School because she was one of the few Greeks.

I empathized with her wish to have been taught Italian or Greek by her parents. I feel that Connie may have connected better with her Greek and Italian heritage had she been taught the languages. It did become rather evident during the course of our interview, however, that Connie's intent to study in Italy was an attempt to "connect” with her Italian heritage. 
Connie grew up living most of her life in Boston but had moved to Pittsburgh to study architecture. Upon completion, she returned to Boston and worked for a number of years in the area. She had earned the Bachelor of Architecture degree from Carnegie Mellon University but had not participated in a student or travel abroad program as an undergraduate. When I asked her why she hadn't participated, Connie answered that she had a very “jaded opinion” about undergraduate study and travel abroad programs. I was initially a little shocked by her response. I could not quite imagine why Connie would have had a jaded opinion about these types of academic opportunities. I pursued the topic a little further with Connie, and I soon realized that money might have been a factor that influenced her reaction. "I think because for me it was the cost and always I found the cost really prohibitive.” I wondered if she felt resentment towards students who could afford the travel abroad opportunities. I was also curious if her viewpoint might have changed because she did eventually participate in a study abroad program.

I've matured a lot since then, but at the time I was really bitter about it instead of actually saying well, maybe, I should figure out a way to make this work if it's something that I actually would like to do instead of just saying like only the rich kids get to go.

Although I was initially surprised by her feelings of "bitterness" and resentment towards those students who had travelled abroad, I was also impressed that she was aware of her feelings and was willing to share her sentiments with me.

Connie had worked for several years in a number of different architectural practices and talked quite candidly about her professional experiences. I wanted to learn more about these experiences because Connie had decided to leave professional practice to return to university to pursue a post professional graduate degree in architecture. I also wanted to learn what might have compelled her to make this decision. As Connie talked 
about her professional experiences, I began to take note of her personality and sensibilities. Not only was Connie open to disclose personal aspects of her life, I felt that she had a strong personality because of some of the issues that she had faced with the principals of the small practices she mentioned. Connie talked about having "personality clashes” with these individuals. I also got the sense that Connie was a collaborative member of a design team because of her willingness to work with engineers and technical designers. Connie had developed a sense of respect for the more senior and technically minded architects at Carlson Associates and she seemed eager to learn from these individuals.

Since Connie had worked for a number of years in various practices before participating in the graduate program in Florence, I wanted to learn if she had integrated aspects of her practical exposure to architecture into her experience of living and studying architecture abroad. I also wanted to understand why she had decided to leave professional practice to pursue a post professional degree in architecture:

I just got an itch to go back to school. When I graduated from Carnegie Mellon I had no interest in continuing the academics because I was really burned out. After 5 years of working, I wanted to get back into academics. Really, I think I was looking at it as a way to figure out what I wanted to do with architecture. And I was very drawn and knew that the only thing I really wanted to do was a program abroad.

From our discussions, I felt that Connie's decision to return to university and to study abroad might have been a means of escape. Connie talked about being "burned out" in practice and she hinted to a sense of dissatisfaction with her work as an architect. Connie also mentioned at different times throughout the initial interview the need to "figure out" what she wanted to do in architecture and saw the study abroad as an opportunity to explore possibilities within the profession. 
In terms of her architecture education, Connie talked about the importance of historical precedence and how she liked learning from past examples:

I loved the architectural history classes and I especially liked learning about precedents. I really did love the idea of learning about lessons from other times and places and people. I loved trying to apply those lessons and understanding that nothing is really that original.

I was happy to hear these positive remarks about architecture history since the focus of much of my teaching is centered on architecture history and theory courses. The study of architecture history and theory are important to the study of architecture because the Influence of the past is inescapable and a total absence of continuity is inconceivable. We cannot purge ourselves of the effect our surroundings have on us; we simply cannot be blind to the existing world, present and past. In any case, the present state embodies the trials of millennia and it would be foolish and wasteful to ignore experience which has accumulated since Adam and Eve. (Brawne, 2003, p. 171)

Not only is it important to understand that architecture is really a continuum of other forms and styles, it is also important to learn from past examples and precedents and apply this understanding to the design development of current projects.

Connie also talked at length about her interest in the building process and approached this topic from a holistic perspective. "I loved the materials and assembly classes; I loved talking about building integration I guess in the later years and thinking about how the building functions and how it breathes.” Her thinking about how a building "breathes" draws interesting theoretical references to the anthropomorphic qualities and understanding about architecture. Architecture is not a static manifestation of form and function, but is a dynamic process by which materials and thought converge to produce buildings (Brawne, 2003). Connie’s mention about how much she "liked 
talking about building integration” makes an important implication about the nature of architecture.

\section{Leslie}

I met with both Leslie and Gloria one evening at a restaurant in the Miami Design district to talk about their experiences living and studying abroad. Although I have known Gloria for the past year in her capacity as an adjunct professor at Miami Dade College, I was first introduced to Leslie the night of our interview. Gloria had mentioned to me about her friend Leslie who had participated in two summer abroad programs while at the University of Florida. Leslie and Gloria have known each other for a number of years on both personal and professional basis having worked for the same architecture practice in Miami Beach. Leslie and Gloria shared many common factors. Both had studied at the University of Florida, at different times, and had earned both undergraduate and graduate degrees from this institution. Both were born in Cuba but had left at different times in their lives; Leslie at the age of nine and Gloria in her late 20s.

Leslie works for a large architectural practice in Miami and was almost insistent on participating in my study because of the importance that foreign study and travel had played in her professional and personal life. Leslie was a primary source of information because she shared examples of her creative work and talked at length about her experiences travelling and studying in Mexico. Although Leslie studied architecture, she currently finds herself working mostly in urban design. "I am actually in the urban design, urban planning team, and do architecture when necessary. I mostly I focus on the planning aspects of projects which is different from everything that I went to school to 
learn, but it’s interesting." Leslie had also participated in two separate study abroad programs both in Mexico.

I didn't do the Italy program. I did the Mexico programs. I did two different summers in Mexico; one as an undergraduate and later one as a graduate student. One program was in Jalapa, Mexico, and the other was in Guadalajara.

Although these programs were not the traditional semester abroad programs taken in the fall or spring semesters, I felt that her experiences would be a good point of comparison since I had already interviewed three other University of Florida graduates who had participated in the Vicenza program.

Leslie's prior travel experience was rather limited. In fact, she mentioned that apart from her travels to Mexico and Cuba, she really hadn’t really travelled much. She expressed great interest in Mexico, almost a love affair, "an infatuation that only gets worse and worse. I go every chance I get.” I was curious about her fascination with Mexico so I pursued the topic a little further with Leslie. Gloria, however, interjected and asked if her fascination with Mexico was because of her interest in the Mexican architect, Luis Barragán. Leslie answered, “no”. According to her:

Barragán came later. It was just the culture. Mexico is a very rich place culturally. The pre-Columbian culture is something that is still really alive, and it is really embraced by everyone there. I think that it is rare to find a place where people are not as influenced by pop culture and by everything that's going on in the modern world. I think that the fact that they still speak Mayan is really important.

I was compelled by Leslie's answer because I had also felt the same way about Mexico. I was very intrigued by its culture and architecture of the country. Like Leslie, I had also travelled to Mexico as part of an educational experience and became captivated by the country and its people. I took note of Leslie’s fascination with Mexico because it was a 
topic that I wanted to explore later in relation to her study abroad experiences in Jalapa and Guadalajara.

Leslie mentioned that she enjoyed every aspect of the design curriculum and she also drew comparison with other careers in terms of the education:

I think that we're taught in a way that other careers and other processions are not taught. Most professions that I can think of are taught with books. Individuals in these professions are taught formulas or things that have been invented or discovered and we're not. We're taught to think. Regardless of whether you later do architecture or not, the ability to think is something that you will always have.

Leslie makes an important observation about how architecture is taught. Unlike many other disciplines, architecture students are taught to develop a rigorous design process that is governed by a critical thinking. This, according to Brian Kelly, director of the architecture program at the University of Maryland, is "a central component of the architectural education and an essential tool for successful professional practice” (Waldrep, p.122).

Leslie's mention of the uniqueness of an architecture education is further apparent in the structure and inclusion of the design studio in the curriculum. This course is not only the central focus of the architecture curriculum, but design studio is primarily an “autonomously directed experience employing talent and tacit knowledge. Aside from creativity, studio is where students expect to master architecture and where the curriculum expects assimilation of core topic areas” (Bachmann \& Bachmann, 2006, p. 3). Many of the participants interviewed expressed that they enjoyed taking the design studio classes the most while studying architecture. This finding came as no surprise to me because the studio is the environment where design happens (Waldrep, 2006). Gloria 
and Leslie, for example, were quick to reply that the design studios were their favorite courses in architecture school.

\section{Gloria}

Gloria provided lengthy descriptions of her study abroad and life experiences. As such, the information that she provided was very beneficial and used as a primary source of information for this study. When asked why she chose the design studio, Gloria answered,

I love that you have to struggle most of the time but you have to find a way to express your idea, express what you see and what you think to represent what you are somehow imaging. It doesn't matter the media...but it's just amazing that it comes from your insights.

I found myself associating with Gloria’s mention of having to struggle in the design process. I would also spend countless hours trying to develop a design solution that at times would not result in anything viable. From my own personal experience as a professor of architecture, I have also often noticed that students who are not willing to work extra hard and encounter some degree of struggle in developing effective design solutions often become frustrated with the curriculum and drop out of the architecture program. The attrition rate in design school is high and those who are not willing to expend long hours in the design process are either weeded out because of low grades or leave on their accord because of misconceptions about the profession and curriculum (Dalton, 1999; McMinn, 1984).

Gloria had had some prior travel experience before participating in the University of Florida study abroad program in Vicenza. Aside from living in Cuba, Gloria had also spent some time in Venezuela before moving to the U.S. She also mentioned that as an undergraduate in the University of Florida, she had travelled to Europe: "I travelled to 
specifically Italy and I remember being fascinated with Rome.” She talked a little about her fascination with the city and felt compelled to return to Italy 6 years later as a graduate student. "Having the opportunity to go back maybe six years later and being in the graduate program at the University of Florida was a totally different experience.” For Gloria, the return to Italy was in many ways an attempt to validate what she had learned in her courses, and the ability to experience in person the spaces and structures that she had read about. "This time you will look for specific architectural landmarks. You will be trying to inhabit the places that you read about in the books. It was a totally different perception.”

Whereas the majority of my participants had studied architecture at either the undergraduate or graduate level, Gloria had begun her studies in civil engineering. It was only by chance that she actually shifted her occupational focus to architecture while taking an introductory class at Miami Dade College. Gloria had begun studying civil engineering in Cuba and she later continued her studies in Venezuela. "It was after I came here that I had to go through the whole process and finally switched to architecture. It's been a very long journey for me. It has been a love affair with architecture.” I wanted to learn more about Gloria’s decision to begin her education in engineering. Although architecture and civil engineering are somewhat related, there are also major differences in the profession and curriculum. Architecture tends to be much more focused on design and civil engineering is a much more technical and science based profession. Studying civil engineering had not been Gloria’s personal decision, but it was the only degree option offered to her in Cuba.

Because my grade point average was very high they thought I could be good in math and structures and physics. In Venezuela, the city where I lived only offered 
civil engineering. Finally, once I was in Miami, I was able to make the decision to study architecture.

As I talked to Gloria about her decision to study architecture, I also learned that she had worked as a paralegal in real estate to make money when she arrived in Miami. Her desire, however, was to study architecture and she worked in order to pay her tuition. "Whenever I had the opportunity and the money, I went back to Miami-Dade and this time I registered for architecture courses than engineering.”

Although Gloria had been admitted to Florida International University’s engineering program, Gloria felt that the course was “too rigid.” She further articulated the need to be creative and express her ideas as an architect. Gloria also talked about how one of her professors had encouraged her to apply to the University of Florida to complete her architecture education.

It was in one of my lower division design presentation and I think that it was actually in D-4 that Professor Oscar de Palma came to the presentation and, after the presentation somehow along the way, I must have impressed him because he asked me what I was doing after Miami Dade College. I had thought about Florida International University because it would allow me to work and study. He said "no, you're going to University of Florida." That was where the journey began. Soon enough, I was speeding to apply to the school of architecture and I think it was the best decisions that I could have made in terms of my professional career.

At 33, Gloria was one of the oldest students in her undergraduate architecture program at University of Florida. She talked about the challenges that she faced transferring to University of Florida because of her age and the fact that her classmates had already been in the design program for a number of years:

Imagine being an adult transferring to a school where you have to work very intensively and compete with students who had already been in the undergraduate program for a number of years. In addition to that, learning more and more about architecture was a huge challenge - a huge challenge but I made it through. 
I empathized with Gloria because transferring into a design school at the midpoint of the degree program can present a number of academic and socially related challenges. Each design program and school of architecture, for example, has a specific teaching methodology, and adapting to the change from one institution to the other may take some time to adjust.

I took note of Gloria’s responses and the fact that she mentioned that her discovery of architecture as a profession and course of study was much like a journey. I was also impressed with Gloria’s determination to undertake architectural studies at 33. I had also begun my studies at the same age, but I was enrolled in a graduate program where the majority of the students were about my age. I was also enrolled in a design program for students who had degrees outside the field of architecture. Because of this, I probably didn't feel as challenged or as displaced as Gloria in a class on undergraduates who were probably at least 12 years her junior. I felt that her determination to study architecture and her background in engineering would provide interesting insights on how she experienced her study abroad in Vicenza.

\section{Sandy}

I initially met Sandy during her lunch break while she was working for the University of Miami, School of Architecture, in the Dean’s office. Because Sandy was rather open about some of the personal aspects of her study abroad experience, I was able to use much of her discussion as primary source data for his study. Although I had never met Sandy before our interview, also present in the conference room was a former student who wanted to listen and learn more about her study abroad experiences. I did not object to the added person in the room because I had already conducted some of the 
interviews with other individuals present. In some cases, I felt that I could obtain more information if the participants engaged in conversation with one another about their experiences. In fact, these types of interviews often lasted much longer than the ones that I conducted with only one person. I also noticed that the transcripts were much lengthier because the individuals would often help each other remember certain instances that they may have otherwise dismissed or have forgotten about.

Sandy is a 22-year-old undergraduate studying architecture at the University of Miami. Her name had been given to me as someone who would not only be available for an interview but would be willing to share her ideas and experiences. Up to that point, I had had some difficulty contacting University of Miami students, and even experienced a certain amount of reluctance on their part to participate in this study. Sandy is Hispanic and was born in Venezuela. Her predominate language is Spanish, but she has an excellent command of English having been living in Minnesota and Miami for the past 12 years. Unlike many of the other participants, Sandy had travelled abroad and throughout parts of the United States before embarking upon a semester abroad in Rome as part of the University of Miami’s study abroad program.

Sandy mentioned that she liked the fact that architecture is related to art:

It's art but after a certain point, you have to serve people, you have to serve certain parameters, it has a purpose other than to look pretty or convey a certain mesSage...it has a lot more to it than just a painting or something.

Her idea of architecture as a functional art is also supported by Rasmussen (1959) who writes that "architecture is a very special functional art because "it confines space so we can dwell in it and creates the framework around our lives” (p.1 0). Roth (2007) discusses that idea that architecture is the unavoidable art. Not only does it have a function, but it 
impossible to avoid architecture because "we deal with it every waking moment when not in the wilderness; it is the art form we inhabit” (p. 6).

When I asked if she liked traveling, she emphatically answered "I love traveling. I love everything and just getting to meet new people, new places, new experiences, and cultures is just so cool.” I not only noticed Sandy enthusiasm about travel, but her age and maturity became rather apparent by the way she expressed herself. She repeatedly used the word "cool" to describe her experiences. Though this might have been an initial bias, it was quickly dispelled in the course of the interview as Sandy began to become more descriptive about her feelings and experiences of the semester study abroad in Rome. When I asked her if there was any place she enjoyed visiting with her family, Sandy gave me three examples:

I really liked the time I went to North Carolina and went white water rafting. It was fun. I had never done that before. We went to Europe as a family and going to Paris was really cool. We went to Slovenia where my dad's family originated. We actually visited some of the family members and that was really cool. We stayed in a castle which was cool.

Because of her age, Sandy was able to talk about the influence of her study abroad on her personal development. Sandy had matured because of her study abroad experience and had learned to become more self-reliant.

\section{Marc}

Kate and Marc are husband and wife. Our interview took place in a Starbucks near their house in Miami. Since the interior was acoustically loud and not conducive to an intimate recorded conversation, we continued our interview outdoors on a wet and humid evening. At times, it was a little difficult to follow the conversations and I was worried that the voices may not have recorded properly because of the sound of traffic. 
As husband and wife, I took note of the dynamic between these two individuals. On several occasions, Marc would support or reiterate Kate's answers to questions that I had asked her. I did not get the feeling that Marc was trying to dominate the conversation, but I felt that his interjections were a way of defending his wife against any possible misinterpretations on my part. Although quiet, Kate was assertive at times and quick to correct Marc if his interpretations of her answers were incorrect or misinformed.

I have known Marc for a couple of years in his capacity as an adjunct professor of architecture at Miami Dade College and Florida International University. In fact, I have often asked him to be part of my end of term review juries because I always found that his input was very beneficial to the students. Marc is of mixed ancestry. His father is an immigrant American from Europe who speaks only English to Marc. His mother was born in Peru. Although she speaks both Spanish and English, Marc was only brought up speaking English predominantly. He does understand Spanish “but I can’t speak much, only a small bit.” Marc is a highly intelligent and articulate individual who had been recently accepted into a Ph. D. program in architecture theory and history at the University of Pennsylvania. What is also equally impressive is the fact that he had earned scholarships for the program. Marc is also extremely well-travelled and has earned undergraduate and graduate degrees in architecture from the University of Florida. He also recently completed as a second graduate degree in architecture pedagogy from the same institution.

I was quite interested in Marc's perspectives about study abroad because he had participated in a number of travel and study abroad programs while at University of Florida at both the graduate and undergraduate levels: 
Yeah, I studied abroad several time while I was studying at University of Florida. As an undergraduate I studied for a summer- 2 months in Hong Kong- and I was able to travel throughout China, also to Japan, and Thailand. That was a summer. Then one of the semesters of my final year of undergraduate studies, I studied in Vicenza. As a graduate student, I studied for a summer in Guadalajara; I was able to travel around Mexico, then again studied abroad in Vicenza as a grad student. After graduating I was enrolled in another master's degree, Kate and I both enrolled and spent 6 months living in Naples, Italy.

I felt that Marc brought a wealth of travel experience that would enliven much

discussion and insight about the influence of study abroad on his life. As such, his input and reflections served as a primary source of information for this study.

When I approached Marc about being part of my study, he mentioned that his wife had also participated in the semester abroad in Vicenza. I thought it would be interesting to learn about the influence of a study abroad from the perspectives of a husband and wife who had actually lived and travelled together. I also thought that interviewing them together would generate much conversation as they would essentially be talking to one another about their experiences. As a result, the transcripts from this interview were one of the longest and probably one of the richest in terms of the material that I was able to analyze.

\section{Kate}

Kate is also very articulate and was readily able to express her sentiments clearly. I used her information as a primary source of data for this research because of the extensive accounts of her study abroad experiences. She is somewhat soft-spoken but also came across assertive at times when she felt the need to express an idea or sentiment. Kate lived much of her life in Daytona. Her exposure to foreign travel was somewhat limited having only taken a cruise to Mexico while she was in high school. Kate had also earned both the undergraduate and graduate degrees in architecture from 
University of Florida. When I asked why she had applied to University of Florida, I expected her to talk about the reputation of the design program. Instead, she mentioned that it was just predetermined that she would attend the institution:

Initially, it was predetermined that I go to the University of Florida because my brother went there. In graduate school, however, I had the choice to go somewhere else and I was looking at different opportunities. The University of Virginia was one of the options and I was seriously considering going there to have a different experience in school.

Her decision to attend the University of Florida was financially motivated but it was also influenced by the study abroad program. Kate realized that she could spend less money in tuition and participate in a semester long study abroad program at the University of Florida:

I opted to go to the University of Florida. For the same cost of going to that school, I could do a whole semester abroad, whereas at the University of Virginia, the only opportunity to go abroad was for I think a six or eight week program, and so I opted to go to University of Florida for the whole semester.

In fact, Kate and Connie were the only participants who mentioned that they were influenced to apply to a specific institution because of its study abroad program.

Like Marc, Kate had also been accepted to pursue additional graduate degrees from various institutions including Harvard. Kate talked about her decision to pursue a graduate degree in landscape architecture and mentioned that she had recently been accepted to the University of Pennsylvania. When I asked her why she decided to study landscape architecture, Kate answered that she had really never been able to separate the two professions in her career as a designer. Kate also felt that she would learn to become a more effective designer. "Getting an additional degree, I feel that I could more comprehensively design something for myself and other people. I also want to learn more about technology and how to work with the environment more closely.” Kate also talked 
about the influence the study abroad and travel had played in her decision to return to graduate school:

Something that I brought back from my travel abroad was the intent to explore cities in the U.S. with the intensity that I did of cities in Europe. I feel that I have overlooked this opportunity in the past. We go to Europe and we think that everything's so wonderful and that things in the U.S. are maybe not so great. There are, however, lots of great things to experience in American cities too.

Marc was quick to support Kate’s point about the close relationship between architecture and landscape architecture:

I think that Kate brought up an important point in saying that she doesn't really distinguish between landscape architecture and architecture. We both think of architecture as really just some ordering or reconfiguration of the world around us, and that applies to the ground, the city, and the spaces between the buildings.

As if content with Marc's interpretation of her earlier response, Kate was quiet and did not respond. Instead, she looked at me and awaited the next question.

\section{Lizette}

I met Lizette and Julian at the Florida International University library Starbucks to talk about their study abroad experience at the Florida International University program in Genoa. I had not met Lizette before our initial meeting and was introduced by Julian who had been a former student of mine. Lizette was one of the younger students who I interviewed and she had just returned from her semester abroad in Genoa. Lizette is of Hispanic origin and was raised speaking Spanish in her home. Lizette had had some prior travel experience and had travelled to Russia, Central America, and France. I was surprised that she had been to Russia since it is not one of the more popular tourist destination sites. I have never travelled to Russia so I was curious about her impressions of the country. "I wasn’t really convinced on going to Russia when the idea was brought up to me, but I was totally blind sighted by how much I loved it.” I was surprised that she 
had enjoyed it so much and was curious to learn what she liked so much about her experience. "It's just so different; the culture, the people, and the architecture. It's different. I mean it took me a lot to get used to it, but it was great. I enjoyed it.” I noted that Lizette was probably adventurous because of her decision to explore Russia and the fact that she enjoyed her experience also gave me an indication of her willingness to associate with foreign cultures. I also noted her flexibility to overcome cultural nuances to make the most of her experience travelling and living in a foreign country. In the course of her architectural studies, Lizette had also taken some humanity courses and even enrolled in Italian courses while she was in Genoa.

\section{Julian}

Julian was one of the oldest male students that I interviewed. He mentioned a couple of times that he had entered architecture at a later stage in his life after having worked in finance. I almost felt that he was being somewhat apologetic because of the tone of his voice and the number of times he mentioned his age.

This is actually my second time in school. I've studied finance originally, I worked for 3 years and I came back to school, which is also part of the reason why I went to Miami Dade to get all of my pre-reqs done.

I reassured him that I also began to study architecture at a later stage in my life after having tried finance as a stockbroker. He seemed a little relieved by my own experience. Julian also expressed the fact that he enjoyed studying architecture because of the creative and technical aspects of the curriculum

To me architecture is a nice mix of math and science with the arts. I like creativity a lot but I can never paint for a living and I can't be a painter. I need something a little bit more structured and architecture is a nice balance of the two.

Since Julian had attended Miami Dade prior to Florida International University, I wanted to learn more about his decision to begin his lower division studies at a 
community college. I was also aware that I had been his professor, and I didn’t want him

to give me an answer that he thought I intended to hear:

I decided to study at Miami Dade College because it's a good school and it's cheaper than the other architecture programs in Miami. That just made sense to me. You get a good education for a lot less money and you actually sometimes get better professors than you do at Florida International University. It’s true, right?

Julian turned to Lizette as if to seek her support. "In some cases, yeah,” answered Lizette.

Julian continued, "In some cases. I mean everything depends on the teacher but...” At this point I felt that the conversation might turn to commenting on specific instructors at the college so I diverted my attention towards Lizette and asked her about her educational experience:

I was enrolled in Florida International University, but I didn't carry architecture as my major. So as not to fall behind, I took my first two classes at Miami Dade College, and then I was called right before Design 3 by my adviser. She told me there's some space, so I was able to come into the architecture program at Florida International University.

In fact, many Florida International University students begin their education at Miami Dade College and either transfer during the first 2 years as did Lizette, or wait to complete their AA as did Julian.
Alex
Julian had also helped me make contact with two other Florida International University students who had also participated in the Genoa program. I had never met Alex or Jaime prior to our initial encounter. Although both students were born in Venezuela, their families are from different parts of Latin America. Alex for example was born in Venezuela and has lived in Miami for the last 10 years. I asked him about his German surname, “my grandfather was from Poland, that's why I understand it, but I don’t speak Polish”. 
Alex completed the four year program of architecture at Florida International University and was taking some additional courses during the summer to graduate. Alex talked about travelling to Europe as a child and was able to recount some of his experiences:

Well, at that time I hadn't gone into the whole world of architecture so when I went back now, it was like I had a different view on things. When I went for the first time, it was exciting just to see new places and new things, but after going with almost three years of architecture you begin to appreciate things better and you see the history of things.

Alex talked a little about his interests outside the file of architecture. He mentioned taking photography and actually receiving a minor in art focused photography. He also engaged in language courses before leaving for Genoa. Jaime, on the hand, had limited travel experience other than travelling to his native country and spending time in Washington DC.

Alex had also expressed being close to home as factors influencing their decision to study at Florida International University. He mentioned the convenience of living in Miami and attending university, "For me it was more of a benefit since we already live here in Miami. It was more of a benefit-I thought it's a great benefit to go school near home.” Jaime also resounded Alex’s sentiment

For me it's similar, like just in my family there's not the tradition of going away as soon as you graduate-it's more of a family thins I guess. Just staying near home was a place for me, and considering the architecture program here at Florida International University seemed like a good plan too.

When asked about what he enjoyed about studying architecture, Alex was quick to point out that really enjoyed history. For him it was really "interesting to learn how, even from earliest times, there has been a class structure.” I first questioned this idea, not quite know if he had inadvertently meant "structure" in terms of building. I later realized in our 
conversation, however, that he was referring to a class system and how this has continued to the present day as witnessed through architecture. From a historical perspective, much of what is introduced or taught in architecture history courses tends to related to structures that are significant in terms of their function, construction methods, and size. For the most past, one learns about palaces, citadels, religious complexes, and funerary architecture. The historian John Julius Norwich writes that after man had learned to build, his ambitions grew to build buildings that were built to last and impress.

It was no longer enough to have a house to live in-now he began to turn his mind towards a tomb in which to be buried, a monument by which to be remembers, a places from which to be governed, a shrine where he and his fellows could worship their gods. (p. 9)

For Alex, architecture is something that has transcended the notion of time and is something that "connects us in this life to the different centuries of the past".

\section{Jaime}

Jaime, on the other hand, was born in Venezuela but his father is from Chile and his mother from Cuba. He has spent 16 years living in Miami. I found him to be quiet and somewhat reserved. I tried to engage him with conversation hoping that it would elicit more response but I had difficulty understanding him because of his rather soft-spoken voice. In fact, Alex tended to dominate the conversation during the interviews. Jaime had decided to study architecture at Florida International University to be closer to home. He did talk about how the travel abroad changed his perceptions because it gave him "new perspectives on different things”.

Jaime also shared what he liked about architecture and why he chose to study this profession: 
Yeah, there are definitely classes that I like better than others. Studio is a great risk and you never know you have deal with the professor's attitude. I tend to lean towards like digital practice and I also like working with my hands.

In terms of his memories of Genoa, Jorge talked about he enjoyed his pedestrian lifestyle and how he engaged the people and urban condition through his daily walks to a from the design studios to his apartment:

I enjoyed walking in the narrow streets full of people especially on the on holidays when everybody's out walking the streets, shopping and looking for food in the open air markets. That was a big experience. That was pretty memorable.

In fact, I noticed that Jaime was more receptive when I asked him to talk about his experiences of the urban conditions he experienced. One of his lengthier responses dealt with his discovery of the piazzas in Genoa:

The piazzas stood out for me in Genoa. You might be walking through a maze of little alleys not knowing where you were and then suddenly discover a tiny piazza. They are all over the place and they help guide and help get you to know the city. You know the city more or less according to the piazza that you are accessing. It was really interesting to walk through a three-foot wide alley and then suddenly end up in a piazza with a church.

As a religious person, Jaime also talked about making it a point to attend services in different churches on Sundays. "I'm accustomed to going to mass here so what I did over there was every Sunday I went to a different church. I must have gone to dozens.” I found his discovery of the churches in Genoa also interesting. It reminded me of my own interest in ecclesiastical architecture and my documentation of the churches along the Camino de Santiago.

JP

I interviewed JP and Alistair simultaneously at the University of Miami. JP was still a student at the university and had limited travel experience prior to beginning is studies at the University of Miami. A native of Kissimmee, JP talked about wanting to 
travel abroad. He had been on the University of Miami Grand Tour of Europe and had enjoyed the experience so much that he decided to spend an entire semester in Rome. JP tended to come across somewhat nervous and his speech was broken at times making it difficult to understand in the recordings. His answers also tended to be somewhat less explicit than the other participants. He did talk about the need to be in a "hands-on" type of profession and was strongly considering continuing post professional degree in architecture at Stanford upon completion of his Bachelor of Architecture.

\section{Alistair}

Alistair, on the other hand, was much more relaxed than JP during the interview. He had recently graduated from the University of Miami and had accepted a position with a practice in Philadelphia. Alistair spoke in complete sentences and elaborated greatly on the questions that I asked. Alistair had been recommended by the semester abroad program director and was the only one that I was able to contact. He had a keen interest in history and its relevance to design. Students who are perceptive about the role of architecture history and the use of precedents can begin to have a greater appreciation for architecture. Alistair was able to reflect on a course he had taken after travelling abroad. He remembered what he had seen and learned based on what was being taught in the class:

I took this call maybe two semesters ago called Colonial architecture and at first when we signed up we thought that it was just going to be like Northeast colonialism, just a simple 3 credit history class, you know to get it out of the way. It turned out to be colonialism throughout the world and different countries and how they brought their architecture. It was kind of a global look of architecture today and in the past and how everything is interconnected.

I found Alistair's perception about the interconnectedness of architecture interesting because I found that he was able to come to one of the most fundamental understandings 
about architecture. There is a sense that all architecture is somehow connected and this becomes especially apparent when travelling and experiencing works from around the world. The sense of interconnectedness may have to do with the function of this art form, but it might also have to do with how architecture is developed from an initial idea and then transformed into a physical manifestation of structure. Architecture does tend to be taken for granted because it is apparent everywhere. Because we take architecture for granted, our sensibilities may not react to it in the same way as to a work of sculpture (Norwich, 2000). But through travel and exposure to monumental works and architecture that historical and cultural significance, our sensibilities may awaken and greater appreciation and understanding of architecture may occur. I feel that Alistair had experienced this transition through his travels because of this awareness.

\section{Reasons for Studying Architecture}

As part of the "focused life history" (Seidman, 2006), I was most interested in learning how the participants had decided to study architecture, and how the experience of foreign travel and study abroad had furthered their initial interest in the study of architecture and shaped their educational experiences. The paths that lead these students to consider architecture as an education and professional pursuit were as varied as their own personal interests in the arts or aptitudes in specific academic disciplines such as math or physics. In other cases, the desire to study architecture had more to do with a personal association with an architect, builder, or even carpenter who had first exposed the individual to ideas of design and construction (Waldrep, 2006).

In my own personal case, I first learned about the study and profession of architecture from my father who is a professional architectural engineer and had studied 
both architecture and engineering at university. My initial exposure and interest really stemmed from a direct exposure to the building process as I would often come with my father to the building sites and witness the development of buildings from the initial designs to the completed structure. The process and development of these structures fascinated me as did the orchestration of materials and human labor to create buildings that appeared to have their own personalities based upon their intent and the architects who designed them.

Some of the participants mentioned problem solving as one of the reasons why they chose to become architects. In fact, the ability to problem solve is probably one of the most important skills that an architect needs to be successful. Carol Ross Barney (FAIA, Principal, Ross Barney + Jankowski, Inc.), writes that "hands down, the important skill is problem solving, with the ability to see the not obvious solution, being able to think in three dimensions is a close second” (Waldrep, 2006, p. 33). The idea of problem solving and the exposure of seeing her father problem solve was one of the most important factors compelling Connie to the profession of architecture. Although her father was a "very small general contractor" she was greatly influenced by him and his ability to "problem solve.” Connie also mentioned that she had worked for her father during a couple of summers and particularly enjoyed the idea of "putting things together" but eventually decided that general contracting was not her future and wanted instead to "learn about architecture”. Connie saw the transition from the practical exposure of general contracting to the academic pursuit of architecture as a natural transition. She "really loved anything academically" and "loved mathematics and geometry and things about form”. In talking about her decision to study architecture, Gloria recounted her 
experience of drawing a "little house" at the age of 11 because her father was a carpenter. She also discussed her interaction with her father in his work by helping him "put things together" and her ability to draw as factors that attracted her attention and interest to architecture.

Direct exposure to the profession of architecture can be a decisive factor influencing ones' decision to become an architect. My decision to become an architect was greatly influenced by experiencing my father's profession. Elizabeth Kalin, architect intern, Studio Gang Architecture, recommends "shadowing an architect before deciding to attend an architecture school; several shadowing experiences is ideal” (Waldrep, 2006, p. 77). Guillermo had mentioned interaction with an uncle who was an architect but he didn’t elaborate much about how his uncle might have influenced his decision to become an architect. Jaime recounted going to work with his mother, an accountant, who was employed by an architectural practice. Through this exposure, Jaime "got into doing models and drawing books.”

Marc, on the other hand, decided upon architecture even though his father, a practicing architect, advised him not to enter the profession. He joking replied that he rebelled and became an architect when asked why he decided upon the profession. "My father's an architect and growing up he always told me whatever you do, don't become an architect. So naturally you rebel and become an architect.” Marc's mention of his father dissuading him from the profession brought back some personal memories. Although my father didn't dissuade me from architecture, I do remember him telling me about the demanding aspects of the architecture curriculum when I was initially considering enrolling in a design program at age 17. I remember having various 
discussions with my father about design school and eventually decided to pursue a liberal arts education because I was still rather undecided as to what I wanted to study.

Architecture is a fusion of art and science, and students who demonstrate interest in both fields may be attracted to architecture. According to Moore (1999) structure and architectural design are inseparable. Whether a simple shelter or a grand enclosed space for worship or commerce, a building is shaped from materials so as to withstand natural forces such as gravity, wind and fire” (p. xiii). The science related to architecture has to do with the technological aspects related to building. These include an understanding of how forces function within a structure, but also relate to the materials used in construction, the design of plumbing, electrical, and environmental systems found in all buildings. Although Kate had limited experience of travel prior to her study abroad experience at the University of Florida in Vicenza, when asked how she decided upon architecture she discussed that she liked both creative and technical things. "I guess I liked creative things growing up but I also liked technical things, and it was a good combination.” Like many students considering architecture, she took drafting course in high school and "really liked it and enjoyed it." She thought that her high school educational experience would "be similar but it was totally different in college" but she "enjoyed it nonetheless and kept going with it."

Sandy, on the other hand, was raised in a household of "artists" but also liked math: "My whole family is artistic I guess. I like math a lot so it’s kind of a fusion of both. I always thought that I wanted to be an architect.” Marc also discussed enjoying both creative and technical things which he considered a "good blend" for the study and practice of architecture. When asked about how she decided to study architecture, Connie 
also expressed: "I love mathematics and geometry and things about form.” She also conceded that she hadn't really questioned why she decided upon architecture but was attracted to the challenge. “It’s one of those things that I actually haven’t questioned almost enough about like where life takes you, but I loved that it was a challenge.”

Marc's path to architecture, however, was not as direct as most of the students that I interviewed. This may be somewhat ironic considering the fact that his father is an architect, but I found myself also connecting to Marc's story because it is very similar to my own path and decision to become an architect. Rather than entering architecture school directly from high school, Marc was already a university student and had attempted other majors before architecture. When asked about his experience, Marc answered:

I actually had five different majors in school though, so it took me a while to get there. I was with creative photography first and then I switched to architecture. I couldn't swing it [architecture] because it was too much work and I dropped out. I then had three different business majors and then I switched to architecture again. I guess that's... yeah, it's five majors.

My own experience is not too dissimilar as I had studied a variety of other disciplines and acquired degrees outside the field of architecture before embarking upon a graduate degree in the field.

Aliana's decision to study architecture was influenced initially by her decision to study interior design after she completed a career study while in high school.

I decided to study architecture in high school after they asked us to do a study of a career that we were interested in. I decided to do interior design and, after studying interior design, that led me to architecture seeing that architecture provided stability for me. I saw it as a great degree that I could use almost in everything. It definitely interested me, and once I jumped in, my first day, first semester in college, I loved it. So I rode the wave all the way. 
Interior design and architecture are related fields but differ in their approach. Whereas architecture may be more concerned with the exterior shell of a building, interior design focuses on the interior spaces. There are also philosophical differences between how architecture and interior designs approach the issue of design. According to Kurtich, interior design is the "holistic creation development and completion for space for human use” (p. 3). It is however, not uncommon for students to switch from interior design to architecture or architecture to interior design during their education. Julia, for example, completed her 4-year degree in architecture but has decided to pursue interior design as a profession: "Interior design is really ultimately the one I want to be focusing on in my career.”

It is also not uncommon for students to earn degrees in interior design or architecture and later pursue an additional degree in landscape architecture. Although Kate had been very clear about her intentions to study architecture at both the undergraduate and graduate level, she had applied to a number of graduate programs in landscape architecture. When I asked why she had opted to pursue landscape architecture after having completed an architecture degree, Kate answered that she had never been able fully distinguished the two professions but that her decision to study landscape architecture was also to some degree influenced by her study abroad experience. Julia had also talked about becoming an interior designer and was even contemplating pursuing a graduate degree in business administration. Alistair also mentioned continuing his education and completing a graduate degree in business administration. 


\section{Chapter Summary}

In this chapter, I introduced the participants of the study. I also identified seven individuals who served as primary sources of information for the research. Because these individuals shared more information than others, I wrote more about their experiences than ones who provided briefer descriptions. The information from these briefer discussions was used to support the findings of my primary sources. In the following chapter, I have address the research questions and provided analysis of the information, artifacts, and data provided by the participants of this study. 


\section{Chapter V}

\section{THE ROLE OF TRAVEL IN ARCHITECTURE EDUCATION}

In this chapter, I have addressed the implications of travel and study abroad experiences by investigating and analyzing the participants' responses to the following questions: (a) How have international travel and study abroad shaped the educational experience of those who are studying or have studied architecture? (b) How have international travel and study abroad complemented the architecture curricula? (c) How have international study and travel experiences enhanced the understanding and awareness of global architecture of those who are studying architecture or have studied architecture? (d) How have international travel and study abroad influenced the personal and professional development of those who are studying architecture or have studied architecture? These questions were answered from the participants' points of views. These research questions also made travel and study abroad central to an understanding of students' experiences and of the architecture education.

\section{Study Abroad and the Educational Experience}

Although some of the participants that I interviewed had travelled prior to embarking upon their study abroad programs, none mentioned that prior travel or exposure to ancient architectural had been a decisive factor compelling them to pursue architecture as a course of study and profession. Many, however, did talk about how their study abroad experiences heightened their interest in architecture and positively impacted their educational experiences. Living and studying abroad not only exposed them to many different expressions of architecture, it also made them consider different opportunities within the design profession. Some of the participants, for example, became 
more interested in teaching as a result of their study abroad. Others even considered continuing their education in architecture and even pursuing interior design and landscape architecture as related professions. Others expressed the desire to return to Europe to pursue post graduate degrees in design to further complement what they had learned during their semester abroad.

A certain amount of introspection and self-discovery is required when one considers studying architecture. It may also require understanding one’s likes and aptitudes, and aligning skills with those required by the profession. Roger Schultz (FAIA, Dean of the University of New Mexico) advises students who are interested in architecture to "pursue a basic college preparatory curriculum, including math and science, and engage in freehand drawing” (Waldrep, p. 76). He also strongly advises students to travel to develop a good sense of inquisitiveness and to question why cities, neighborhoods, and landscapes have developed in their current state and form (p. 76). In deciding upon architecture, Alistair had travelled abroad, but he had also taken architecture, art, and graphics courses in high school. He also participated in the University of Miami Explorations program in architecture, which is a 3-week college level program for high school students. This experience, according to Alistair, confirmed his desire to study architecture, and to apply only to the University of Miami.

The study abroad in Rome had also proven to be a very important part of Alistair's undergraduate education. He not only talked about it as being one of the "best experiences” that he ever had, he also talked about how the semester abroad heightened his interest in architecture and how it complemented his education as an architect. When I asked Alistair if he would recommend the study abroad to all incoming freshmen, Alistair 
answered that he was surprised that it wasn’t mandatory for all architecture majors. Alistair was not alone in his sentiment. In fact, all of the participants recommended the study abroad because for many reasons including the fact that it heightened their interest in architecture. Not only did Alistair have the opportunity to visit the buildings that he had studied in his architecture courses, he also came to the realization that he could live and practice architecture abroad:

I think for me it's kind of opened up that idea that I can practice outside of the U.S. We are educated here but there are different opportunities to practice in Europe, Africa, and in South America. I want to explore that possibility of either working for a global firm or even being relocated to a different area to practice.

I believe that Alistair's semester abroad gave him the self confidence that he could live and work abroad. I also believe that this realization was probably one of the most important outcomes of Alistair's study abroad experience because it has helped him expand upon his personal and professional ambitions.

Guillermo, on the other hand, had taken art, graphics, and architecture related courses while in high school having graduated from the Design Architecture High School Magnet program in Miami. Even before enrolling in high school, Guillermo had been involved in a number of art and theatre related magnet programs from elementary school through to junior high school. He had discovered from a rather early age that he had a strong interest in the arts. He was able to pursue this interest by completing an undergraduate degree in Art and Anthropology from the University of Miami before applying to graduate programs in Architecture. He even mentioned the influence of an uncle "who came from Cuba and was in architecture. It just felt right that I should continue to study architecture.” 
Guillermo also talked about the importance of his study abroad in relation to his interest in architecture and art. Ernest found that he became more interested in architecture because he actually had the opportunity to experience contemporary and ancient buildings. He also talked about how his interest in art was also positively influenced because of his study abroad. Sitting in an urban area and sketching a building made him analyze and observe features of the architecture and its site that he would have otherwise probably overlooked. In fact, his observations and documentation of the decay of Roman and medieval buildings in Rome was something that inspired him to develop a thesis proposal around the idea of using discarded shipping containers as spatial units for an art center.

Not all students, however, had the opportunity to take art or architecture related courses while in high school. JP, for example expressed his need to do something other than sitting behind a desk and "studying and researching." JP stressed that he "wanted something that was definitely more hands-on, and something more creative” that would allow him control of what he was doing. In fact, this need to be creative is often an indication and motivating factor to embarking upon the profession of architecture. When asked what he liked about the study of architecture, JP replied: "I like that it is creative, you're not obviously writing papers, and you're making drawings that have the potential to be something other than 2D graphics.” In terms of his study abroad experience, JP did experience a heightened interest in architecture because of his semester in Rome.

I also believe that JP' s educational experience was positively complemented by his study abroad in Rome because he did not have to just write papers but had the opportunity to engage in design projects that were specifically related to the sites he 
vested in the city. Because of his limited travel experience and his limited exposure to architecture living in Miami, JP was also able to learn about the diversity of architectural expression while travelling in Europe:

The study abroad has heightened my interest in architecture in a sense. Again, I feel here you get a monotony of architecture. I haven't been very much outside of Miami and other places so I'm a little sheltered in that aspect. I found it interesting travelling and seeing these different places and how things change so drastically from one place to another even though they may only be 50 or 100 miles apart.

I feel that JP's exposure to this sense of diversity may have also had an impact on other aspects of his life. The study abroad may not have only heightened his interest in architecture but it might have also given him the self-confidence to travel and experience “different things.” When I asked JP what he intended to do after his graduation, JP answered that he wanted to move to California and study architecture at Stanford University just for the "sheer experience" of the move:

I have one semester left. I don't know what I'm going to do yet. In my ideal picture, I would end up at Stanford for the Masters program in architecture. Like with the travel abroad experience, I very much want to go to California just for this year of graduate study. I want to go to Stanford to see if I like living in California. I hear it is nice but expensive.

I believe that JP's decision to study at Stanford was strongly influenced by his study abroad experiences. The intention of going to California was mirrored by his decision to study abroad to "experience something different.”

Julia recounted always being creative as a child and further expressed her need to be in a creative profession. "As a kid, I was always drawing and painting and very into the art. I really found out after a while, I guess, that I enjoyed architecture and interior design.” Although Julia had recently graduated with a pre-professional degree in architecture, her study abroad experience had actually heightened her interest in interior 
design: 'I'm interested in interior design because it's a related field. I like being able to see how people interact with interior spaces. I also think that the difference in scale of space makes a big impact as well.”

Although architecture and interior design are related professions, interior design focuses on the design and configuration of interior spaces. Julia talked about how her observations and interactions with the architecture in Europe had changed her understanding of the importance of design and had made her more interested in interiors. She began to better understand ideas of scale and proportions. She became more perceptive of architectural details and also saw how culture plays an important role in shaping and defining architecture:

When you travel abroad you notice that it's just such a different experienceeverything is so different. The architecture is incredibly different. The treatments of the façades, the structures, even the approach to the buildings themselves are different because of the differences in transportation. Even the difference of the culture makes a big impact on how the architecture is developed.

As with many of the other participants, Julia returned from her study abroad with a renewed sense of self confidence. Her desire to pursue a graduate degree in business and have her own design firm was partially influenced by her semester abroad experience. The exposure abroad to foreign cultures and varying expressions of architecture made her interested in different aspects of design. I believe that Julia's ability to live and function abroad also gave her the self-confidence to explore other professional and educational opportunities.

Leslie grew up with art but later realized that she needed a reason to justify her art. The justification she sought was in the form of architecture. In fact, Leslie even laughed and joked when thinking about herself as an artist: 
I grew up thinking I was an artist and then I realized I wasn't. I could draw really well, I could, but I was missing that thing that artists have. I needed a reason for my art, and building was the reason that I found.

I was somewhat mystified by her laughter. I was not certain if she thought of herself lacking the necessary talent to be an artist, or thought she could not express her creative ideas through an artistic medium.

As a professor of architecture, I have often experienced students lacking the selfconfidence to draw or sketch. In many cases, these students just give up and may stop coming to class, or may even drop out of the program entirely. I also found Leslie’s observation interesting because of her reference to architecture as an art form. There is often much theoretic discussion about the close association between art and architecture. Whereas the architect and artist may engage in similar work, Rassmussen (1959) writes that there are major differences between the vocations:

The architect works with form and mass just as the sculptor does, and like the painter he works with color. But alone of the three, his is a functional art. Architecture is a very special functional art; it confines space so we can dwell in it, creates the framework around our lives. In other words, the difference between sculpture and architecture is not that the former is concerned with more organic forms and the latter with more abstract. Even the most abstract piece of sculpture, limited to purely geometric shapes, does not become architecture. It lacks a decisive factor: utility. (pp. 9-10)

In finding a reason for her art, Leslie was able to channel her creative talents towards the profession of architecture. I associated with Leslie’s experience because I also often thought of myself as an artist, but I wanted to engage in a creative profession that had a specific purpose or utility. I enjoyed making 3-D abstract compositions but I believed that architecture would allow me to transcend abstract compositions into structures that had specific purposes. Instead of earning a Master of Fine Arts in sculpture, I also felt that I 
could do more with a professional degree in architecture. I also felt that being an architect offered more professional options than being a sculptor or painter.

Leslie's semesters in Mexico gave her the opportunity to explore and express her creative ideas both artistically and architecturally. I believe that her exposure to the art and architecture of Mexico helped her to look at architecture from a new and different perspective. She even used her artistic talents to develop creative design proposals in her design studios. In one example, Leslie talked about how she developed her design models using folded sheets of paper. Because she could not find the supplies that she needed to make her design models, Leslie improvised by folding paper to create the necessary forms:

In Mexico, you had to create tools for yourself, you had to invent new ways of building models, and that alone I think taught us important lessons. For me, in particular, it completely changed the way that I designed from then. I think that every single one of my projects after that was influenced by what I learned to do in Mexico.

I was impressed by Leslie’s resourcefulness in developing her projects from folded sheets of paper. I even asked her to elaborate upon how she developed this idea:

I developed this way of creating paper models, which I learned later on was a Japanese technique called kirigami. It's like origami but it's about cutting and folding. I started to do that and basically just creating models in a way that I could fold them up and put them on my suitcase and take them with me and that was a challenge on its own. I developed this way of folding paper and cutting paper that would allow me to prop things up and then take them apart.

I believe that Leslie probably wouldn't have thought about this type of creative presentation if she hadn't been challenged to develop an alternative means of creating a design model. I also believe that Leslie was inspired to think creatively because of the location of her study abroad. Leslie talked about how much she loved exploring and experiencing Mexican culture. She talked rather enthusiastically about walking in Xalapa 
and just “getting lost.” It didn’t seem to bother Leslie that she was lost, but used the opportunity to find her way and explore more aspects of the city. I believe that this act of exploring a foreign culture may have also increased Leslie's sensitivities to explore other areas of her life including her own sense of creativity and artistic expression.

Leslie shared some of her creative work and was eager to have it included in this study to illustrate what she learned and developed during her study abroad programs. These projects also show her use of the kirigami technique that she used to develop her design models. Her design studio project in Xalapa entailed creating a bridge walkway linking parts of the city to an existing church structure and community center adjacent to the building. Figure 8 shows the actual site and also reveals the existing church structure, ravine, and bridge. The type of site documentation is part of the site analysis that is

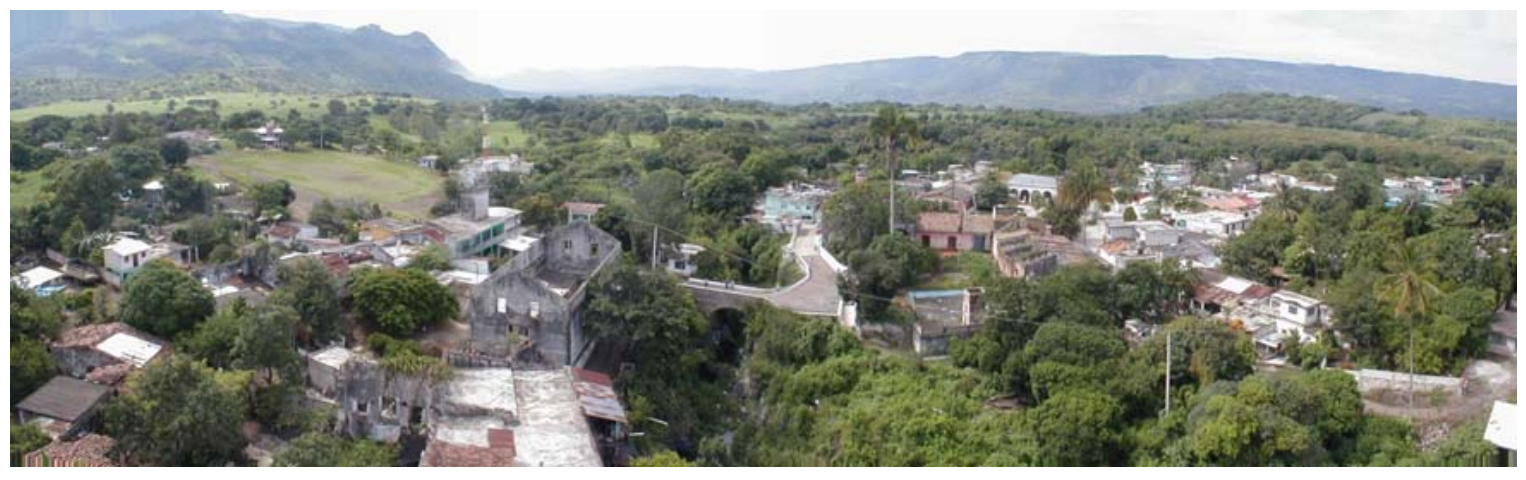

Figure 8. Panoramic photograph taken by Leslie Sanchez of Xalapa, Mexico.

conducted prior to the commencement of any design work. Also included in the site analysis are sketches that illustrate existing conditions including changes in elevation or the relationship of site to the existing structure. Figure 9 is a rendering drawn as a section that illustrates changes in topography and the relationship of existing buildings to the site. Also included are images of people that give the rendering a sense of scale. 


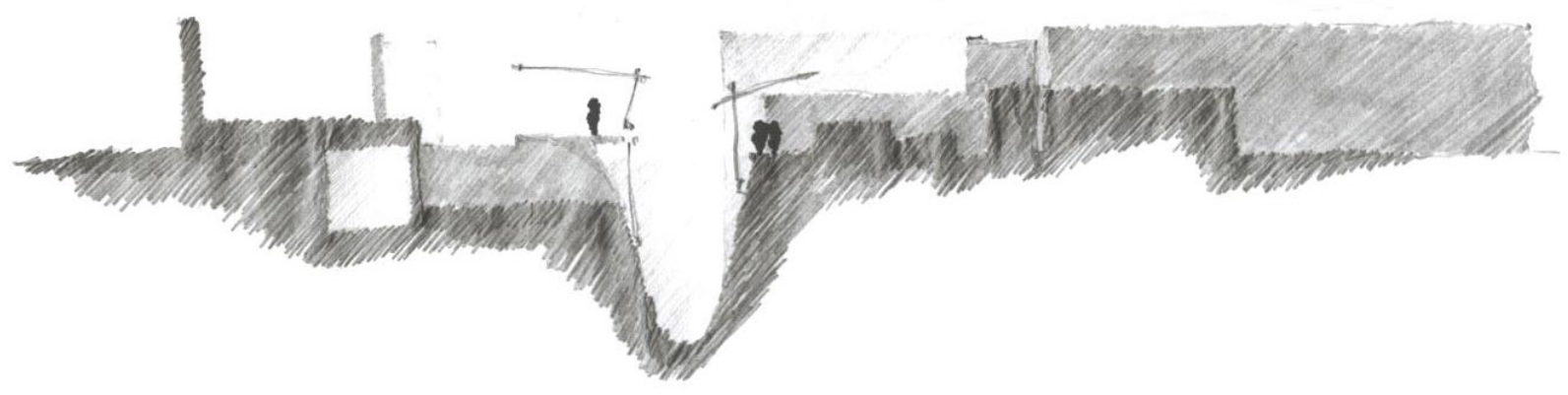

Figure 9. Section analysis of site in Xalapa, Mexico drawn by Leslie Sanchez.

Figure 10 shows examples of Leslie's design project as it developed in stages to include the walkway and its connection to the church, and the subsequent development of a community center adjacent to the church that terminated the pathway. These images were given to me in digital format as they had been included in the portfolio of her design work at the University of Florida, School of Architecture. The design models are of particular interest because they were constructed using simple folds of paper. This is not a traditional method of constructing architectural models, but was developed, according 
to Leslie, "out of necessity because of the lack of necessary materials and equipment
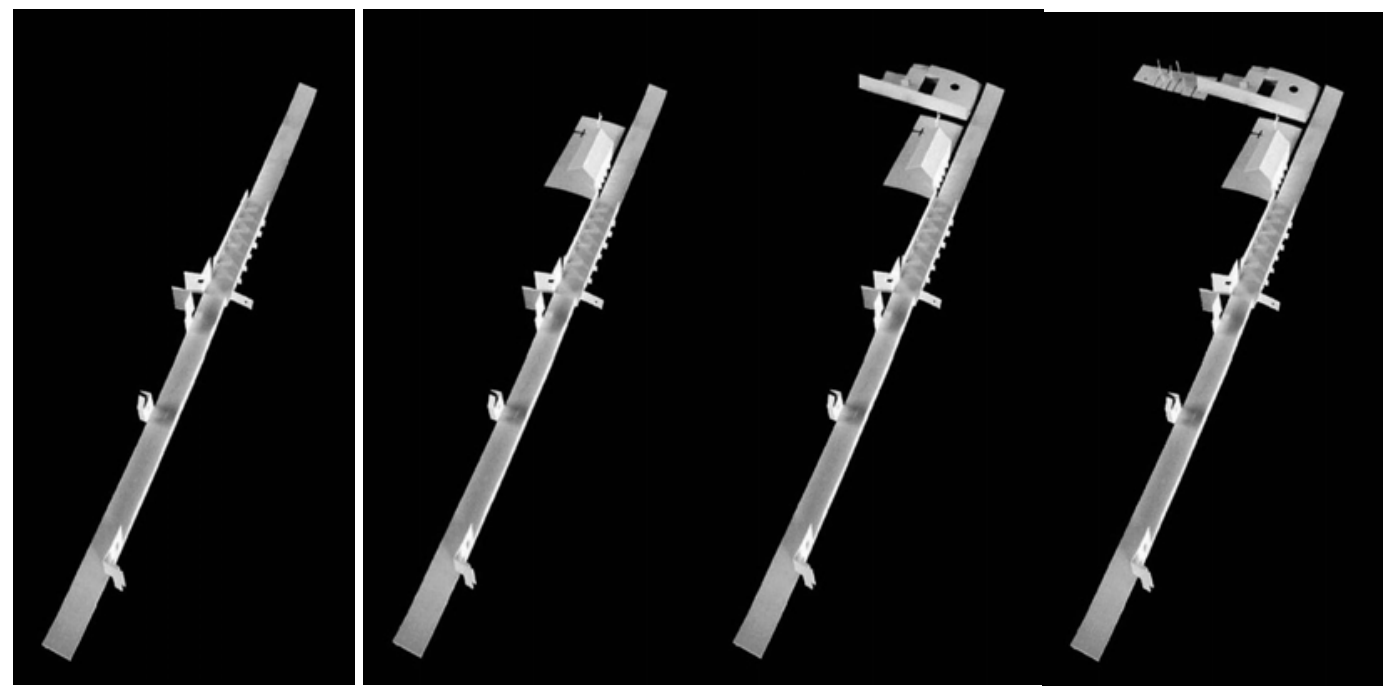

Figure 10. Design Model created by Leslie Sanchez of a Walkway, Church, and Community Center in Xalapa, Mexico.

needed to make the models." The design implications for this project are interesting because they indicate how planar surfaces can be transformed through simple folds. In fact, these folded planes also articulate and strengthen the connections established between the walkway, church, and community center.

Subsequent images show examples of her presentation materials illustrating the community center design proposal in the form of a plan and a 3-D rendering. The plans are hand drawn using straight edges but the isometric rendering appears to be a freehand drawing. Both images were also given to me in digital form and had also been included in Leslie’s studio design portfolio. 


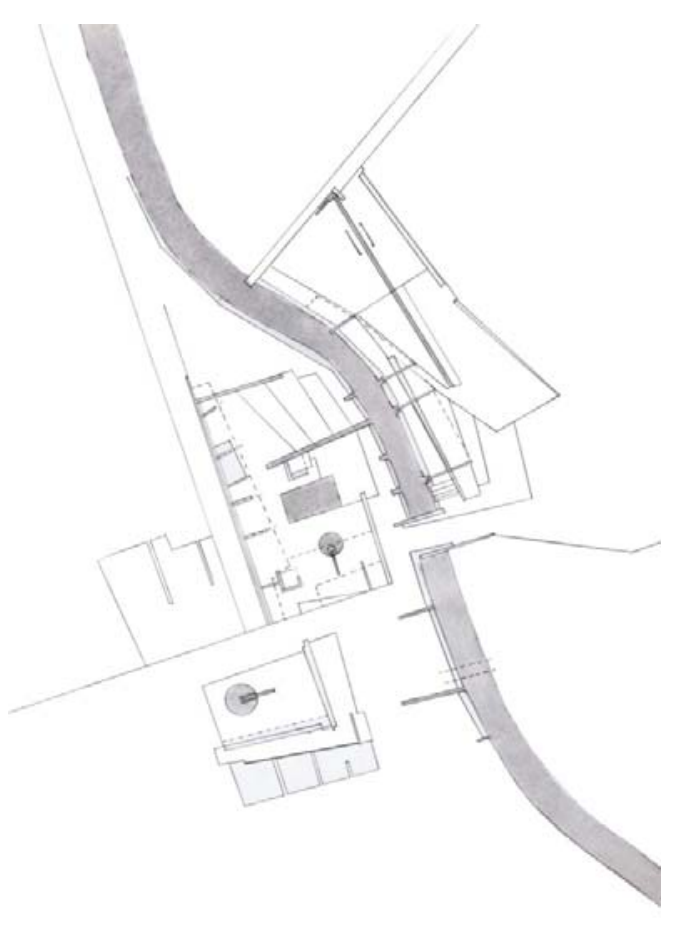

Figure 11. Plan by Leslie Sanchez.

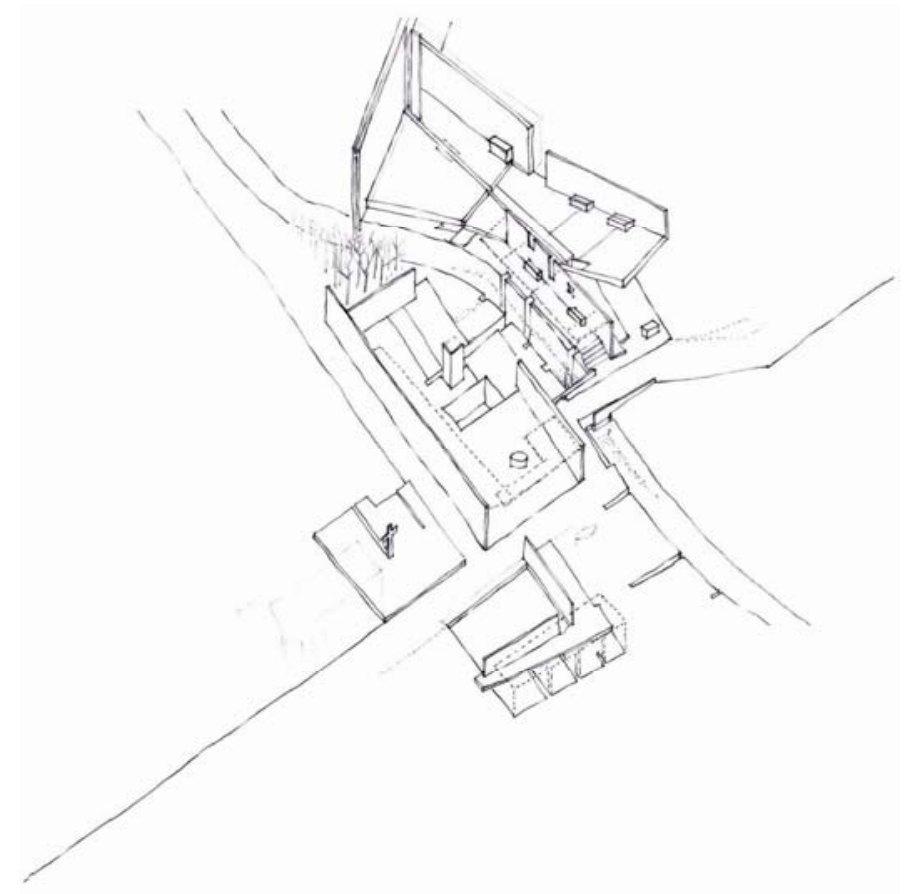

Figure 12. Axonometric by Leslie Sanchez. 
Upon her return to the University of Florida, Leslie implemented some of the design ideas and kirigami techniques that she first used in Xalapa. In her Design 7

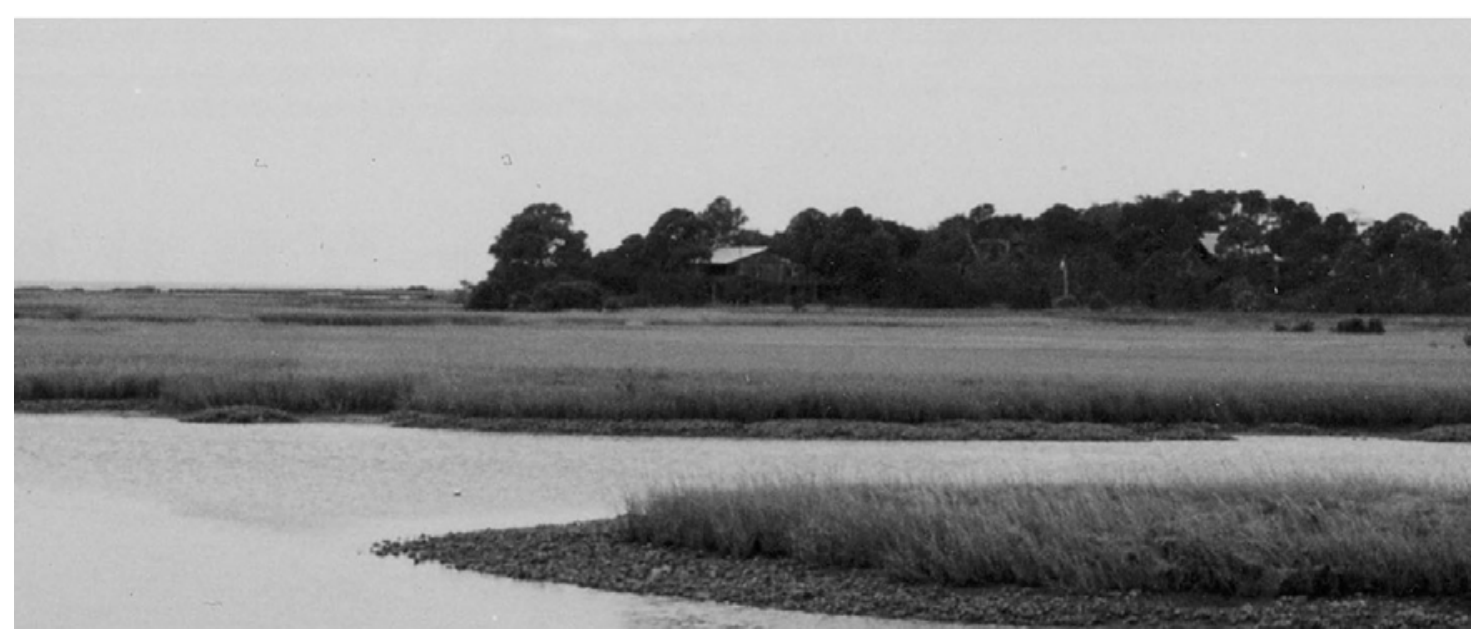

Figure 13. Photographic image of the proposed project

studio, Leslie was asked to develop design concepts for small sustainable pavilions to be erected in a proposed tide water site shown in Figure 13. Leslie developed her designs based on the concept of folded planes. In fact, her models were entirely made of folded plans to illustrate her design ideas. Even though Leslie was on her home campus with ample access to the necessary supply materials needed to make traditional design models, she was intrigued by what she had developed in Xalapa and wanted to explore the ideas further.

Her design work also included a sectional drawing to further illustrate the interior spatial dimensions of the pavilion and its association with the ground plane. In Figure 15, we can also see the subtle changes in topography and the relationship between the structure and its natural environment. 


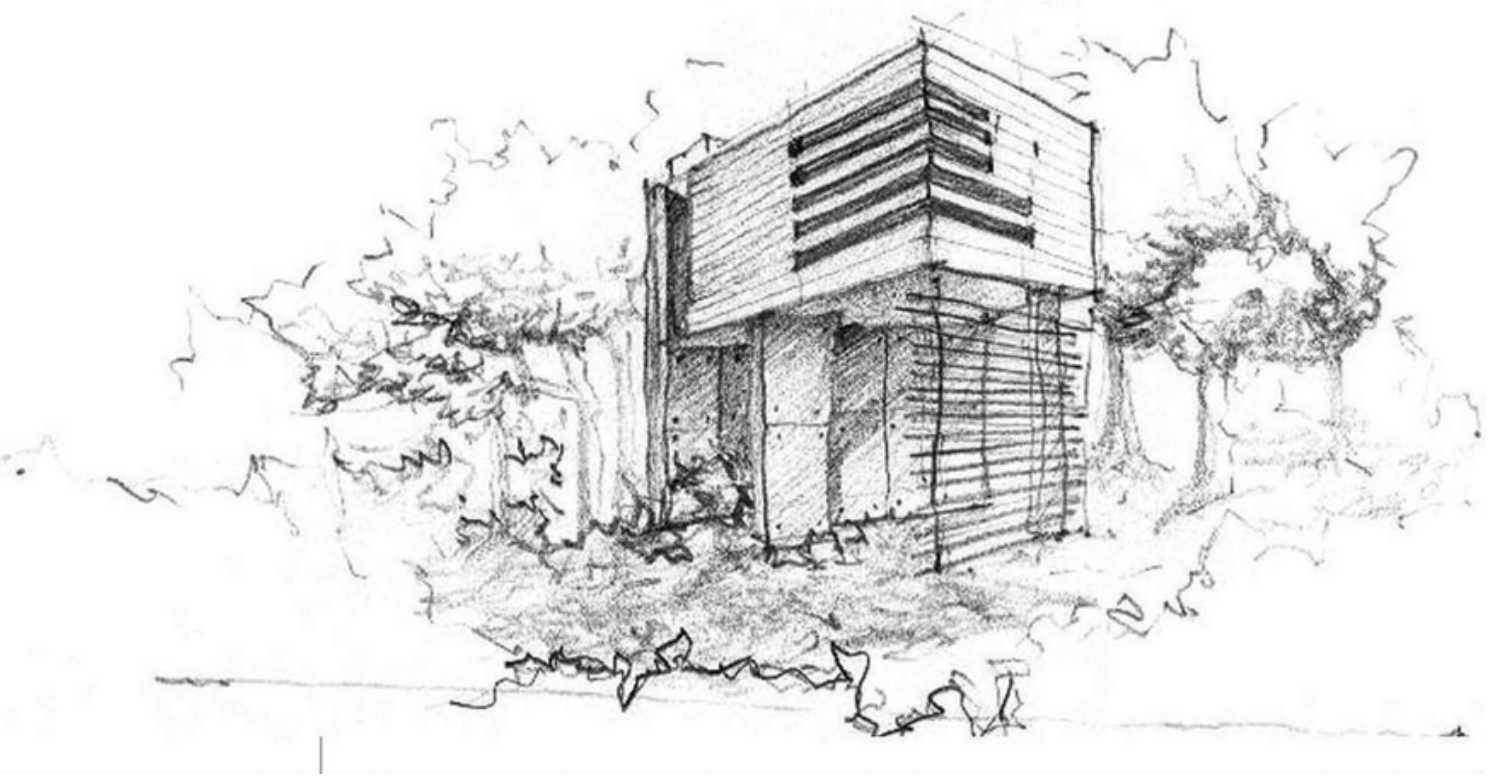

Figure 14. Perspective grashite rerdering by Leslie Sarchez.

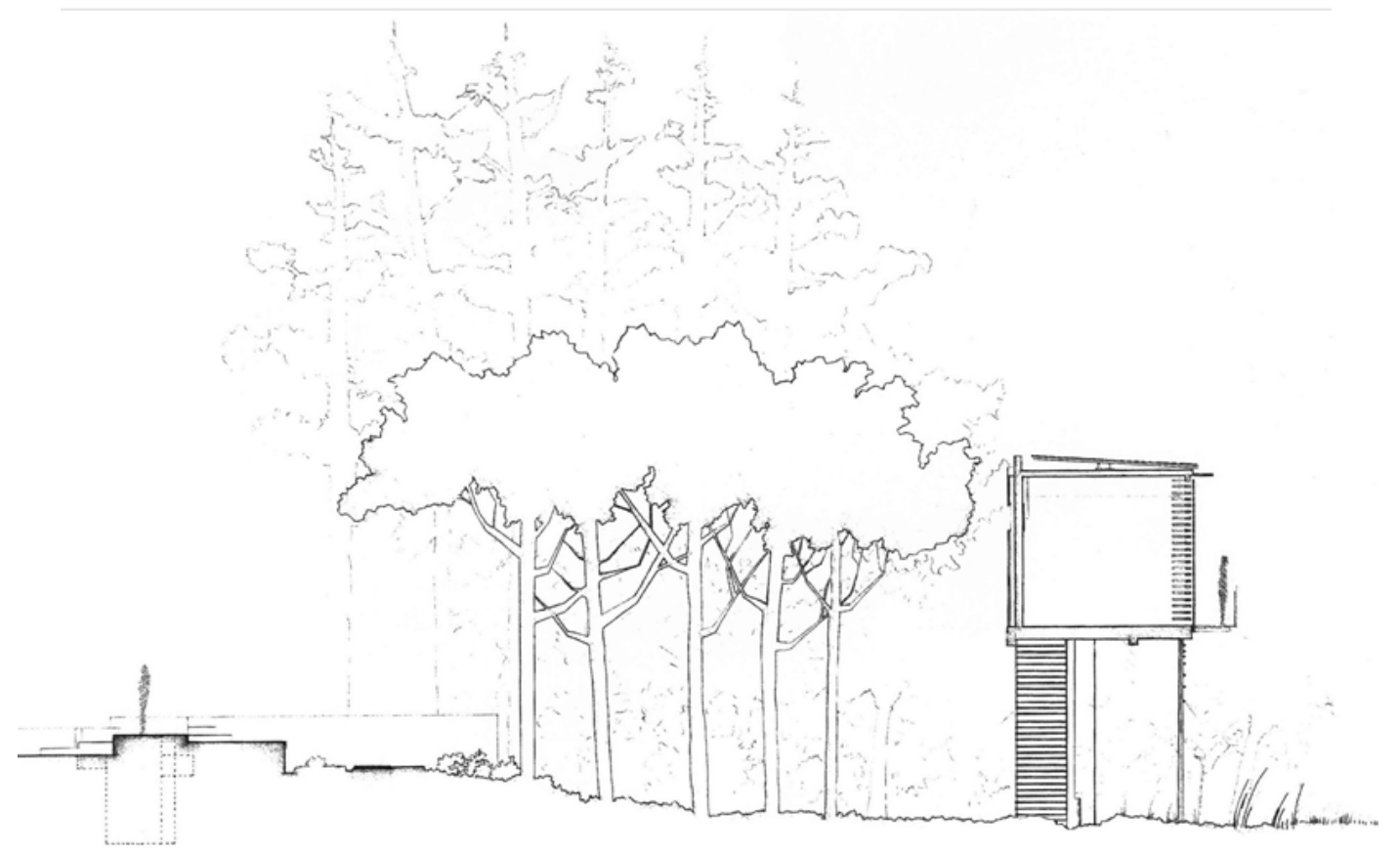

Figure 15. Section by Leslie Sanchez. 
Although I was impressed with Leslie's design and her presentation materials, I was most compelled by the sectional model that she created using only one sheet of paper. "I became known as the paper folding lady in the design studios. My professors encouraged me to explore this technique and its implication in design. I guess I managed

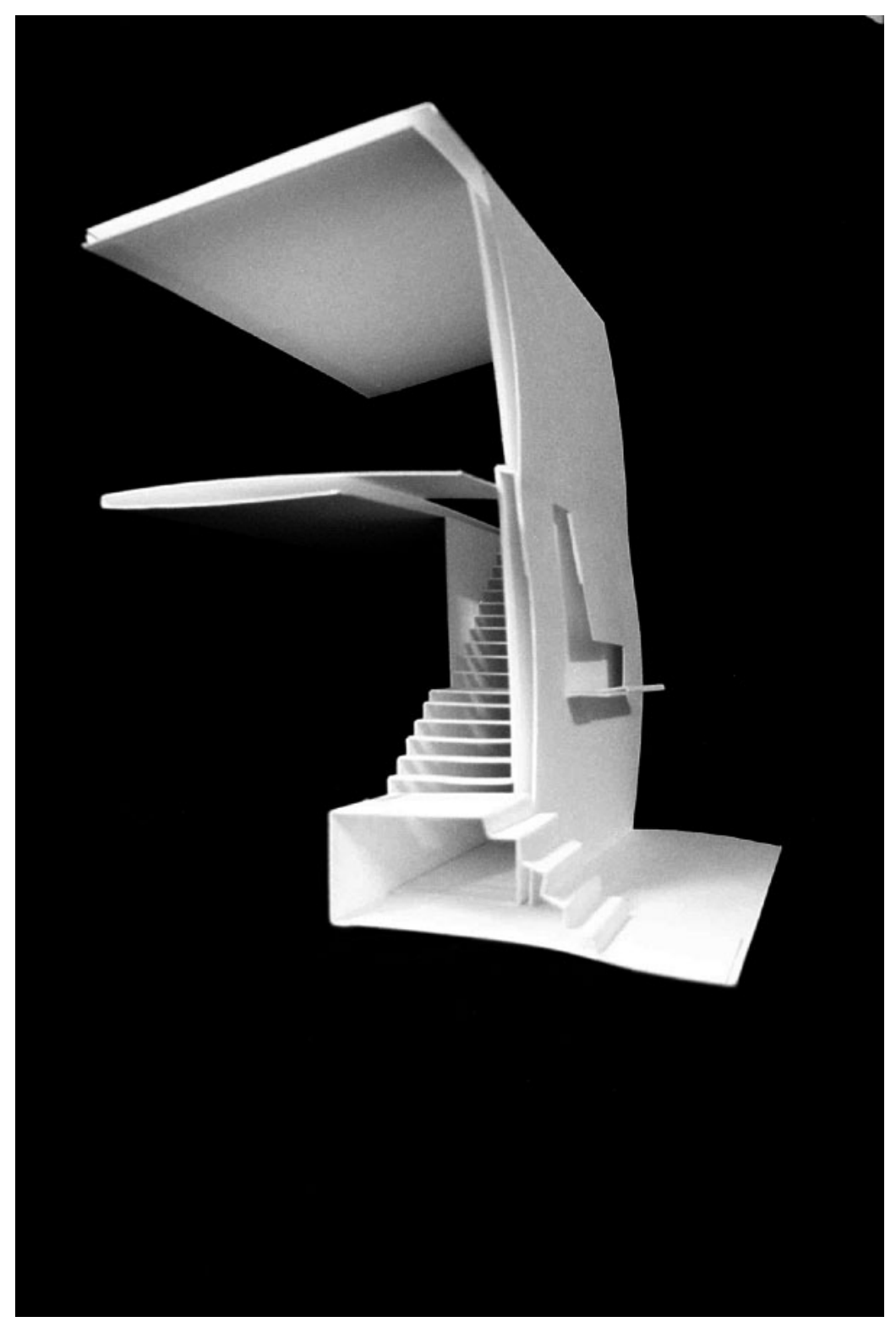

Figure 16. Section model by Leslie Sanchez. 
to impress them.“ The model in Figure 16 illustrates the notion of folded planes that are used to create structural and spatial conditions. The surfaces that define of the outer walls are fully integrated with the interior walls, ceiling, and floors. Everything about her design proposal appears to be fully connected. Even the circulation appears to be an extension and continuation of the ground plane. To create this type of model requires not only precision but also the ability to plan the exact location of the cuts and folds. It is evident that Leslie learned to develop creative ways of things and representing her design work from her experience in Xalapa. I also believe that it is evident that a summer in Xalapa gave her the opportunity to explore design related ideas that she might have otherwise not considered had she remained in Gainesville her entire education. According to Leslie, "I would have probably never explored this method of creating models had I stayed in Gainesville.” All of these images were also given to me in digital format and were also used in Leslie’s academic design portfolio.

Study abroad and travel has also positively influenced some the participants’ educational experience by motivating them to pursue graduate degrees in fields related to design. Marc and Kate both talked about how their study abroad compelled them to continue learning about architecture. Kate decided to apply to graduate programs in landscape architecture as a means of complementing her architecture degree and as a means of leaning more about design. Kate was also eager to explore and learn about American urban development based upon what she had experienced and learned about the urban environments of European cities. Marc, on the other hand, had decided to pursue a Ph.D. in architecture history and theory to further his intellectual understanding about architecture. His study abroad had exposed Marc to many different aspects of 
architectural design that he wanted to further explore and study in a doctoral program.

His decision to pursue a Ph.D. in architecture history and theory was also strongly influenced by his desire to teach.

Some of the participants even expressed the desire to pursue graduate studies in business administration, but wanted to use the degree as a means of creating their own design practices or assuming management level positions within existing firms. Julia had become interested in interior design during her semester abroad was exploring the option of an MBA to launch her own design business. She had even begun working for a Brazilian importer of high end furniture and it was evident that she was probably following her desire to become an interior designer. Alistair had graduated with a minor in business administration and was also considering completing an MBA with intention to manage a design practice. He also talked about how his study abroad experience opened the possibility of working for an international practice or even moving abroad to work as an architect.

Julian, however, enthusiastically talked about wanting to return to Europe to pursue a post graduate degree in design. He even expressed an interest in applying to design programs in Germany. During the course of the interview I had the feeling that Julian went abroad to explore his interests:

I know now a little bit more of what I like and what I don't like and what I'm looking for. I guess the semester abroad helped with a number of things. Like the uncertainty of what I wanted has become a little clearer. What I'm looking for in a place to live, what are some of the things that I can live without and some of the things that I'd rather have also become a little clearer.

I also feel that because of the semester abroad, Julian returned with a clearer intention of what he wanted in terms of his educational and professional aspirations. Julian, for 
example, talked about how the semester in Genoa motivated him to consider all aspects of design:

I'm still in the architecture but I want to be more complete - see, I don't want to limit myself to just architecture. I would want to be more complete - something a little bit more integrated. I want to be like the old school architects who designed all kinds of things including furniture, spaces, landscapes, and clothes. I want to work in the design field.

I also believe that Julian's experience abroad also gave the drive to complete his undergraduate degree. Although not explicitly stated, his desire to explore all aspects of design was an indication of his motivation to explore the professional and academic possibilities related to design. With his undergraduate degree almost complete, Julian was already beginning to chart his next course of action.

Alex and Jaime also expressed the positive impact of his study abroad on their educational experiences. Like many of the participants, both students talked about how the study abroad made them want to learn more about the buildings that they had studied and visited as part of field trips. Alex compared his experience of study architecture in Miami to learning about it in Europe. "When you study history of architecture in Miami, you never get a one to one experience with whatever you're studying. Like I mentioned before, just seeing those buildings in person makes you want to learn more about it, and want to study it more.” Jamie also talked about the positive implications of his study abroad on his educational experience. For him, the opportunity to live and travel in Europe was an “eye opener” because he had never really travelled. “I hadn’t been anywhere else before. I think even if you have travelled, you'll learn a lot more travelling and learning with the same group of students.” I found Jamie’s realization that his learning was enhanced because of his interacting with other students an important aspect 
of the semester abroad. As a communal experience, I also remember benefiting greatly from my interactions with other students while travelling and studying abroad.

Several other participants including Julia, Alistair, and Connie also talked about the importance and relevance of their interactions with their classmates as aspects of their semester abroad that enhanced their educational experiences. Alistair talked about the close relationships that he had established with his classmates and how he continued to "get together" with them even a year after returning from Rome. In comparing the educational experiences of students who participated and students who did not participate on semester abroad programs, Alistair cited the close interaction of semester abroad participants as an important part of the educational experience:

The students who went benefited from the semester abroad because of how they approached architecture and how they collaborated with each other and shared ideas. They also benefited from the experience because they were removed but yet together learning from each other's different strengths. We all lived that experience and the students who didn't go are missing that.

Julia also talked about the close bonds that she established with her classmates abroad as one of the most important aspects of her educational experience. She cited time spent together travelling, socializing, and cooking as some of the most memorable moments of her study abroad.

Connie, however, not only talked about her interactions with her own classmates, she made it a point to meet Italian architecture students who were enrolled at the University of Florence where she took her classes. The interactions not only gave her an opportunity to socialize with local nationals, but it also made her realize how fortunate she was to study architecture in an American university. Her Italian counterparts did not have the same educational opportunities and were forced to live and study in rather 
“cramped” conditions. In fact, for many of these Italian students finding employment as an architect after their education was difficult if they lacked the necessary "connections":

I was exposed to how difficult it was for them not to have connections to get work. I also saw how things were difficult for them in other ways. I lived in a spacious apartment with a roommate paying in American dollars. They lived in an apartment that was probably the same size with four people.

Connie had made an attempt to be partially fluent in Italian by taking classes prior to her departure and during her stay in Italy. Her ability to converse probably gave her the added opportunity to interact with the Italian students that would have otherwise been more difficult if she hadn't been able to speak the language. I believe that Connie was able to enhance her educational experience by associating with Italian students and learning about different educational systems because of her study abroad.

\section{Study Abroad and the Architecture Curricula}

Study abroad complements the architecture curricula because it is a form of experiential learning. Although experiential learning is very difficult to quantify because it is based on experiences, it supports the individualized knowledge that occurs outside the classroom wall, and allows students to stretch in unique and creative directions (Montrose, 2002). Students are seeing and inhabiting the spaces that they have read about in architectural journals and history books. They are also able to experience the scale, materiality, and even the smells of the buildings they encounter. All of these direct encounters with architecture and urban spaces have a profound impact on how students begin to appreciate and understand the significance of design (Kitsantas, 2004; NorbergSchulz, 1976; Pallasmaa, 1986). These experiences also become the memories of architecture and urban conditions which the students can later reference, and apply in their studio and professional work. Kate, for example, talked about how the sensory 
experiences of the buildings she encountered while studying in Europe served as examples that she later tried to recreate in some of her studio projects. In a follow-up interview, Guillermo talked about how he remembered certain things about the buildings that he encountered while studying abroad, which he later applied in his subsequent studio projects and professional work. "I saw myself designing and wondering where the ideas came from. It was later that I realized that I had seen these things in Rome.”

All of the participants expressed the importance of the lived experience as helping them to gain greater knowledge and understanding about architecture. For many, this understanding surpassed what they had learned in the classroom environment. Guillermo mentioned that the "lived experience" is "a lot more educational than what was taught. You can only tell a person what a building looks like, but when you walk into a space it's a completely different story.” Guillermo expressed the idea that architecture transcends any abstract or even concrete verbal description. The experience of a building is more than an observation of its physical attributes of shape, texture, color, and substance. Architecture is a phenomenon which includes a host of intangible notions such as feelings, atmosphere, spirit, that give life to the building and its spaces (Norberg-Schulz, 1976). Architecture must be experienced in its totality, and study abroad often provides students with this opportunity to develop a greater understanding and appreciation of the buildings and urban spaces they have studied or read about.

Sandy recounted the time she visited the Pantheon and St. Peter’s Basilica. For her the notion of scale became much more apparent when she experienced the voluminous spaces of both structures:

Everyone says that when you study architecture, you have to go to Rome. There's so much information out there that you can't learn from pictures. You can learn 
theory, you can learn all about a building, but you won't really know what the architect wanted you to feel until you're inside. We've been studying these buildings for years but until we stepped into these buildings we had no idea how big they were...Yeah, I knew that the Pantheon is huge. I knew that St. Peter's is huge, but once you're in it, it’s just like, oh my gosh! I finally know what huge means. You just sort of grasp it a lot better when you're there.

This aspect of experiential learning brings the student into the realities of what is being learned in the classroom environment (Montrose, 2002). In Sandy's case, she understood the importance of scale, and how it can be implemented in an architectural context to evoke certain sensations and experiences. For her, the vast scale of both buildings appeared to be overwhelming and impressive. According to Pallasmaa (1986), an impressive architectural experience

Sensitizes our whole physical and mental receptivity. It is difficult to grasp the structure of feeling because of its vastness and diversity. In experience we find a combination of the biological and the culturally derived, the collective and the individual, the conscious and the unconscious, the analytical and the emotional, the mental and the physical. (p. 453)

Architecture is a multisensory experience, and study abroad experiences give students an opportunity to engage architecture and urban spaces in a manner not possible in the studio or classroom.

Connie was also able to relate to urban scale because of her experience of travelling and living in Italian cities during her year-long study abroad. In her discussions about the relevance of scale, she also made some interesting comparisons to cities that she was quite familiar with in the U.S. Connie mentioned how her professors took her and her fellow students on a number of field trips to medieval Italian cities including Rome:

I loved the comparison of Rome to me as New York, and Florence as Boston because I felt personally much more comfortable in Florence. It had a much smaller scale. I felt I could walk from one end of the city to the other. I would be 
tired, but I knew how to get around, and I was comfortable. Whereas in Rome, I always felt like I was a little bit more on my defenses like I feel when I'm in New York.

In fact, her experience of these cities and the references she made to American ones actually went beyond the physical experience of architecture and urban spaces. Connie also talked about the significance of scale in terms of how she emotionally experienced Italian urban centers. In Rome, for example, Connie felt apprehensive because of the density and size of the city. In Florence, however, Connie felt most comfortable because of the intimacy of the sidewalks and streets. She talked about having to interact with people on her daily walks to school because the sidewalks were so small. "That was the most enjoyable part of my day because there was so much window shopping on the way and there was so much interaction in the streets with people. It was just wonderful.” Unless one lives and studies in urban centers like New York or Boston, these types of experiences are very rare on home campuses in American institutions. In Connie’s case, her understanding about the fabric of an urban center, and the significance of scale in urban design became much more apparent because she walked in many Italian towns:

I understood how buildings, and urban spaces more so, were orchestrated to make us experience certain things. I think that this understanding was possible because we did so much walking and because we entered through the paths that you were sort of supposed to take or would have taken back when. It made a big difference to experience it that way versus in a photograph.

Students often referenced the Pantheon as an example of how the experience of a building surpasses was is taught or studied in a traditional classroom environment. For Jaime, "being in the Pantheon is not the same as looking at it in a book." Julian, for example, mentioned that the “Coliseum and Pantheon are places you don't really understand in terms of scale and materiality until you've seen it in person. And 
understanding it that way gives you a fuller grasp of it.” Alistair expanded upon Julian's notion and discussed specific aspects of the Pantheon he observed. He also talked about how he experienced the Pantheon in terms of its environment and urban context. Pictures, according to Alistair, often only reveal one aspect of the structure. They tend to detach the buildings from "their environment and relationship to other buildings." It was only until he actually walked to the Pantheon that Alistair began to develop a greater appreciation and better understanding of the building:

I don't know how many times I've seen pictures of the Pantheon but just the front or the oculus, and never really seeing the back. What always kind of intrigued me was the back of it because it's where you can see the changes in elevation of the street from antiquity to the modern day.

I was intrigued by Alistair’s response because I had never imagined approaching the Pantheon from the rear. As he mentioned, many of the images of this building in the history and theory books always reveal the interior, the oculus, and the front elevation. His observation of the building and its urban context could only have been possible by engaging in some form of experiential learning during his study abroad in Rome.

I was also intrigued by Alistair's observation of how the street elevation changed in terms of time, as he approached the Pantheon from the rear. According to NorbergSchulz (1976), "the structure of a place is not a fixed eternal state. As a rule places change, sometimes rapidly” (p. 422). In essence, Alistair was talking about the Pantheon in relation to its site, and the importance that site plays in architecture and urban design. He also talked about the importance of experiencing the site to gain a better image and understanding of the building and its relation to its environment:

You never see the space around it and how the other buildings have grown around the Pantheon and how the streets have merged there. I think that until you actually 
see it, you only have one image of the building and you can’t really understand it without knowing the full picture.

For Alistair, pictures give a limited and biased account of the building. "When I look at pictures of buildings I haven’t seen yet, I always keep asking myself some the following questions: Is this the image that they want me to see and what does the building really look like?”

In addition to understanding the relevance of site to a building, I believe that Alistair was also able to draw from this experience to understand the relevance of site in terms of his own design work. In fact, he was able to put this notion into practice in his study abroad design studio project of a visitor's center and entrance to the Imperial Fora that was located next to the Temple of Peace. His design, for example, had to take into account of the existing structures in their various forms of decay and levels of historical significance. Contemporary architects and theorists like Tadao Ando (1991) place great emphasis on the importance of site. "The presence of architecture-regardless of its selfcontained character- inevitably creates a new landscape. This implies the necessity of discovering the architecture which the site itself is seeking” (p. 461).

As part of semester abroad studio projects, design students are often asked to create urban interventions in the cities where they reside. Guillermo, for example was asked to design a visitor’s center at Hadrian’s Mausoleum in Rome. He was also required to do site analysis of the area to generate ideas for his overall design. The site analysis included a study of the pedestrian and vehicular circulation. It also included studying and documenting the buildings on and around the site as well any topographical conditions of relevance. Guillermo generated a design that not only responded to the program in terms of its function, but his design was also informed by site relevant conditions. 
Some of the participants also used their study abroad experience to develop thesis projects. Kate, for example, used this opportunity to investigate the importance and relevance of site and cultural context in the design of a public bath. Situated in Vicenza, Kate had to undertake a thorough investigation of urban related conditions to develop a project that would function well in terms of its program and site location. Her investigation and design, however, were also focused on the cultural context the site offered. "I carried the most of the literal program of the bath, but I took more ideas of the cultural interactions and specifics about the city to explore the idea of cultural interaction. The bath part wasn't such a big part of it.” Kate’s experience living in Vicenza as part of study abroad provided her with the experience to better understand the implications of culture and cultural context to architectural design.

Marc's thesis project was also less about program than it was about aspects of the site in determining the outcome of the architecture. Marc, however, more closely investigated the notion of detail as a generative element in design. Architects and theorists like Marco Frascari (1984) look at details as the generators of architecture. "Details are much more than the subordinate elements; they can be regarded as the minimal units of signification in the architectural production of meanings” (p. 500). Marc used the site and program as a means of exploring the implications of the detail in architecture. "For me, it was all about the generative detail, and the site and program were a sort of vehicle to test that.”

In addition to providing students with the opportunity to come into direct contact with buildings and urban spaces, study abroad also allowed students to validate their understanding of architecture. It gave some of the students an opportunity to develop new 
realizations about the buildings they studied in the traditional studio and classroom environments on their home campuses. Connie, for example, gave me two examples of how her study abroad experience changed her perception of a particular building, and how it confirmed her impressions of an urban space.

Many of the architecture history textbook pictures of the Renaissance Palazzo Medici-Riccardi in Florence, for example, show the building from the front façade. These images reveal the outward transition of material from rusticated to ashlar stone vertically along its three floors. The images also show specific details of the building including the belt courses, and the main threshold articulated by a large arched opening defined by large voussoirs. The most impressive aspect of the structure, however, is the use of massive boulders that define the main floor of the palazzo. One assumes from the images that the use of this material continues along the only other exposed side of the building perpendicular to the main façade. Seeing the building in person, Connie came to the realization that she had been deceived by the images she had seen of the building in the history books:

It felt like I was being deceived compared to the photographs. I felt that the façade was an appliqué. It didn't look to me, like when it wrapped around the corner, that the detailing just continued and turned the corner. And so I guess, it wasn't as much of a main street condition, but I couldn't believe that the Medicis only decorated the façade of this building.

In the course of our interview, I also felt deceived and a little embarrassed about my own ignorance about this building.

Connie also recounted how her experience of the Piazza of San Andrea in Mantua confirmed her memories of the urban space, which she had first studied in her history course years earlier. In fact, when I asked her if she had any memorable experiences of an 
urban space, Connie referenced this piazza because she was amazed of how much she remembered, and how much the images in her architecture books resembled the façade of the Church of San Andrea. "I think the reason that the Piazza of San Andrea was so memorable for me was that I remembered studying the façade in undergrad and being in the space, I couldn't believe how much I remembered, how similar it was to the photographs. “ I was able to empathize with Connie on both of her examples of deception and validation. Often times one can read and see images of a particular building or urban space, and develop an image or impression that is completely contrary to its reality. Study abroad experiences help students develop a greater understanding and appreciation of urban or architectural conditions because they are able to see and explore these environments. Because students are also able to make their own discoveries, this type of learning leads to different ways of processing how they acquire knowledge which greatly enhances how they learn about architecture and design (Montrose, 2002). Conversely, the act of validating one's memory about a given space or condition may also serve as an important learning experience. Students may come to the realization of relevant site and design considerations that may have otherwise remained somewhat dormant in their minds.

The travel and study abroad experience can also profoundly impact how students learn about urban and architectural spaces because it motivates them to want to learn more. For some of the participants, the act of inhabiting spaces while abroad was a transformative educational experience. Gloria, for example, compared her education in Gainesville to describe how her study abroad experience compelled her to want to learn more about architecture: 
The studios in Gainesville were very focused on developing a design, a program. Once you are travelling, you want to learn, you want to inhabit the places, you want to feel, and you want to react to the spaces. It's not like you are building these models imagining the spaces any more. You're actually occupying the spaces created by other architects, accomplished architects who have been able to build something.

JP also shared Gloria's sentiments about the limitations of studying architecture at his home-campus in Miami. "When you study the history of architecture in Miami, you never get a one to one experience with it. Just seeing those things in person just makes you want to learn more about it and study it more.”

Gloria and JP, however, were not the only participants who talked about how study abroad increased their desire to learn more about architecture. Julian was also quite adamant by stating that travel increased his "thirst for knowledge". He also talked about the limitation of studying architecture on his home campus of Miami. His exposure to foreign cultures and architecture broadened his understanding about architecture. It also made him think about the implications of human interaction, circulation, and spatial usage with the apartment multi use complex he was developing as part of his Design 8 studio. "Miami has a very limited style, and a very limited idea." He went on to give me an example of an apartment building design in Miami:

You have your parking garage on the bottom floor and residential on top. With the study abroad you learn that are other systems. You learned what a community should be, and how to design it. Up to this trip, I had never really considered about the pedestrians. You think of the form of the building, but you really never ask how people are going to walk on the ground floor.

In fact, Julian continued at some length describing this project to illustrate what he had learned as part of his semester abroad program. He discussed how he developed a design for an apartment building in Mary Brickell Village (Miami) that not only took into account pedestrian circulation as an important factor of the design, but how the building 
itself began to engage the public spaces of the mall. Julian also talked about the need to make design related connections to the existing buildings, and how his design would reinforce the idea of pedestrian circulation:

Instead of putting a building that would take up the entire site, we only used part of it with the idea that whoever builds next to our structure, would further extend the pedestrian circulation rather than creating atypical street in Miami. Our intent was to create a pedestrian friendly street. Before my study abroad, I would have never considered pedestrian circulation. I would have worried more about the form of the building.

In the course of our conversation about his project, he often made reference to the public spaces as "piazzas" almost as a direct reference to the public spaces in Italy.

A study abroad experience can help to broaden student understanding about design because it exposes them to the diversity of architectural expressions globally. Students realize upon travelling that there are many different ways to develop buildings and urban spaces. These differences are often shaped but not limited by cultural influences, and this realization becomes much more evident when travelling abroad (King, 2006). Marc and Kate came to the realization that there is so much more to be explored beyond the U.S. In fact, Marc talked about the common misconception for many Americans that "American is the world." His travel and study abroad experiences made him realize that" it's impossible to think that way after you've travelled abroad.” Even the interaction with people from different countries can also greatly influence a person's worldview, and increase her/his sense of a global awareness, multicultural understanding, and appreciation (Van Reken \& Rushmore, 2009).

Architecture students who study abroad can develop a greater understanding and appreciation of architecture by interacting with architects and architecture students from different countries. Kate gave me an example of her participation in a design charette to 
illustrate how she learned to connect with students from other countries through

sketching. For her, that sense of connection to other students from different countries was probably one of the most profound experiences of her study abroad:

They brought students from two other school in the area - Slovenian and Pescara; which was in Italy - and we all came and had an international mix so about one student from each, and we would learn to communicate through sketching and language because we were all a little good at communicating by then, and it was just an experience that you really did connect with somebody who was from a different culture

This interaction also helped Kate learn how people relate to one another differently abroad. She also learned different ways of designing through this interaction with Slovenian and Italian students, which she later applied to her studio projects. Because of the design charette, Kate was exposed to "how things can work, and how you can employ them that people here just probably didn’t look at, or hadn't seen, so they didn't know.”

In addition to experiencing and learning what works in a given project, Leslie talked about seeing what doesn't work and experiencing the effects during her study abroad as important lessons to be learned in architecture:

I think you have to see what's been done, and I think you have to experience what works and what doesn't work. I think you need to hate the spaces as much as we need to love other places. You need to inhabit the spaces in order to design them.

Lizette also shared some of Leslie's ideas by talking about the relevance of historical precedence, and experiencing architecture that "works." What Lizette learned the most

"was how classical architecture applies to what we do today, and that's not just something that we read about in books and learn about.” She views the validity of learning from past examples, and applying those lessons to contemporary design:

I guess what I am trying to say is that they've been around for so long because they work, something about them is right and they're not necessarily old fashioned. There's a lot that you can take and we as students and as architects can take and apply into modern architecture. 
Leslie also discussed about the relevance of ancient buildings and her "amazement of how those spaces still work so well.”

Study abroad programs also complement the architecture curriculum because it gives architecture majors the opportunity to work on international design projects in their host countries. The international design studio component is an integral part of the architecture study abroad program and it is also a very unique aspect of the architecture curriculum. Students are required to immerse themselves in their foreign surroundings to develop effective design solutions that address and explore a host of conditions related to the site and culture of their host nations. This type of exposure and experience working on international projects would certainly not have been possible on a student's home campus. Visiting the location of a proposed project in Guadalajara, for example, allowed Leslie to explore a multitude of conditions and issues related to the site that she would not have been exposed to had she been given the same project in Gainesville. Leslie was able to walk throughout the proposed site while developing a site related analysis of existing buildings and vegetation, vehicular and pedestrian circulation, and orientation that would help to inform and direct her design intentions. Living in Guadalajara also gave Leslie the unique opportunity to better understand aspects of Mexican culture that she could integrate in her design proposals. Leslie, for example, was able to develop a design proposal that related to the manner in which Mexicans use their public spaces.

Figures 17 to 24 are examples of Leslie's design work from her international design studio in Guadalajara. I decided to use these images because they are good examples of the type of international studio work that students are generally required to accomplish as part of their study abroad experiences. Leslie's work was also complete in 
that she provided digital examples of her design in the form of 2-D and 3-D presentation materials and a model. In terms of the project and its program, the area in the center of the image was the designated site for an athletic center in the city that also included an

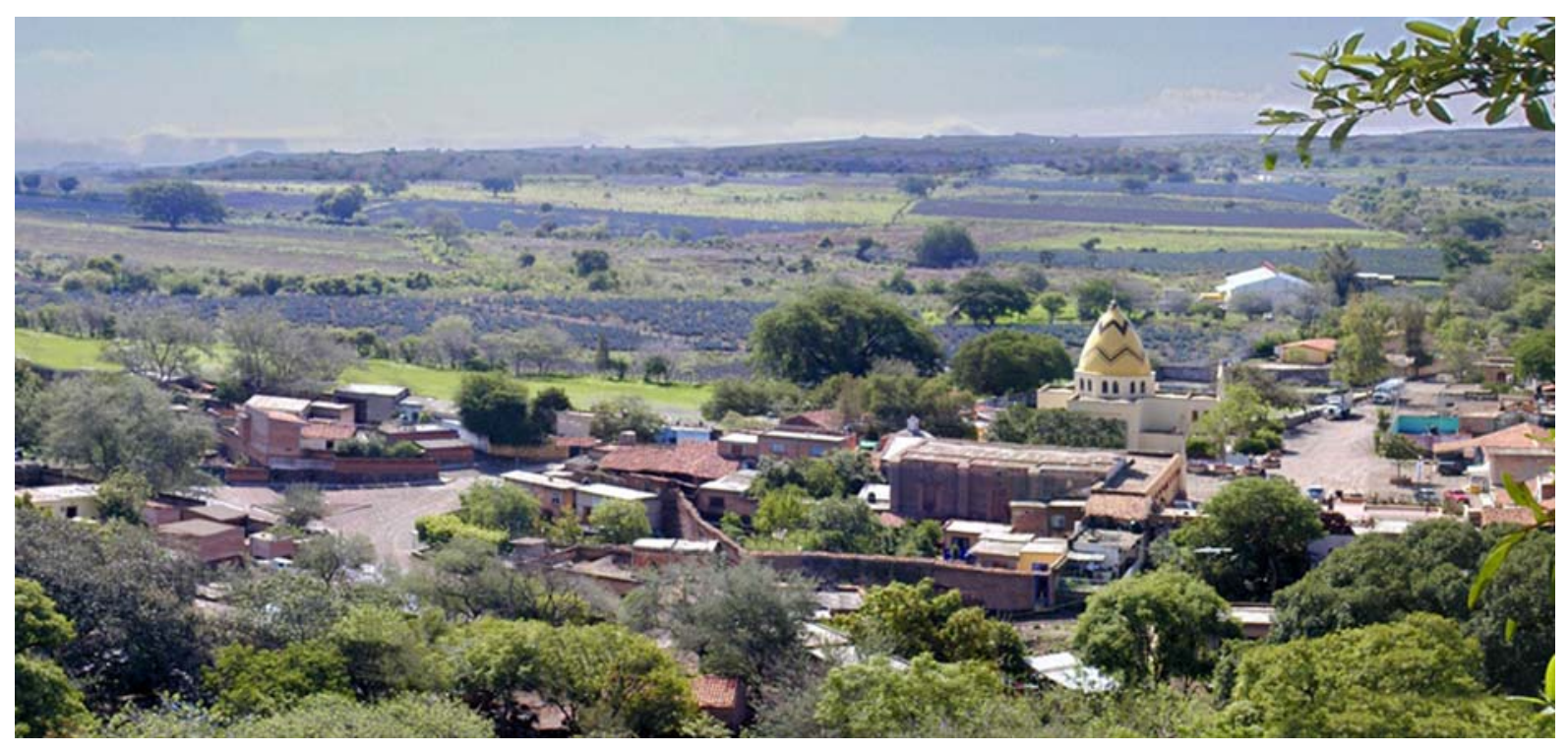

Figure 17. Photograph of Guacal ajara by Leslie Sanchez.

outdoor pool. Part of the design project also included using and integrating aspects of the existing architecture into the proposed design. It also required integrating aspects of the existing urban conditions into the proposed design. These urban conditions included some of the existing pedestrian and vehicular circulation around the site. 
Figure 18 is a 2-D aerial plan view of the complex. The areas highlighted in yellow show the roof tops of the buildings. The areas depicted in light grey show the areas of pedestrian circulation and the darker areas in grey show the pools. In as much as this presentation shows the relationship between the horizontal planar conditions of pool areas, roof tops and terraces, it also reveals the existing urban conditions of roads and buildings that are drawn as lines. This image also shows the relationship between the

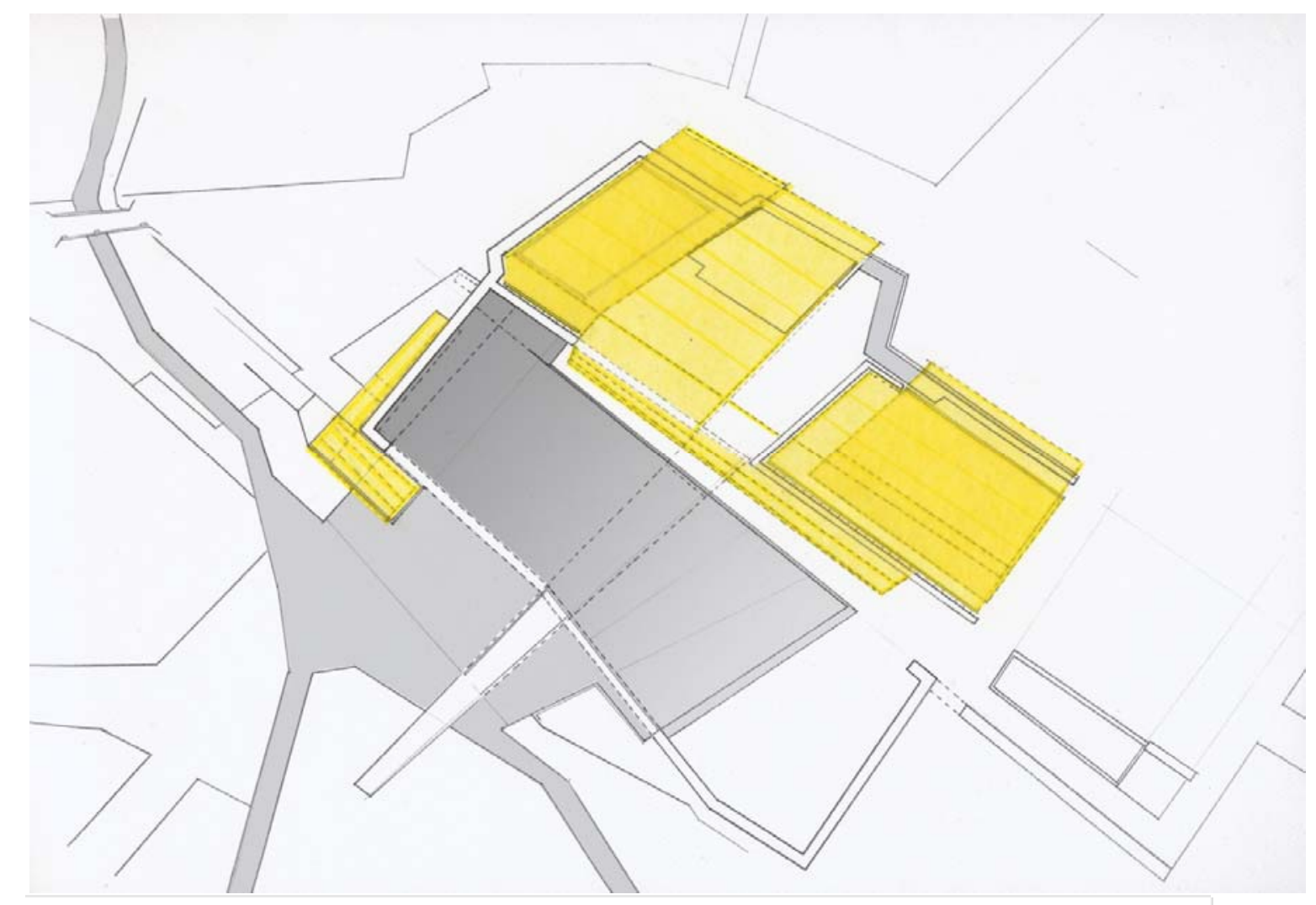

Figure 18. Aerial Plan-View by Leslie Sanchez.

proposed project and its urban setting. It also shows how some of the design ideas related to pool and buildings are developed because of the pathways and the edge conditions of the site that were defined by the existing buildings, walled enclosure, and streets. 
To get a better understanding of the implications of the design proposal, Leslie also developed an isometric 3-D drawing of the project. In Figure 19, the proposed buildings and pool areas are seen. The relationships between the vertical and horizontal planar surfaces are also clearly delineated.

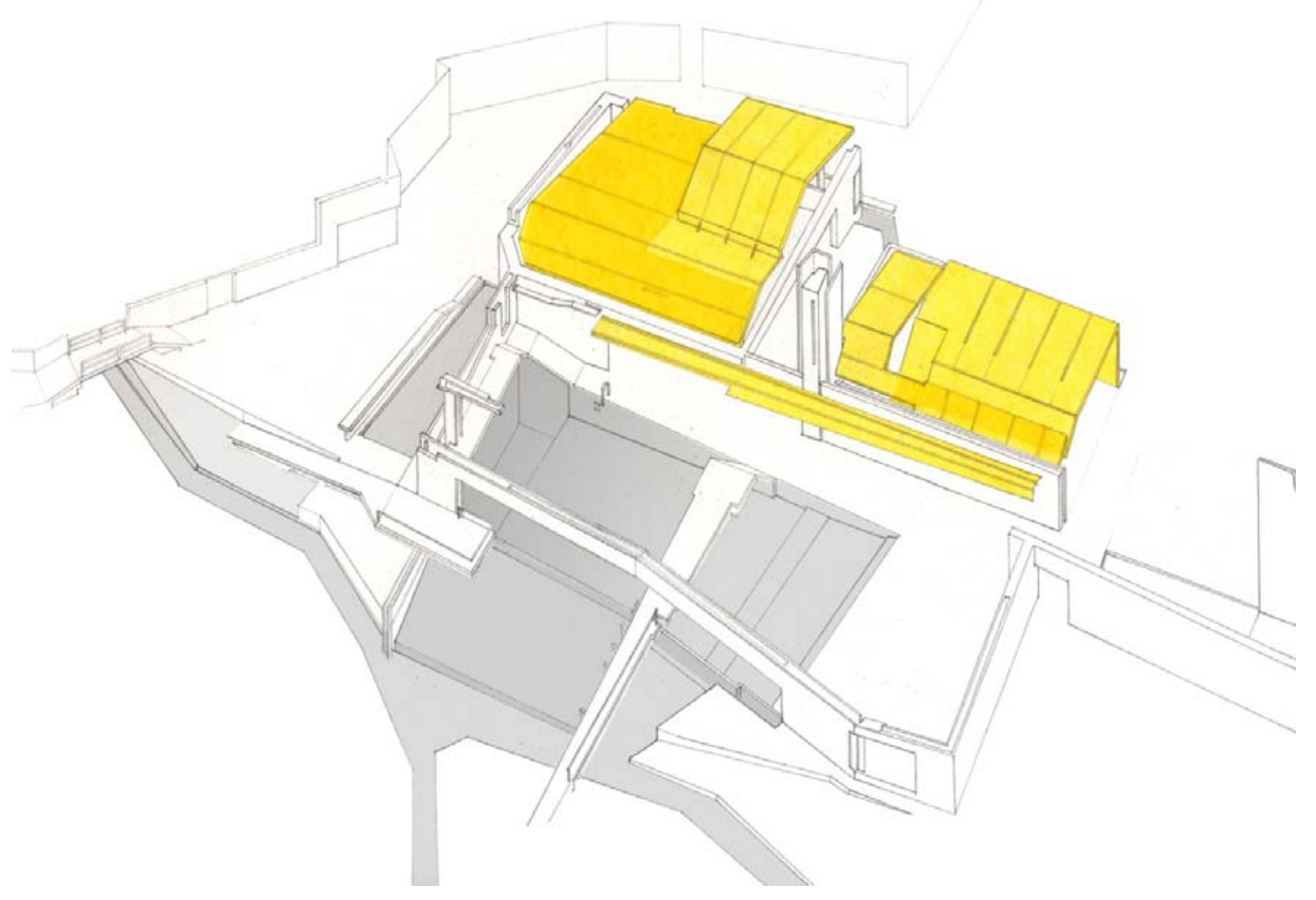

Figure 19. Isometric rendering by Leslie Sanchez. 


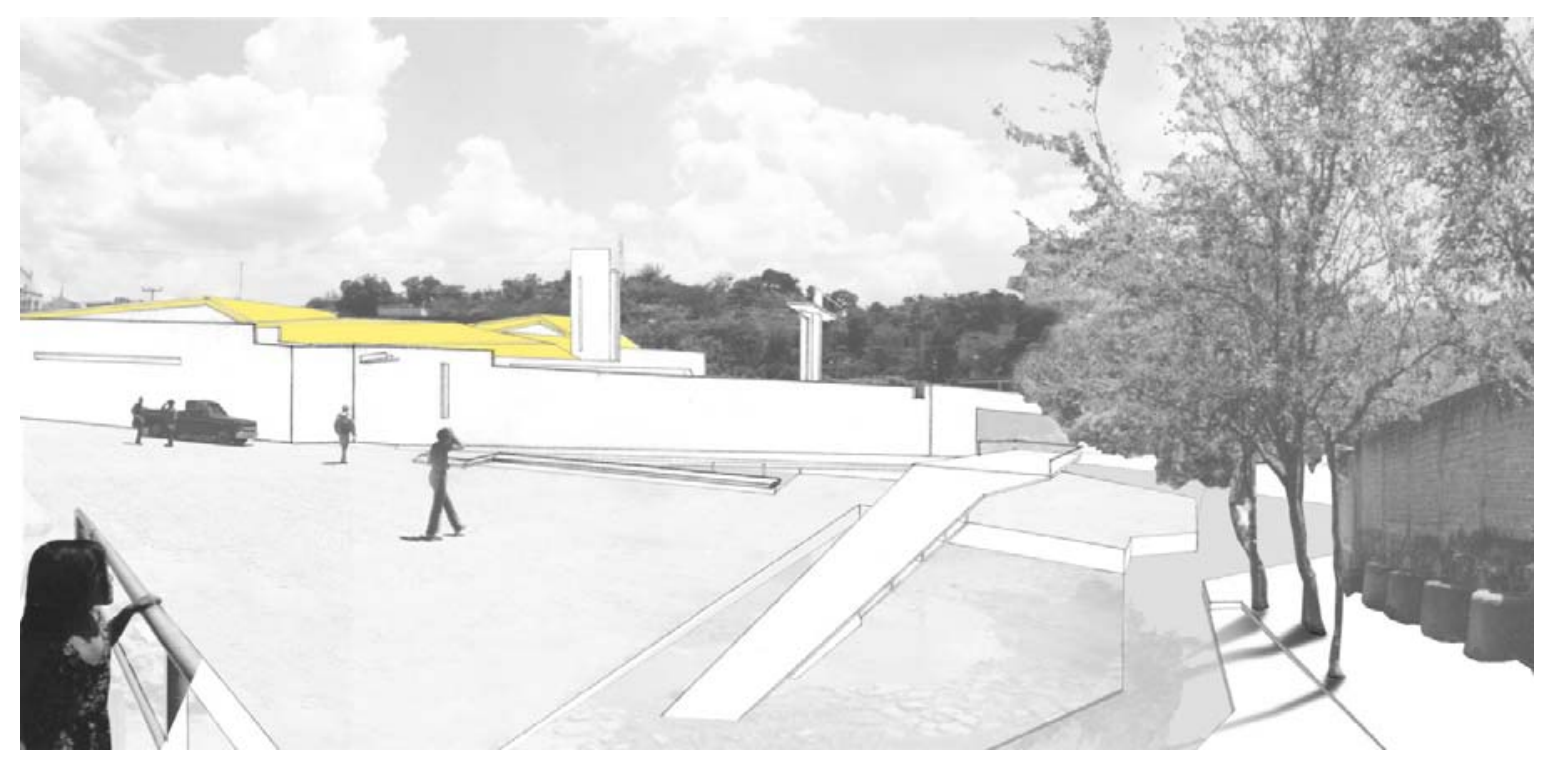

Figure 20. Collage by Leslie Sanchez.

Figure 20 shows an example of a collage whereby Leslie integrated contextual images of existing architecture, people, and vegetation into an image of her completed design proposal. In this rendering, we see people interacting with the site and project. The area of vehicular circulation is also understood because of the picture of a car parked adjacent to the wall enclosing the sports complex. The scaled model of the site and sports complex is another manner to illustrate Leslie’s design proposal. Leslie used her technique of folded paper and cardstock to develop the vertical and horizontal planar surfaces. These conditions are expressed as outer and inner walls of the complex and buildings associated with the center. The horizontal surfaces are expressed as walkways, ramps, terraces, and the pool areas. 

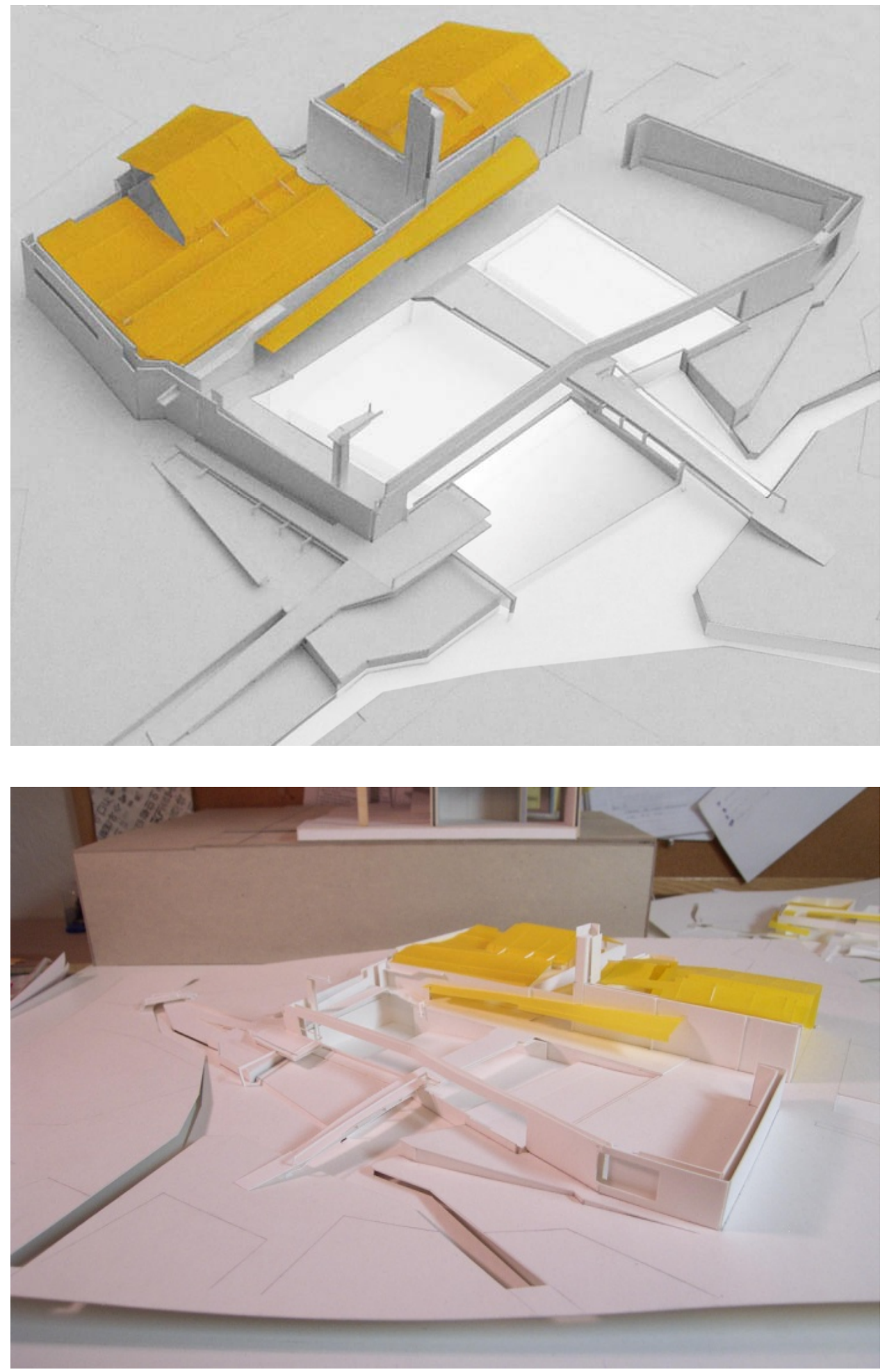

Figures 21 \& 22 . Scaled model by Leslie Sanchez. 


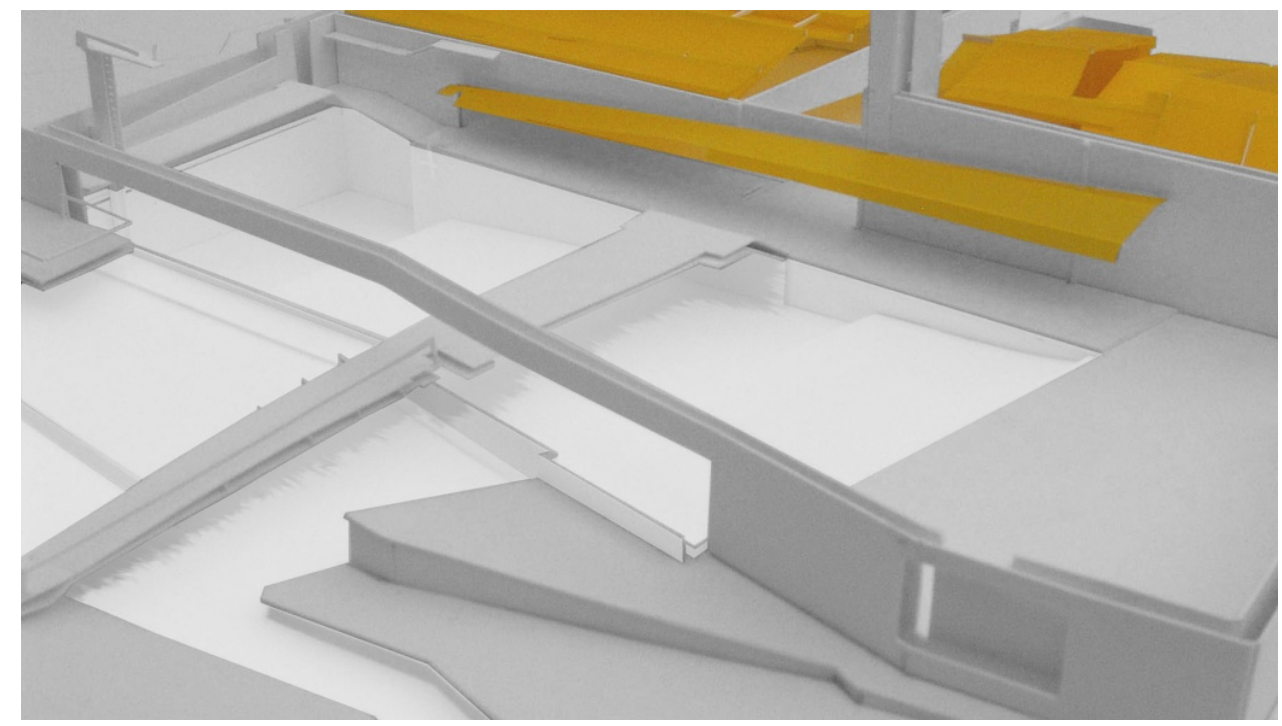

Figure 23. Scaled Model by Leslie Sanchez.

\section{Study Abroad and Architecture Appreciation}

There is evidence to suggest that students who participate in study abroad programs report positive learning outcomes and stress that their retention of the information is greater than in a traditional learning or classroom setting (Younes \& Asay, 2003). There is also evidence to suggest that a study abroad experience has a positive influence on student creativity (Angulo, 2008; Gurman, 1989). In terms of my study, all of the participants commented about the positive effects of studying abroad on their understanding and appreciation of architecture. Some even stressed the importance of making a study abroad mandatory for all design majors because of the unique learning experience it offers. Because the learning is essentially experiential, study abroad affords the student the opportunity to experience the building and urban sites in a manner not 
possible in a traditional classroom environment. Students can also see and experience how the development of architecture and urban design is influenced by a multitude of factors that cannot always be discerned in a lecture or classroom format.

Not only did study abroad influence the professional and personal development of the participants of this study, it also enhanced their understanding and appreciation of architecture. I found this idea to be most evident when I asked the participants to describe urban and architectural spaces they encountered while studying abroad. I asked this question to get a better idea of how their understanding of site specific conditions and the sensations of space were clearly articulated and explained by the participants. Students, for example, who are able to use an architectural language and grammar to illustrate ideas pertaining to the form and organization of space, may display a heightened understanding and appreciation of the principles that define architecture and urban design.

I also wanted to learn the degree to which the participants had become aware of their environment and the elements that define and constitute architecture or urban conditions. In terms of describing an intimate urban or architectural space, for example, Connie not only talked about the sidewalks as a means of defining pedestrian circulation through Florence, she also talked about the experience of engaging people and circumstances because of the sidewalks. Having an awareness of what a sidewalk offers in terms of an urban experience is a strong indication of her awareness of the factors that influence urban or architectural design. For Connie, the sidewalk was an opportunity to engage with people, shops, and traffic:

An intimate space would have to be the sidewalks, the fact that they're 2 feet wide. It was a big anxiety when I used to walk home from school and not knowing what do when there was a car coming and a lady walking on the 
sidewalk with a bag of groceries who wasn't going to move. I would then just walk into shops.

I found Connie's experience of avoiding collisions with people and cars a unique way to experience and learn about the architecture and urban conditions of Florence. She was not

only walking from one destination to another, she was also aware of the experience of movement through Florence because of the anxiety and tension she initially felt walking home from school.

Leslie also illustrated her appreciation of architecture by giving a rather vivid description of her experience walking through Luis Barragán’s Giraldi House that is located in Mexico City. According to Leslie, one of the unique aspects of this structure was the manner in which Barragán defined the spaces in terms of their configuration, the use of natural light, and the introduction of vibrant colors on the wall surfaces. Leslie was aware of these design intentions as she moved from space to space. I believe that Leslie also began to gain a much greater appreciation of the building because she was present to experience its architecture. In our conversation about the house, Leslie talked about her approach to house and procession like movement through the building:

What make this house amazing are the spaces, the manner in which Barragán focused on how you entered the space, and the way he wanted to manipulate the way you moved through his spaces. For Barragán it was like a procession how you had to get to know the spaces, little by little.

Using the word procession to describe her movement through the house was a strong indication of Leslie's understanding of how the architect organized the sequence of spaces and defined the path and circulation within the building. It was also an example of how Leslie used a specific architecture language to describe a condition or event within the house. 
Leslie provided vivid experiential descriptions of the spaces that she encountered as she moved throughout the Giraldi House. Her language was not limited to a discussion of the outward appearances of the interior surfaces, but it was much more direct in terms of articulating the architectural ideas and sensations that the spaces evoked. Leslie, for example, mentioned how the vestibule created the sensation of compression. "When you walk into the vestibule you notice that it is very compressed and it’s kind of bizarre. You don't even feel like you're walking into a house.” She also talked about how aspects of the house felt discontented and how the use of natural light defined and transformed the interior spaces. As she described her movement through and experience of the house, I was actually beginning to get a much better understanding of and appreciation for Barragán design intentions:

You see this staircase that is completely disconnected from everything else. You then enter a hallway that is narrow and has yellow panes of glass that completely take over the entire space, just the light is overwhelming. You then continue and the space opens up into a courtyard defined by a pool, light, color, and texture. The light is just amazing, and the manner in which Barragán was able to play with the light and manipulate the textures and colors was just incredible.”

Leslie's discussion not only heightened my interest in the building, it also became evident that her experience of the architecture was transformative and very memorable. She even talked about being afraid that her subsequent visit to the house wouldn't be the same as the first in terms of the impressions and memories that it created:

I had the opportunity to go twice, and on the second visit I was actually scared that I wouldn't feel the same way about the house. I almost didn't want to walk in because I didn't want to ruin it. I had such a great memory of the house and when I walked in the second time, it was as if I had seen it for the first time. It was just as amazing. 
Leslie's visit to the Giraldi House is an example of how study abroad can increase a student's understanding and appreciation of architecture.

Gloria talked about how her study abroad experiences enhanced her appreciation and understanding of architecture and urban design. Having participated in two study abroad programs, Gloria was also able to compare her experience of Venice from the first and the most recent visit to the city. Her most vivid impression of the city was not the romantic traditional image of the city with its Gran Canal and gondolas. Instead, Gloria talked about her observations of the how people circulate throughout the city as something that captured her attention:

When you see pictures of Venice it is very romantic. You get another perspective when you are there and you are assigned to go to a specific courtyard or piazza and start the investigation it is a completely different scenario. It is something totally new as you study the way people move in the space. It is important to study or observe how people activate the space. That was my take on Venice.

The first time Gloria visited Venice, she noticed that the city was “dead” at 8 o'clock. "I went in the fall and after a certain time it was so cold that you couldn't see anybody. I didn’t know that people were in the bars at the point.” On her subsequent visit years later, she had developed a different appreciation for the city and took the opportunity explore the city from a different perspective. She was interested in the idea of movement and explored this idea from different angles. According to Gloria' "the city was now talking to me.” She talked about taking time to sit and observe the movement of water around the buildings and the movement of people throughout the city. "I was able to sit down and see the water moving, and the buildings receiving the water, and the people activating the city. It was something new.” Like Leslie, Gloria had developed a greater 
understanding and appreciation of urban design because of her study abroad. Gloria had also developed a specific understanding and appreciation of urban movement because of her investigation and observations of how people and water moved within the urban context.

In terms of studying the influence of study abroad on students' appreciation and understanding of architecture, I also asked the participants to provide examples of their creative work. In some cases, students provided scanned images of their study abroad studio design projects. In these instances, I looked for how closely students were able to relate issues that pertained to site and context into their design proposals. The ability to understand the relevance of site related issues such as location, historical and cultural context may indicate the level to which students began to assimilate with their host nations. It may also indicate the degree to which these students began to understand the relevance of cultural influences on the development of architecture.

Guillermo shared aspects of studio design project to illustrate how he began to assimilate aspects of Italian culture into his studio design. The actual project was to develop a museum at the Mausoleum of August in Rome. Prior to commencing this project, however, Guillermo was also assigned to conduct an analysis of the Via Emmanuelle in the heart of the ancient city. As part of the exercise, Guillermo mapped the street in terms of its spatial and textural conditions. Guillermo also examined the street in terms of historical context and identified areas that had retained aspects of its original composition. Guillermo talked about he became particularly interested in the types of experiences and views of Rome the street offered its pedestrians. "Sensations, views, texture and spatial conditions were all mapped using a series of overlays and 
abstractions to indicate moments of transition, views, and experiential changes along the Via Emmanuelle.” Based on his findings and analysis of this thoroughfare, Guillermo decided to develop a design that would thematically reference his investigation of path and the experience of the urban context.

Figure 24 shows a scaled model of Guillermo's final project. At the center of the model is the Mausoleum of Augustus. Guillermo has also included scaled representations of the buildings surrounding the mausoleum to show his design proposal in light of its

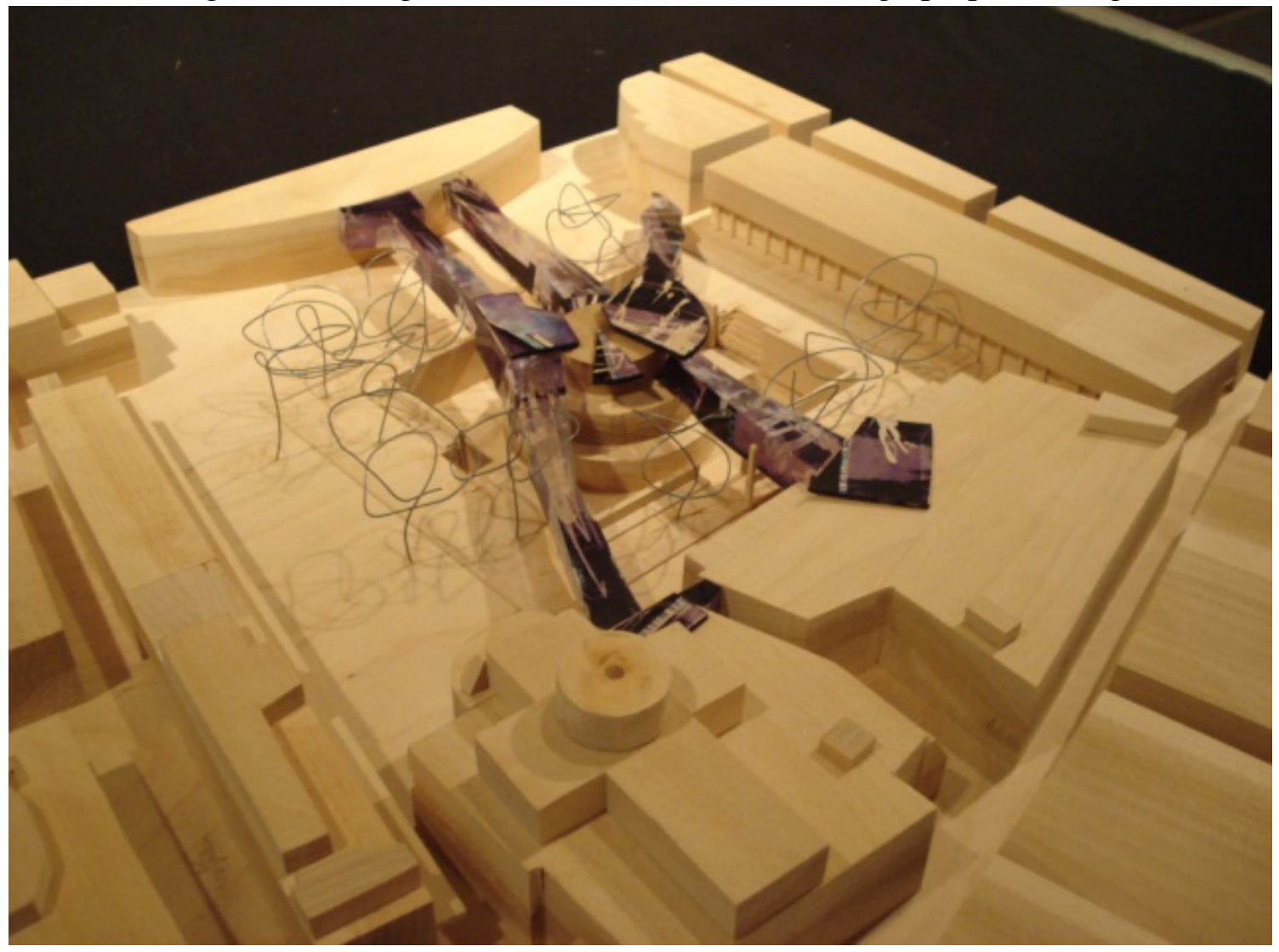

Figure 24. Study abroad design project by Guillermo.

urban context. Much like an avenue of point of circulation, Guillermo developed his idea of the art museum like a series of paths that interest in the mausoleum. The experience of the art museum is not limited to an enclosed experience contained with the wall of a 
traditional building. Instead, Guillermo talked about expanding the museum into the urban space around the mausoleum. Like arms, the art museum branches in different directions and begin to engage the other buildings on the site. The art is exhibited along the outer walls of the museum and as becomes an exterior experience. Guillermo talked about the projecting arms referencing the sense of movement and representing an aspect of the urban experience of the street. Movement is not only referenced as the extension of the wings of the museum but is also abstractly captured by his representation of trees and vegetation in the form of bent wire.

I was interested in using the design studio projects as a means of understanding how the study abroad experienced influenced student learning about architecture. The following image shows Aliana’s design project that was part of her study abroad experience. As part of the curriculum, Aliana travelled and took classes as part of the University of Miami Grand Tour and then was assigned a design project based on her experiences and what she learned in Europe. In our conversation about her studio project, Aliana talked about how certain influences became the focus of her design. While in Europe, she became particularly interested in the use and the notion of the atrium or courtyard as an architecture idea. She had seen examples of Roman villas and became particularly interested in the use of atriums in the residential architecture.

The basis of her studio project assignment was to develop a beach house in northern Florida. In terms of style, Aliana expressed her design in a rather classical fashion. The outer appearance of the house is very reminiscent of an Italian villa, and the use of courtyards reminds one of ancient Roman villas. Like Pompeian homes, the individual spaces of Aliana's project were developed around a series of atriums. Each 
atrium had a specific function that included an impluvium, or space to collect rain water. In other instances, the atriums were used to provide the interior spaces with natural light.
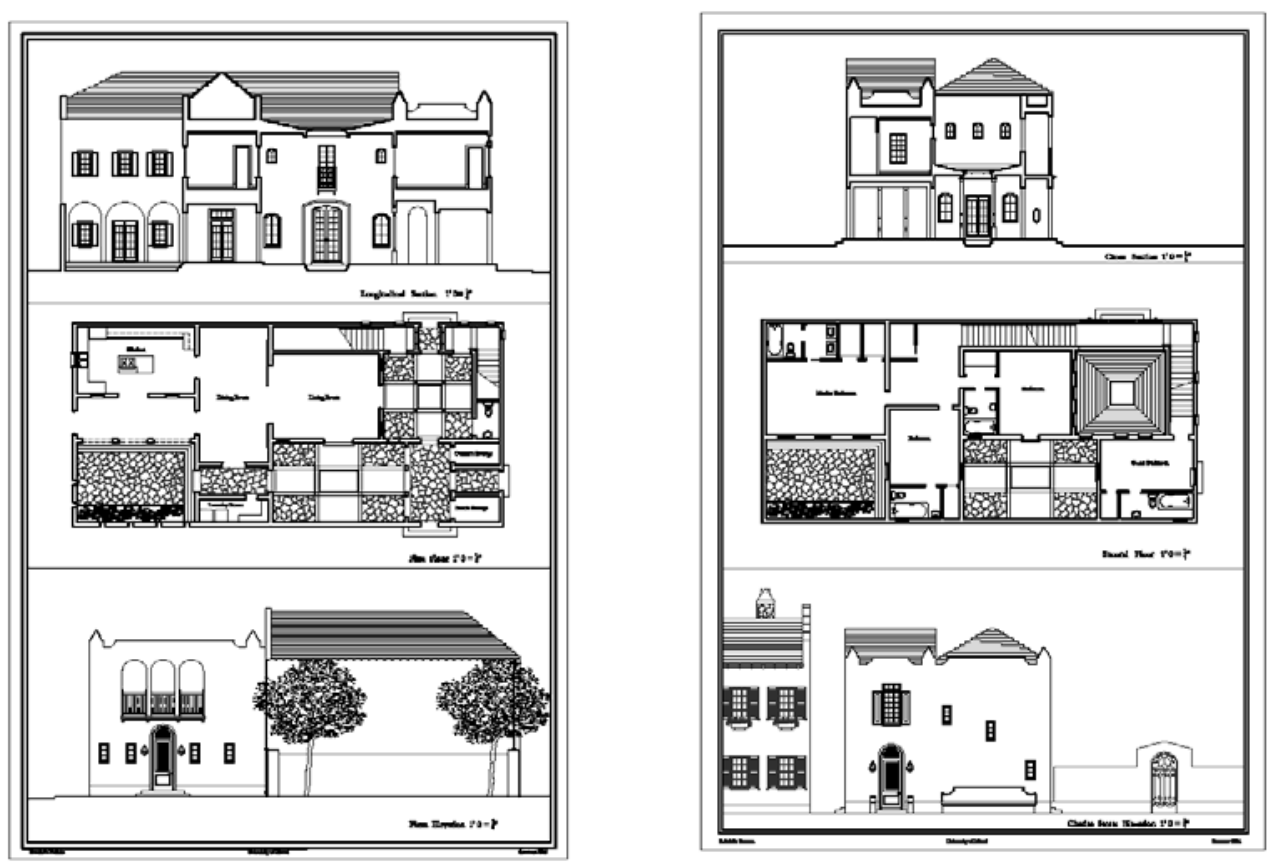

Figures 25 \& 26. Plans, elevations, \& sections of a Pompeian Inspired Villa by Aliana.

As the central space of the house, the atrium also served as the architectural datum that linked all of the individual spaces. As a means of reinforcing a sense of privacy, many of the windows focused inward towards the atriums. Like Roman villas, gardens were also introduced as part of Aliana's design and placed within the atriums. In terms of historical precedence, Aliana conducted a careful analysis of Roman villa architecture and used this as the basis of her design. In terms of her study abroad experience, Aliana was able to integrate her understanding of Roman architecture into a design project. While abroad, Aliana engaged in experiential learning by visiting and studying ancient Roman villas in Italy. As part of the study abroad experience, Aliana was required to put her 
understanding into practice by developing a project that focused on one strong aspect pertaining to Roman residential architecture. I believe that her exposure to Roman architecture allowed her to gain better insight and understanding about the historical significance of this type of architecture.

I also asked students to provide examples of their sketches as digital images to gain a better understanding of how they observed and documented their physical environment. I wanted to analyze the participants’ illustrations because drawings are an essential aspect of the design process. They are the designer's principal means of thinking and the methods of obtaining knowledge in architectural design (Herbert, 1993). In terms of the participants' creative work, I was looking to see if the sketches illustrated specific architectural details, or if they revealed other factors that might have captured the student's interest. I was also interested to see if their illustrations were not just of facades, but were of three dimensional isometric or axonometric drawings that showed the spatial and structural organization of buildings. Analytical drawings reveal the extent to which students begin to understand the relevance of composition and organization in design.

Having received an undergraduate degree in art and anthropology, Guillermo might have already illustrated some sensitivity to the influence of culture on the development of architecture. His ability to document his ideas and experiences was probably more advanced than some of the other participants. In our discussions about some of the classes he took and the projects he was asked to design, Guillermo talked about spending time in the urban spaces of Rome to study the effects of natural light. I listened to his observations of how these spaces transformed because of the quality of 
light. As the day progressed, the urban sites were in continual mode of transformation because of the effects of shade and shadow.

You hang out at the Campo De’ Fiori from 8 a.m. to 8 p.m. for 12 hours, and see how the space changes. That in itself is a space that takes on many different forms during different times of the day. I think that this observation was the best part of the class.

For designers, light is one of the most important variables that affect the quality of a given structure or urban space. The incidence of light, shade and shadow, for example, create and reinforce a sense of depth which also greatly affects the way we perceive and experience the physical world (Porter, 1997).

Our visual image of the real world embodies a complex pattern of perceptual patches; shapes that each have a color and a tone, and that, apart from responding to the intensity and direction of the light source, each communicate textural attributes describing surface quality which, in turn, describes differently sized planes and shapes, that using different levels of brightness, pinpoint different locations in the illusions of space. (p. 51)

Although Guillermo might have made a similar observation of an urban space in Miami, I believe that his realization and observation may not have been as marked had he not travelled and studied abroad. The fact that he was in a foreign environment and was required to make specific site related observations, might have heightened his awareness of things that he either took for granted or never bothered to notice.

Of all the participants interviewed, Guillermo provided a fairly extensive number of sketches that were taken from his journals. I was also able to talk with him at length about each of his drawings at different times after our initial interview. Guillermo gave me insight into the significance of each illustration in terms of what he was trying to convey. The drawings are for the most part contour illustrations that show urban sites, individual buildings, details, and ornamental motifs. His drawings also capture the 
sensation of depth through the use of varying line thicknesses and perspective. Guillermo also introduces the notion of scale because of the inclusion people in some of the sketches. In terms of the drawings, each illustration captures a time and moment of Guillermo’s study abroad experience. As such, his drawings not only serve as architectural observations, but as recording of memories illustrated through the use of continuous line forms.

As an example, Figure 27 illustrates one of Rome’s most famous urban spaces, the Piazza del Popolo, and it is draw from the central point of the square as a multiple point perspective. As an urban setting, Guillermo has included ghost images of people interacting with the space. The inclusion of people adds to the relative sense of scale of

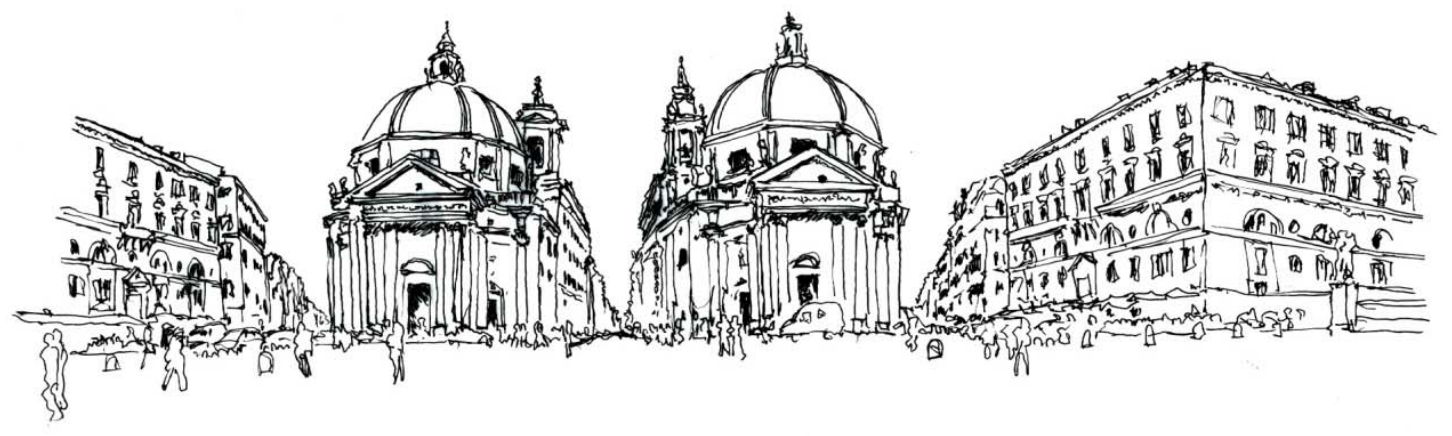

Figure 27. Pen \& ink rendering of the Piazza del Popolo by Guillermo.

the buildings, and his use of perspective reinforces the sense of depth of the urban site. In as much as this illustration is a depiction of an urban setting, it is also a study of site related conditions. "We were always people watching and studying how people interact with the urban spaces. This was part of the learning process.” The buildings on the perimeter of the square reinforce the edge conditions of the piazza. The space in between the twin churches of Santa Leslie in Montesanto and the Santa Leslie dei Miracoli 
illustrates the Via del Corso. Forming part of the trident, the Via del Babuino and the Via di Ripetta on either side of the twin churches all intersect at the midpoint of the piazza. From this image, one can begin to understand the relation of the buildings to the site, and the relation of pedestrian and vehicular circulation to the site. Although the Piazza del Popolo was used for parking and vehicular circulation until quite recently, we can see from Guillermo’s drawing that the site is primarily used as a pedestrian zone. "Cars were allowed to invade the site only at specific times. Otherwise, it was always full of people.”

In Figure 28, Guillermo also introduces the idea of how people interact with the architecture and urban conditions of Rome. The sketch depicts the Church of The Holy Name of Mary, located adjacent to the Imperial Fora in Rome. Directly in front of the church is Trajan’s Column. In as much as this image illustrates the façade of the church, it also indicates how people move and act within an urban space. "We gathered information in our drawings about where people sat and how they sped up and slowed down in urban places. We also examined where they took pictures of the buildings.” People are drawn as contour outlines void of any facial expressions. Instead, Guillermo focuses on their movement and interactions. Guillermo also draws these people as ghost like images. The contour lines that define the people transition to the contours that define the urban conditions of buildings and sidewalks. This transition illustrates the connection that Guillermo establishes between people and architecture. This visual connection is further compounded by the use of varying line thickness to define people and architecture. As ghost like images, the human forms and movements that Guillermo 
draws eventually transition vertically to the domes and lanterns of the church, which are subsequently drawn using heavy line weights. These transitions of form and context also

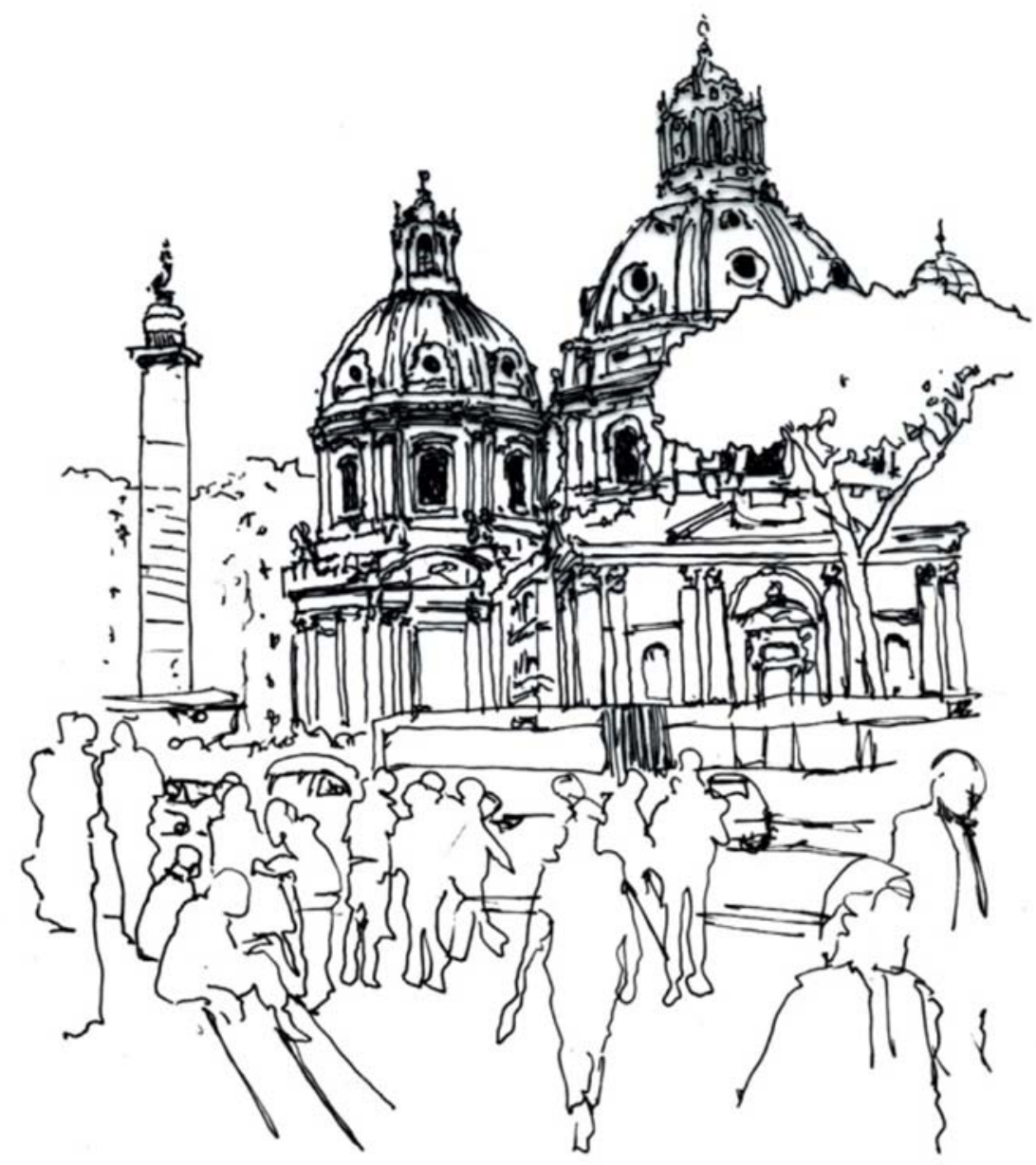

Figure 28. Pen \& ink rendering of the Church of the Holy Name of Mary by Guillermo. 
illustrate Guillermo’s observations and his thought process. Not only is Guillermo establishing the relationship between people and architecture, he is also studying the idea of movement. In this image, people, however, are not the only physical examples of movement. The structure details of the church, the spacing of the columns, and the ribs of the domes, are also dynamic examples of how the structure visually moves and transitions from the ground plane vertically to the lanterns of each dome. "I was really captivated by architecture of Rome and used my drawings as means of remembering and studying the buildings and their features.”

Figure 29 shows the urban center of Florence. From this image, we can begin to make some initial assumptions about Guillermo's location as he drew this sketch. He was sitting on an elevated terrace looking down at the urban center. "This was the actual site used by Michelangelo to look out over the city of Florence. This drawing was part of an assignment to study the urban skyline of the medieval city. " From this drawing we also get a sense of the density of the city in relation to the rolling landscape seen beyond the outline of the buildings. Guillermo's sketch not only illustrates some of the famous historical buildings of Florence including the Palazzo Vechio with its imposing tower and the Cathedral of Florence with its magnificent dome, but it also begins to show the relationship between the vertical and horizontal conditions of the ancient city. "This drawing really shows how the dome of the Cathedral of Florence dominates the urban condition. I also got the chance to understand how other buildings also served as visual landmarks in Florence.” Guillermo is careful to draw the domes and towers that define the urban landscape of Florence in addition to the horizontal qualities that also define the religious and secular buildings that were built during the 
Middle Ages and the Renaissance. Probably one of the most interesting aspects of this drawing is the subtle transition of horizontal linear elements that define the urban architecture to the horizontal lines that define the rolling hills of the Tuscan landscape. In

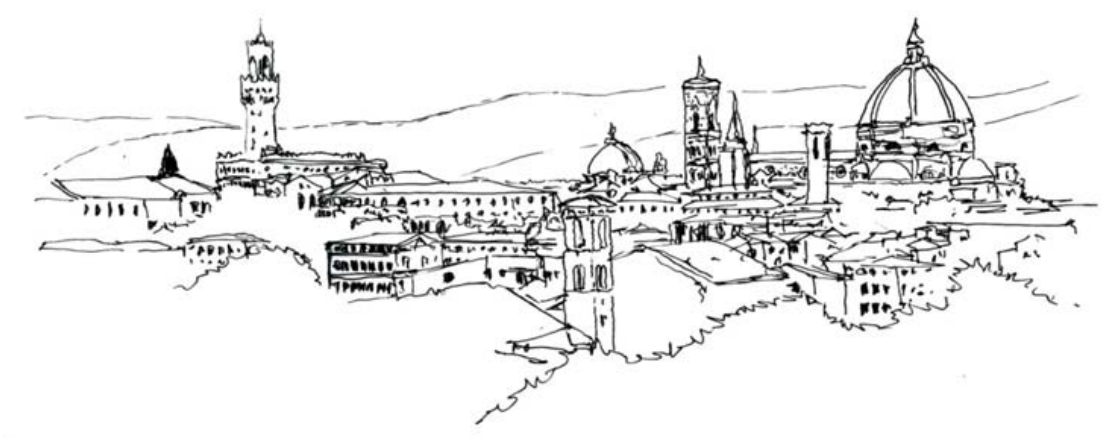

Figure 29. Pen \& ink rendering of Florence by Guillermo.

this drawing, Guillermo is not only illustrating the relationships that exist between the individual buildings, he is also establishing the relationship that exists between the urban and natural landscape.

The sketch in Figure 30 also depicts important landmarks and illustrates how Guillermo associates one building relative to the other. From this image, St. Peter’s Basilica is visible on the upper left side of the drawing, and towards the bottom right is the Church of Sant'Andrea della Valle. Because of the angle and perspective of the image, we can assume that Guillermo is drawing this urban site from an elevated position. What is interesting about this image are not only the details of architectural elements that he portrays, but the transition and visual movement he establishes in the form of contour lines. The dome of Sant'Andrea della Valle is partially introduced but it 
is also visually linked to a number of urban and natural conditions. The outline of a tree engages with the dome as do several other buildings. The ribs and lantern of the dome direct our attention vertically to several buildings that include the Cortile de Belvedere and other structures associated with the Vatican. Visually, we are then drawn to the left because of the horizontal qualities of these buildings, and vertically because of the structural ribs of the dome to the lantern of St. Peter's Basilica.

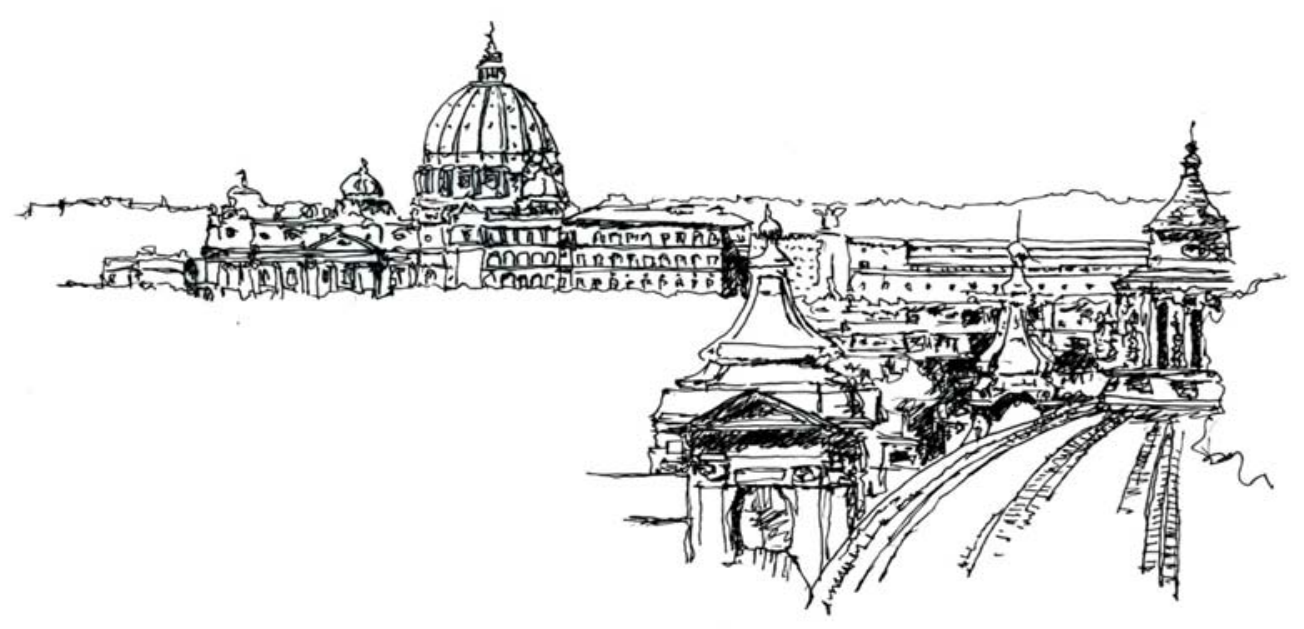

Figure 30. Pen \& ink rendering of the Vatican by Guillermo.

Instead of drawing every urban condition visible from his vantage point, Guillermo omits to include certain structures, but instead focuses his attention on the relationship established by the domes of the two churches that he portrays. "I loved the domes in Rome. I loved drawing them and studying every detail about them. " In terms of hierarchy, Guillermo reinforces the importance of St. Peter's Basilica relative to the Church of Sant'Andrea della Valle by drawing the latter as a complete structure and 
placing it vertically higher than the former. "This drawing was part of an exercise to identify churches and their domes. “ He also establishes the dominance of St. Peter’s Basilica and its dome by engaging the structure graphically with the contour line that defines the urban and natural skyline to the distance. The ability to establish architectural relationships between existing structures and landscape illustrates Guillermo’s keen perception and understanding of important concepts that define architecture and urban design. "I spent hours atop this hill just trying to graphically capture what I could of Rome. This image brings back some great memories.”

Many of Guillermo’s drawings also depict individual buildings and details of buildings. Figure 31 is an illustration of the Tempietto in Monotorio. As a commemorative building erected to mark the site of St. Peter's martyrdom, the Tempietto an example of one of the most harmonious buildings erected during the Renaissance (Trachtenberg \& Hyman, 2002). Portrayed in this illustration are some of the 16 continuous Doric columns that define part of the base of this structure. From this image, one can begin to understand the building in terms of its constituent parts. The dome of this building is noticeable because of Guillermo's use of a darker line weight to illustrate its shape. The drum or central space of the building is also perceivable because of the use of hatching to illustrate its location relative to the colonnade. The balustrade is also clearly visible and drawn with a degree of detail. The plinth is also included and one gets the sensation that the approach to the structure is from a lower elevation. In every aspect, Guillermo has carefully depicted the defining qualities of this small building, and he has also accurately depicted the location of the structure relative to the ground plane. Guillermo also mentioned that he was most interested in the proportions of this structure. 
“This building was built using the proportions of a 5' 7” man. The spacing of the columns, for example, are 5' 7'. I drew this structure because I am also 5' 7’.”

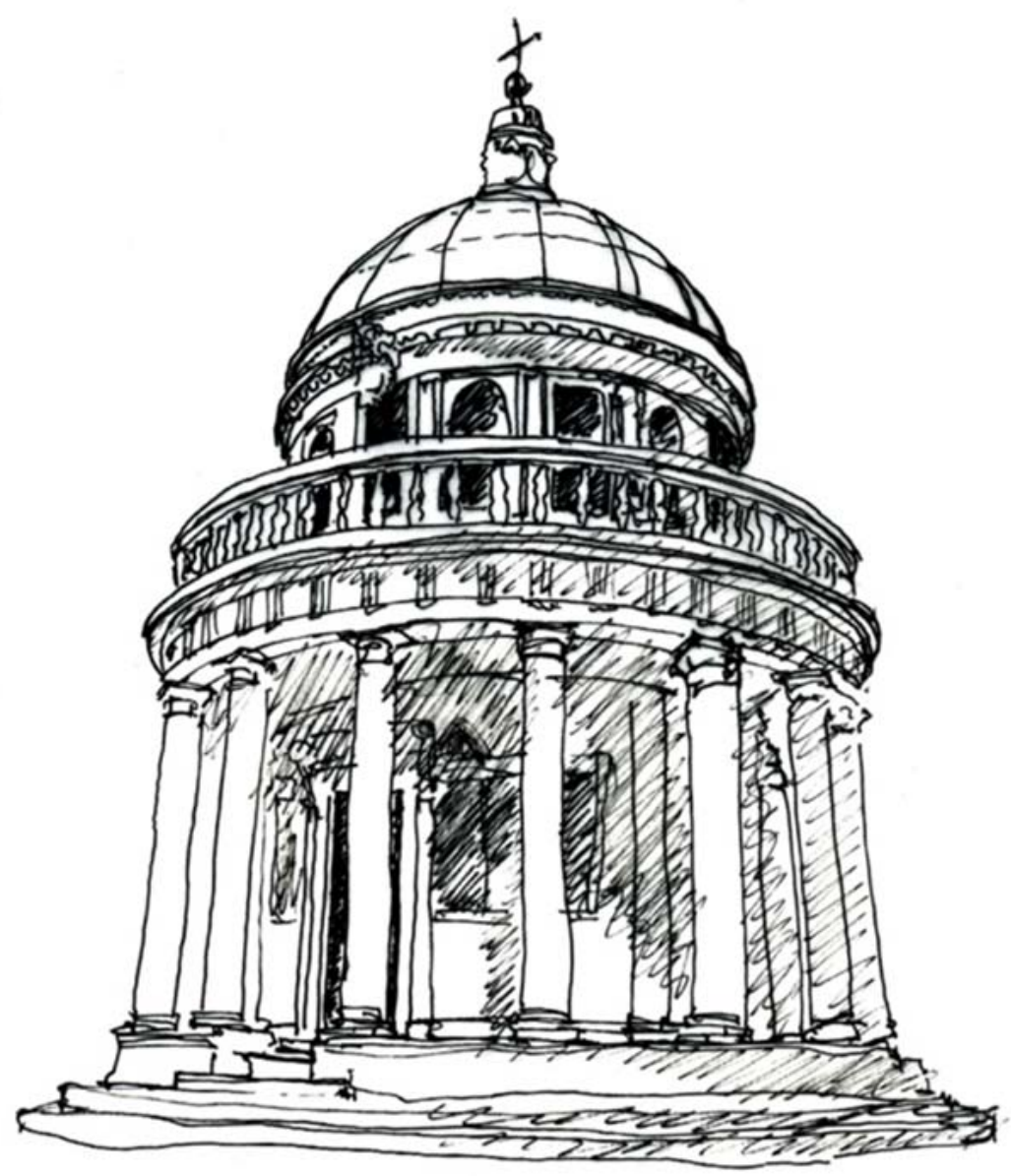

Figure 31. Fen \& ink render:ng of the Tempietto in Monotorio by Gu:11ermo. 
Guillermo’s inclusion of architectural details is also an indication of what he found of interest in his analysis of buildings. The use of sculptural form can be used in a multitude of different ways that include enhancing the overall aesthetics of buildings, illustrating events or people of significance, and reinforcing architectural ideas and themes relevant to the structure. The following image shows what remains of the statue of the Emperor Constantine that once stood erect in the Basilica of Maxentius and Constantine that was built in Rome in c. A.D. 307-12. The image is a combination of

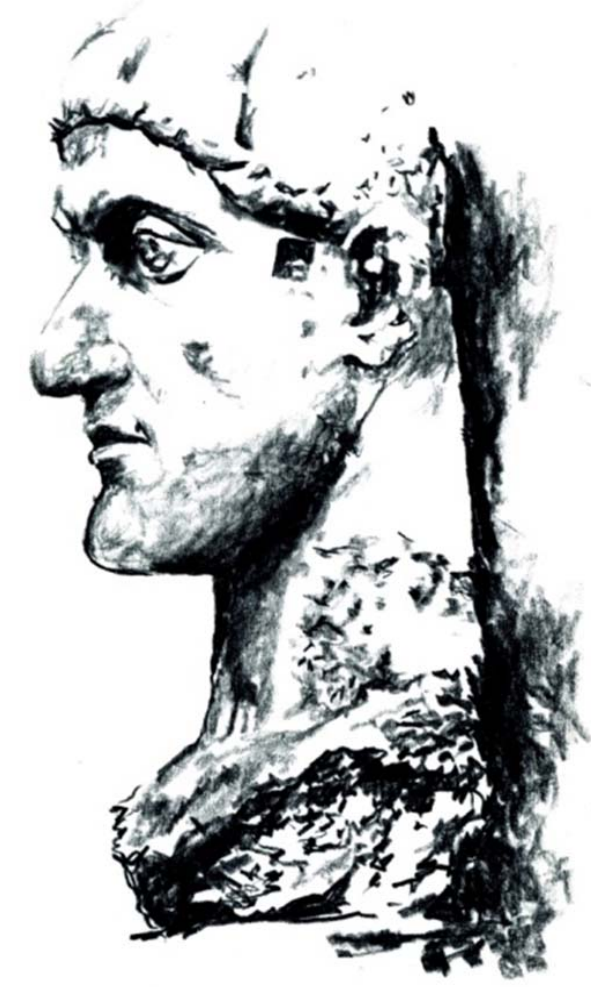

Figure 32. Pen \& ink rendering of Constantine by Guillermo.

graphite and ink used not only to depict the contours of the face and facial expression, but the graphite reinforces and enhances the effect of light and shadow to illustrate the 
concave and convex forms of the bust. This statute is of historical significance because it is only one a few impressions of the emperor that dates back to Ancient Rome.

Other examples of architectural details include Guillermo’s graphic studies of domes. Figure 33 is drawn looking directly at a portion of the dome of the Cathedral of

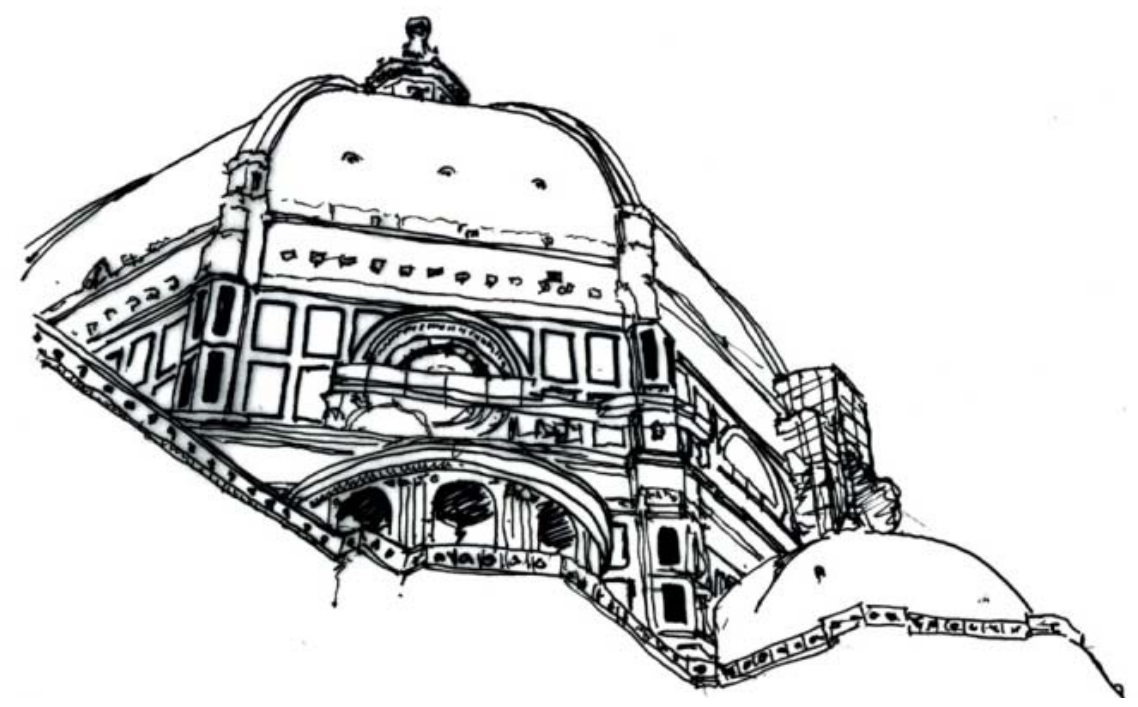

Figure 33. Pen \& ink rendering of the Dome of the Cathedral of Florence by Guillermo.

Florence. The perspective is slightly awkward because of the angle of the image, but it is used to convey the apparent height of the dome relative to the ground plane. In as much as this image illustrates the outer details of the structure, it also shows how the dome is constructed. The image also illustrates how the load and structural forces of the dome are partially contained by the ribs of the dome and the radiating chapels erected around the base of the dome walls. From this perspective, one gets a glimpse of the lantern that is connected to the outer structural ribs of the domes. The ribs transition graphically and structurally to the dome walls of the cathedral. These walls are in turn buttressed by the radiating chapels that are partially visible in this image and located adjacent to the dome 
walls. Although this image is not an analytical diagram illustrating how the structural forces act upon this section of the cathedral, one does get an indication of how these forces are contained and transitioned to the ground.

In Figure 34, Guillermo not only illustrates the Dome of San Ivo della Sapienza located in Rome, but he is also illustrating two different concepts and ideas related the

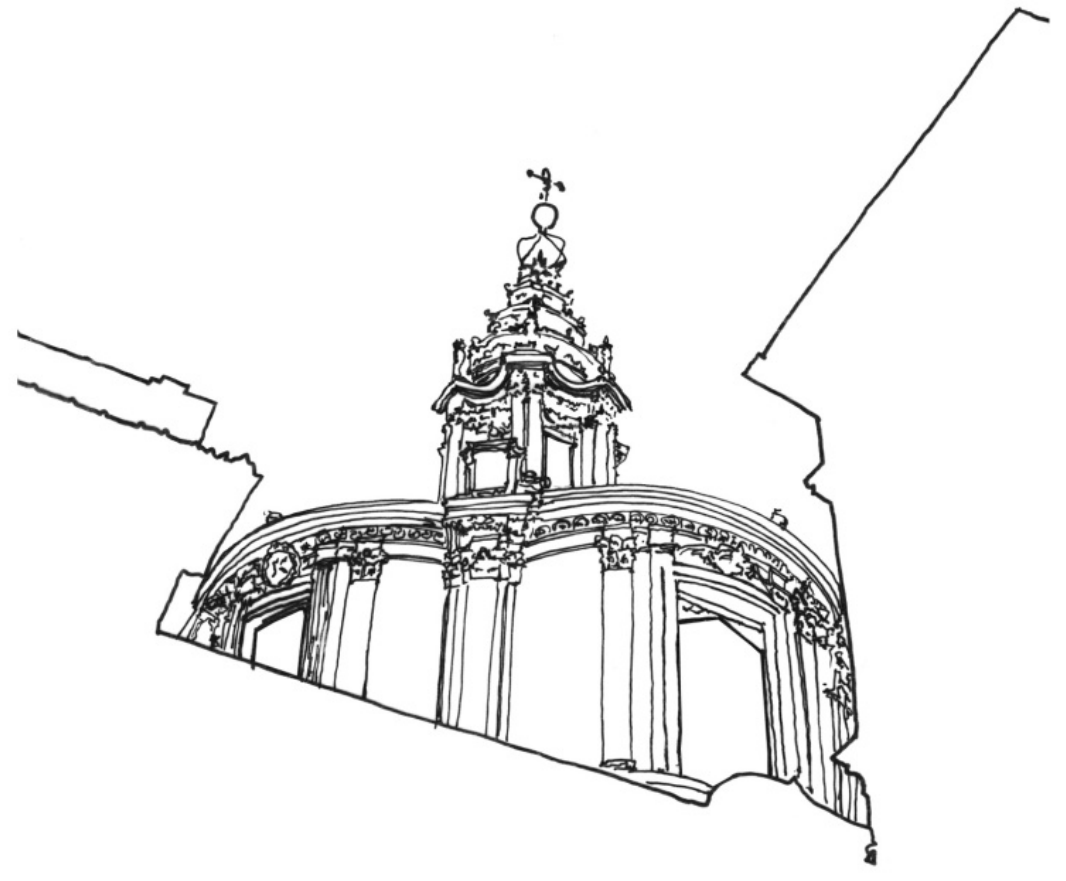

Figure 34. Pen \& ink rendering of the Dome of San Ivo della Sapienza by Guillermo.

"frame." In one instance, the idea of frame can be linked to the notion of structure and the tectonic expressions of architecture. From this image, the engaged pilasters along the outer walls of the church illustrate an example of the structural "frame" of the building. 
Although the ribs of the dome are not visible, we do get some indication of their unique configuration based on the ribs of the lantern. "This had to be one of the most unique domes that I drew." The structure or "frame” of this particular church provides one of the most interesting examples of architecture designed and erected during the Baroque in Italy. The church is composed of one interior space in the form of two intersecting equilateral triangles that form a six-pointed star. What is particularly interesting about this structure and partially visible for this image are the structural conditions that exist throughout this building. Designed by Borromini and begun in 1634, this structure exemplifies the use of intricate geometry and flexible forms, intended to create the sensation of spatial and structural fluidity (Trachtenberg \& Hyman, 2002).

The second idea that relates to the idea of the "frame" has to do with the visible expression of architecture. In this image, Guillermo has framed his graphic depiction of the church by framing it in the context of the existing structures around the building. The forms that define the shape of the dome and walls of the church can only be made apparent in context to the architecture and urban conditions that surround this building. Much like a picture frame, the buildings that surround the church visibly frame portions of the church. The simple rigid outlines of the buildings erected around the church also offer the sensation of contrast to the fluid and curvaceous forms of the church. Guillermo has very deliberately chosen the angle and perspective of his sketch to illustrate how the church of San Ivo della Sapienza visibly exists in context to its environment.

The following images submitted by Jaime and Lizette are much more indicative of analytical drawings. They are used to study in more abstract and analytical ways the spatial and structure configurations of buildings. The drawings do not show the level of 
detail or site related context that Guillermo provides in his work. These types of drawings, however, do present a variety of ideas that relate to each building in more abstract ways. All these illustrations can be drawn as two dimensional representations of the buildings, the spatial ramifications of the plans and sections can only be best understood in a three dimensional paraline format. Unlike the majority of Guillermo's drawings that were composed as multiple point perspectives, Jaime and Lizette use paraline drawings to convey the three-dimensional nature of a form or construction in a single pictorial view. As the name indicates, the parallel lines in the object remain parallel in the drawing. There are different types of paraline drawings but the most common is the axonometric projection which is an "orthographic projection of a threedimensional form that is inclined to the picture plane in such a way that its three principal axes are foreshortened” (Ching, 2009. p. 33). As an example, Figure 35 illustrates a three dimensional volume where three sides of the cube are drawn using consistent angles of projection.

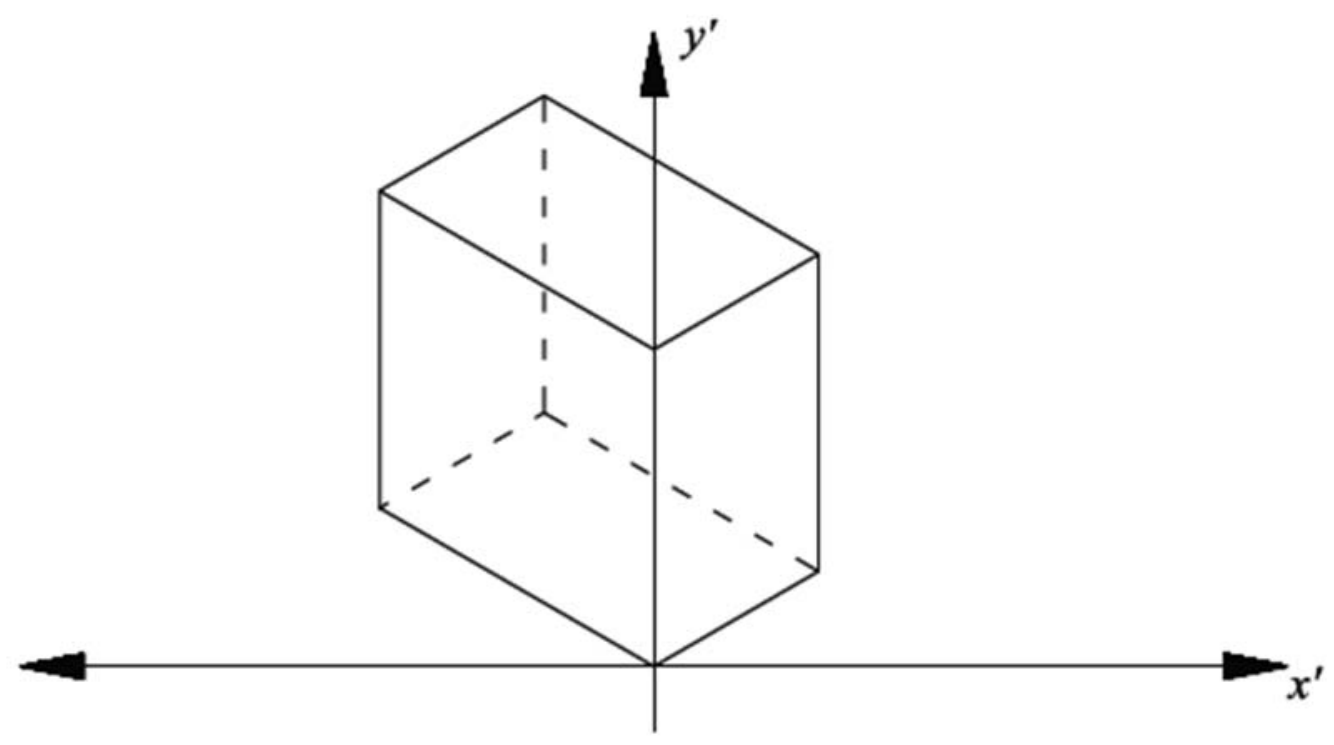

Figure 35. Paraline diagram by F.D.K. Ching. 
Figure 36 was scanned from Jaime’s sketchbook and illustrates a good example of an axonometric projection. The drawings are representations of the Basilica of Santa

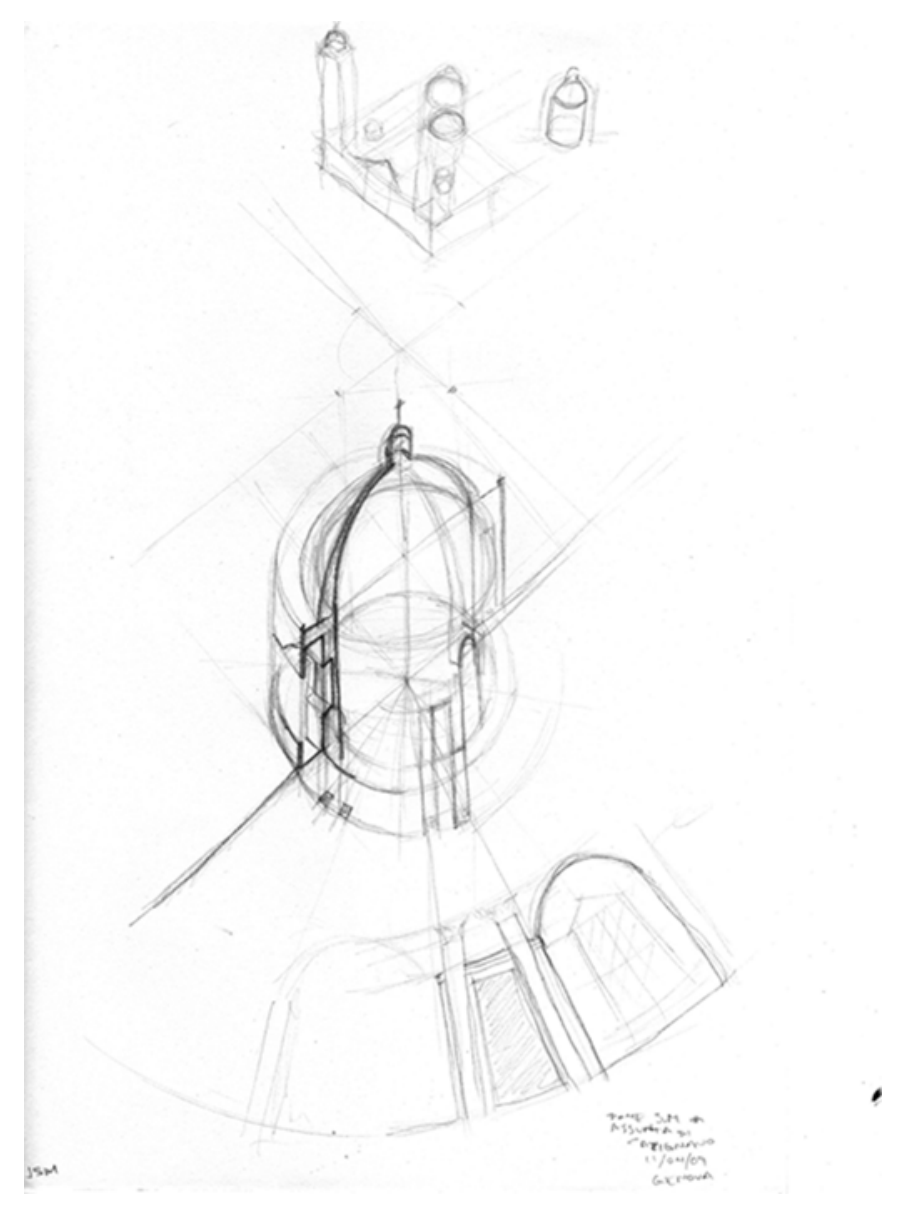

Figure 36. Fen \& inc render:ng of the Basilica of Santa Maria Assunta by Jaime.

Maria Assunta in Genoa. From the drawing, we are able to discern that the church has a central rotunda space. The center of the structure is illustrated as a section diagram with the actual cut lines drawn using heavier lines weights to indicate the location and direction of the vertical cut. From these cut lines we begin to understand the structure of the outer walls and configuration of the dome shell. In addition to this three dimensional 
representation, Jaime has also included a two dimensional projection of the interior to show the shape and configuration of the Roman arches and columns. There is a wealth of information presented in these analytical drawings that is intended to show the main design and structural ideas of the building. These images not only reveal Jaime’s graphic talent and ability, but it demonstrates his understanding of how to read and analyze a building.

Figure 37 is another example of a three dimensional orthographic projection and shows the main spatial and structural configuration of the Church of Santa Maria Assunta. In this image, we not only understand the church in terms of its overall plan but because of its vertical projection, we also begin to understand the structure in terms of its volumes. The central rotunda space is now better understood in relation to its location within the church. Jaime uses varying line weights so as not to confuse the reader between the horizontal and vertical expressions of the church. The plan, for example, is clearly visible because he uses a darker line weight to show the form of the church. Light and medium lines weights are used to illustrate the inner and outer walls of the church as well as the shape and configuration of the roof. 


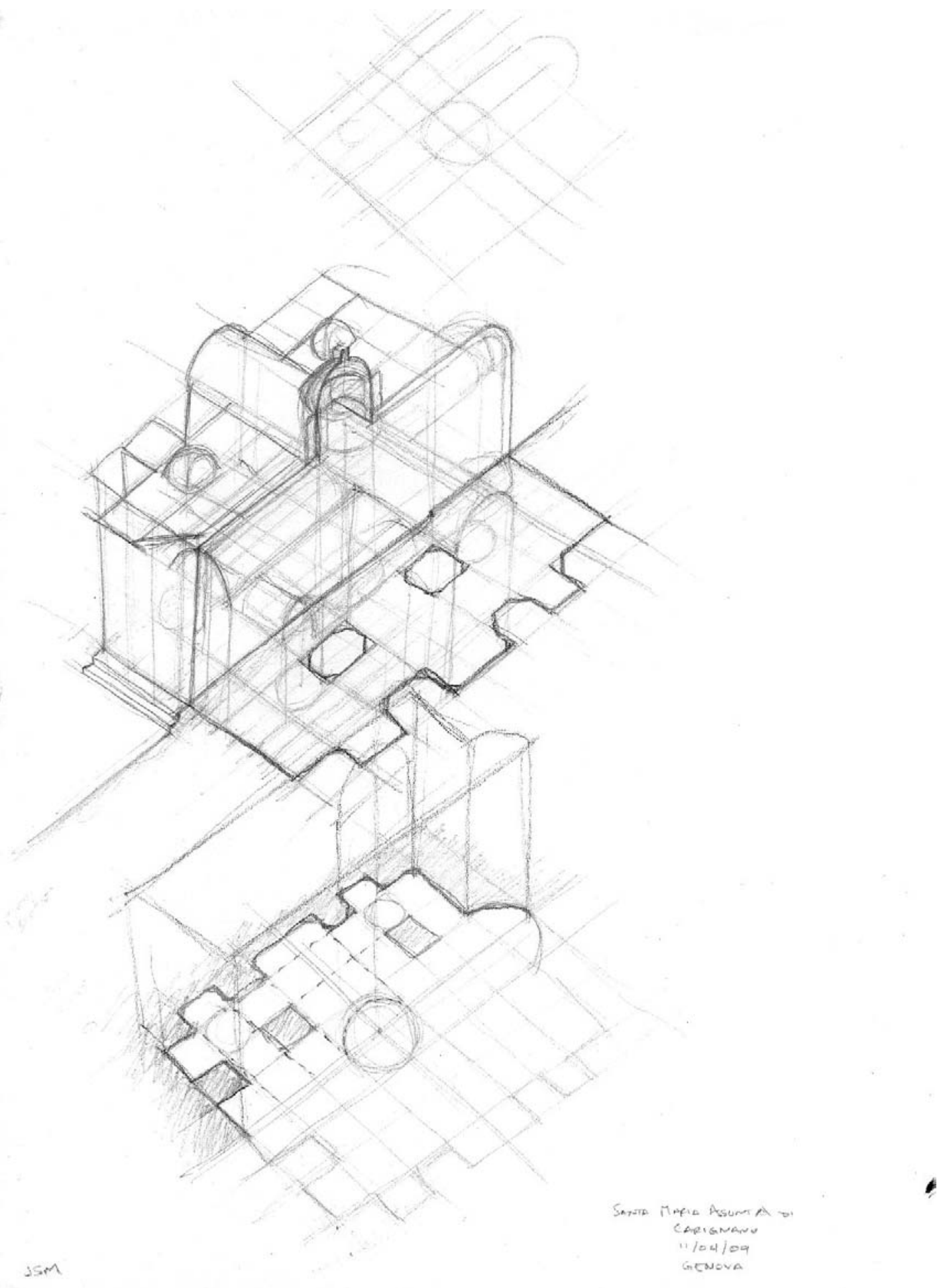

Figure 37. Pen \& ink rendering of the Basilica of Santa Maria Assunta by Jaime. 
Jaime created a series of drawings that illustrate the geometric, spatial, and volumetric composition of the church. He also undertook a detailed study of a portion of the interior of the structure through an analysis of the rotunda and it dome. The final diagram of the Church of Santa Maria Assunta illustrates the building's façade and its geometric composition. In this drawing of the church, Figure 38, Jaime is not only

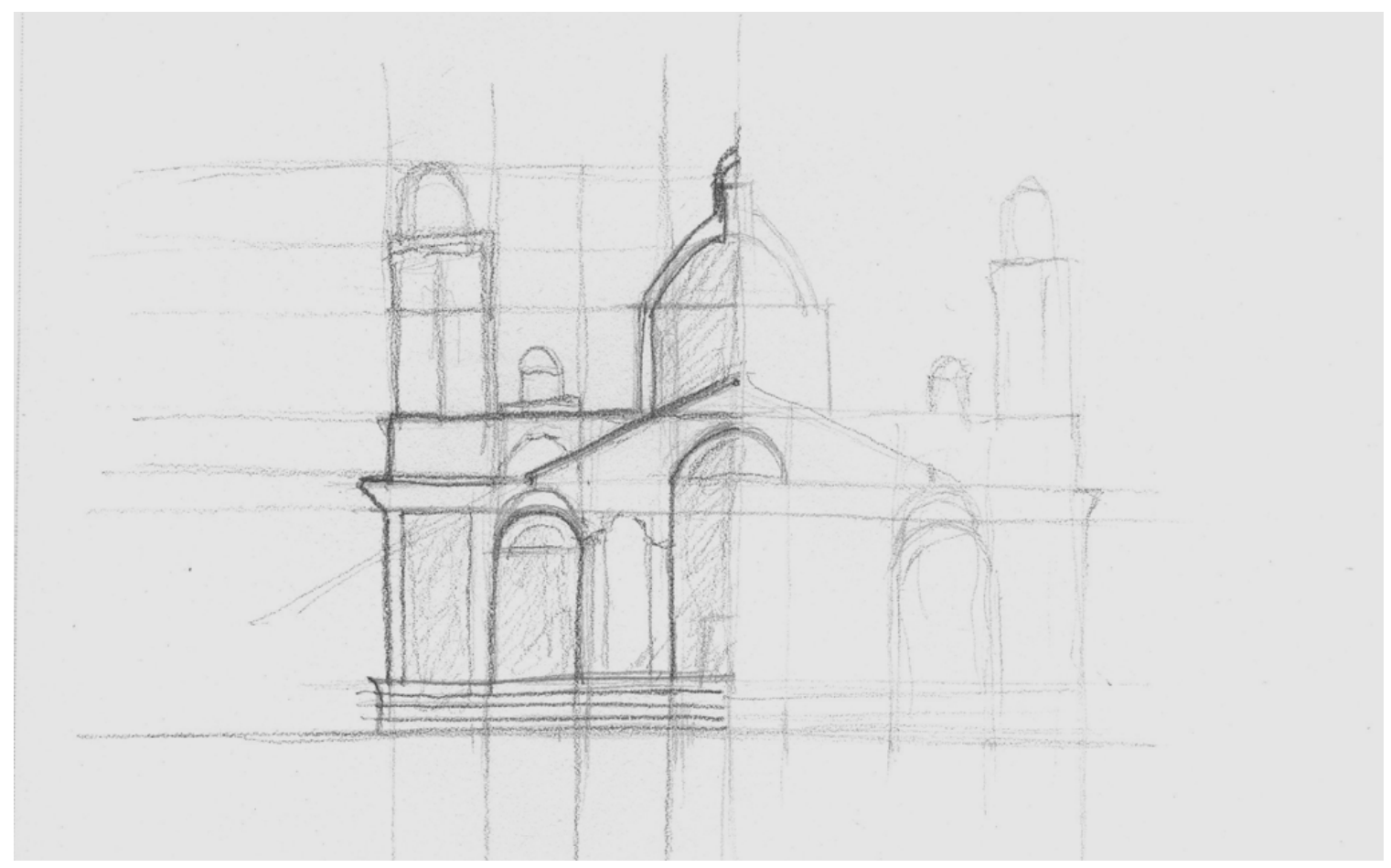

Figure 38. Graphite rendering of the Façade of the Basilica of Santa Maria Assunta by Jaime.

representing the façade of the church, he is also showing aspects of the interior. Although the façade of the church reads as a dimensional representation, there is also a subtle 
reference made to the rotunda space which is drawn as a partial section. The wall and dome structural configurations are partially visible because of the dark line weights and hatching used to illustrate contrast. In as much as Jaime is graphically depicting the outer façade of the church, he is also making a study of its geometric composition. The extended lines to the left, top, and bottom of the image are intended to show the spacing and relationships established between architectural components of columns, arches, pediments, domes, and towers of the church. This image has multiple layers of information that represents Jaime's understanding about composition of the church façade, and the relationship between the façade to the interior of the church. Jaime's illustrations are for the most part study drawings of buildings and urban sites. In as much as these images represent actual architectural and urban site conditions, they also illustrate a critical thought process. There is an implied internal dialogue present in his drawings that shows what he found of importance and of personal interest in the building and site he was studying. As an example, Figure 39 shows an analysis of the Church of Sant Ignazio in Rome. This series of diagrams illustrate two- and threedimensional studies of the Baroque church. Also included alongside the diagrams are his notes about the interior dome fresco painted by the architect Andrea Pozzo. 


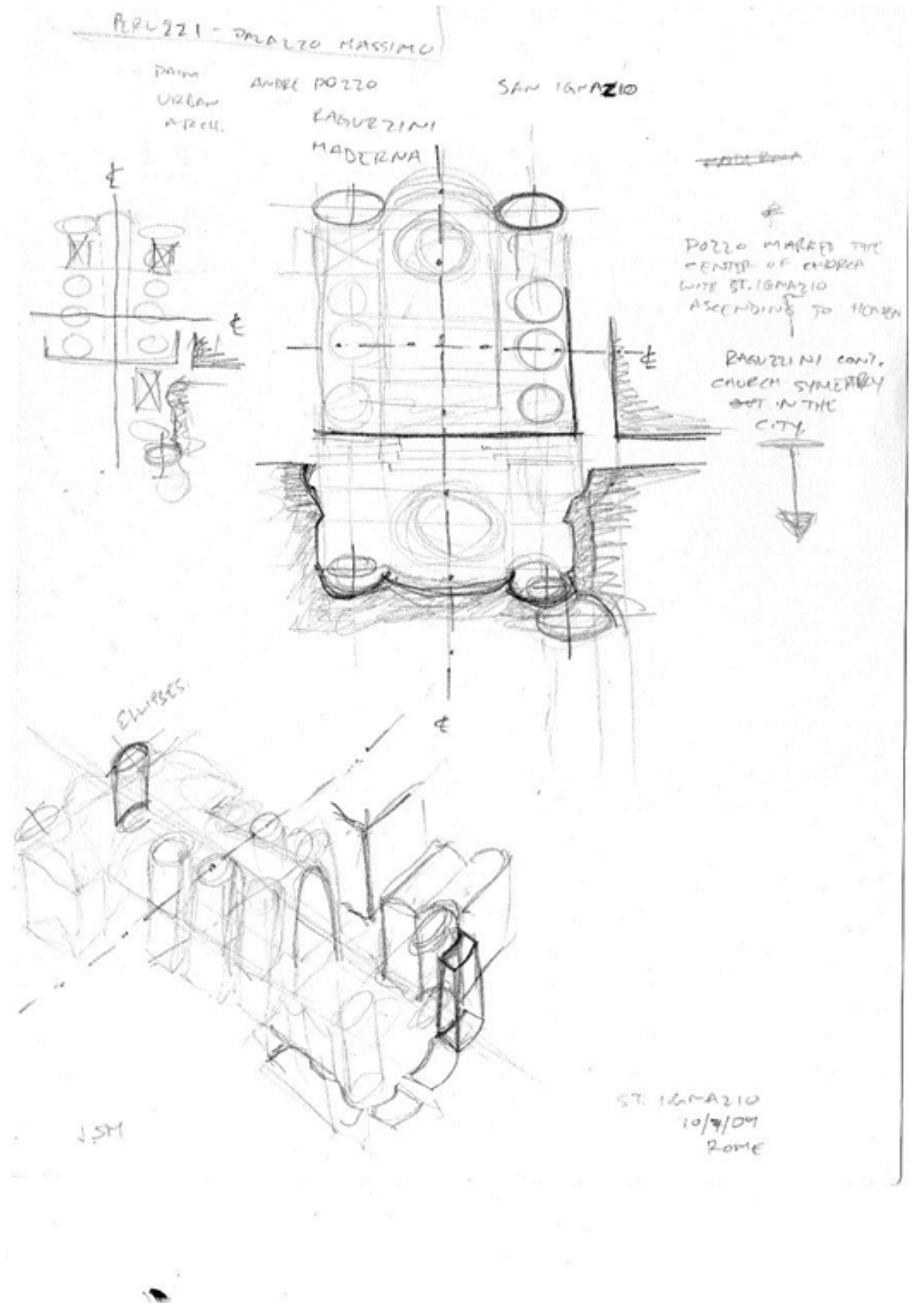

Figure 39. Graphite sketches of the Church of Sant Ignazio by Jaime. 
Jaime also includes notes and diagrammatic representations about how the architect, Fillippo Raguzzini, intended to project the church’s symmetrical composition and façade towards the Piazza of San Ignazio. The two-dimensional drawings illustrate the plan and spatial configuration of the interior of the church. Jaime has also diagrammatically shown the repetition of specific geometries and used dashed lines to illustrate the main axis and point of symmetry of the structure. The axonometric drawing is an extension of his observations projected into a three dimensional understanding of the spatial and structural layout of the church. In just one page of his sketchbook, Jaime has undertaken an analysis of the church and demonstrated his understanding about this building through his diagrams. Having the opportunity to experience the church in person has also given Jaime a unique perspective and understanding about the main design ideas of the building as shown in his drawings.

Some of Jaime’s diagrams were site related studies of specific buildings in Rome and Genoa. In one example (Figure 40), Jaime drew a series of diagrams to illustrate a palazzo on the Via Garibaldi in Genoa. The first image shows the building as a section and Jaime has illustrated some of the spaces using a heavier line weight to show the location of the individual floors. The section shows the interior courtyard which he also shows in the second diagram as a plan. Vertical lines are projected from the first to the second diagram to illustrate how spatial conditions are read and transformed from a vertical to horizontal conditions. The third diagram illustrates the building as a three dimensional representation. The main volumetric conditions are delineated as is the street in relation to the building. In these three images, Jaime has illustrated his understanding 
of the main spatial and volumetric conditions of the building in two and three dimensional drawings.

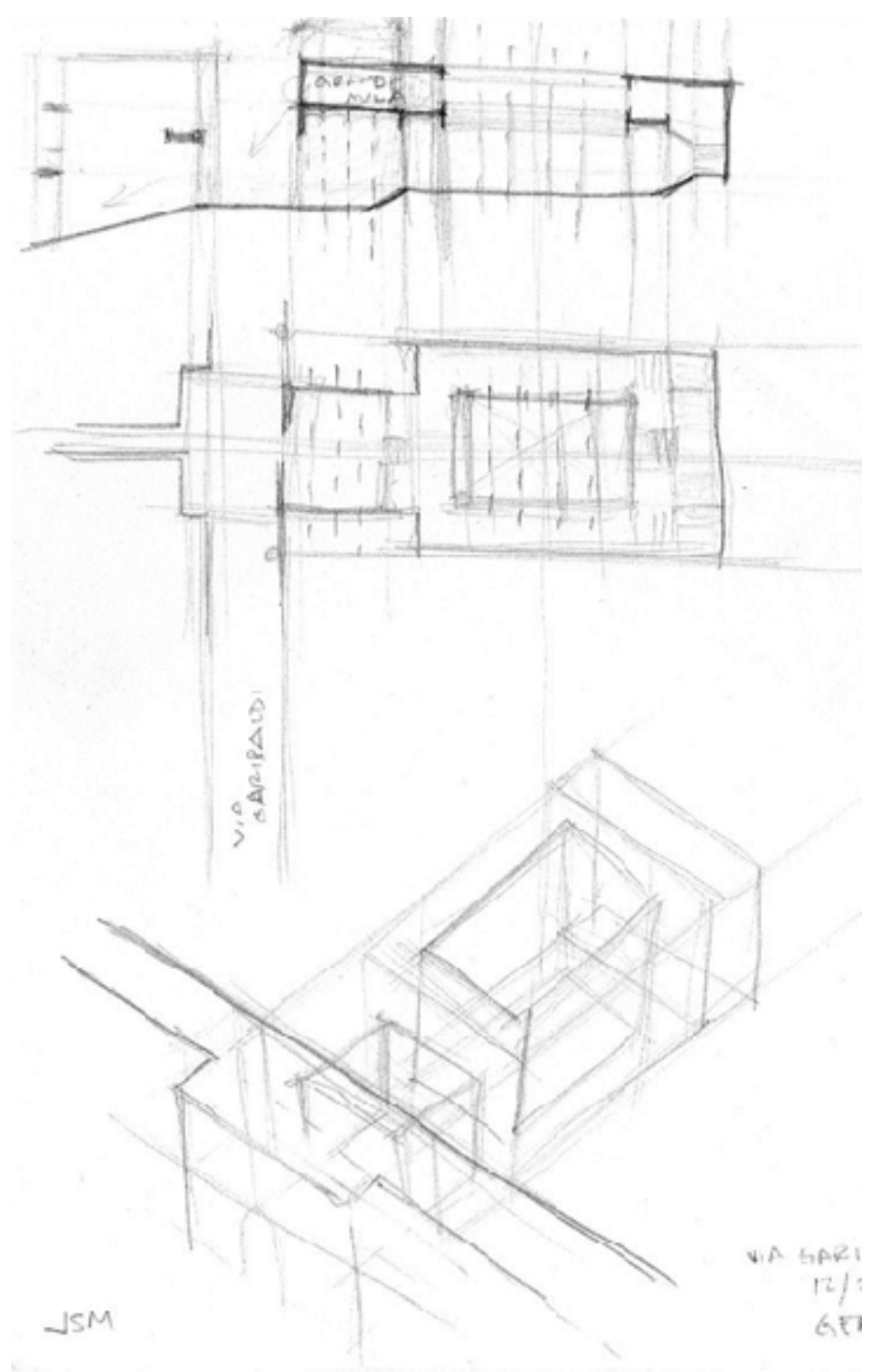

Figure 40. Graphite sketches by Jaime.

Like Jaime, Lizette also submitted some examples of her sketches that illustrate her understanding about the buildings she visited and experienced. Her drawings represent both two- and-three dimensional analysis of the structures and demonstrate her 
ability to think three dimensionally through the use of axonometric projections. Lizette integrates the use of varying line weights to show depth and mark the areas where the buildings are sectioned vertically and horizontally. In Figure 41, for example, Lizette has undertaken a fairly extensive analysis of the Pazzi Chapel in Florence. Her drawing illustrates an axonometric projection, but also shows vertical sectional cuts through the

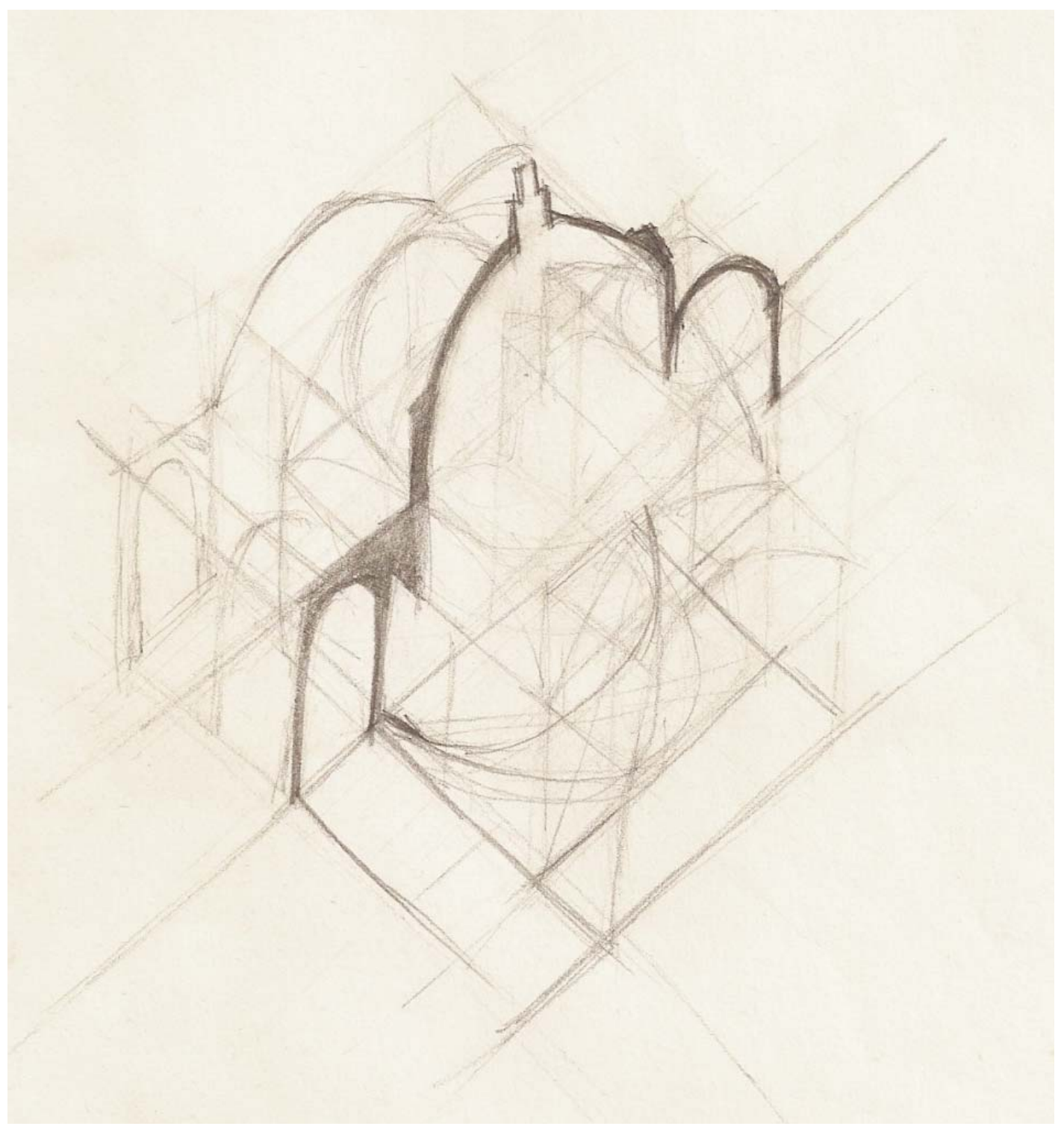

Figure 41. Axonometric Sectional Diagram of the Pazzi Chapel by Lizette. 
building. The sections are shown using a darker line weight. Lizette not only uses the contrasting line weight to show the configuration of the interior spaces and domes, but she also uses the dark line weights and darkened areas to establish the location of the vertical section cut. From this location, Lizette makes a series of horizontal projections to define the location of the interior spaces and show their geometric shapes. Although not explicit, the diagrams within the drawing begin to reference the use of proportions explicit in this building that dates from the Renaissance.

Figure 42 is an example of site analysis that shows the Church of Santa Maria de la Pace located within a small piazza not far from the Piazza Navona in Rome. In this image, Lizette shows the church in relation to the public space of the piazza. She also illustrates specific details about the church in terms of the radiating chapels extending beyond the interior perimeter of the church. From this image, we begin to understand how the church engages the piazza with its façade and portico projecting in to the square. The faint lines that project into the square illustrate path and movement into and though the urban space. The significance of this illustration is to show how the Church of Santa Maria de la Pace integrates with the piazza. We also begin to get a sense of the how the piazza is formed and shaped by the buildings that define its boundary conditions.

Although this image in not an exact representation of the piazza and plan of the church, it does show the relationships established between the private spaces of the church and the public space of the piazza. This illustration also establishes the relationship secular and profane space. 


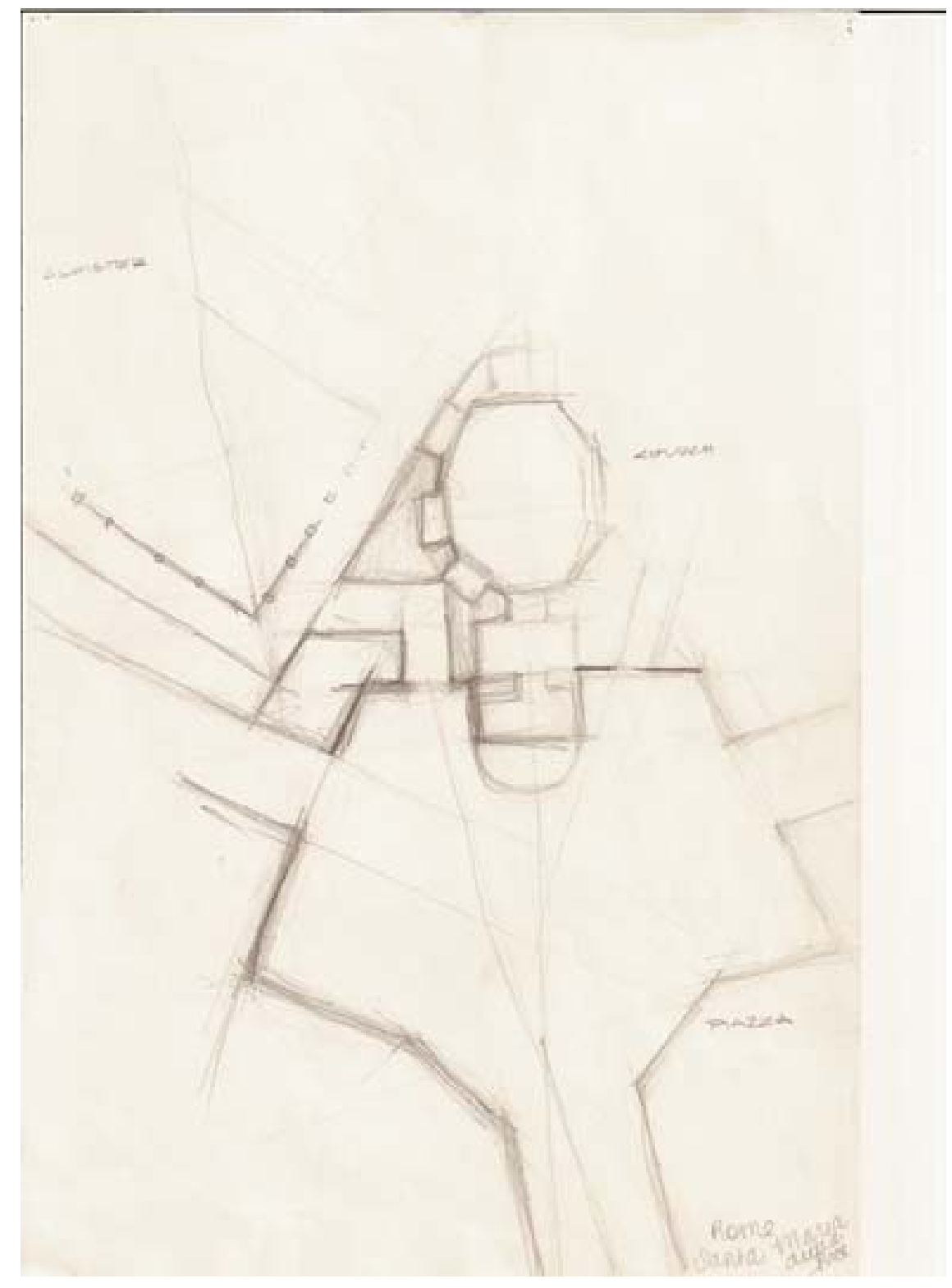

Figure 42. Graphite sketches of the Church of Santa Maria de la Pace and Piazza by Lizette.

\section{Study Abroad and Personal Development}

Study abroad experiences have profound impact on the personal development of students. The personal development of students who study abroad may be one of the most important factors of a study abroad experience (Wortman, 2002). Many students talk about how they became more independent and self-reliant from their study abroad 
experience. Not only do students who participate in study abroad programs display greater global awareness and demonstrate increased levels of cross-cultural interests than those who remain on their home campuses, these students also undergo personal change while abroad (Angulo, 2008; Pascarella \& Terenzini, 2005). Students who participate and return to their home campuses from study abroad programs often report increased selfconfidence, greater maturity, and even display a greater sense of creativity (Angulo, 2008; \& Gurman, 1989). These same students also show greater tolerance towards others, and empathize better with minorities (Hoffman, 2008).

Gloria and Leslie, for example talked about how their sense of self confidence grew as a result of their study abroad experiences. For Leslie, the act of walking and finding her way through a foreign city was enough to give her a sense of accomplishment. "It was something I had never done in a foreign place, and I think that it gives you a certain confidence that you know you'll be okay.” Gloria also encountered a similar experience in terms of finding her way from one location to another while in Europe. Although Gloria had already travelled to Italy prior to her study abroad, her ability to overcome any apprehensions of travelling alone at night was a personal revelation of self-reliance. "First of all, I was independent before, but I became totally independent after finding myself travelling overnight, taking the train and leaving Vicenza at seven at night and travelling to Amsterdam.” Although the act of catching a train form one county to another or walking alone in a foreign city may seem rather insignificant for some, it can present a significant challenge for others. Gloria's ability to overcome fear or apprehension of travelling alone abroad was an empowering experience, and demonstrated personal independence and self-reliance. 
In terms of personal growth, several participants of this study revealed that they not only learned more about themselves, but their semester abroad also proved to be a “liberating experience.” They had the opportunity to experience their new surroundings without being inhabited by their daily regime of tasks and responsibilities living and studying on their home campuses. Other students talked about becoming self-reliant as a liberating experience. These students soon realized that they could become self-sufficient while abroad as the learned to clean and cook for themselves. For some, the act of grocery or detergent shopping actually proved to be a transformative experience because they were no longer dependent upon a parent or guardian making these household decisions for them. Making a conscious decision, for example, to purchase a specific washing detergent in an Italian grocery store was enough to give some of the participants a greater sense of maturity and self-confidence.

Alistair felt liberated because he didn't have to worry about his car or appointments. "You're really there and you're free. Free with 12 other people to just kind of go crazy. Everyone's there. No one has anything, we're always together, and it's kind of a unique experience to be in that situation.” Lizette, on the other hand, had a sense of personal discovery while studying and living in Italy because she learned to rely on herself:

I found myself, you know even though I was 21, I always found myself as just a little kid, and just living at home with mom. I always relied a lot on my family and my sister. I think I came back as my own person, and I didn’t need anybody to help me out.

For students who live at home and attend commuter-heavy institutions like FIU, travel abroad may provide them with an opportunity to experience not only a foreign 
environment, but a setting far from home where they may begin to experience a liberated sense of freedom and exploration.

Alistair and Lizette represent two different aspects of liberation that many students experience while abroad. Travel and study abroad does afford the opportunity to escape, for at least a semester, the daily repetitive activities of living and functioning in familiar surroundings. It forces students to react and function in ways that they would probably not consider living at home (Kolmar \& Pieretti, 2008). For Alistair, his study abroad experience in Rome was liberating because it placed him in an environment that was quite unique and different from anything that he had experienced prior to his departure. This sudden change made him inquisitive and anxious to explore the city with his friends and classmates. He felt free to explore his host country and even went "crazy" as he went about making his own personal discoveries of Rome and his new surroundings. Although Lizette also talked about exploring her environment, her sense of liberation was very personal. Being away from her family and her boyfriend, Lizette was offered the chance to be on her own, and the opportunity to get to know herself. She felt liberated from the constraints of certain relationships during her semester abroad and was able to grow and become her "own person.”

Sandy, who also lives with her family, expressed that she became more selfreliant while in Rome. She became more independent and self-confident because she learned to do things that were otherwise done for her at home by her parents. Her new range of activities included learning how to cook, clean, and better manage her finances:

I became more independent, more able to take care of myself. I had to cook for myself. I had to clean the apartment. I help my parents out but it is still not to the degree that I was doing on my own in Italy. I actually learned to cook a little bit and I started to invent some recipes. My mom wouldn't eat them but I liked them. 
Sandy made another discovery about herself in terms of her shopping habits. Prior to her study abroad, Sandy was used to spending money on her clothes and other necessities like gasoline. Because she had to do her own washing and cleaning, she soon found herself looking at consumables in a completely different light:

I was managing my money not to buy only clothes, gasoline, and food that I had been used to, but I had also to buy cleaning products, and wash clothes, which were different types of expenses that I had to take into account.

Shifting her purchasing focus from gasoline and clothing to detergents may not only be a strong indication of Sandy's self-reliance, but it may also be an indication of her personal growth and maturity.

JP also mentioned that his study abroad in Rome was a liberating experience because he had the "freedom to explore and see other things.” Like Alistair, JP felt that he didn’t have the "same responsibilities" as he did at home, and could do things that he wouldn’t otherwise do in Miami. JP also talked about how the study abroad changed aspects of his personal life. Not only did he learn to become more self-reliant, he also became more tolerant and accepting of others:

I think that the study abroad taught me to be more tolerant and adjusting towards people. I also learned that your way isn't always the way it is going to work out and to improvise when your plans don't go according to plan.

Learning to improvise may have demonstrated JP's resourcefulness, but it might also be an indication of his creativity in finding solutions to some of the problems or issues her faced while abroad. Like Sandy and Lizette, JP was also very reliant on his family and the institutional services on his campus to provide him with basic necessities of food and shelter. "I also benefited from learning how to cook because of having to live on my own. I had never done it before. I’ve lived on campus where food's served for me.” Learning 
how to cook and live on his own were important learning experiences that added to his personal sense of growth and independence.

Students who participate in study abroad programs often experience a profound change in how they view themselves in a global environment. For many, the study abroad experience also transforms their thinking because it teaches them to be globally minded, inquisitive about other cultures, and more interested in international affairs and world politics (Kisantas, 2004; Sandell, 2007; Van Reken \& Rushmore, 2009). Marc, for example, had a profound experience during his study abroad experiences because he felt that it changed his “viewpoint on everything.” He came to this realization after seeing how people in different parts of the world live. "I feel that I saw everything differently going to Asia and going to Europe, and seeing the different ways that people live, and really appreciating that people live differently in those places.” Marc's decision to participate in a number of study abroad programs was fueled by his desire to learn about other cultures. Aliana’s study abroad experience also “opened her mind” and showed her that "there's better things out there" than what she had seen or experienced prior to her travels. Having been raised in Miami, Aliana’s study abroad was her first experience to be away from home. "It was definitely great to get out of Miami. I had been born and raised here so this is all I knew, these four walls. I experienced new cultures, a new life.” Because Aliana had limited travel experience before her departure to Europe, her study abroad transformed her perception of the world around her. It gave her a greater sense of the possibilities and opportunities available in terms of personal and professional development. Aliana realized that her "world” was not limited by the boundaries of a city or county; it was far more expansive than she ever imagined or dreamed. Travelling to 
other countries, Aliana was exposed to a variety of cultures and lifestyles that "opened” her eyes and mind to the diverse nature of human existence and creative expression.

Marc saw great value in his study abroad experiences because he not only gained a greater appreciation for diversity, but he also learned the benefits of incorporating aspects of these various cultures into his life. His decision to assimilate with his host nations was also a strong indication of his tolerance and acceptance of other ways of living and thinking. "There is great value to the way that they live, and perhaps we should incorporate some of that here in America. I feel like it really, it impacted me a lot.” I initially wanted to continue this conversation with Marc further because I also remember having a similar impression after my study abroad. I felt that I could enrich my life by learning the cultural customs of other countries, and making some of these a part of my life. When I asked Marc to elaborate on how he intended to integrate some of these foreign values and customs, Kate was quick to respond that they had purchased a coffee pot in Italy, which they "use every day.” As a cultural reference, making coffee each morning in their Italian coffee pot is one way that Marc and Kate are able to reconnect with their life in Italy. In fact, the coffee pot may also represent an aspect of the Italian lifestyle. As part of a daily ritual, many Italians enjoy drinking their espressos in cafes while socializing with others. Making and drinking coffee is not only a relaxing and pleasurable experience, it also a daily active that might remind Kate and Marc of what they liked most about Italian culture.

Many of the participants mentioned how much they enjoyed the Italian lifestyle because it was much more relaxed than the American way of life. They also talked about how they learned to better appreciate life from the Italians. Connie, for example, 
observed how the Italians appear to be less concerned with work, and how they place greater emphasis on enjoying life and having fun. There tends to be a greater emphasis on spending time with friends and family than the office. Connie also discussed the extent to which Italians value art and culture. These observations revealed important lessons for Connie on how to live her life and integrate these aspects of Italian culture into her life in the U.S.:

I think they're important, really incredibly important lessons to be learned about how we live our life, and the things we value. I mean I just felt as though people that I met didn't work as hard over there in a lot of ways and had more fun. The just seemed to have a much greater appreciation for life. I don't know if it's also just a pride of being Italian, but they also value art and culture a lot more than people here who think it's such an elitist thing to do, I guess. So it was just wonderful to see that there's other ways of living and other ways of being I guess.

Although I initially reacted to Connie's comment about valuing art and culture in the U.S. as an elitist endeavor, I did begin to agree with her sentiment after I thought more about my own experiences living abroad. I remember on many occasions having long and informed conversations with Europeans about a variety of topics ranging from the arts to politics. In many instances, these individuals were also extremely well informed about many aspects of American culture and were able to comment on recent political developments within the U.S.

Connie, however, was not the only participant to make the observation of how Italians value their art and culture. One of Marc's most profound memories of his study abroad experiences in Italy, for example, was his interaction and conversation with a street sweeper who gave him insight into the Carlos Scarpas’ Banca Popolare in Verona. Marc was not only amazed that a seemingly uneducated person could provide a fairly sophisticated level of understanding about architecture, but he was equally impressed by 
the passion for art and architecture which Italians from varying socio economic levels seem to share:

A find of mine and I were standing outside the Carlos Scarpa's Banca Popolare in Verona and we were standing there sketching it. A guy was sweeping the street and he walked up to us. I think he was the parking attendant because there was a parking lot there or something like that. He walked up to us and he started taking to us about the building, and about the circle and the geometric motifs. It was like a commentary and he was right on. It was just amazing that this guy is sweeping a parking lot, and that's his job, and he still has some passion for his environment and the place, and he has some knowledge of it. We don't have that in America. We don't have the same passion for our culture, not in that way. Not for our architectural culture at least.

Like Connie, Marc also expressed the importance of integrating a passion for art and culture in his own life. During the interviews, Marc gave examples of ways in which he applies this passion in aspects of his life. He talked about his trips to New York, and visits to various museums in the city as things that he enjoys doing and finds fulfilling.

Several of the participants interviewed talked about their daily ritual of walking to their classes as one of the most enjoyable and relaxing aspects of their study abroad experience. Not only did walking give them a sense of freedom and independence from the automobile, it was also a way that some of the participants were able to assimilate and integrate aspects of the Italian lifestyle in their own lives. Connie, for example, initially found the experience of walking to class a stressful one because she was so accustomed to using a car in Boston. By the end of her academic year in Florence, walking was the "most enjoyable part of my day because there’s so much window shopping on the way, and there's so much interaction in the streets, and it was just wonderful.” Many Italians who live in urban environments either walk or take public transportation. They are not consumed by the stress of traffic. 
Marc, for example, talked about "having to slow down." You know you have to slow down your pace of life. You have to walk places and I've always liked walking, but I think maybe even more so since we've studied abroad we have become really avid walkers.” Walking is not only a means of slowing down, but Marc views this activity as another way he is able to integrate aspects of Italian culture and lifestyle into his own life:

When we go to New York, we went down to Wall Street and went down all the way to Columbia to the north of the park. I think that's something that maybe we've brought back is that kind of wish and hope for that pedestrian lifestyle.

Although their opportunity to live a pedestrian lifestyle in Miami was limited, Marc and Kate expressed their intent to move to a pedestrian friendly city. Their decision to study architecture and landscape architecture in Philadelphia was in part influenced from their desire to live in an urban setting where they could be less reliant on a car.

Guillermo became so accustomed to walking that his return to the U.S. proved to be an awkward transition. Guillermo, for example, felt "weird" about driving from the airport to his house in Miami when he returned from Rome. He had not used a car for months and had begun to experience his environment from the perspective of a pedestrian. In addition to walking, Guillermo also learned to simplify his life and do without many of the material conveniences in Miami. Although he initially missed the "television, the comforts of home such as a washer, dryer, a large refrigerator, air conditioning, and a cell phone," he soon discovered that he could live better without these “conveniences.” Like many of the participants, Guillermo had begun to shift his priorities from wanting certain material comforts, to seeking personal fulfillment in the simplest of activities. 
Guillermo also talked about how much he enjoyed sketching the architecture and piazzas of Rome. He also talked about spending time with friends, or enjoying an afternoon sitting in a café as activities that gave him this sense of personal enjoyment and fulfillment. Because of this shift, Guillermo had also begun to engage in aspects of selfdiscovery. He not only became more introspective because of his study abroad experience, but he also began to have a greater appreciation for his family, friends, and home:

It makes you a different person, I think. Once you leave your element, you come back, for better or worse, different person. I like to think that I'm a better person. I know you really find yourself. You have a lot of time to think, and to analyze who you are, what you want to do, and where you're going, and where you are. All of these kinds of thought lead you to think how lucky you are. You really start appreciating all of your previous experience, and your family, and your friends, and your home, and where you are from.

During the interview, Guillermo emphasized that his introspection could only have happened during his study abroad experience. "I mean, this kind of stuff doesn't happen often whenever you're driving around Miami.” Guillermo felt that the experience of being away from home afforded him the opportunity to live according to a different set of standards. It also gave him the chance to question the way he thought about himself, and the lifestyle he had been accustomed to living in Miami.

Like Guillermo, Julia also experienced a shift in terms of the things she valued the most. For Julia, it was the simple things that counted the most in terms of her memories of Italy. She placed greater value on her daily routines and interactions with friends, than she did of the actual sites she visited and experienced:

The best moments of the study abroad were the everyday routine types of things that while it's happening, you kind of take for granted, and then it's what you miss the most in the end. It's not the big huge cities, and the big trip; it's the little 
experiences, and spending time with all of your friends. That was the best part of the study abroad.

Probably one of the most profound aspects of Julia's study abroad experience was that she learned to live in the moment. She was not consumed by any past or future occurrence. For her, living in the moment was an appreciation and awareness of her daily routine of activities. She also learned to appreciate life and her study abroad by the "little experiences.” When talking about her study abroad memories, it was time spent with her classmates that mattered most for Julia. She talked about getting together with her friends to cook in the evenings as some of the more memorable activities of her experience in Genoa. Looking back at my study abroad experiences, I can also vividly remember the moments spent with friends attempting to cook a meal as probably some of my fondest memories. Cooking and sharing a meal can be an intimate activity that gives the participants an opportunity to talk and laugh with one another. I believe that Julia and Guillermo represent examples of how study abroad experiences can significantly influence personal development and even change how people value aspects of their lives. These lifestyle changes are indicative of the transformative nature of travel and study abroad experiences.

Connie also discussed at length her need to create a sense of personal identity as a motivating factor behind her decision to study abroad. Of Italian and Greek heritage, Connie viewed the opportunity to study abroad as a chance to connect with her cultural heritage. She also viewed the opportunity as a means of struggling with her professional identity, "I think I was struggling with what is my place in architecture, which I guess in a bigger way, I was even just struggling with what is my place in the world, where am I going to be.” I believe the fact that Connie was one of the older participants alludes to the 
fact that her descriptions and discussions were much more involved when it came to discussing her personal reasons for study abroad.

Connie also viewed the study abroad opportunity as a means of connecting with her cultural identity. It was also a way in which she could not only connect with her father's side of the family, but also as a means of associating with her grandmother with whom she had a close relationship. "I started thinking about my ancestry and so growing up I had a much stronger connection with my father family than I did with my mother's simply because my father's family was together and my mom's was fractured.” I found myself associating with Connie’s response because one of my reasons for studying abroad was also personal. I was not trying to connect not so much with my heritage as I was my past. As a child, I had lived in France and the experience had not been particularly positive. I viewed my opportunity to study in Paris as a means of overcoming some of the challenges that I faced living abroad and attending foreign schools.

I found Connie’s discussion about her "matriarchal” grandmother interesting. Although she had passed, Connie talked about her study abroad experience as a means of connecting with her grandmother, and the family traditions that she feared were lost when her grandmother died:

There's so much about my upbringing that I really liked and my grandmother was sort of that matriarch that brought everyone together and when she passed, it definitely felt like as a family and a extended family, we didn't hold onto a lot of the traditions.

Connie talked about the need to hold onto her traditions intensified while she was in college and she also felt the need to pass her traditions on to her own family someday. Her decisions to study abroad were very much influence by a longing to connect with her heritage: 
And that really bothered me and it was one of those things that I really didn't think about at the time and then I was in college and then I thought about it afterwards like well, how am I going to hold on to these things in my future and you know not even knowing exactly what was in the store for my future but assuming that there might be a family there of my own.

Connie also talked about the romantic notion of travelling to Italy, how she would somehow find instant assimilation with the culture and place:

I got very interested in the idea of going to Italy, and I think I had a very sort of romantic notion that I would go to Italy and it would just click with me. I don't even mean like the romantic notion of meeting someone. I mean that like the culture would click with me. I would know - I don't know. I really wanted to experience what that was like and how it was different from American culture.

I was able to connect with Connie's romantic notions of assimilating culturally with her host county. I also remember having romantic notions of "clicking” with the French as I prepared and contemplated spending a year abroad during my undergraduate studies. In fact, I tried to assimilate as much as possible with my host culture, often trying to disassociate myself with anything American including my fellow classmates from Washington University.

I wanted to learn if Connie had actually "clicked” with her host culture so I pursued the conversation further. Although Connie had managed to do so in "a lot of ways," her realization of how much she assimilated became only apparent upon her return:

It's very funny because when I came home, I felt more distant from my family than ever before because no one in my immediate family has ever really traveled, well, at least at that time they hadn't, and I felt as though the experiences that I brought back that they thought I was being very anti-American, even just expressing some of them and that was kind of hard because you go and you have this experience and I felt sort of very liberated and very, I don't know, informed. You know I felt a very different person and I honestly felt as though it helped me appreciate what I have as an American but it was interesting that nobody around even to pick up on that that they felt like I was constantly complaining about the way things are here I guess. 
Connie's reaction and sense of feeling alienated upon her return is not uncommon. I had also felt a sense of culture shock upon returning to the U.S. after my year abroad. Although I do not remember feeling alienated from my family, I did feel that the experience had given me a greater sense of personal identity. I had also lived on my own for the first time in a completely foreign environment. That exposure had helped to increase as sense of greater self-confidence. Much like Connie, I had learned to better appreciate not only many aspects of my host nation but I had also come to appreciate things about being an American. One of the things I was most grateful for was the freedom to choose.

The idea of culture shock for people experience or adjusting to new environment has been well researched. In fact, many researchers indicate that "culture shock” is prevalent and normal process of adjusting to a culture (Christofi, 2003). There is also research to indicate that a student who returns after having spent a year abroad may also encounter a sense of "culture shock” and may have to experience a time of assimilation into their native country (Christofi, 2003). There is no doubt that Connie experienced culture shock having to assimilate back into her familiar surroundings of Boston.

In terms of wanting to connect with their host countries, Leslie and Gloria also expressed the need to recover aspects of their own culture while living in Mexico and Italy. Leslie and Gloria were both born in Cuba and had left their homeland at different times during their lives, but felt the urge to recover aspects of their memories of Cuba. Leslie had initially sought to spend her semester abroad in Cuba as part of an established program through the University of Florida. Because she was very young when she left Cuba, Leslie talked about the need to verify her memories of her homeland. Studying in 
Cuba would give her the opportunity to experience the country from a different perspective, but would also give the chance to validate her memories. "I left Cuba when I was nine and my memories and everything are very vivid, but here's still a gap - you get to a certain point where you think that you are reinventing memories and you almost need see it again.” Again, from personal experience I began to associate with Leslie’s reasons for participating in a study abroad program. Not only did I wish to study in France because I had lived in the country, but I also wanted to relive aspects of my childhood. There were certain things that I wanted to remember.

I also associated with Leslie on another level and probably deeper level. Of Cuban heritage, I understood her desire to return to her homeland. Although I never lived in Cuba, I often recall exiles talking about their memories and expressing the desire to return to their homeland. There is an underlying desire for immigrants or refuges to return to their place of origin to engage in the act of remembering (Smith, 2003). Leslie was quick to point out that she had no intention of travelling to Cuba under the present political situation but she was "at the same time I saw this as an exception because I figured that it was going to be a really rare opportunity to see Cuba from a different perspective”. In her eyes, the study abroad program to Cuba would give her the opportunity to experience Cuba from a safe emotional distance:

If I went to Cuba by myself, there was going to be the emotional, you know, seeing the family, and seeing the places where I grew up. If I went to Cuba through the program, it was going to be seeing it from a completely different perspective.

As she spoke, I tried to image myself returning to a homeland under the conditions Leslie described. I questioned whether I would be able to be able to take an objective approach 
to the experience of return through a study abroad program. I also questioned if this was possible for Leslie in light of her experience leaving Cuba and settling in the U.S.

Although Leslie’s program to Cuba was eventually cancelled, I was particularly interested in how she would associate her experiences of Cuba in light of her decision to study in Xalapa:

To make a long story short, the program got completely sidetracked because the administration at the time didn't approve us going to Cuba and it was coming to the time where we had to leave so they changed it and made it in Xalapa.

As Leslie spoke, I was trying to notice if there was any inflection or noticeable change in her voice marking a sense of disappointment. She appeared to be somewhat relieved that she didn't go to Cuba. In fact, her tone of voice was rather upbeat, "Well, if that is true for Cuba, the same is true for Xalapa, even though I have never been there. I'm going to learn just as much probably, and maybe have even a better time because it won’t be so emotional.” She reaffirmed being happy about the decision to study in Xalapa, “I decided to go along with it, and it was the best decision I ever made.” Leslie enjoyed the experience so much that she returned to Mexico two years later to participate in a second study abroad program in Guadalajara.

I was still intrigued by Leslie’s desire to reconnect culturally and even emotionally with her Cuban heritage. This curiosity might have been an aspect of my cultural bias, and I was careful not to make this a dominant aspect of our conversation. I made a note in my journal as a reminder of this issue, but I engaged Leslie further with this topic. Having never travelled to Cuba, I was curious how Mexico reminded Leslie of Cuba. Again, the basis of my inquiry might have been personal. My aunt and uncle had been exiled to Mexico during the Cuban Revolution, and I had heard of many other 
Cubans settling in Mexico because of the cultural and historical link to Cuba. I have travelled to Mexico on many occasions, and I have a particular interest in its culture and architecture. Leslie did see a close cultural connection between Cuban and Mexico. "I think culturally it is really reminiscent of my experience in Cuba at least. I think that's why I keep going back to Mexico. Honestly, it is. I mean it’s a Cuba I could go to.” I was compelled by Leslie association of the two countries. It confirmed what I had suspected about the attraction to Mexico for many Cubans. For Leslie, Mexico was culturally more similar than other countries she had visited including Italy, "Culturally, it is very similar and I think more-I mean having been to Italy after this, I think more so.” The similarity had much more to do with the people than any other aspect of the culture "I think they are a lot more humble than the people in Italy, and Italy is like every other European country”.

Leslie was not the only participant who expressed the need to connect culturally with her homeland. Gloria is also a Cuban exile although she left her homeland when she was already in her late twenties and had lived for a few years in Venezuela before settling in the U.S. Unlike Leslie, Gloria had spent her graduate semester abroad studying in the UF program in Vicenza, Italy. Aside from expressing the desire to experience both contemporary and ancient architecture, Gloria also discussed how her discovery of small street and piazza reminded her of her hometown in Cuba. "I found myself walking and going to these little market places, or just stores to buy the cheese that we will eat at lunch, or the vegetables, whatever it was, and it was like being back in Cuba and my neighborhood.” I didn’t view her association of Cuban architecture and urban layout with the city streets of Vicenza as unreasonable. After all, Cuba was settled predominantly by 
Europeans and many of its cities display similarities to those found in Spain, France, and even Italy with its narrow streets, plazas, and colonial architecture (Constantino, 1984). Gloria was also perceptive to the sense of scale which reminded her of the towns and cities of Cuba. In comparison to the streets and shopping malls of Miami, things may appear to be smaller in the urban centers of European cities. According to Gloria, the urban center of Vicenza was small and orientated according to human scale. "For me it was a way to go back to my own culture and reconnect totally.”

Some of the students interviewed mentioned that their desire to study abroad was an attempt to seen and experience the buildings they had studies in the history, theory and design classes. Gloria, for example, viewed the study abroad as opportunity "to visit everything” and she felt that “I couldn’t miss that opportunity” even though it was a financial sacrifice. Julian also viewed the experience as an opportunity to explore. It was a chance to visit the buildings he had read and studied in the history and theory courses:

For me it was wanting to go and explore, see all these places that you've always-you know we see a lot of pictures, but it's not the same thing as being there. For me, I think the main reason to go was to really go and travel, and live there and see all of those buildings firsthand.

Julian was not alone in his sentiments. In fact, I noted in my journal that many of the participants expressed a need to experience the spaces in person. Marc was very direct and explicit about his reasons for participating in a study abroad program while at UF:

I felt that I had to go and see for myself the projects I had studied in history and theory; and that was a big draw for me. That was something that I really, really wanted to do was to go and experience those things.

Some of the participants, however, were not specific about their reasons for studying abroad. JP, for example, wanted to acquire a broad perspective, "I'd never been outside of the U.S. and I wanted something that was more than U.S. architecture, U.S. 
culture, something that was different, and not the same.” I noted in my journal that I was

a little surprised that JP hadn't been more specific about his idea because up to that point he had been rather direct in his answers often providing explicit details about his experiences. Others even mentioned that they decided to go abroad because of the social aspect of the experience. Like JP, Alistair also expressed the need to get away from his familiar surroundings, but it was also the participation of his friends that actually compelled him to apply for the University of Miami study abroad program in Rome:

I decided it was important to get away and live in a different city and really experience it. I did not want to go away for a weekend or a week but I really wanted to make it worth my while. We were 13 in our group and we were all really good friends.

Aliana also talked about her initial interest in the study abroad program because some of her friends had signed up to spend the semester abroad. "A group of my friends were interested in that program, the Grand Tour of Europe.” After she research the program and talked to her parents about traveling, Aliana realized that she could see the countries she wanted within a 6 week period, "It was definitely what I wanted.” Jaime also discussed the socials aspect of travel as one of the motivating factors leading to her decision to participate in a study abroad program.” In addition to seeing it at as a lifetime opportunity, Jaime said that he:

Wanted to get in on that experience because going by yourself you, can never duplicate that experience. The people can get you into certain buildings that you would never get into see otherwise and you're just with a community of people traveling to see the same things that you're interested in seeing.

\section{Study Abroad and Professional Development}

In as much as participants talked about how study abroad influenced aspect of their personal lives, they also discussed the experience in terms of their professional 
development. Study abroad can enhance their intellectual development, and have a direct impact on their professional development (Sandell, 2007). In the case of my study, I asked the participants to comment on ways in which the study abroad influenced aspects of their professional lives. In many instances, the participants were able to draw direct reference to their study abroad experiences and provide specific examples of ways in which their study abroad enhanced their career development. For many, the act of remembering certain urban or architectural conditions proved beneficial in their design studios and later in their work as architects. Connie, for example, talked about how she was able to make comparisons in terms of the urban sites she experienced abroad:

From an urban standpoint, I'm able to compare things to it on a daily basis. I'm like, "Oh that's like this plaza, or I feel horrible because that's what this place felt like.” You have something tangible that you can always relate to. You don't need the Internet to find things.

In her current work as an urban planner at a major design practice in Miami, Connie’s ability to relate to tangible ideas has helped her make design decisions to develop urban sites within a number of cities.

Kate also talked about the importance of her study abroad in relation to the memories it created. Having a bank of images and impressions of architecture and urban conditions has also benefited her design work. Kate has been able to reference and develop design solutions based upon her experiences of the architecture and urban spaces she visited while abroad. "It's helpful whenever you're working and you know what you kind of want because you have bank of images in your head that you can sort through and see what fits." Kate also talked about her ability to recall specific conditions because she had "been there and seen it". Although Kate was able to talk about how she was able to use these images as references for her designs, she also talked about how her decision to 
pursue a Master of Landscape Architecture was also influenced but what she had seen and experienced doing her study abroad in Vicenza. Kate became very observant of how cities were developed and functioned as she travelled from one European country to another, and she wanted to study and learn more about landscape and urban design at the graduate level.

In describing her impressions of Barcelona, for example, Kate was quick to draw reference with Miami. The experience of both cities is very different because of the manner in which people move through these urban environments and interact with one another. According to Kate, most people drive in Miami which gives the city the impression of being “desolate.” In Barcelona, however, "more people are on foot and moving around in closer proximity so it seems more alive.” When I asked Kate more specifically why she decided to study landscape architecture, she replied that she saw a strong correlation between architecture and landscape architecture. According to her, the two fields are very closely related and one can not be an effective architect without understanding the impact of design on the environment. Kate also talked about her study abroad experience had also made her want to study and explore American cities with the same intensity she had of European cities. "With my travel abroad experience, I wanted now to explore our own cities in the U.S. with the same intensity that we did over there because I feel like we overlooked it.” Although Kate had initially been critical of certain aspects of Miami in our discussions, she also recognized that American cities have much to offer. "We go over to Europe and think that everything's so wonderful there and here in the U.S. things maybe are not so great, but there are lots of great things to experience in American cities too.” Kate felt that pursuing an advanced degree in landscape 
architecture would give her an opportunity to become a more effective designer. It would also give her the chance to explore her interest in urban design and academically further what she had learned and experienced about urbanism in Europe.

Like Connie and Kate, Marc also discussed how the study abroad not only created a "bank of images," but it also allowed him to experience the architecture in a more direct and personal manner. Unlike taking a design or theory class on his home campus, Marc saw and experienced many different examples of architecture and urban spaces in various European and Asian countries during his semesters abroad. "It's like a library of experiences. As far as the experiences go, I think that it's one of the most critical parts of the study abroad.” According to Marc, experiencing architecture on a more personal level not only creates a vivid impression and memory of the structure, but it allows for a much better understanding of the intent and implication of its design. In terms of professional development, this type of experience and understanding was a very beneficial learning experience for Marc as a student and practitioner.

In fact, for Marc, there is very little personal distinction between the "idea of being a student, and the idea of being a professional.” He sees being in school and practicing architecture as different expressions of the same reality. "People think of school as one thing and a professional practice as something else, but I think it should be more of a gradient where it just takes on a different level of reality.” Unlike seeing picture of a building or reading about it in a book, the experience of architectural space was an intimate occurrence for Marc:

It's like meeting a person, in a way. If somebody shows you a picture of a person and tells you their name, and you read a little bio of them, you still don't know the person. But when you actually experience a building, it's like spending that time with that person, and then that's how you get to know somebody. 
Marc has since been able to draw heavily from his study abroad experiences to develop his design ideas as a student and practicing architect. His motivation to pursue a doctorate in architecture was also strongly influenced by study abroad experiences and his desire to teach and practice. "I want to live bad make things, and enjoy the process."

Like Kate and Marc, other participants also talked about how their decision to pursue graduate and post graduate degree in architecture was influenced by their study abroad experiences. Since a semester or year studying architecture in a foreign country can introduce students to a variety of architecture, landscape, and urban conditions, many of these students wish to continue learning about design at the graduate or post graduate level. In terms of professional development, these participants also indicated that they wish to become better designers in light of what they saw and experienced abroad. Guillermo, for example, recently enrolled in a post graduate design degree program specializing in Historical Preservation. He mentioned in a post interview that he really never really enjoyed studying architecture history on his home campus but his interest in the field grew "exponentially" while abroad. He returned to Florida International University and became a graduate teaching assistant in the architecture history courses and years after his graduation continued to have an interest in architecture history. His decision to pursue a Master of Arts in Historic Preservation was very much influenced by the initial exposure to the architecture of ancient Rome that he experienced and studied while in the FIU semester abroad in Rome. Having both a Master of Architecture and Master of Arts in Historic Preservation can offer Guillermo the opportunity to specialize within the area of historic preservation in addition to teaching design, architecture history and theory, and historical preservation in college or university. 
Jaime and Alejandro’s decision to apply to graduate school was greatly influenced by what they had learned and seen while studying abroad. Their experience also gave them the self-confidence to apply to graduate school and ultimately pursue their professional goal of becoming architects. Alex, for example, talked about how the study abroad:

Left me with the confidence that I can just go out and do whatever I like. I guess go out of the house and live by myself, and it's nice to know that you can do it. You tried it for 4 months and it seems fine. I'm looking to go back, and I'm also looking to go away for graduate school.

In looking where to apply for graduate school, Jaime and Alex talked about the importance of being in cities that offer cultural variety. Having participated in the Florida International University Genoa program, they greatly valued the cultural diversity the city offered. They also took advantage of exploring Italy and parts of Europe by extending their time abroad and travelling after the conclusion of the academic semester. In our discussions about their study abroad experiences, it became rather evident that Alex and Jaime's interest in architecture was greatly enhanced by what they saw and learned. Jaime, for example, described his semester abroad as an "eye opener" and a "must” for all design majors. Because of their exposure, both participants felt the need to apply to architecture programs in cities that would complement culturally what they had experienced abroad.

Alex and Jaime also expressed the need to enhance their educational and professional development by studying in prestigious design programs that would further what they learned during their semester abroad. Although not specific to the actual institutions, Jaime mentioned that he had an interest in "urban studies but something definitely related to design build or green design.” Both students, however, also realized 
the limitations and differences of living in the U.S. in comparison to a Europe country. As Alex mentioned, “I know there’s other places here that I would benefit, maybe not as much as bring in Europe, but still benefit from the location.” Alex even talked about wanting to return to Europe to complete his post professional degree:

Ever since I got back, I've been looking into going back to Europe to do my graduate studies. I just got back from New York yesterday, and I think that I could just learn a lot by living in one city, but I was really looking into maybe going to Paris.

Jaime also talked about applying to schools in places like Chicago, New York, and St. Louis.

Although Jaime and Alex have yet to complete their undergraduate degrees, their study abroad experience has made them consider aspects of the education and profession that they may not have considered had they stayed in Miami. The experience has also given them each a greater sense of self confidence to apply to various graduate schools and move to cities away from their homes. These decisions are not only examples of how study abroad has influenced their personal development, but are also examples of how study abroad has influenced their professional development. Deciding upon where and what to study may have a direct impact on where they will initially live, and the type of work or specialty they will engage upon graduation from graduate school.

Study abroad experiences not only helped to heighten student interest in architecture, but it also gave them an opportunity to consider professional options within the field. Because students who study abroad are exposed to variety of architectural manifestations, they may also begin to consider the profession in a completely different manner. Some of the participants expressed an interest in working for multinational organizations and having an international career. Alistair, for example, mentioned that his 
study abroad experience "opened up that idea that I can practice outside the United States. We are educated here but here are different opportunities to practice in Europe, Africa, and in South America that I want to explore.” He also talked about exploring the possibility of working for a global firm and living abroad. For Alistair, the opportunity to live on a foreign country while working as an architect would not only give him unique challenges, but it would also motivate him as a designer:

I would easily want to live abroad again and do it again. I would love to work for a firm that worked internationally, that would allow me to work in other places because it's a challenge having to work with not just the architecture but the culture. You have to integrate all of these things. It's really motivating.

Although Alistair had not found work in a foreign country at the time of our interviews, he had recently graduated and found employment with a practice in Philadelphia that specializes in urban design and low-income housing.

Because Connie had worked as an architect prior to going on a study abroad, she was able to discuss the relevance of her experience in terms of her decision to return to school. She was able to talk about her year abroad and the influence it has had on her subsequent professional development. Connie had worked for a number of architectural practices and gotten to the point where she felt "burned out" from the excessive work. She also talked about the need to reconsider her own professional aspirations, and saw the year abroad as opportunity to explore some professional options. Of all the participants that I interviewed, I felt that Connie was the most direct about her reasons for studying abroad, and was able to provide the most in depth examples of how her study abroad influenced and impacted her professional development. Although not the oldest participant of this study, Connie had probably worked the longest as architect. Her experience as an architect was also quiet varied as she had been employed in a variety of 
practices and had worked both in the private and public sectors. I also discovered that Connie had a particular interest in my study and was quite willing to talk on more personal issues as they related to the variety of topics that I addressed in our interviews.

Connie’s decision to apply to Syracuse's yearlong study abroad in Florence was based on a need for change and she alluded to the fact that she had become somewhat disenchanted with the profession. In terms of study abroad, Connie talked about how the experience "refreshed and restored me, and I needed that. I mean after being in academics for 5 years and really being bogged down with it, and then being in the practicing field for 5 years and being bogged down with it.” Connie continued and explained how the experience was a "very, very refreshing to start, looking at design again, and being exposed to all of these things I had never experienced before.” Even while studying abroad, Connie also came to realization that “there's so much out there that I haven't explored very carefully.” Having graduated from a professional program and worked as an architect prior to her study abroad, Connie was probably more acutely aware of her environment and things she wished to investigate than an undergraduate.

Connie's study abroad not only gave her an opportunity to pursue a post professional qualification, but it also gave her the chance to question what she sought in terms of personal and professional fulfillment. Although Connie had received financial sponsorship from her employer to participate in the yearlong study abroad in Florence, she soon realized that her priorities had changed upon her return to the U.S. When I asked Connie to comment about her study abroad has influenced aspects of her professional development, Connie mentioned that she decided to leave the firm that had initially supported her study abroad. After working for a year, Connie decided to work for a 
developer for higher pay and greater level of responsibility. Since the initial agreement with her employer was that she would work for 2 years as a means of compensating for the costs of the study abroad, Connie only worked for a year and paid back half of the tuition costs to her former employer.

The study abroad program had instilled the necessary self confidence in Connie for her to seek employment that was well compensated and required a much greater level of responsibility. Connie was rather frank that her initial motivation to change companies was for the "money." She not only saw the chance to work for a developer as an opportunity to make more money, but she was offered more in terms of responsibility. Connie also made another important realization in terms of her professional development that influenced her decision to work for a developer. Connie not only wanted the added responsibility but she also talked about wanting to make the "important decisions" regarding how her projects were designed and developed. Connie felt limited working in a traditional design practice where the client, and not the architect, "calls the shots.” By working for a developer, she would in essence be working as the owner, and would have the necessary influence to decide how the buildings were designed and built:

I wanted to get involved on the owner side where you are making the decisions. The decisions that really affect where and how I am going to build this structure. I guess I just realized that I wanted to have more responsibility for lack of a better word.

Connie also came to the realization that her own personal strengths were not as a design architect. When she returned from her study abroad, Connie really didn’t want to continue working as she had prior to her departure:

And so when I came back, I was thinking that I'm not a design architect. The study abroad experience helped me realize that. I mean not that I didn't really know that before, but I knew that my strengths were not as a design architect. 
That's not where I'm going to blossom so I am not going to try to get with an architecture firm.

Connie’s study abroad experience had made her personally introspective about her professional ambitions as she came to the important realization that she would not "blossom” as a design architect working in a traditional architectural firm. The study abroad had also given her the self-confidence to make decisions about her own professional development, and the necessary motivation to make a career change.

\section{Chapter Summary}

In this chapter, I have discussed the relevance and importance of international travel and study abroad on the personal and professional development of architecture students by exploring the following research questions: (a) How have international travel and study abroad shaped the students' educational experience? (b) How have international travel and study abroad complemented the architecture curricula? (c) How have international study and travel experiences enhanced student understanding and awareness of global architecture? (d) How have international travel and study abroad influenced the personal and professional development of the students? In the following chapter, the implications of study abroad and international travel are discussed as they relate to the research questions and conclusions are also drawn about the findings of this study. 


\section{Chapter VI}

\section{DISCUSSION AND RECOMENDATIONS}

International travel and study abroad experiences have important implications in the study of architecture. This study focused on how architecture students benefited from the exposure to foreign cultures through study and travel abroad programs. I interviewed students who were enrolled in the graduate and undergraduate architecture design programs at the University of Miami and Florida International University. I also interviewed alumni from these institutions and from the University of Florida and Syracuse University to assess how study and travel abroad experiences had complemented their education, and influenced their understanding of and appreciation for architecture. The participants of this study were also questioned about the influence of these experiences on their professional and personal development.

In this chapter, I discuss the implications and make conclusions about the findings of this study. I begin the chapter with a review of the research project and answer the study related questions individually. The limitations of the study are addressed and conclusions are also drawn about the benefits of study abroad programs on the personal and professional development of the architects and architecture students that I interviewed.

\section{Review of the Study}

This research project study shed light upon an unexplored, yet important aspect of the architecture curriculum, and provided insight into the benefits of international study and travel. This study was an empirical investigation, and reflected the perspectives and views of students and practitioners. It was not limited to a theoretical understanding of 
the benefits of study abroad programs. This study also addressed another serious shortcoming in the literature about the architecture curriculum because the findings were based on student responses. The current literature on architecture is predominantly theoretical, and taken from the perspective of academics and practitioners (Bachmann \& Bachmann, 2006). Because this study was based in part on narrative interviews, the participants were encouraged to engage in open conversation about their study abroad and relate stories about their experiences living and travelling overseas. They were also encouraged to talk about what they learned in terms of architecture and urban design during their study abroad.

This study used a qualitative research mode to investigate how travel and study abroad influenced student learning about and appreciation for architecture, and how it enhanced their personal and professional development. A qualitative investigation lent itself to this study because the process of qualitative research is very similar to the process of travel (Kvale, 1996). In a qualitative study, for example, the researcher embarks upon a metaphorical journey when interviewing the subjects. These interviews eventually develop into the stories or narratives of their experiences. Kvale (1996) draws this analogy of the interviewer as a traveler, and writes that the interviewer/traveler metaphorically wanders into foreign environments and locations while engaging people through conversation, which is the basis of the research process. In addition to interview generated personal experiences, introspection, and life stories, Denzin and Lincoln (2003) suggest that qualitative researchers may employ artifacts and visual texts—-to describe and study, and develop an understanding of the routines and experiences in individuals' lives. Life stories, personal experiences, and sketch journals (artifacts), design projects 
and analytical drawings of buildings (visual texts) were used in the study to better understand how study abroad influences student learning and appreciation for architecture, and how it enhanced the students' personal and professional development.

The interview process was important to develop an understanding of how travel and study abroad can complement the architecture curriculum, influence students' understanding and appreciation for architecture, and enhance their personal and professional development. As part of this study, I interviewed 15 individuals who had participated in architecture related study abroad programs at the University of Miami, Florida International University, the University of Florida, and Syracuse University. This sample included professional architects and students who were enrolled in the graduate and undergraduate design programs at the University of Miami and Florida International University.

Although there are many different types of interviews, I used a narrative interview that centered on the stories the subjects tell, and on the plots and structures of their accounts (Kvale \& Brinkmann, 2009). I also used open-ended questions to develop an understanding of how each participant benefited from the experience of travel and study abroad, and how it influenced his or her learning about architecture. Each interview lasted approximately 60 to 90 minutes, and was electronically recorded for analysis. During the first interview, I asked 5 of the participants to voluntarily submit examples of their sketches, analytical drawings, photography, and studio design work as digital files. These artifacts and visual texts were used to analyze what the participants experienced and learned in terms of architecture and urban design during their study abroad. I also conducted a second interview with these individuals to check and verify that the 
transcripts of the first interview were accurate, and to provide feedback concerning my preliminary analysis of data from their first interview, artifacts, and visual texts.

Once the participants' interviews were conducted, I analyzed the data within an experiential learning conceptual framework to determine the general meaning of the experiences, and the specific relationships found in the descriptions. An understanding of these relationships, however, could only occur through an effective analysis that included working with the transcripts, organizing and synthesizing the information, searching for patterns, categorizing responses, and determining what was important, and what was to be learned from the interviews (Bogdan \& Biklen, 2006; Seidman, 2006). During the course of the interview, I actively analyzed the data by interpreting and condensing the responses of the participants, and asking them if my understanding of their responses was accurate. I also maintained a research journal to document any observations, questions, or information relevant to the interviews.

The analysis continued based on data collected in a second interview with 5 participants. After I had the opportunity to analyze the transcripts, I engaged in member checks and met with the participants to validate my understanding of the data. This gave the participants the chance to comment on my interpretation of the data, and allowed them to elaborate upon their original statements (Kvale \& Brinkmann, 2009). The second interview also gave me an opportunity to address any questions about the participants’ creative work taken from their design studios and sketch journals. Sketches for example, provided important information about what students found to be important during their travels and studies abroad (Bogdan \& Biklen, 2006). The studio design projects also illustrated and provided examples of what each student learned in terms of architecture 
and design while studying abroad. I analyzed how their cultural understanding and observation of site specific conditions were integrated into their design projects

In addition to member checks, I also developed an audit trail by maintaining a sense of transparency in terms of how I conducted the interviews and analyze the data. I documented the length and the site and location of each interview. I maintained accurate transcripts of the interviews and maintained digital images of the participants' creative work for analysis. I also asked a competent and disinterested auditor to verify the dependability and confirmability of my study (Lincoln \& Guba, 1986).

\section{Discussion of Primary Research Questions}

The influence of study and travel abroad on the study of architecture has significant implications. The proposed study analyzed ways in which undergraduate and graduate students benefited from these experiences. Taken from the perspective of professional architects and students who are currently enrolled in the undergraduate and graduate architecture design programs of institutions identified above, this investigation addressed a number of questions about how study abroad and travel enhanced awareness and understanding of architecture and complemented the architecture curriculum. It also addressed a more personal aspect of travel; how the experience and exposure of foreign cultures influenced the personal and professional development of the participants. This

development included a changed perception or appreciation of specific foreign cultures. It also included a greater appreciation of and understanding about architecture.

This study addressed the implications of travel and study abroad experiences by investigating the following questions: 
1. How have travel and study abroad shaped the educational experiences of those who are studying or have studied architecture?

2. How have travel and study abroad complemented the architecture curricula?

3. How have travel and study abroad experiences enhanced the understanding and appreciation of architecture of those who are studying or have studied architecture?

4. How have travel and study abroad influenced the personal and professional development of those who are studying or have studied architecture?

These questions were answered from the participants' points of view. These questions also made travel and study abroad central to an understanding of their experiences and of the architecture education.

\section{Primary Research Question \#1}

It was quite clear from the interviews that travel and study abroad was a positive influence on the participants' educational experiences. This notion is generally supported in some of the literature about study abroad programs (Jones, 2001). Study abroad programs also provide students with experiential learning opportunities that helped to broaden their understanding about global architecture and foreign cultures (Montrose, 2002). Living and studying abroad was a challenging and rewarding experience because it forced the participants to assimilate with foreign cultures as they attempted to live and function within their new surroundings. In terms of the experiential learning cycle (Kolb, 1984), the participants not only talked about the courses and design projects they were assigned as examples of the concrete experiences, but they also reflected on what they had learned as part of the study abroad. The study abroad afforded these students the 
opportunity to explore new ideas and possibilities in terms of their creative expressions that they would have probably otherwise not attempted on their home campuses. The limitations of not being able to buy the needed supplies for architectural models, for example, soon became creative challenges and opportunities to express design related ideas using other methods and materials. One student learned how to develop origami like models because she did not have the tools to create traditional architectural models. What developed because of the apparent lack of materials was an exploration of the implications of folded planes as they apply to architectural design.

As an experiential learning experience, study abroad not only opened the possibilities of creative and professional expression, but it also enhanced their learning about architecture. For many, this was also the most important aspect of their education as architects because it heightened their interest in architecture. These individuals talked about how they had the opportunity to experience contemporary and ancient buildings that they had learned about in their history and design classes on their home campuses. In the course of interviewing these participants, I sensed excitement in their voices as they began to describe some of the structures that they had encountered as part of their sojourn. They seemed eager to share their impressions and memories of these buildings with me. Not only were these students exposed to a great variety of architectural expressions, but they also had the opportunity to live in urban environments that were in part shaped and defined by the very buildings that they had read about in their architecture courses. As they functioned within these cities, many of the participants talked about how they explored and discovered hidden aspects of their urban environments. The excitement of discovering something new or different in their host 
nations was a positive factor fueling their interest in and curiosity about architecture and the urban landscape. One of the participants even stated this type of experience and learning opportunities would not have been possible had he remained on his home campus.

Not only was their interest in architecture heightened because of the experiential learning, some of the participants even talked about how they became interested in related fields such as art, urban design, and interior design. Sitting in urban settings and sketching buildings, for example, made one of the participants interested in exploring his talents as an artist. It also gave him the unique opportunity to analyze and study the architectural and spatial features of the buildings and its site that he would have otherwise overlooked had he just taken a picture or walked past the building. In fact, his observations of the decay of ancient Roman buildings also gave him the idea to develop a thesis proposal based on the idea of using discarded shipping containers to develop architecturally relevant spaces.

Some of the participants talked rather openly about the sense of freedom that they experienced while on their semester abroad. This is an aspect of experiential learning that cannot be duplicated in the classroom environment. Although these academic programs have a defined structure, the participants used the time in-between the travel excursions and classroom sessions to explore their environments and host nations. This sense of freedom was rather instrumental in helping some of the participants to develop a greater sense of self-confidence. In this sense, the study abroad had a transformative influence on the individual's learning process. Several talked about how they became more self-assured by taking the opportunity to travel on their own to other cities and 
countries. The freedom of public transportation was another factor that liberated these students from the constraints of automobiles, traffic, and unwarranted expenses to move about cities and travel to other countries rather affordably and easily. This experience would have probably not been possible if these individuals had stayed at home and continued to rely on their automobiles as they primary means of transportation.

Other participants discussed how their study abroad experiences influenced their decisions to continue their education at the graduate level and post graduate levels. Some were continuing their studies in architecture at the masters and doctoral levels because they wanted to expand upon what they had learned and experienced abroad. Others were even considering continuing their education in business administration, interior design, and historic preservation because they had been exposed to specific conditions and had developed ideas as to what they wanted to accomplish professionally because of the study abroad experience. Several even expressed the intent to return to Europe or move to large American cities to pursue graduate studies in order to live in culturally stimulating environments. In many respects, the intent to pursue further education is an example of how study abroad experiences complete the Kolb’s (1984) learning cycle model. The participants desire to acquire greater understanding or more knowledge about a given field indicates that the individual has engaged in every aspects of the experiential learning cycle and is ready to embark upon a new cycle of learning.

\section{Primary Research Question \#2}

In terms of the second research question, it was also quite evident that study abroad complemented the architecture curriculum in a number of important ways. This notion is supported in Jones (2001) work pertaining to the positive effects of travel and 
study abroad for architecture students. As a form of experiential learning, study abroad gave the participants of this study the unique opportunity to see and inhabit the spaces that they had read and learned about in their architecture courses. Because of this direct exposure to the architecture and urban sites, these students were able to get a much better sense of the scale and materiality of the buildings that they visited. They were also able to gain a greater appreciation for and understanding about the significance of architecture and design.

The participants were all rather emphatic in expressing the importance of the lived experience in helping them to gain greater knowledge and understanding about architecture. For many, the lived experience helped them learn more about architecture than in the classroom environment. The participants also talked about the limitations of trying to grasp architecture in terms of verbal descriptions, pictures, or analytical diagrams. They all understood that the experience of a building transcends any observation of its physical attributes. As a phenomenon, architecture includes a host of intangible notions such as feelings, atmosphere, and spirit that gives life to the building and its spaces (Norberg-Schulz, 1976). Students were able to experience these conditions by actually walking through the spaces and studying the buildings in relation to their physical locations and cultural contexts.

Study abroad also complements the architecture curricula because of the memories students have of the buildings and places that they visited. This was probably one of the most fundamental aspects of experiential learning. The participants not only had the opportunity to reflect upon their observations and experiences of the architecture and urban conditions, but many of the participants also discussed the importance of being 
able to reference specific examples to use in their creative work as students and professionals. They felt that they had a much better understanding of architecture because they were able to better articulate their ideas based on what they had seen and remembered. Notions of scale and order, for example, became much clearer when these individuals were able to talk about these concepts in terms of specific buildings that they had experienced. One participant even talked about using urban sites that she had visited during her study abroad as examples of design ideas and proposals in her current work as an architect and urban designer. In fact, she also talked about knowing what worked and what did not in terms of urban spatial planning based upon what she seen and experienced of cities in Mexico.

Study abroad programs also complement the curricula because they help to broaden student understanding about global architecture. Students realize that there is a great diversity of architectural expression globally because they are able to experience the architecture directly. They also realize that there are many different ways to develop buildings and urban spaces. These differences are often shaped by cultural influences and this notion becomes much more evident when travelling abroad (King, 2006). Study abroad programs also provide students with the unique opportunity to learn more about global architecture through their interactions with other students and architects from different countries. Design charrettes and exchange opportunities are just some examples of experiential learning opportunities that allow students to interact with local nationals to learn about design practices and architecture from their host nations. This interaction with people from different countries also greatly increases student multicultural 
understanding and global awareness (Van Reken \& Rushmore, 2009) which would have otherwise not been possible or rather limited in a traditional classroom.

\section{Primary Research Question \#3}

With regards to the third research question, all of the participants of this study commented about the positive effects of studying abroad on their understanding and appreciation of architecture. They gained a greater appreciation and understanding about architecture because they were able to experience the buildings and urban sites in a manner not possible in a traditional classroom environment. Based upon the interviews, I noticed that the participants had developed a clear understanding of important elements that define and constitute architecture and urban conditions. This was most evident when I asked them to describe architectural or urban conditions that they had encountered as part of their study abroad experience. It was also quite evident in the images and renderings that some of the participants shared with me illustrating their design projects, sketches, and analytical diagrams of buildings and urban spaces. In terms of experiential learning, some of these students were able to reflect upon their experiences through their design projects, photographs, and sketches.

I also noticed that the narrated segments that related to this research question were much lengthier than the narrated segments that related to the other research questions. The participants of this study were very descriptive in giving me accounts or examples of how they began to have a greater appreciation for architecture based upon their experiences of specific buildings and urban conditions. The Pantheon in Rome was often cited as an example of a building that transcended any literal or graphic representation given in a history lecture or textbook. Several students told me that they could only have 
appreciated the monumentality of this structure by being present in and around the structure. Another participant walked me through a contemporary Mexican structure verbally illustrating the sequence of enclosed and open spaces that define the house. Her experience of this building was revealing in the sense that she really began to understand the subtleties that transformed a series of spaces into a work of architecture.

The participants were also quite perceptive of their urban environments because they were forced to engage the cities as pedestrians. For many, this was the first time that they had spent any considerable amount of time walking in cities. They began to understand the city in term of its paths, public spaces, and districts. This type of experience was fundamental to the study abroad because of the location of these programs in urban centers. Students were not only required to walk or take public transportation from the classrooms to their residences, they were also required to sketch and learn about the ancient and contemporary buildings of their host cities. One of the participants talked at considerable length of how she engaged the residents and the traffic of Florence on her daily walks to and from the school. Having an awareness of what the sidewalk offered in terms of an urban experience, for example, was a strong indication of her awareness of some of the factors that influence the development of architecture and urban design. This awareness reinforces the positive aspects of experiential learning that study abroad programs can offer students.

I analyzed some of the participants' sketches to gain a better understanding of how they observed and documented their physical environments. These images are examples of experiential learning in that they document observations and in some cases reveal what the individual learned about the structure in terms of its spatial composition 
and organization. I also noticed that the sketches revealed many factors that captured the students' interest about architecture and the buildings that they were studying. In some cases, the sketches also began to illustrate relationships between individual buildings. In others, they revealed the interaction of people with urban spaces. Some of the participants also provided examples of analytical diagrams which revealed an understanding and appreciation of the buildings in terms of their composition and organization in design. Because students were often required to visit buildings and sites and graphically document their experiences, the study abroad programs gave these individuals the opportunity to engage with architecture and urban conditions on a much more intimate level than otherwise possible in a traditional classroom environment. Sketching or documenting a building was a means through which these students could begin to show their appreciation for and understanding about architecture.

\section{Primary Research Question \#4}

With regards to the fourth research question, study abroad experiences displayed the most significant example of experiential learning. This idea is also supported in some of the current literature about the positive effects of travel and experiential learning (Mouton, 2001; Montrose 2002; Van Reken \& Rushmore, 2009) The participants of this study talked about the transformative aspect of their study abroad experiences and how it positively influenced their personal and professional development. Many of the students learned to become more independent and self-reliant because of their study abroad experiences. They also displayed a sense of global awareness and were interested in the culture of their host nations. In some cases, these same students returned home mature and more determined to complete their academic degrees in architecture. In fact, several 
talked about how their decisions to continue their education at the graduate level were influenced by their study abroad experiences.

It was also very evident that study abroad had a positive influence on the participants” personal growth. Many revealed that they not only learned more about themselves but their sojourn abroad was a liberating experience. They had the opportunity to freely explore their surroundings without having to worry about the responsibilities of living and studying on their home campuses. I believe that this freed their minds to explore ideas and possibilities in a manner not possible had they remained on their home campuses. The freedom to travel from one country to another was a very empowering experience. Living in the U.S., most people do not consider the option of travelling abroad because of the financial and time constraints. Living in Europe, however, students took the opportunity to travel to other countries because it was easy and didn't require as much time. They had the option to explore other countries which furthered their curiosity about other cultures and their architecture and urban expressions.

Some of the participants also talked about assimilating or incorporating aspects of what they experienced abroad into their daily lives in the U.S. This was a strong indication that these students became tolerant and acceptant of other ways of living and thinking. It was also a strong indication that they had engaged in Kolb’s (1984) experiential learning cycle by testing what they had begun to change their thinking and apply these changes in new circumstances (Montrose, 2002). Some of the students, for example, enjoyed the laid back lifestyle of the Italians and many missed the conveniences of public transportation. Several talked about wanting to move to urban centers where they could enjoy a vibrant multi-cultural experience and be able to walk from their homes 
to their work or schools. Some of the participants also talked about moving back to Europe to work or study. In fact, these same students appeared to experience a reversal cultural shock upon returning to the U.S. What they might have initially missed as American conveniences of larger refrigerators, washing machines and TV were soon dispelled as they began to live like Italians.

For some, there was also a personal shift in terms of what they valued the most that developed because of the study abroad. One participant talked about she began to place greater value of her daily routines and the interactions with her friends. She began to live in the moment and was less concerned with any past or future occurrence. One participant saw the opportunity of living in Italy as a chance to connect culturally with her heritage and create a greater sense of personal identity. Others participated in study abroad as a means of recovering aspects of their own culture while living in Mexico and Italy. Having left Cuba, these individuals were looking for a means of reconnecting with their childhood memories of their homeland.

Study abroad experiences also had positive influence in terms of professional development because of the experiential learning that the participants experienced. Students were readily able to provide example of ways in which their study abroad experience enhanced their professional development. For many, the act of remembering urban or architectural conditions proved beneficial in their creative work as architects and urban designers (Jones, 2001). The study abroad also allowed the participants to experience architecture in a more direct and personal manner. They felt that because of this experience, they were able to become better designers. Their interest in the field also expanded because of their study abroad. One participant talked about wanting to get 
involved in historical preservation and another became increasingly interested in interior design because of what she had seen in terms of interiors while studying abroad.

It was also interesting to note that many of the participants talked about continuing their education because of their study abroad experiences. I interviewed several participants who were applying to graduate programs in architecture, landscape architecture and historical preservation. These participants talked about the need to continue their educational experiences based upon what they had learned and seen while abroad. The study abroad experiences had fueled their interest in architecture and design and they wanted to learn more.

In terms of the actual discussions with the participants, I noticed that individuals who had participated in the study abroad programs ten or more years earlier shared more information about the transformative aspects of the experience than those who had recently returned from their sojourns. In fact, these participants were very eager to be part of the study because they felt that their study abroad experiences had transformed aspects of their personal and professional lives. Some of these transformative qualities didn’t even become personally evident until years later. In some cases, it took time for the actual experiences to positively influence aspects of the participants' personal and professional developments. Some of the participants related that some of their professional and personal decisions were influenced by their study abroad experiences. Lifestyle changes were based on these experiences as were decisions to change jobs or careers. Study abroad experiences offer a great variety of experiential learning opportunities. The outcomes of these experiences are multi-dimensional and tend to live and grow within the professional and personal lives of the participants. 
It was also evident form the interviews that the semester and yearlong study abroad programs provided greater opportunities for personal and professional growth and transformation. The opportunities for experiential learning were also more pronounced in the longer study abroad programs that the shorter ones. In the longer programs, the participants had the opportunity to meet local nationals and begin to assimilate into their host nations. The interaction with local nationals and the development of daily routines of walking to class or enjoying an afternoon break in a café were important learning experiences that were not possible in the short term travel programs. Students tend to act like tourists in the shorter travel programs because they have limited time to explore the countries that they are visiting. In the longer programs, the students are able to explore and make contacts with the local nationals. These students are also able to learn what it is like to be an Italian because they are more formally immersed in the Italian culture if they are living and studying in Rome.

\section{Limitations}

There were some limitations associated with this study. Probably the most fundamental dealt with the participants of this study. Because individuals were selected to interview from 4 institutions, the results of this study may not entirely represent the sentiments of other architecture students in the U.S. who have participated in study abroad programs. My intent, however, was to address the issue of study abroad experience from the perspective of the participants to gain a better understanding of how the experience of living and studying abroad had influenced their professional and personal development (Bogdan \& Biklen, 2006). 
The issue of biases was another limitation with my study. Because I had participated in a number of study abroad experiences as an undergraduate and graduate student, I was aware that my attitude towards the subject was generally positive. I had greatly profited from the experiences and I have encouraged many students to take advantage of study abroad experiences. Rather than lead the conversation or address the questions from a generally positive or supportive standpoint, I tried to be as objective as possible during the course of the interviews. I did not talk about my study abroad experiences to any of the participants, nor did I verbally agree or disagree with their statements during the course of the interviews. I maintained field notes during the interviews to review any reactions that I might have had regarding what the participants were sharing with me. As a researcher, my primary intent was to gather knowledge and not pass judgments (Bogdan \& Biklen, 2006). I developed open-ended questions that would allow the participants the opportunity to create narratives about their study abroad experiences. I felt that I could limit my biases if the participants had the freedom to talk openly about the study abroad experiences.

A third limitation of my study had to do with my own presence conducting the interviews. In some cases, I had been a professor to some of the participants. In other cases, I had worked with some of the individuals. As a professor of architecture, I was also aware that my position and status may have had some effect on how the participants behaved towards me and even answered the questions. Bogdan and Biklen (2006), recommend trying to interact with the participants in a normal and unobtrusive manner. I also tried to approach each participant from a professional if not collegial perspective. I did not refer to myself as a professor but as a doctoral student conducting research on the 
influence of study abroad experiences of the personal and profession lives of architecture students. I felt that this approach would mitigate the possibility of placing me into an authoritative role. In particular, I wanted those participants who were currently studying architecture or who had recently graduated to a view me as a fellow student or researcher. When some of the participants shared their studio work as part of the interviews, I was careful not to offer any formal or informal critique of their design projects. I did, however, complement them on their creativity and thanked them for their willingness to show me their sketches and design work.

\section{Recommendations for Practice and Policy}

The results of my study reveal the positive effects of study abroad on the personal and professional lives of the participants that I interviewed. As such, I feel that many architecture students should be required to spend at least a semester abroad preferably during their junior year. The opportunities for learning and personal growth are far too great to ignore. Making study abroad mandatory, however, will change the architecture curricula and the manner in which architecture is taught. This recommendation, however, may ultimately lead to resistance on the part of some administrators, faculty, and even students for a variety of reasons.

Although all the participants of my study highly recommended the study abroad experience, some students may be reluctant to participate because of the expenses incurred. Study abroad programs are not cheap and are usually more expensive than regular tuition and board at the home campuses. I believe, however, that if students are made aware of the benefits of spending a semester or year abroad, they will show willingness to participate even though they may have to take on additional loans for the 
experience. Without having actually participated in a study abroad it is difficult to understand the benefits of the experience. Letting students know of the benefits and allowing them to interact with students who have recently returned from study abroad programs will have a positive effect.

In terms of helping students pay for the study abroad programs, administrators can develop methods to help the students save and pay for their semester abroad programs. For the first 3 years of their education, students may be encouraged to save money or pay a surcharge on their tuition as a means financing their semester abroad. A portion of a design program's endowment may also be used to help finance study abroad opportunities. Some study abroad programs are cheaper than others depending upon their location. By offering a variety of options, students may also be able to choose the program that corresponds best to their interest and financial constraints.

Helping students financially with study abroad programs may also have a positive impact on retention and enhance student affinity with the institution. Although I did not find any study or literature supporting these claims, architecture design programs may argue for increased institutional funding for their study abroad programs as a means of recruiting and retaining students. If architecture graduates of design programs had positive experiences of their study abroad programs, their willingness to support alumni financial campaigns may also have positive implications.

Administrators and faculty can also be very instrumental in facilitating study abroad programs and making it mandatory for all students to participate. Study abroad should be part of the academic culture of the architecture program and administrators and faculty need to actively promote the experience from the time that students enter as 
freshmen. Since most study abroad opportunities are offered in the third and even fourth years of undergraduate studies, there is ample time to make the case for the experience. Those organizing the study abroad programs ought to make the overall experience positive for the students. They must be vigilant of complaints and should conduct return interviews of the students to learn what they liked and disliked about the programs. The organizers must also be willing to make necessary changes to the programs should there exist any major problems or issues.

Faculty need to be convinced of the benefits of study abroad programs in order for them to encourage student participation. To help motivate the faculty, I highly recommend that architecture professors be given the opportunity to teach or lead design studios abroad on a rotational basis. The length of time that they would be required to spend abroad could vary depending upon their personal constraints, but teaching in a study abroad program should be part of their job description and responsibilities. I also believe that administrators need to be actively involved in the semester abroad programs by travelling abroad to insure that the programs are being managed and conducted to adequate standards. Administrators are ultimately responsible for the success or failure of the study abroad programs and they need to be held accountable.

Administrators and even faculty should develop an option of overseas study opportunities. Students ought to be given the opportunity to study architecture globally. I do not think it enough to have just one program centered in Europe or hosted in Italy. Architecture design programs need to offer study and travel abroad opportunities in Asia, the African continent, and Latin America to help broaden student understanding and appreciation of global architecture and world cultures. The types and lengths of the study 
abroad opportunities can also vary and do not necessary need to be semester based. I would, however, recommend that students participate in at least one semester based study abroad program. The shorter travel programs do not give the students enough time to benefit from the advantages of a lengthier sojourn in a foreign country.

The architecture curricula will have to be restructured if study abroad programs are made mandatory. Design programs will become much more globally focused and additional courses may need to be offered to support this trend. Students may, for example, be required to take some language courses to help them better communicate with their host nationals. These additional courses may have an impact on adding additional credits to an already lengthy curriculum. Making it mandatory for all students to study abroad presupposes that they do not have any family constraints, are healthy and able to travel, and have some financial support for the semester abroad. If students are unable to participate, design programs will need to offer alternative solutions and allow those individuals to continue in the sequence of design related courses.

Some faculty and administrators may resist this restructuring because of the change and work that it will require making study abroad programs mandatory. I believe, however, that these pockets of resistance may be limited and over time a general census of all faculty and administrators will develop in agreement to the benefits of study abroad for architecture students. In fact, the study abroad may transcend the notion of an academic opportunity and become a rite of passage like the Grand Tour of the 18th and 19th centuries was for aspiring artists and architects.

In terms of the traditional Eurocentric traditional of the Grand Tour, architecture programs should consider expanding study abroad opportunities to include possible third 
world and developing countries (Jones, 2001). As a general observation, there tends to be an over preponderance of study abroad programs in Europe and more specifically in Italy. This illustrates an implicit and even explicit bias towards Italy as the center for the study and experience of international architecture. Although some architecture history textbooks focus much of their attention on the historical development of western architecture in the area of the modern nation state of Italy (Trachtenberg \& Hyman, 2002), others are beginning to offer a more global perspective to the historical and cultural development of architecture (Fazio, Moffett, \& Wodehouse, 2009). This shift in offering a more enhanced global perspective to the study of architecture should begin to encourage design programs to develop study abroad and student exchange programs in Latin America, Asia, and even the African continent. I believe that students can gain as much about studying a Roman temple as they can about experiencing a Chinese or Japanese pagoda.

\section{Recommendations for Research}

The findings of my study suggest some areas of research. I would recommend a study that analyses the impact of study abroad programs by first interviewing the participants prior to their department and then upon their arrival. By conducting sets of interview before and after the experience, the researcher can gain a better understanding of how the study abroad experience influenced specific areas of the participants' lives. It might also give the researcher the opportunity to see how the study abroad changed the participants based on their prior interview. It might be easier to conclude, for example, that students returned more mature and self-assured from the study abroad experience if 
the interview prior to the departure revealed a sense of immaturity or insecurity on the part of these individuals.

Interviewing participants prior to their departure and after their arrival might also give the researcher an opportunity to examine how the individuals’ perceptions and expectations of their host nations might have changed because of the study abroad. A change in perception may also be an indication of the students' cultural and racial tolerance, and interest in world affairs. It would also be interesting to learn about the participants' own expectations of the semester abroad prior to the department, and then to inquire if those expectations were met or even exceeded in an interview post arrival.

Although I interviewed men and women who were representative of different ethnic groups, the focus of my study was not to compare and contrast their responses based upon their specific backgrounds. I do believe, however, that various studies can be conducted to analyze how men and women experience study abroad programs. This type of study may also be expanded to include responses from individuals from different ethnic and racial groups. One may also look at interviewing students from different socio/economic backgrounds to understand if and how study abroad experiences vary from one representative group of people to another.

Another area of research is the comparison between short and long-term study abroad programs and how they influence student understanding about architecture. Although I would hypothesize that the longer the program the more opportunities for learning and growth, short-term study programs are the less expensive alternative to the semester or yearlong study abroad programs. If students are reluctant to incur added expenses and debt to spend an entire semester abroad, they may opt for the travel 
programs and visit a number of countries in the matter of a few weeks. Since short-term programs may be increasingly popular alternatives, it would be important to learn the degree to which these programs have enhanced student learning and understanding about architecture.

\section{Summary and Final Thoughts}

This study revealed that international travel and study abroad experiences have important implications in the study of architecture. I interviewed architecture students and graduates of architecture programs from a variety of institutions to better understand how their study abroad experiences enhanced their understanding about architecture and influenced aspects of their personal and professional development. I learned that the experience of living and studying abroad was personally transformative and it did enhance their understanding and appreciation of architecture. These individuals were able to show how they benefited from the experiences in their personal and professional development as architects.

From a personal perspective, this study also brought back many memories of my travels and study abroad experiences. In fact, my reasons for conducting this type of study was to better understand if other students had shared similar experiences and transformative changes in their own lives because of study abroad opportunities. Study abroad does have very important implications for the study of architecture. In as much as students will gain a much better exposure to global architecture, it will also inspire them think of themselves as global citizens. They will have greater interest about foreign cultures and people from around the world and hopefully display greater tolerance and empathy towards minorities and people from different racial and ethnic backgrounds. I 
also personally believe that people who are tolerant towards others are also better able to bring about some pace and harmony into this world through their own creativity and design work. 


\section{REFERENCES}

Ando, T. (1991). Tadao Ando. New York, NY: Museum of Modern Art.

Angulo, S. (2008). Identity change in students who study abroad. (Unpublished doctoral dissertation.) The University of Texas, Austin.

Anthony, K. (2003). Reflections on designing for diversity. In L. Kiisk (Ed.), 20 on 20/20 vision (pp. 33-38). Boston, MA: Boston Society of Architects.

Bachman, L., \& Bachman, C. (2006). Student perceptions of academic workload in architectural education. Journal of Architectural and Planning Research, 23(4), 271-304.

Bogdan, R., \& Biklen, S. (2006). Qualitative research for education: An introduction to theories and methods (5th ed.). Boston, MA: Allyn and Bacon.

Borrego, M., Douglas, E., \& Amelink, C. (2009). Quantitative, qualitative, and mixed research methods in engineering education. Journal of Engineering Education, 98(1), 53-66.

Brady, S. (1999). Using a travelogue to learn a region. Journal of Geography, 98(2), 7978.

Brawne, M. (2003). Architectural thought: The design process and the expectant eye. Boston, MA: Architectural Press.

Bryman, A., \& Burgess, R. (Eds.). (1994). Analyzing qualitative data. London: Routledge.

Callihan, D. (2009). A case for student travel. The Delta Kappa Gamma Bulletin, 75(3), 27-29.

Carsello, C., \& Creaser, J. (1976). How college students change during study abroad. College Student Journal, 10, 276-278.

Chang, M., Denson, N., Sáenz, V., \& Misa, K. (2006). The educational benefits of sustaining cross-racial interaction among undergraduates. The Journal of Higher Education, 77(3), 430-455.

Chickering, A. (1971). Education and identity. San Francisco, CA: Jossey-Bass.

Ching, F. (1998). Architecture: Form, space, and order. New York, NY: John Wiley \& Sons. 
Christofi, V. (2003). Returning home and leaving again: A phenomenological investigation of a sojourner's experience. (Unpublished doctoral dissertation). The University of Tennessee, Knoxville.

Constantino, G. (1984). Cuba. Milan, Italy: Jaca Book.

Dahir, M. (1995).Why architecture still fails to attract minorities. Architectural Record, 7, 32-33.

De Marrais, K. (Ed.). (1998). Qualitative research reflections: Inside stories. Mahwah, NJ: Lawrence Erlbaum Associates.

Dekaney, E. (2008). Students’ pre-departure expectations and post-sojourn observations in a short-term international program abroad on the culture, music, and art of Brazil. International Education, 37(2), 17-29.

Denzin, N., \& Lincoln Y. (Ed.). (1994). Handbook of qualitative research. Thousand Oaks, CA: Sage.

Denzin, N., \& Lincoln Y. (Ed.). (2003). The landscape of qualitative research. Thousand Oaks, CA: Sage.

Dixon, J. (1994). A white gentlemen's profession? Progressive Architecture, 11, 55-61.

Domer, D., \& Johnson, A. (1982). Selective admissions and academic success: An admissions model for architecture students. College and University, Fall, 19-30.

Douglas, J (1985). Creative interviewing. Beverly Hills, CA: Sage.

Drexler, D. (2006). Student perceptions on self-development variables in selected community college study abroad programs: A quantitative study using Chickering's theory of student development. (Unpublished doctoral dissertation). The University of Florida, Gainesville.

Farkas, G. (2003). Racial discrepancies and discrimination in education: What do we know, how do we know it, and what do we need to know? Teachers College Record, 105(5), 1119-1146.

Fazio, M., Moffett, M., \& Wodehouse, L. (2009). Buildings across time. Boston, MA: McGraw-Hill.

Fisher, T. (1994). Can this profession be saved? Progressive Architecture, 2, 46-49, 8486. 
Florida International University, Office of Planning \& Institutional Effectiveness. (2008). Statistical report on ethnicity student distribution in the FIU School of Architecture-upper and lower division. 2007-2008.

Florida International University, College of Architecture and the Arts. Retrieved October 16, 2009, from http://www.fiu.edu/ soa

Frampton, K. (1993). Prospects for a critical regionalism. In K. Nesbitt (Ed.). (1996). Theorizing a new agenda for architecture: An anthology of architectural theory 1965-1995. New York: Princeton Architectural Press.

Franck, F. (1973). The Zen of seeing. New York: Vintage Books.

Frascari, M. (1984). The tell-the-tale detail. In K. Nesbitt (Ed.). (1996). Theorizing a new agenda for architecture: An anthology of architectural theory 1965-1995. New York: Princeton Architectural Press.

Golay, P. (2006). The effects of study abroad on the development of global mindedness among students enrolled in international programs at Florida State University. (Unpublished doctoral dissertation). Florida State University, Tallahassee, Florida.

Groat, L. \& Ahrentzen, S. (1996). Reconceptualizing architectural education for a more diverse future: Perceptions and vision of architectural students. Journal of Architectural Education. 49(3), 166-183.

Gubrium, J., \& Holstein, J (1997). The new language of qualitative method. New York, NY: Oxford University Press.

Guer, S. (2007). Modernity vs. post modernity in architectural education. Journal of Architectural and Planning Research, 24(2), 91-108.

Gurman, E. (1989). Travel abroad: A way to increase creativity? Educational Research Quarterly, 13, 12-16.

Herbert, D. (1993). Architectural study drawings. New York: Van Nostrand Reinhold.

Hoffman, J. (2008). "You have to travel a long way to learn a lot.” Reflecting on issues of literacy, equity and tolerance. Journal of Reading Education, 33(3), 5-8.

Holland \& Knight LLP (2005). Demographic diversity audit final report. Washington, DC:AIA

Hollway, W. \& Jefferson, T (2000). Doing qualitative research differently. London: Sage. 
Hurol, Y. (2004). Intellectual; friendship in architectural education. The Journal of Aesthetic Education, 33(3), 73-90.

Institute of Classical Architecture \& Classical America. Retrieved October 16, 2009, from http://www.classicist.org/

Johnson, R., \& Onwuegbuzie, A.J. (2004). Mixed methods research: A research paradigm whose time has come. Educational Researcher. 33(7), 14-26.

Jones, K. (2001). Unpacking the suitcase: Travel as process and paradigm in constructing architectural knowledge. In Piotowski, A. \& Robinson, J. (Eds.). (2001). The discipline of architecture. Minneapolis, MN: The University of Minnesota Press.

King, A. (2006). Internationalism, imperialism, post colonialism, globalization: Frameworks for vernacular architecture. Perspectives in Vernacular Architecture. 13(2), 64-75.

Kitsantas, A. (2004). Studying abroad: The role of college students' goals on the development of cross-cultural skills and global understanding. College Student Journal, 38(3), 441-52.

Kolb, D. (1984). Experiential learning: experience as the source of learning and development. (Electronic Version). Retrieved March 27, 2011from http://www.learningfromexpereince.com/images/uploads/process-of-experientiallearning.pdf

Kolmar, W., \& Piereiti, M. (2008). Reading Paris and London: Teaching the city through literacy and film representations and on-site experience. Transformations, 19(1), 36-43.

Kuh, G., Kinzie, J., Buckely, J., Bridges, \& B., Hayek, J. (2007). Piecing together the student success puzzle: Research propositions, and recommendations: ASHE Higher Education Report, 32(5), 1-182.

Kurtich, J. (1995). Interior architecture. New York: Van Nostrand Reinhold.

Kvale, S. (1996). Interviews: An introduction to qualitative research interviewing. Thousand Oaks, CA: Sage.

Kvale, S. \& Brinkmann S. (2009). Interviews: Learning the craft of qualitative research interviewing. Los Angeles, CA:Sage.

Leccese, M. \& McCormick, K. (Eds.). (1999). Charter of the new urbanism. New York, NY: McGraw-Hill.

Lincoln, Y. \& Guba, E. (1985). Effective Evaluation. San Francisco: Jossey-Bass. 
Lincoln, Y. \& Guba, E. (1986). But is it rigorous? Trustworthiness and authenticity in naturalistic evaluation. New Directions for Program Evaluation, 30, 73-85.

May, T. (Ed.). (2002). Qualitative research in action. London: Sage

Merriam, S (Ed.). (2002). Qualitative research in practice. San Francisco: Jossey-Bass.

Montrose, L. (2002). International study and experiential learning: The academic context. (Electronic Version). Frontiers Journal. Retrieved October 1, 2009 from, http://www.frontiersjournal.com/issues/vol8/vol8-08_montrose.htm

Moore, F. (1999). Understanding structures. Boston: McGraw-Hill.

Moustakas, C. (1994). Phenomenological research methods. Thousand Oaks, CA: Sage

Mouton, W. (2001). Naturalistic research and experiential learning in a travel/residential environment. The Delta Kappa Gamma Bulletin, 67(3), 18-23.

Mouton, W. (2002). Experiential learning in travel environments as a key factor in adult learning. The Delta Kappa Gamma Bulletin, 69(1), 36-42.

Nesbitt, K. (Ed.). (1996). Theorizing a new agenda for architecture: An anthology of architectural theory 1965-1995. New York: Princeton Architectural Press.

Norberg-Schulz, C. (1976). The phenomenon of place. Architectural Association Quarterly, 8(4), 3-10.

Norberg-Schulz, C. (1983). Heidegger's thinking on architecture. Perspecta: The Yale Architectural Journal, 20, 61-68.

Norwich, J. (2000). Great architecture of the world. London: Da Capro Poress.

Olsen, S. (1994). Architecture doesn’t look much like America. Architectural Record, 25(11).

Pallasmaa, J. (1986). The geometry of feeling: A look at the phenomenology of architecture. Skala: Nordic Journal of Architecture and Art, 4(6), 22-25.

Pascarella, E. \& Terenzini, P (2005). How college affects students. San Francisco: Jossey-Bass.

Patterson, P. (2006). Effect of study abroad on intercultural sensitivity. (Unpublished doctoral dissertation). The University of Missouri, Columbia. 
Pietig, J. (1997). Architecture as a metaphor for education. Art Education, 3, 45-51.

Piotowski, A. \& Robinson, J. (Eds.). (2001). The discipline of architecture. Minneapolis, MN: The University of Minnesota Press.

Portoghesi, P. (2002). Aldo Rossi: The sketchbooks (1990-1997). New York: Thames \& Hudson.

Porter, T. (1997). The architect's eye. London: Chapman \& Hall.

Prasad, P. (2005). Crafting qualitative research - working in the postpositive traditions. Armonk, NY: M.E. Sharpe

Psathas, G. (Ed.). (1973). Phenomenological sociology. New York:Wiley.

Quantrill, M. (1992). The myth of Daedalus and the house of the architect. Practices, 3-4, 20-31.

Rasmussen, S. (1959). Experiencing architecture. Cambridge: MIT Press.

Rawes, P. (2007). Reflective subjects in Kant and architectural design education. The Journal of Aesthetic Education, 41(1), 74-89.

Roth, L. (2007). Understanding architecture. Boulder, CO: Westview Press.

Sandell, E. (2007). Impact of international education experiences on undergraduate students. The Delta Kappa Gamma Bulletin, 73(4),12-18.

Scheunpflung, A. (1997). Cross-cultural encounters as a way of overcoming xenophobia. International Review of Education, 43(1), 109-116.

Seamon, D. (1983). A phenomenology of life world and place. Phenomenology \& Pedagogy, 2(2), 130-135.

Seamon, D. (2002). Phenomenology, place, environment, and architecture: A review of the literature. Retrieved October 18, 2010 from Phenomenology Online. http://www.phenomenologyonline.com/articles/sources.html

Shannon, S. (1996). Architecture and equity: Education and practice. Architecture Theory Review: The Journal of the Department of Architecture, Planning and Applied Arts, 1(1), 48-62.

Seidman,I. (2006). Interviewing as qualitative research. New York: Teachers College Press. 
Smith, A. (2003). Place replaced: Colonial nostalgia and pied-noir pilgrimages to Malta. Cultural Anthropology, 18 (3), 329-64.

Stanitski, D., \& Fuellhart, K. (2003). Tools for developing short-term study abroad classes for geography studies. Journal of Geography, 102, 202-215.

Syracuse University (2010), School of Architecture. Retrieved December 16, 2010, from http://soa.syr.edu/index.php

Tashakkori, A \& Teddlie, C.(Ed.). (2003). Handbook of mixed methods in social \& behavioral research. Thousand Oaks, CA: SAGE.

Trachtenberg, M., \& Hyman, I. (2002). Architecture from prehistory to postmodernity. New York: Prentice Hall.

Tzonis, A. \& Lefaivre, L. (1990). Why critical regionalism today? In K. Nesbitt (Ed.). (1996) Theorizing a new agenda for architecture: An anthology of architectural theory 1965-1995. New York, NY: Princeton Architectural Press.

The University of Florida, School of Architecture. Retrieved December 16, 2010, from http://www.dcp.ufl.edu/arch/

The University of Miami, School of Architecture. Retrieved October 16, 2009, from http://www.arc.miami.edu

The University of Miami, School of Architecture. (2008). Student prospectus publication.

Van Reken, R. \& Rushmore, S. (2009). Thinking globally when teaching locally. Kappa Delta Pi Record. 45(2), 60-68.

Vellani, M. (2004). Architecture and the poetics of curriculum. JCT, 20(3), 7-29.

Waldrep, L. (2006). Becoming an architect. Hoboken, NJ: John Wiley \& Sons.

Walker, K. (2001). Architectures of globalization. Places, 14(2), 70-73.

Williams, B. (2006). Expanding perceptions of self and other through study abroad. (Unpublished dissertation). The Ohio State University.

Wortman, T. (2002). Psychological effects of studying abroad: Openness to diversity. (Unpublished doctoral dissertation). The Pennsylvania State University.

Yeguel, F. (1991). Gentlemen of instinct and breeding. New York, NY: Oxford University Press. 
Yachomowicz, D. J. (1987). The effects of study abroad during college on international understanding and attitudes toward homeland and other cultures. (Unpublished doctoral dissertation). The University of California, Riverside, CA.

Younes, M., \& Asay, S. (2003). The world as a classroom: The impact of international study experiences on college students. College Teaching, 51(4), 141-147. 
APPENDICES 


\section{APPENDIX A \\ INTERVIEW GUIDE}

\section{A. Life History}

Ethnicity, language and prior travel experience

1. How would you describe your ethnicity and what is the predominant language spoken in your household?

2. Please describe some of the places you have lived and travelled.

3. How did you travel to these countries?

4. What were some of your impressions of these countries in terms of the culture, history, language, food, and sites?

\section{Education}

1. How did you decide to study architecture?

2. What do you enjoy about studying architecture and what are some of your favorite classes?

3. What are some of the courses you have taken outside the discipline of architecture including history, anthropology, language or fine arts?

4. Why did you choose to study architecture at this institution and was your decision based on its study abroad program?

5. Why did you decided to study abroad? How did you go about this process?

B. Experience

Narrative of day to day experiences

1. Discuss your daily activities in your host country and the structure of the study abroad program. 
2. How did you explore your foreign environment?

3. What were some of your experiences in terms of the food, music, language, and lifestyle of your host country?

4. How independent did you feel while abroad and how did you make contact with the local nationals?

5. What are some of the memories you will always retain from your semester abroad experience?

Structure and experience of study abroad program

1. What were some the courses you were required to take?

2. What did you find challenging about the courses taken?

3. Discuss about some of the excursions you took as part of the study abroad program. What did you see and do?

4. How much free time were you given as part of the study abroad program and what did you do with your time?

Exposure to global architecture

1. Describe a structure or urban space that impressed you in terms of scale, materials, history, or significance.

2. Describe a more intimate spatial experience. How was this sense of intimacy achieved in terms of architecture or even urban design?

3. How did you experience the architecture and urban spaces of your host country?

4. What comparisons to the architecture and urban spaces of your native country did you make? 
5. How did examples of modern architecture relate culturally to the countries you visited?

Data Sources

1. How did you document your travel experiences?

2. How did you decide to use a travel journal?

3. Did you find that certain means of documenting experiences were more effective than others? Why?

4. Describe an image and describe to me what you were seeing and experiencing while sketching or photographing the subject.

C. Meaning of the experience

1. How did you personally benefit for the experience of international travel and study?

2. In what ways did international travel and study abroad influence aspects of the architecture curricula?

3. How was the connection made between the lived experience and the classroom experience?

4. In what ways has your understanding of global architecture been affected through international travel and study abroad?

5. In what ways has the experience of international travel and study abroad served or not served to heighten your interest in the field of architecture.

6. Why would you either recommend or possible not recommend a travel or study abroad experience to other architecture students? 


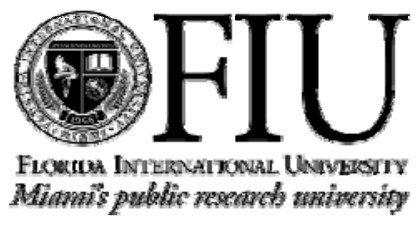

\section{CONSENT TO PARTICIPATE IN A RESEARCH STUDY}

\section{Title: THE INFLUENCE OF STUDY AND TRAVEL ABROAD ON THE PERSONAL AND PROFESSIONAL DEVELOPMENT OF STUDENTS IN ARCHITECTURE DESIGN PROGRAMS}

You are being asked to be in a research study. The investigator of this study is Lyle Culver and he is a student at FIU. The study will include about 14 people who are architecture students at the University of Miami, School of Architecture and Florida International University, School of Architecture. Your participation will require 1 hour of your time. As part of this study, we intend to learn how your international travel and study abroad experience and how it has shaped aspects of your curricula. We also intend to learn about the potentially transformative nature of international travel and study abroad in your life.

If you decide to be a part of the study we will tell you what day and time to come to a designated location on your university campus. You will be asked to answer general questions about: 1) your life history; 2) your travel and study abroad experiences; and 3) the significance of travel and study abroad experiences in terms of your personal life and academic pursuit.

Open ended questions will be used as part of the interview process to better understand how you benefited from the experience of international travel and study abroad, and how it has impacted your curricula. We will electronically record the interviews for subsequent analysis. We will also take notes during the interview. We do not expect any harm to you by being in the study. You may skip any questions that you do not want to answer. If you get upset or feel discomfort during the interview, you may ask to take a break. There is no cost or payment to you as a subject. You will not get any direct benefit from being in the study. However, your help will give us information about the importance of international travel and study abroad for architecture students. You will get a small gift as a token for being in the study.

All of your answers are private and will not be shared with anyone unless required by law. You may ask questions about the study at any time. If you choose not to participate no one will be upset with you. You may also choose to stop your participation before your finish the survey. Even if you do not finish the survey you will get the gift. 
If you would like more information about this research after you are done, you can contact me at 305-237-2486. If you feel that you were mistreated or would like to talk with someone about your rights as a volunteer in this research study you may contact Dr. Patricia Price, the Chairperson of the FIU Institutional Review Board at 305-348-2618 or 305-348-2494

\section{Florida International University University Park, Miami, Florida 33199}

Your signature below indicates that all questions have been answered to your liking. You are aware of your rights and you would like to be in the study.

$\overline{\text { Signature of Participant }} \quad$ Printed Name $\quad$ Date

I have explained the research procedure, subject rights and answered questions asked by the participant. I have offered him/her a copy of this informed consent form.

Signature of Witness

Date 
VITA

\section{LYLE D. CULVER}

1985-1986

1987

1988

1990-94

1996-97

1999

2000

2001

2001-2002
European School of Management

Washington University Study Abroad

International Business

Paris, France

A. B. in French and International Development

Washington University

St. Louis, Missouri

Post Graduate Diploma in Arts

Management, Economics \& Politics

The University of St. Andrews

Scotland, United Kingdom

International Marketing \& Sales Manager

Rank Xerox, GmbH

Düsseldorf - F.R. Germany

Licensed Securities Broker (Series 7 \& 63)

JC Bradford \& Co.

Charleston, South Carolina

University of Coimbra

School of Urban Design

The University of Tennessee Summer Program Studies in

European Urban Policy

Coimbra, Portugal

University of Bonn

Center for European Integration

Fellowship - Studies in European Law, History, Fiscal

Policy, Defense, \& Culture

Bonn, F.R. Germany

Master of Architecture (M.Arch.)

The University of Tennessee, College of Architecture

Knoxville, Tennessee

Chaplain Resident

The University of Tennessee Medical Center

Knoxville, TN 
Clinical Pastoral Education (CPE)

Certificate

The University of Tennessee Medical Center

Knoxville, TN

2002-2003

Adjunct Professor

Miami Dade College, School of Architecture \& Interior

Design

Miami, Florida

2003-2005

Instructor

Miami Dade College, School of Architecture \& Interior Design

Miami, Florida

2005-2007

Assistant Professor

Miami Dade College, School of Architecture \& Interior Design

Miami, Florida

2007 to present

Associate Professor

Miami Dade College, School of Architecture \& Interior

Design

Miami, Florida

2008

M.Sc. in Higher Education Administration

Florida International University

Miami, Florida

2010

Dr. Robert H. McCabe Endowed Chair

Miami Dade College

Miami, Florida

\section{PRESENTATIONS}

Culver, L. (2010, October). Role of the MDC School of Architecture \& Interior Design in helping to diversify the study of architecture. Paper presented at the annual National Council of Hispanic Community Colleges, Miami, Florida.

Culver, L. (2007, February). - The role of community college design programs in diversifying the study of architecture. Paper presented at the national conference of the Association of Collegiate Schools of Architecture, Philadelphia, Pennsylvania. 